\title{
High concentration oxygen and hypercapnia in respiratory disease
}

\begin{abstract}
By
Janine Marie Pilcher

A thesis submitted to Victoria University of Wellington in fulfilment of the requirements for the degree of Doctor of Philosophy
\end{abstract}

Victoria University of Wellington

2019

\section{Supervisors}

Professor Richard Beasley (Primary)

Professor Anne La Flamme (Secondary)

Professor Kenneth McNatty (Administrative) 


\begin{abstract}
Oxygen-induced elevations in arterial carbon dioxide tension have been demonstrated in patients with chronic obstructive pulmonary disease (COPD), asthma, pneumonia, obesity hypoventilation syndrome (OHS) and acute lung injury. A randomised controlled trial (RCT) in acute exacerbations of COPD (AECOPD) found an over two-fold increase in mortality in patients randomised to high concentration oxygen, compared to titrated oxygen. These findings support guideline recommendations for titration of oxygen therapy to a target oxygen saturation range, reducing the risks of hypoxaemia and hyperoxaemia.
\end{abstract}

This thesis focuses on the potential implications of oxygen-induced elevations in carbon dioxide in the acute clinical setting. The reviews and studies in the following chapters are all aimed at addressing gaps in knowledge which may have practical implications for oxygen therapy and/or the identification of patients at risk of oxygen-induced hypercapnia in clinical practice.

Numerous studies have demonstrated that high concentration oxygen continues to be administered to acutely unwell patients, despite guideline recommendations for titrated therapy. The first study in this thesis is a clinical audit evaluating the effects of a staff education program, which included face-to-face and written training for ambulance staff. The education program was associated with reduced the rates of high concentration oxygen administration to patients with AECOPD. This suggests active education may increase adherence to oxygen guidelines among clinical staff.

The ability to avoid hypoxaemia and hyperoxaemia during titrated oxygen therapy relies on appropriate lower and upper target oxygen saturation limits, which may be impacted on by pulse oximeter accuracy. The second study in this thesis is a multicentre observational study in which 400 paired pulse oximeter $\left(\mathrm{SpO}_{2}\right)$ and arterial blood gas saturation $\left(\mathrm{SaO}_{2}\right)$ values were collected in the hospital setting. A $\mathrm{SpO}_{2}<92 \%$ had $100 \%$ sensitivity for detecting $\mathrm{SaO}_{2}<90 \%$. This indicates guideline recommended target oxygen saturations of $92-96 \%$ adequately avoid hypoxaemia. 
Two studies in OHS patients have investigated the effects of oxygen administration on carbon dioxide, however their designs, including recruitment of stable participants, have limited their generalisability to clinical practice. Therefore, a cross over RCT was conducted in 24 morbidly obese hospital inpatients, randomised to the order they received high concentration and titrated oxygen, each for 60 minutes. The mean change in the transcutaneous partial pressure of carbon dioxide $\left(\mathrm{PtCO}_{2}\right)$ from baseline was $3.2 \mathrm{mmHg}$ higher during high concentration oxygen, compared with titrated oxygen $(\mathrm{P}=0.002)$. This supports guideline recommendations to titrate oxygen in patients with obesity, regardless of whether they have a diagnosis of OHS or not.

The effects of oxygen in patients with bronchiectasis, neuromuscular disease or kyphoscoliosis are uncertain. Stable patients with these conditions were recruited to doubleblind randomised cross over trials administering air and 50\% oxygen, each for 30 minutes. A trial was also performed in stable COPD patients for comparison. There was no significant change in $\mathrm{PtCO}_{2}$ with oxygen therapy in the neuromuscular disease/kyphoscoliosis patients. In the bronchiectasis and COPD patients, oxygen was associated with increased $\mathrm{PtCO}_{2}$ from baseline compared to air, but the differences were not clinically significant $(0.4 \mathrm{mmHg}, \mathrm{P}=0.012$ and $1.3 \mathrm{mmHg}, \mathrm{P}<0.001$, respectively). The lack of a clinically significant $\mathrm{PtCO}_{2}$ increase in the COPD patients indicated the study findings were unlikely to be generalisable to the clinical setting, and highlights the potential limitations in applying data from stable participants to patients who require acute oxygen therapy.

These studies support current guideline recommendations for titrated oxygen therapy, provide insight into the limits of studying the effects of oxygen in stable participants, and demonstrate the utility of an educational program to aid the translation of research findings into relevant changes in clinical practice. 


\section{Acknowledgements}

Firstly I would like to thank my Supervisors Professor Richard Beasley and Professor Anne La Flamme for the supervision and support given to me in completing the studies for this thesis. I am especially grateful to Professor Beasley for inviting me to be a part of the Medical Research Institute of New Zealand and for everything I have been taught, which was so much more than the textbook essentials.

To Darmiga, James G and my Dad- in each of your own ways you were essential in ensuring I made my way through to get this thesis completed. Thank you.

I am very grateful to everyone at the Medical Research Institute of New Zealand that I have worked with over the years. I have consistently been supported and encouraged by all of you. To the 'team oxygen' members specifically, so much of your hard work is woven into the studies in this thesis and I feel extremely fortunate to have worked on these and other studies with you.

Thank you to the teams that I have worked with at Wellington Free Ambulance, Westmead Hospital and Christchurch Hospital, for being fantastic to collaborate with and for all of your hard work to get the studies completed.

Thank you to my sister Natalie, for your support and for proof reading portions of this thesis.

I would also like to say thank you to Mark Weatherall, for your patience and careful explanations for my seemingly endless stream of sentences starting with "how does...", "why does..." or "what if...".

Lastly, I would also like to acknowledge the financial support from the Health Research Council, which has been gratefully received as a Clinical Research Training Fellowship to complete this thesis. Additionally, research funding towards the studies in this thesis has been received from Capital and Coast District Health Board and the Neuromuscular Research Foundation Trust, funded by the Richdale Charitable Trust. 


\section{Contents}

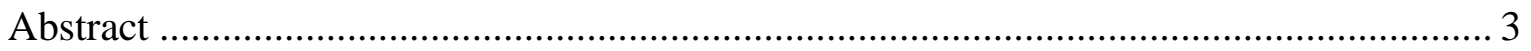

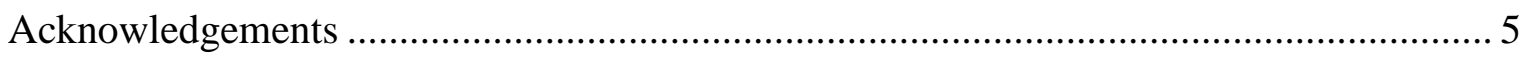

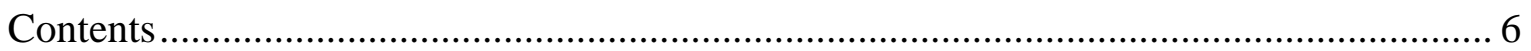

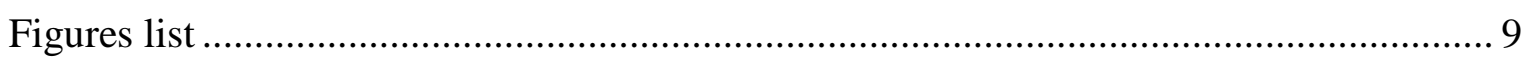

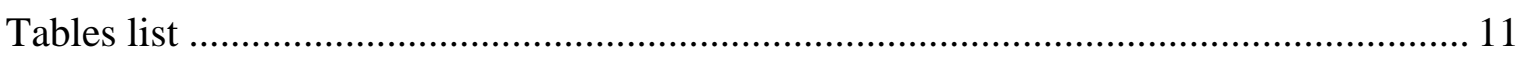

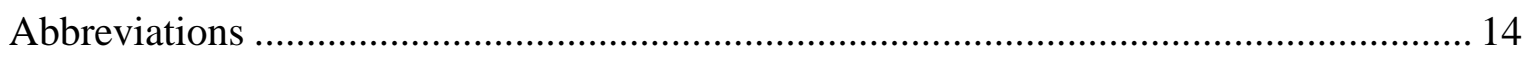

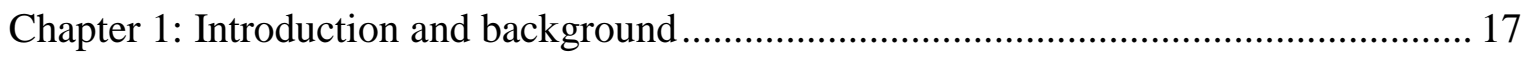

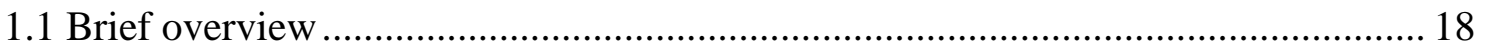

1.2 Key concepts in respiratory physiology and the pathophysiology of COPD ........... 21

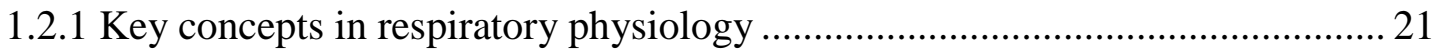

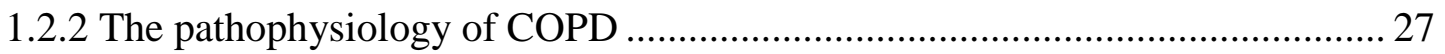

1.3 Evidence for oxygen-induced elevations in $\mathrm{PaCO}_{2}$ and the benefits of titrated oxygen

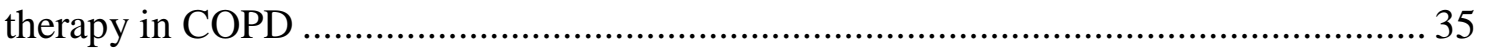

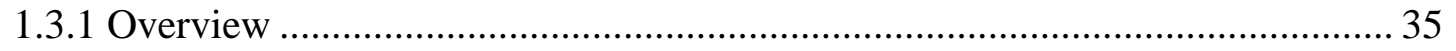

1.3.2 Studies investigating the effects of oxygen on clinical outcomes in AECOPD 35

1.3.3 Studies investigating the effects of oxygen on $\mathrm{PaCO}_{2}$ in $\mathrm{COPD}$...................... 40

1.3.4 Mechanisms behind oxygen-induced hypercapnia in COPD .......................... 70

1.4 Evidence for oxygen-induced elevations in $\mathrm{PaCO}_{2}$ and the benefits of titrated oxygen

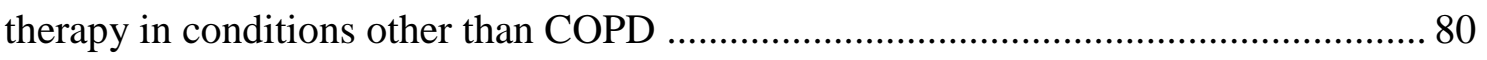

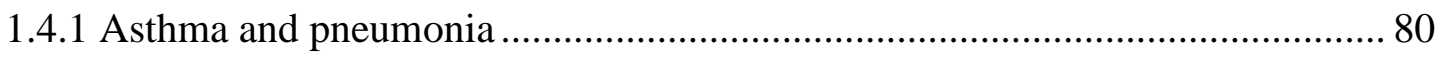

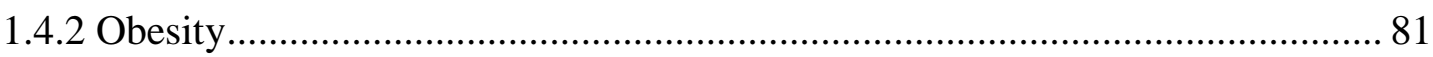

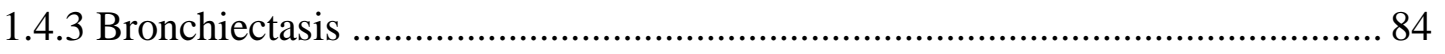

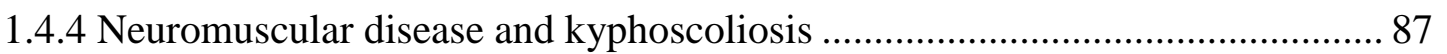

1.5 Practical considerations in the titration of oxygen therapy ................................. 91 
1.5.2 The optimal target saturation range for oxygen titration and the impact of pulse oximeter accuracy 92

1.6 Summary, gaps in knowledge and the studies in this thesis 94

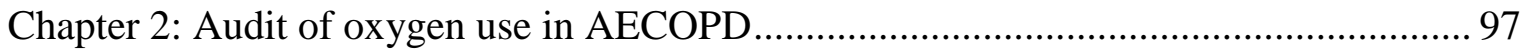

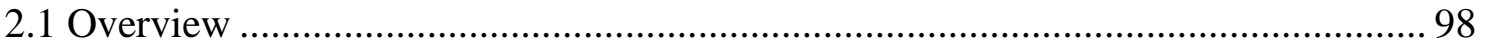

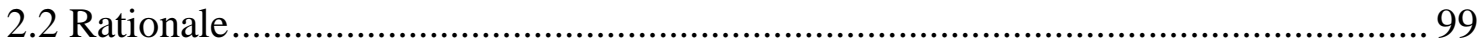

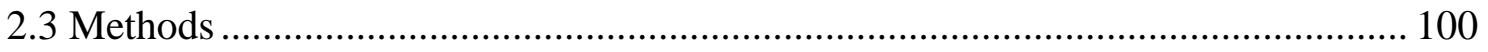

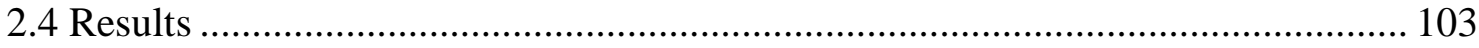

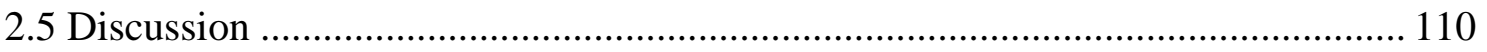

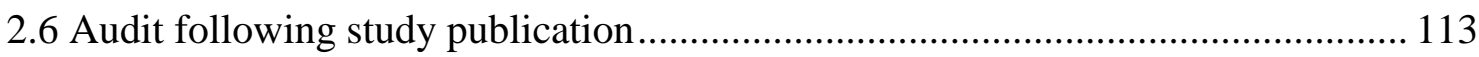

Chapter 3: Multicentre study comparing ABG values to those obtained by pulse oximeters used in Australian and New Zealand Hospitals............................................................ 115

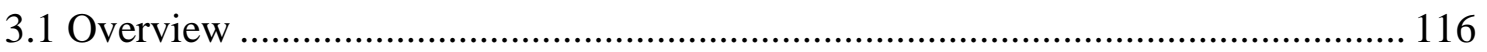

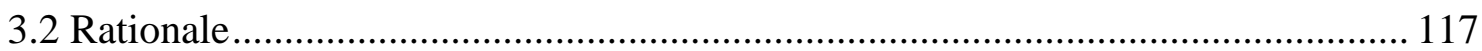

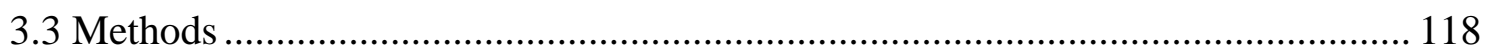

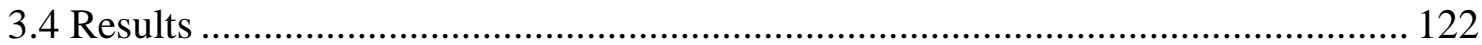

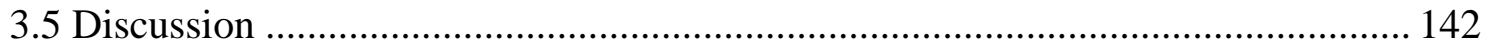

Chapter 4: Randomised controlled trial of oxygen in obese hospital inpatients .............. 145

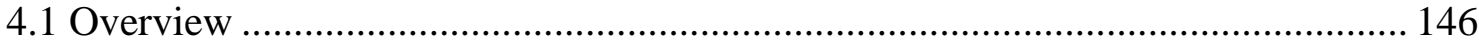

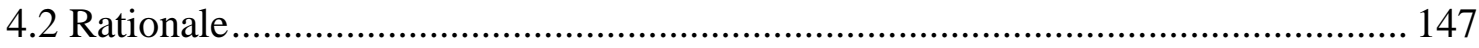

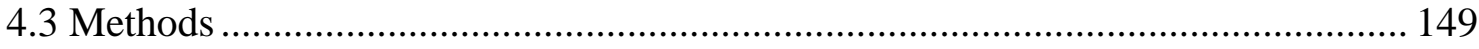

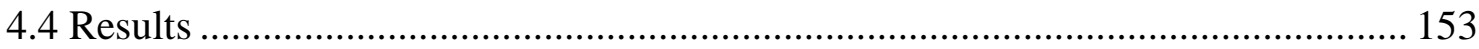

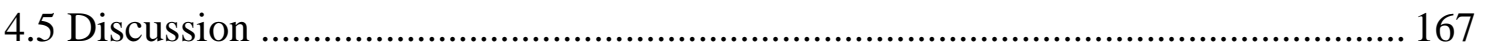

Chapter 5: Randomised cross over trials on the effect of 50\% oxygen on $\mathrm{PtCO}_{2}$ in patients with stable COPD, bronchiectasis, and neuromuscular disease or kyphoscoliosis.......... 171

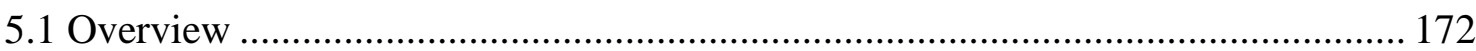


5.2 Rationale

5.3 Methods

5.4 Results

5.5 Discussion

Chapter 6: Conclusions

References

Appendix 1: Original study data and assessments of transcutaneous monitor function .. 243

Appendix 2: Supporting information and documents

275 


\section{Figures list}

Figure 1.1 Categories of evidence to support guideline recommendations for titrated oxygen therapy

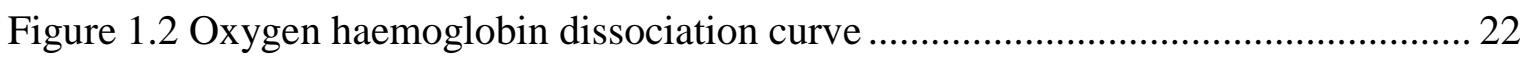

Figure 1.3 Description of V/Q matching in healthy lungs: examples of two alveoli with V/Q

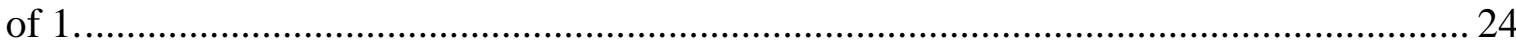

Figure 1.4 Description of areas with decreased V/Q matching with and without physiological compensation .

Figure 1.5 Description of areas of dead space with and without physiological compensation 32

Figure 1.6: Mean $\mathrm{PaCO}_{2}$ changes compared to $\mathrm{FiO}_{2}$ in patients with AECOPD 53

Figure 1.7a Graph of mean $\mathrm{PaCO}_{2}$ changes compared to $\mathrm{FiO}_{2}$ in patients with AECOPD and stable COPD

Figure 1.7b Tables of mean $\mathrm{PaCO}_{2}$ changes compared to $\mathrm{FiO}_{2}$ in patients with AECOPD and stable COPD 66

Figure 1.8 Main mechanisms proposed to account for oxygen-induced hypercapnia ....... 71

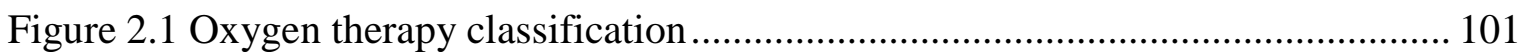

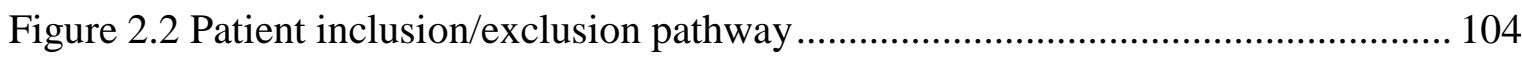

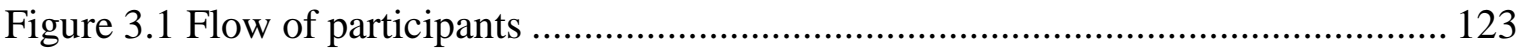

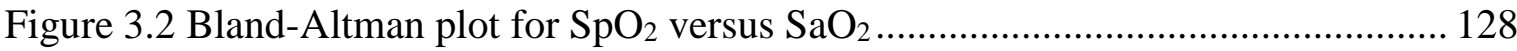

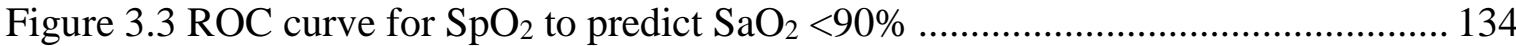

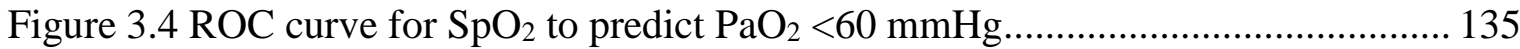

Figure 3.5 Predicted oxygen haemoglobin dissociation curve and data from ABG samples

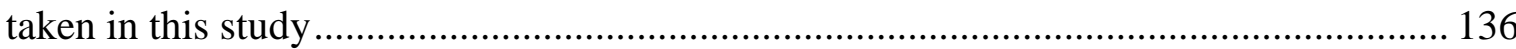

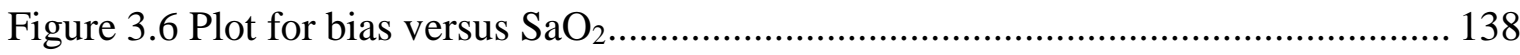

Figure 4.1 Overview of study procedures and measurements....................................... 151

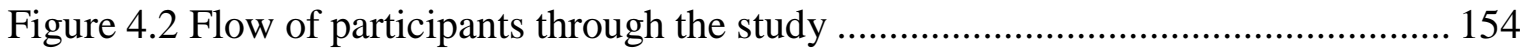

Figure 5.1 Overview of study procedures and measurements...................................... 178

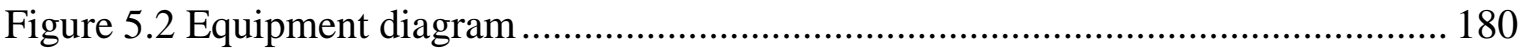

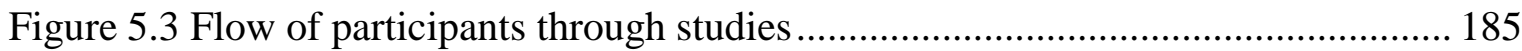

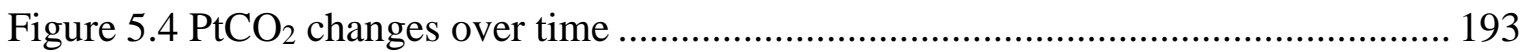


Figure 5.5 Change in $\mathrm{PaCO}_{2}$ by $\mathrm{FiO}_{2}$ in studies investigating the effects of oxygen on $\mathrm{PaCO}_{2}$

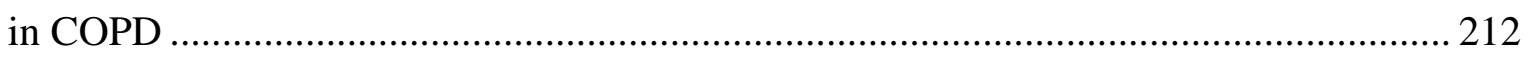

Figure 6.1 Flow of participants through the study ................................................... 252

Figure 6.2 Example of drift corrected (blue) and uncorrected (green) $\mathrm{PtCO}_{2}$ data.......... 268 


\section{Tables list}

Table 1.1 Randomised trials investigating the effects of oxygen therapy on mean $\mathrm{PaCO}_{2}$ in AECOPD

Table 1.2 Non-randomised trials investigating the effects of oxygen therapy on mean $\mathrm{PaCO}_{2}$ in AECOPD..... 46

Table 1.3 Randomised trials investigating the effects of oxygen therapy on mean $\mathrm{PaCO}_{2}$ in stable COPD 58

Table 1.4 Non-randomised trials investigating the effects of oxygen therapy on mean $\mathrm{PaCO}_{2}$ in stable COPD

Table 1.5 Studies investigating mechanisms behind oxygen-induced hypercapnia in patients with AECOPD

Table 1.6 Randomised studies investigating mechanisms behind oxygen-induced hypercapnia in patients with stable COPD 76

Table 1.7 Non-randomised studies investigating mechanisms behind oxygen-induced

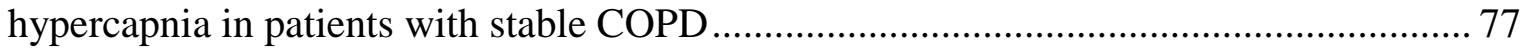

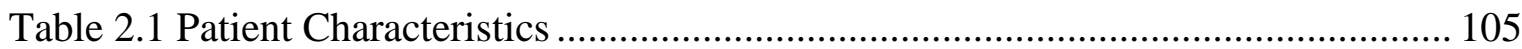

Table 2.2 Ambulance treatment and patient outcomes ................................................. 107

Table 2.3 Last oxygen saturation before hospital arrival ............................................. 109

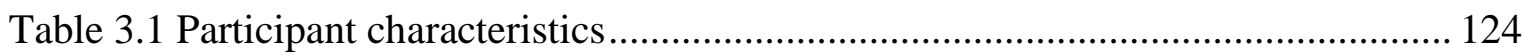

Table 3.2 Oximeter and ABG analyser details by hospitals.......................................... 126

Table 3.3 Participants with discrepancy of at least $4 \%$ between $\mathrm{SpO}_{2}$ and $\mathrm{SaO}_{2} \ldots \ldots \ldots \ldots . . .129$

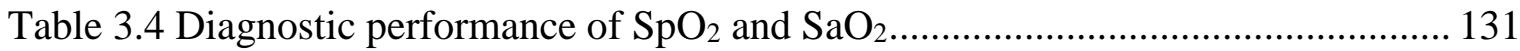

Table 3.5 Sensitivity and specificity for $\mathrm{SpO}_{2}$ less than or equal to the nominated level for $\mathrm{SaO}_{2}<90 \%$. 132

Table 3.6 Sensitivity and specificity for $\mathrm{SpO}_{2}$ less than or equal to the nominated level for $\mathrm{PaO}_{2}<60 \mathrm{mmHg}$ 133

Table 3.7 Contingency tables and ANOVA results for factors from Textbox 3.2 .......... 139

Table 3.8 Variation due to oximeter 141

Table 4.1 Baseline characteristics 156

Table 4.2 Differences in outcomes at 60 minutes, for high concentration vs titrated oxygen therapy, adjusted for baseline. 158 
Table 4.3 Mean values and mixed linear model differences for $\mathrm{PtCO}_{2}$, heart rate, respiratory rate and oxygen saturations

Table 4.4 Change in $\mathrm{PtCO}_{2}$ from baseline at 60 minutes, stratified by baseline values and by admission diagnosis 161

Table 4.5 Characteristics $\mathrm{PtCO}_{2}$ in participants with an increase from baseline $\geq 4 \mathrm{mmHg}$ 163

Table 4.6 Data description and comparison of paired proportions for increase in $\mathrm{PtCO}_{2} \geq 4$ $\mathrm{mmHg}$ from baseline 165

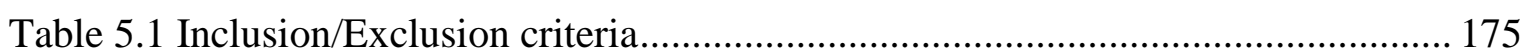

Table 5.2 Ethical approval and trial registration details ............................................ 183

Table 5.3 Participant characteristics and study baseline measurements ......................... 186

Table 5.4 Participant ethnicity 187

Table 5.5 Neuromuscular disease diagnoses for neuromuscular disease/ kyphoscoliosis study 188

Table 5.6 $\mathrm{PtCO}_{2}$ outcomes 191

Table 5.7 $\mathrm{PtCO}_{2}$ values at each time point for the neuromuscular disease/kyphoscoliosis study 194

Table 5.8 $\mathrm{PtCO}_{2}$ values at each time point for the bronchiectasis study ......................... 195

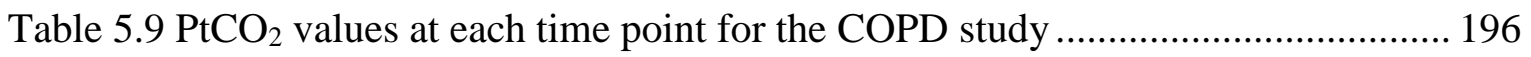

Table 5.10 Time-treatment interaction terms (P values) ................................................ 197

Table 5.11 Secondary outcomes.

Table 5.12 Neuromuscular disease/kyphoscoliosis study: Minute ventilation, respiratory rate and tidal volume 201

Table 5.13 Neuromuscular disease/kyphoscoliosis study: Alveolar minute ventilation and alveolar volume 202

Table 5.14 Neuromuscular disease/kyphoscoliosis study: $\mathrm{ETCO}_{2}$, volume of dead space, $\mathrm{VD} / \mathrm{VT}$ and heart rate 203

Table 5.15 Bronchiectasis study: Minute ventilation, respiratory rate and tidal volume. 204 Table 5.16 Bronchiectasis study: Alveolar minute ventilation and alveolar volume....... 205 Table 5.17 Bronchiectasis study: $\mathrm{ETCO}_{2}$, volume of dead space, VD/VT and heart rate206 Table 5.18 COPD study: Minute ventilation, respiratory rate and tidal volume.............. 207 Table 5.19 COPD study: Alveolar minute ventilation and alveolar volume.................... 208 Table 5.20 COPD study: $\mathrm{ETCO}_{2}$, volume of dead space, VD/VT and heart rate ............ 209 
Table 6.1 Baseline characteristics

Table 6.2 Mean values and mixed linear model differences for respiratory rate (breaths per

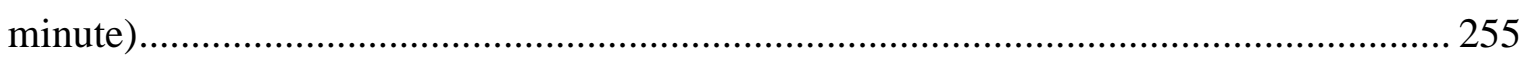

Table 6.3 Ethical approval and trial registration details for the Original Studies ............ 259

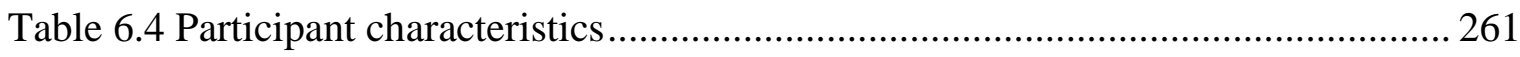

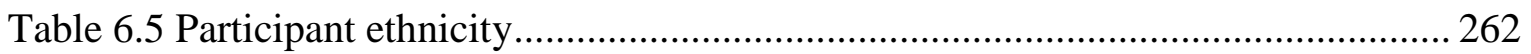

Table 6.6 Neuromuscular disease diagnoses for neuromuscular disease/ kyphoscoliosis

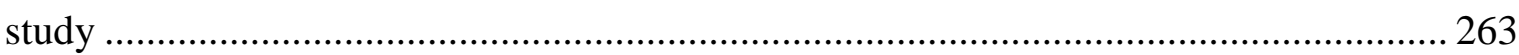

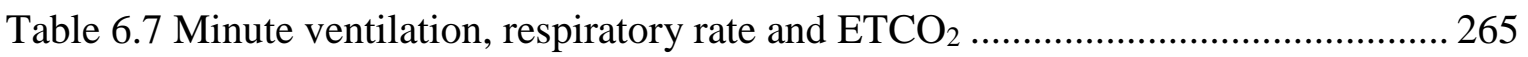

Table 6.8 Bias and limits of agreement between SenTec and ABG measured values of $\mathrm{PCO}_{2}$ 271

Table 6.9 Comparisons in capillary blood gas measured $\mathrm{PCO}_{2}$ and $\mathrm{SenTec}$ measured $\mathrm{PCO}_{2}$ 


\section{Abbreviations}

ABG Arterial blood gas

AECOPD Acute exacerbation of chronic obstructive pulmonary disease

ANZCTR Australian New Zealand Clinical Trials Registry

BMI Body mass index

BTS British Thoracic Society

$\mathrm{CO}_{2} \quad$ Carbon dioxide

$\mathrm{CoHb} \quad$ Carboxyhaemoglobin

COPD Chronic obstructive pulmonary disease

CRF Case report form

CT Computerised tomography

ED Emergency Department

$\mathrm{ETCO}_{2} \quad$ End tidal carbon dioxide

FDA Food and Drug Administration

$\mathrm{FEV}_{1} \quad$ Forced expiratory volume in 1 second

$\mathrm{FiO}_{2} \quad$ Fraction of inspired oxygen

FVC Forced vital capacity

HbA1c Glycosylated haemoglobin

HDU High dependency unit

ICU Intensive care unit

$\mathrm{MetHb} \quad$ Methaemoglobin

MI Myocardial infarction

MIGET Multiple inert gas elimination technique

MRINZ Medical Research Institute of New Zealand

MV Minute ventilation

NA Not applicable

NIV Non-invasive ventilation

NR Not recorded or reported

NZ New Zealand

OHS Obesity hypoventilation syndrome

$\mathrm{PaCO}_{2} \quad$ Arterial partial pressure of carbon dioxide 
$\mathrm{P}_{\mathrm{A}} \mathrm{CO}_{2} \quad$ Alveolar partial pressure of carbon dioxide

$\mathrm{PaO}_{2} \quad$ Arterial partial pressure of oxygen

$\mathrm{PavCO}_{2} \quad$ Arterialised-venous partial pressure of carbon dioxide

$\mathrm{PcCO}_{2} \quad$ Capillary partial pressure of carbon dioxide

$\mathrm{PCO}_{2} \quad$ Partial pressure of carbon dioxide

$\mathrm{PECO}_{2} \quad$ Expired carbon dioxide

$\mathrm{PO}_{2} \quad$ Partial pressure of oxygen

$\mathrm{PtCO}_{2} \quad$ Transcutaneous partial pressure of carbon dioxide

Q Perfusion

RCT Randomised controlled trial

$\mathrm{SaO}_{2} \quad$ Oxygen saturation measured by arterial blood gas sample

SNIP Sniff nasal inspiratory pressure

$\mathrm{SpO}_{2} \quad$ Oxygen saturation measured by pulse oximetry

TSANZ Thoracic Society of Australia and New Zealand

V Ventilation

V/Q Ventilation-perfusion ratio

VA Alveolar ventilation

VC Vital Capacity

$\mathrm{VCO}_{2} \quad$ Carbon dioxide production by the body

VD Volume of dead space

VD/VT Dead space to tidal volume ratio

VT Tidal volume

WFA Wellington Free Ambulance

WRH Wellington Regional Hospital 
Chapter 1: Introduction and background 


\subsection{Brief overview}

The potential for oxygen therapy to increase the arterial partial pressure of carbon dioxide $\left(\mathrm{PaCO}_{2}\right)$ in patients with chronic obstructive pulmonary disease (COPD) has been reported for over 80 years. ${ }^{1-6}$ A number of trials have confirmed $\mathrm{PaCO}_{2}$ can increase during oxygen therapy in patients with stable COPD and in patients during an acute exacerbation of COPD (AECOPD). ${ }^{2,3}$ Elevated $\mathrm{PaCO}_{2}$ can lead to impaired neurological and cardiorespiratory function, and a number of reports have associated oxygen-induced hypercapnia with coma, confusion and/or death. ${ }^{2,7-9}$

A practical method to reduce the risk of oxygen-induced hypercapnia is to titrate the concentration of oxygen delivered to a target oxygen saturation range, as measured by pulse oximetry. ${ }^{10,11}$ This aims to avoid the risks of both hyperoxaemia and hypoxaemia. The clinical benefits of this regimen have been demonstrated in Austin et al's 2010 randomised controlled trial (RCT) in patients with AECOPD, which found delivery of titrated oxygen therapy resulted in an over $50 \%$ reduction in mortality compared to high concentration oxygen therapy. ${ }^{12}$

Recent studies have found that oxygen therapy is also capable of elevating $\mathrm{PaCO}_{2}$ in patients with asthma, ${ }^{13}$ pneumonia, ${ }^{14}$ obesity hypoventilation syndrome (OHS) ${ }^{15,16}$ and acute lung injury. ${ }^{17}$ This suggests oxygen-induced hypercapnia can occur over a wide range of respiratory conditions. As a result, guidelines recommend the titration of oxygen therapy, as required, to relieve hypoxaemia in acute medical patients with and without COPD. ${ }^{10,11}$

This Chapter will provide a brief overview of the respiratory physiology relevant to oxygeninduced hypercapnia, followed by reviews of the evidence to support guideline recommendations for titrated oxygen therapy. The majority of the evidence is from studies in patients with COPD, which can be grouped into studies investigating the clinical consequences of high concentration oxygen therapy, trials investigating the effects of oxygen on $\mathrm{PaCO}_{2}$, and investigations into the physiological mechanisms behind oxygeninduced hypercapnia (Figure 1.1). 
The final Section of this Chapter identifies key gaps in knowledge in this area and how they relate to the studies that make up this thesis. Each of these gaps potentially has practical implications for oxygen therapy and/or the identification of patients at risk of oxygeninduced hypercapnia in clinical practice. 


\section{Studies in patients with COPD}

Studies investigating the effects of oxygen on clinical outcomes in AECOPD:

- Case studies

- Observational studies

- Interventional trials

(Section 1.3.2)

Trials investigating the effects of oxygen on

$\mathrm{PaCO}_{2}$ in:

- AECOPD

- Stable COPD

(Section 1.3.3)

Trials investigating the

mechanisms/biological plausibility behind

oxygen-induced elevations in $\mathrm{PaCO}_{2}$

(Section 1.3.4)

Studies in patients with conditions other than COPD

- Case studies

- Observational studies

- Interventional trials

(Section 1.4)

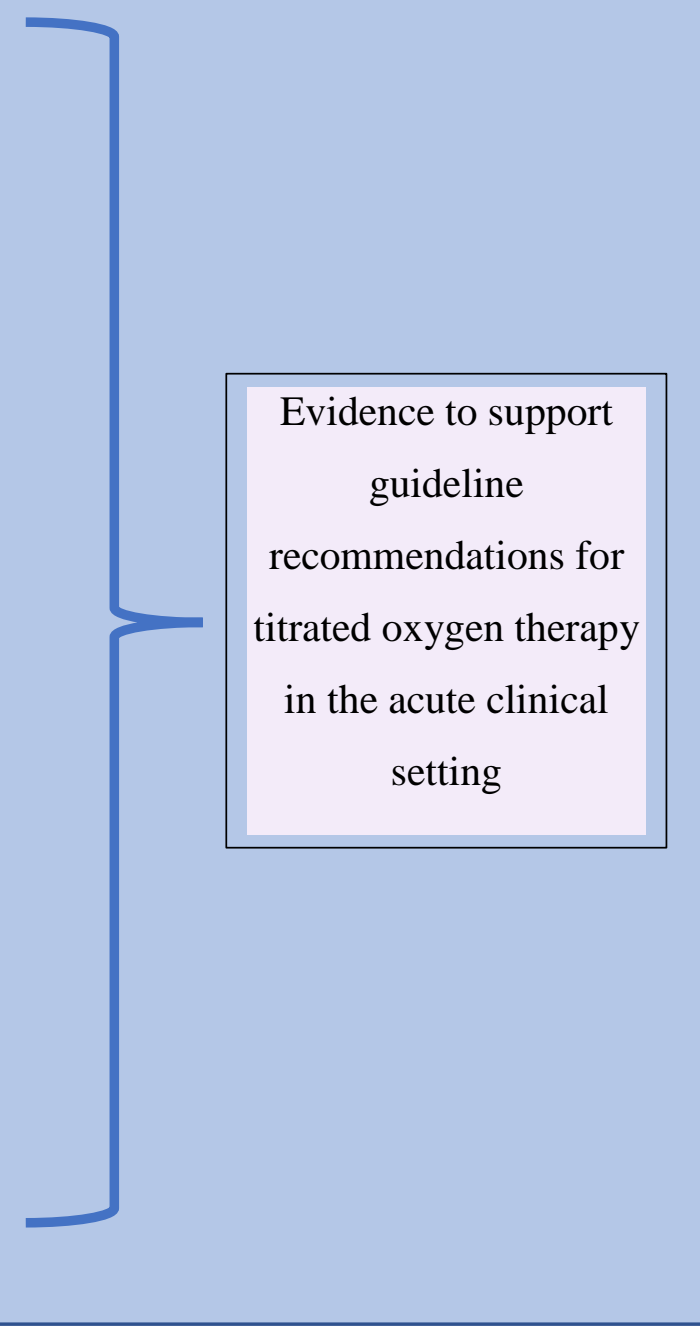

Figure 1.1 Categories of evidence to support guideline recommendations for titrated oxygen therapy

AECOPD: Acute exacerbation of chronic obstructive pulmonary disease, COPD: Chronic obstructive pulmonary disease, $\mathrm{PaCO}_{2}$ : Arterial partial pressure of carbon dioxide. 


\subsection{Key concepts in respiratory physiology and the pathophysiology of COPD}

\subsubsection{Key concepts in respiratory physiology}

A good way to understand the pathophysiology behind respiratory conditions and why patients are at risk of oxygen-induced hypercapnia is to first look at how healthy lungs function. Lungs are inflated through tightening of the diaphragm and other respiratory muscles. The expansion creates negative pressure, allowing air to be inhaled. Exhalation relies on relaxation of these muscles and elasticity of the lung to return the lungs to their original size. Gas exchange occurs at the alveoli where oxygen from the inhaled air is transferred to blood in the surrounding capillaries. The blood travels along the pulmonary vessels to the heart, which circulates it around the body. Oxygen travels in the blood in both a dissolved form and bound to haemoglobin. The percentage of haemoglobin with oxygen bound to it is expressed as the oxygen saturation in the blood, which can be measured via pulse oximetry or an arterial blood gas sample (ABG). The haemoglobin dissociation curve describes the relationship between haemoglobin saturation and partial pressure of oxygen $\left(\mathrm{PO}_{2}\right)$ (Figure 1.2). 


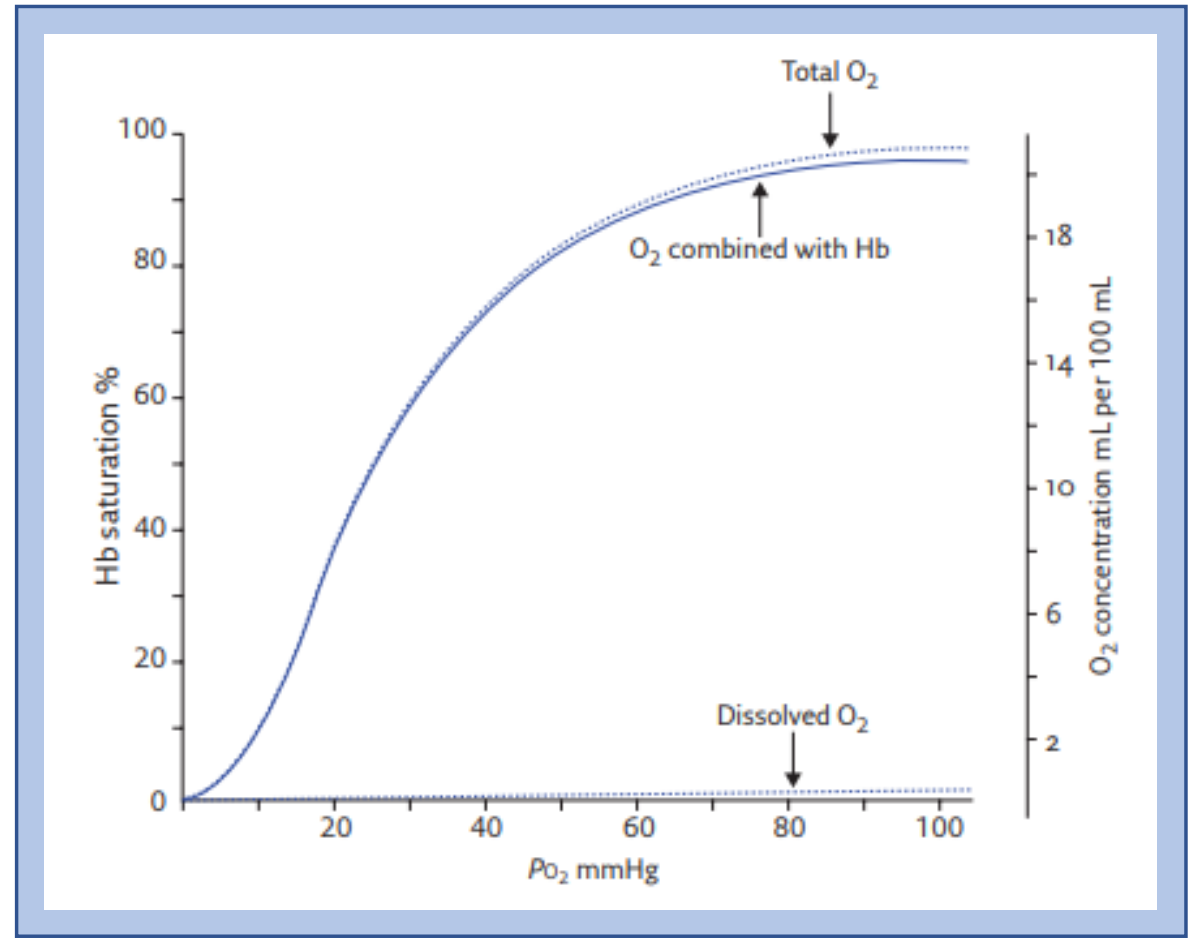

Figure 1.2 Oxygen haemoglobin dissociation curve

$\mathrm{Hb}$ : Haemoglobin, $\mathrm{O}_{2}$ : Oxygen, $\mathrm{PO}_{2}$ : Partial pressure of oxygen.

Image from Collins et al 2015. ${ }^{18}$ Reproduced with permission of the () ERS 2018. Breathe Sep 2015, 11 (3) 194-201; DOI: 10.1183/20734735.001415 
Carbon dioxide $\left(\mathrm{CO}_{2}\right)$ is a byproduct of the body's metabolism (expressed as $\mathrm{VCO}_{2}$ ), and is transferred from the tissues to capillaries to be transported though the venous circulation to the lungs. $\mathrm{CO}_{2}$ travels in the blood mainly in dissolved form, however a small amount is bound to haemoglobin. $\mathrm{PaCO}_{2}$ is measured via $\mathrm{ABG}$. However, arterialised capillary blood sample values $\left(\mathrm{PcCO}_{2}\right)$ and transcutaneous measurements $\left(\mathrm{PtCO}_{2}\right)$ can be used as surrogate values (further detail on these measures is provided in Appendix 1).

Expiration of $\mathrm{CO}_{2}$ is dependent on alveolar ventilation (VA), which is the volume of air that enters the alveoli and takes part in gas exchange. The relationship between $\mathrm{CO}_{2}$ production and expiration that results in $\mathrm{PaCO}_{2}$ can be summarised by the equation below:

$\mathrm{PaCO}_{2}=\left[\mathrm{VCO}_{2} \times 0.863\right] / \mathrm{VA}$

VA is dependent on the amount of air transferred into the respiratory system through inhalation, expressed as minute ventilation (MV), and total dead space, also referred to a physiological dead space (VD). VD is defined as the volume of air that is inspired that does not take part in gas exchange. This means that:

$\mathrm{VA}=\mathrm{MV}-\mathrm{VD}$

VD is the sum of anatomical dead space (the airways that do not take part in gas exchange) and alveolar dead space (alveoli that are ventilated but have little or no blood in their capillaries for gas exchange to take place).

Effective gas exchange is dependent on the matching of ventilation (V) and perfusion (Q) at the alveolus. The ideal standard ventilation-perfusion ratio (V/Q) of an individual alveolus is 1 (Figure 1.3). In reality, gravity causes higher V/Q ratios at the lung apices, and lower at the bases, with an overall ratio for the entire lung of $0.8 .{ }^{19}$ If $\mathrm{V}$ and $\mathrm{Q}$ are mismatched, $\mathrm{PaO}_{2}$ and $\mathrm{PaCO}_{2}$ can be adversely affected, as outlined in Section 1.2.2. 


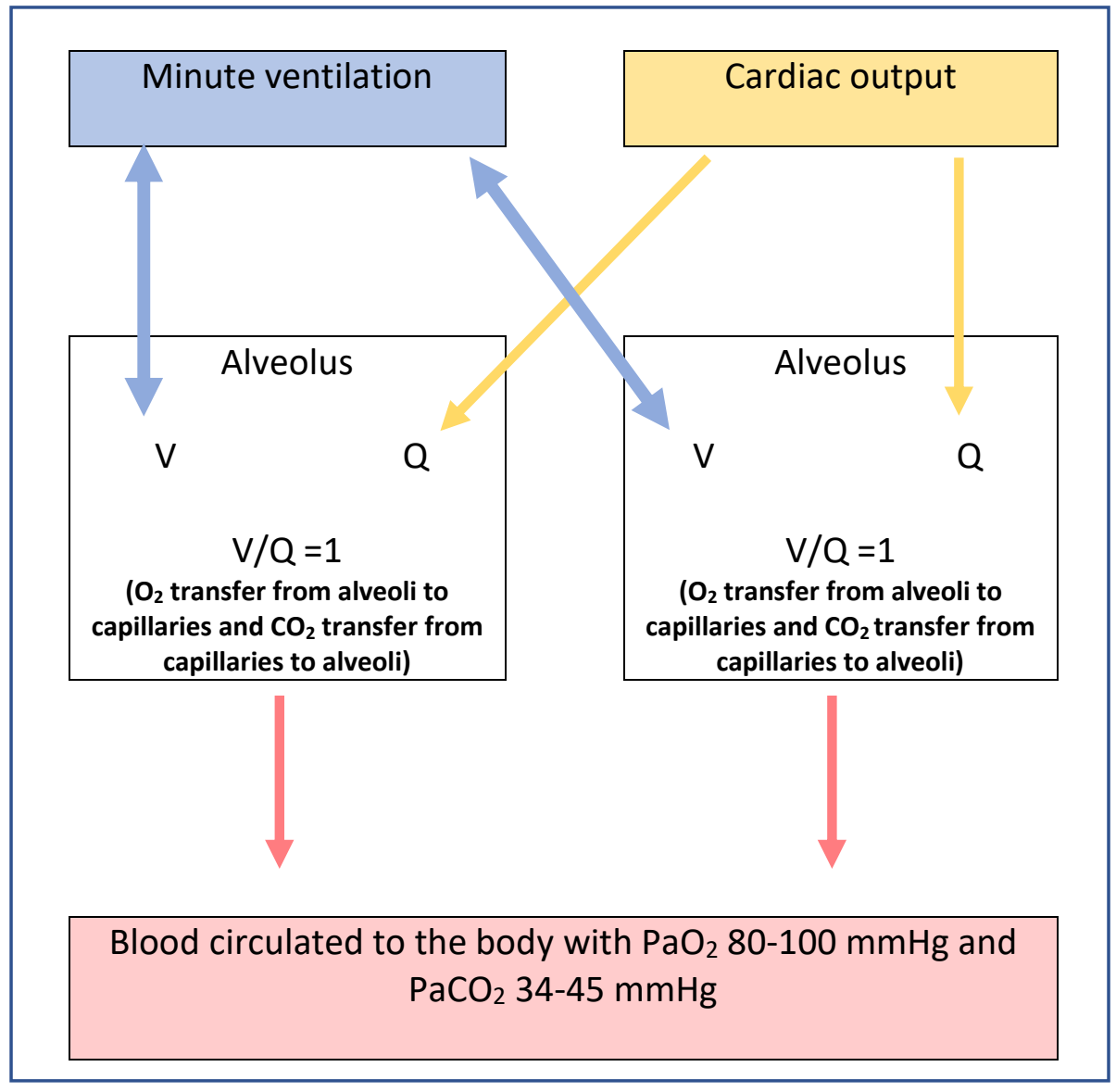

Figure 1.3 Description of V/Q matching in healthy lungs: examples of two alveoli with V/Q of 1

$\mathrm{CO}_{2}$ : Carbon dioxide, $\mathrm{PaCO}_{2}$ : Arterial partial pressure of carbon dioxide, $\mathrm{PaO}_{2}$ : Arterial partial pressure of oxygen, Q: Perfusion, V: Ventilation.

Figures 1.3 through 1.5 outline concepts based on information from reviews by Barberà et al in 1997, ${ }^{20}$ Naeije \& Brimioulle in 2001, ${ }^{21}$ O'Donnell \& Parker in 2006, ${ }^{22}$ Papi et al in 2006, ${ }^{23}$ Cooper \& Celli in 2008, ${ }^{19}$ and Petersson \& Glenny in 2014. ${ }^{24}$ 
The normal ranges for $\mathrm{PaO}_{2}$ and $\mathrm{PaCO}_{2}$ are generally considered to be $80-100 \mathrm{mmHg}$ and $35-45 \mathrm{mmHg}$, respectively. Type I respiratory failure describes the situation where $\mathrm{PaO}_{2}$ is $<60 \mathrm{mmHg}$, and $\mathrm{PaCO}_{2}$ is normal or low. Type II respiratory failure occurs where $\mathrm{PaO}_{2}$ is $<60 \mathrm{mmHg}$ and $\mathrm{PaCO}_{2}$ is elevated.

The body has a number of physiological responses aimed at limiting or preventing reductions in $\mathrm{PaO}_{2}$ and increases in $\mathrm{PaCO}_{2}$, including chemoreceptor control of ventilation, hypoxic pulmonary vasoconstriction, renal compensation for elevated $\mathrm{PaCO}_{2}$, the relationship between $\mathrm{PaO}_{2}$ and $\mathrm{SpO}_{2}$ outlined by the oxygen dissociation curve, the Bohr effect and the Haldane effect (as outlined in Textbox 1.1). However, compensation is not always possible, leading to hypoxaemia and/or hypercapnia in a number of respiratory conditions, including COPD. 
Binding of $\mathrm{CO}_{2}$ to haemoglobin and the Haldane effect

As $\mathrm{PaO}_{2}$ increases, the $\mathrm{CO}_{2}$ bound to haemoglobin decreases. The displaced $\mathrm{CO}_{2}$ becomes dissolved in the blood, elevating $\mathrm{PaCO}_{2}$. This is called the Haldane effect.

At the tissues a low $\mathrm{PaO}_{2}$ facilitates the movement of $\mathrm{CO}_{2}$ from tissues to haemoglobin. At the lung the increased $\mathrm{PaO}_{2}$ acts to facilitate movement of $\mathrm{CO}_{2}$ from haemoglobin to the lung, as oxygen from the lung displaces it by binding to to haemoglobin.

Changes in ventilation to control $\mathrm{PaCO}_{2}$ and $\mathrm{PaO}_{2}$

Minute ventilation is the amount of air that passes to the lungs per minute. It is a function of tidal volume (volume inhaled per breath) and respiratory rate.

Peripheral chemoreceptors located in the aortic and carotid bodies can detect $\mathrm{PaO}_{2}, \mathrm{PaCO}_{2}$ and $\mathrm{pH}$. Central chemoreceptors in the medulla oblongata also detect $\mathrm{pH}$ levels (which may result from changes in $\mathrm{CO}_{2}$ levels). When $\mathrm{PaO}_{2}$ gets too low, $\mathrm{PaCO}_{2}$ is elevated or $\mathrm{pH}$ is reduced, the minute ventilation increases with the aim of moving each of these factors to the normal range. An example of this role is presented in Figure 1.5.

Changes in perfusion to control $\mathrm{PaCO}_{2}$ and $\mathrm{PaO}_{2}$

Hypoxic pulmonary vasoconstriction is a physiological response to low alveolar oxygen, which results in vessel constriction to redirect blood from poorly ventilated areas of the lung to well ventilated areas, reducing ventilation-perfusion mismatch. Details of the effects of hypoxic pulmonary vasoconstriction are presented in Figure 1.4 .
Control of oxygen transfer: the oxygen dissociation curve and the Bohr effect

Oxygen moves from areas of high partial pressure to low partial pressure. The relationship between oxygen saturation and $\mathrm{PO}_{2}$ is described by the oxygen dissociation curve (Figure 1.2).

As blood enters the capillaries surrounding the alveoli it is exposed to a high $\mathrm{PO}_{2}$. Once the blood $\mathrm{PO}_{2}$ reaches about $60 \mathrm{mmHg}$ the dissociation curve flattens out which is protective in that it takes a significant drop in $\mathrm{PO}_{2}$ to reduce the proportion of oxygen molecules bound to haemoglobin for delivery to the body's tissues (i.e. haemoglobin saturation).

Conversely, at the tissues it is advantageous for the slope of the dissociation curve to be steep. There needs to be a gradient between $\mathrm{PO}_{2}$ in the blood and the tissues for oxygen transfer. This means it is advantageous to have smaller reductions in $\mathrm{PO}_{2}$ associated with a greater drop in arterial oxygen saturation, as oxygen is released from haemoglobin to the tissues.

The Bohr effect shifts the dissociation to the right when $\mathrm{PaCO}_{2}$ is elevated (or $\mathrm{pH}$ is low), resulting in increased ability for oxygen to be delivered to tissues.

Changes in renal function to control $\mathrm{pH}$ in hypercapnia

When there is an acute increase in $\mathrm{CO}_{2}$ in the blood it creates carbonic acid which decreases $\mathrm{pH}$. If the increase is sustained there is a metabolic renal compensation by which carbonic acid excretion is increased and bicarbonate excretion is reduced. This acts to restore the $\mathrm{pH}$ to the normal range, despite elevated $\mathrm{PaCO}_{2}$. This means that measurement of an elevated $\mathrm{PaCO}_{2}$ value could be due to chronic or acute respiratory failure. $\mathrm{pH}$ values can indicate whether the failure is acute or chronic.

The alterations to the oxygen dissociation curve and ventilation described in the boxes to the left and above occur in response to increases in $\mathrm{PaCO}_{2}$ and decreases in $\mathrm{pH}$.

Text box 1.1 Key physiological responses regulating $\mathrm{PaO}_{2}, \mathrm{PaCO}_{2}$ and pH

$\mathrm{CO}_{2}$ : Carbon dioxide, $\mathrm{PaCO}_{2}$ : Arterial partial pressure of carbon dioxide, $\mathrm{PaO}_{2}$ : Arterial arterial pressure of oxygen, $\mathrm{PO}_{2}$ : Partial pressure of oxygen. 


\subsubsection{The pathophysiology of COPD}

Over 65 million people are estimated to have COPD, ${ }^{25}$ which is the fourth leading cause of death worldwide. ${ }^{26}$ When the disease is stable there can be a significant impact on daily activities, work productivity and healthcare costs. ${ }^{27}$ Additionally, AECOPD carries a significant risk of hospitalisation and mortality. In New Zealand, COPD rates are disproportionately high in Māori, with hospitalisation rates over 3.5 times that of non-Māori (1,499 per 100,000 versus 417 per 100,000, respectively) ${ }^{28}$ Similarly, the mortality rate for Māori is around three times higher (108.5 per 100,000 versus 37 per 100,000, respectively). ${ }^{28} \mathrm{COPD}$ is a growing problem, with projections that it will be the third leading cause of mortality worldwide by $2030 .^{25}$

COPD is most commonly caused by tobacco smoking or inhalation of other noxious substances, leading to inflammatory responses that affect the structure and function of the respiratory system. ${ }^{27}$ As outlined by the 2017 Global Initiative for Chronic Obstructive Lung Disease (GOLD) document, there are a number of pathophysiological processes which occur in patients with COPD. ${ }^{27}$ Chronic inflammatory processes lead to parenchymal tissue destruction and fibrosis, which in turn lead to airflow limitation and gas trapping. This results in hyperinflation of the lungs, leading to reduced respiratory muscle efficiency, which manifests as dyspnea and limited exercise capacity.

AECOPD is generally defined as the worsening of a patient's baseline symptoms (cough, dyspnea or sputum) sufficient to warrant a change in medical management. ${ }^{22,23,27}$ Thought to be initiated by a trigger (such as in infection or pollution), excessive inflammation causes acute increases in hyperinflation and gas trapping. ${ }^{22,23,27}$

Gas exchange in COPD is potentially affected in a number of ways, ${ }^{19,24}$ which may vary from person to person, and in individuals as the disease progresses over time or when exacerbations occur. It has been suggested that localised areas of low ventilation, leading to low V/Q ratios, significantly contribute to hypoxaemia in AECOPD. ${ }^{20,22,24}$ Causes for the reduction in ventilation might include inflammation of the airways, bronchospasm or mucous. ${ }^{20}$ Figure 1.4 provides an overview of this concept. Areas with low V/Q ratios can 
have reduced delivery of oxygen to the capillaries, and reduced removal of $\mathrm{CO}_{2}$ from the capillaries. Blood that has participated in gas exchange at the unaffected alveoli is mixed with the blood from the alveoli with low ventilation, and the end result can be hypoxaemia and hypercapnia. A key protective strategy in this situation is hypoxic pulmonary vasoconstriction, which is thought to significantly improve both $\mathrm{PaO}_{2}$ and $\mathrm{PaCO}_{2}$ levels (Figure 1.4). Hypoxic pulmonary vasoconstriction has been suggested to be particularly important in AECOPD, where it has been suggested to contribute to as much as $20 \mathrm{mmHg}$ to the total $\mathrm{PaO}_{2}{ }^{21}$ 
Decreased ventilation in some alveoli

(no physiological compensation)

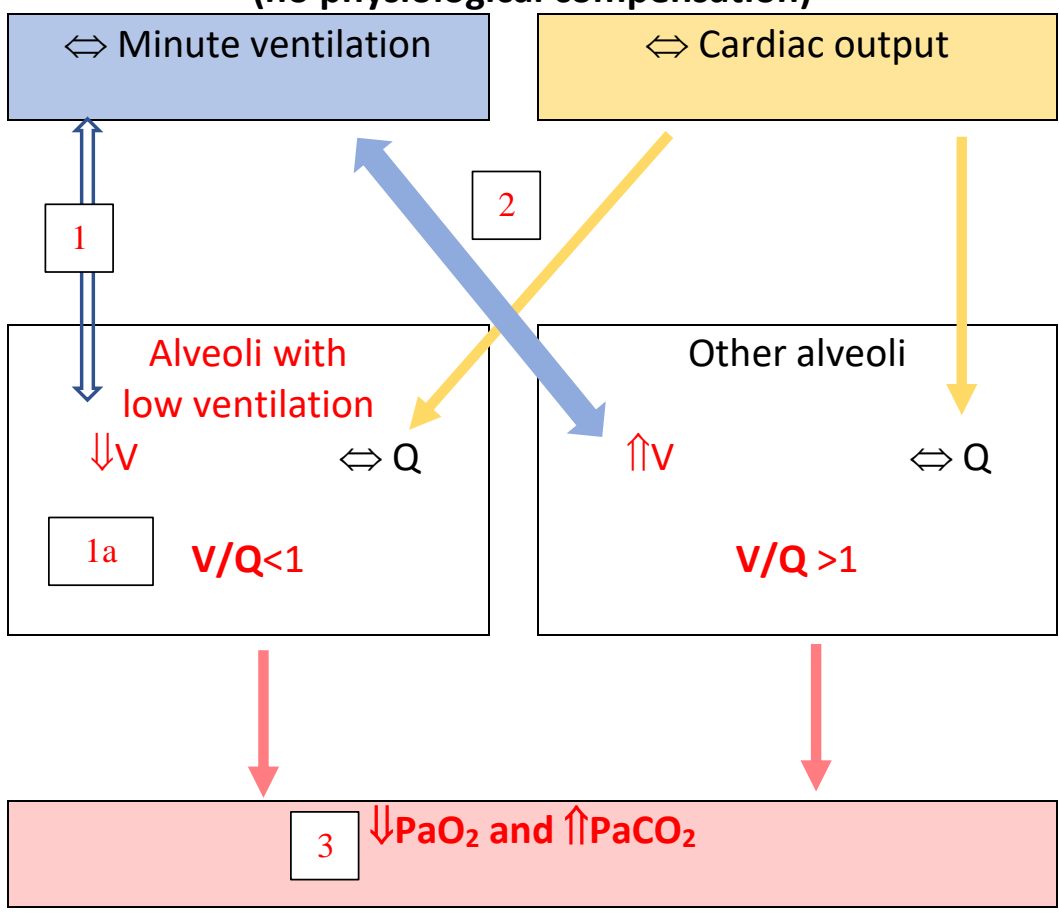

\section{Local areas of reduced ventilation}

1. Obstruction leads to decreased ventilation of alveoli which:

a. Reduces $\mathrm{V} / \mathrm{Q}$, decreasing oxygen supply to the capillaries and potentially decreasing $\mathrm{CO}_{2}$ removal from them.

2. The decrease in ventilation to the alveoli with obstruction means ventilation is transferred to other alveoli (assuming minute ventilation is unchanged). While this can improve oxygen delivery to these alveoli, the effect on oxygen uptake is limited by the complete saturation of haemoglobin.

3. Overall, when the blood supply from the capillaries is combined for transfer to the rest of the body there is a decrease in $\mathrm{PaO}_{2}$ and potentially an increase in $\mathrm{PaCO}_{2}$.
Decreased ventilation in some alveoli (with hypoxic pulmonary vasoconstriction)

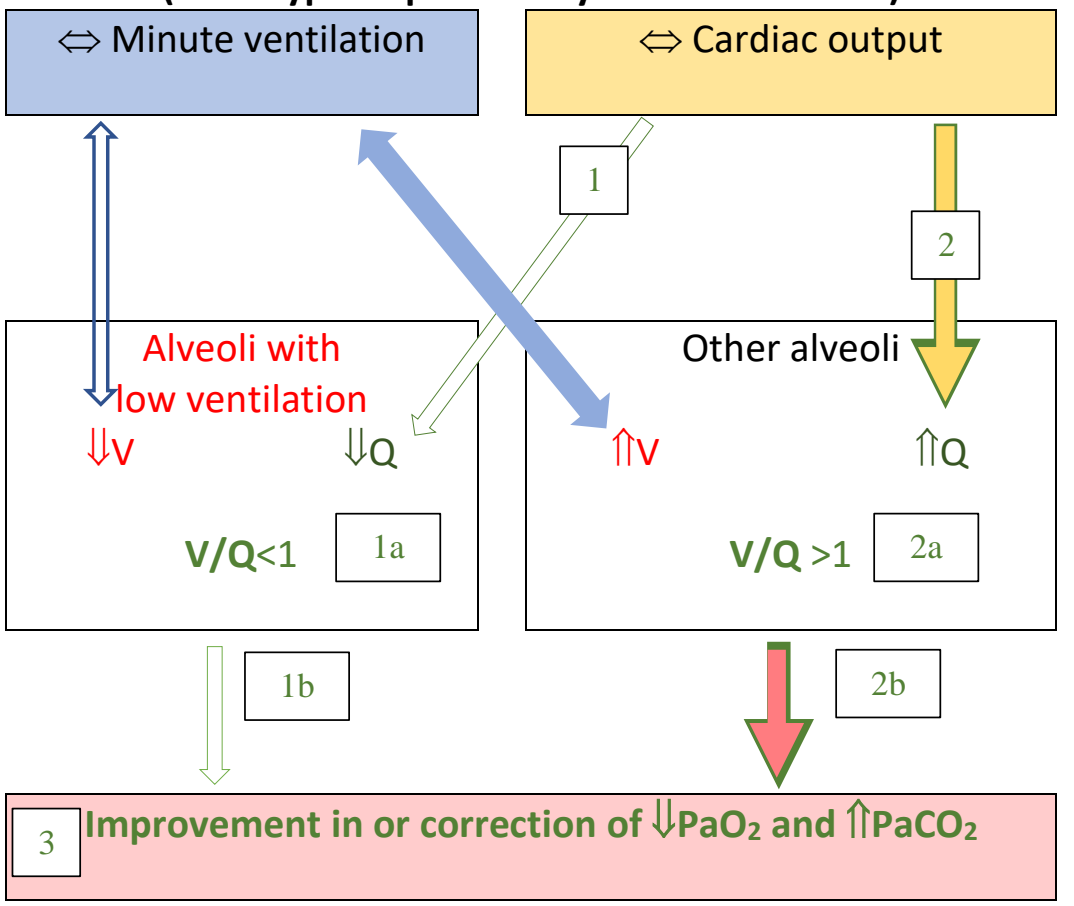

Hypoxic pulmonary vasoconstriction

1. Low oxygen content in the alveoli with low ventilation leads to local vasoconstriction, which decreases perfusion and:

a. Moves the $\mathrm{V} / \mathrm{Q}$ ratio in these alveoli towards 1.

b. Leads to reduced overall contribution of blood from these alveoli back to the circulation

2. Decrease in perfusion to the low ventilation alveoli means redirected blood flow to other alveoli which: a. Moves the V/Q ratio in these alveoli towards 1.

b. Leads to an increase in the proportion of blood flow from these alveoli back to the circulation.

3. Overall this leads to an improvement in or correction of $\mathrm{PaO}_{2}$ and $\mathrm{PaCO}_{2}$

Figure 1.4 Description of areas with decreased V/Q matching with and without physiological compensation Legend overleaf. 
Figure 1.4 Description of areas with decreased V/Q matching with and without physiological compensation continued

$\mathrm{CO}_{2}$ : Carbon dioxide, $\mathrm{PaCO}_{2}$ : Arterial partial pressure of carbon dioxide, $\mathrm{PaO}_{2}$ : Arterial partial pressure of oxygen, Q: Perfusion, $\mathrm{V}$ : Ventilation.

Red text indicates changes that occur in to response areas of decreased ventilation. Green text indicates effects of hypoxic pulmonary vasoconstriction to improve $\mathrm{PaCO}_{2}$ and $\mathrm{PaO}_{2}$.

Figures 1.3 through 1.5 outline concepts based on information from reviews by Barberà et al in $1997,{ }^{20}$ Naeije \& Brimioulle in 2001, ${ }^{21}$ O'Donnell \& Parker in $2006,{ }^{22}$ Papi et al in $2006,{ }^{23}$ Cooper \& Celli in 2008, ${ }^{19}$ and Petersson \& Glenny in 2014. ${ }^{24}$ 
The pathophysiology of COPD can also have the opposite effect on V/Q, as a result of reduced or absent perfusion. These changes are suggested to be due to abnormalities in alveolar structure or vessel destruction, and are thought to be the key contributors to hypercapnia in COPD. ${ }^{24}$ Figure 1.5 demonstrates the situation where alveoli have no perfusion so they do not take part in gas transfer (otherwise known as alveolar dead space, where ventilation is 'wasted'). In most situations, an increase in minute ventilation is sufficient to increase ventilation to perfused alveoli, restore V/Q matching in perfused alveoli, and maintain $\mathrm{PaO}_{2}$ and $\mathrm{PaCO}_{2}$ within the normal range. ${ }^{24}$ However, in severe COPD, this may not be physically possible, especially in the setting of AECOPD. ${ }^{24}$ 

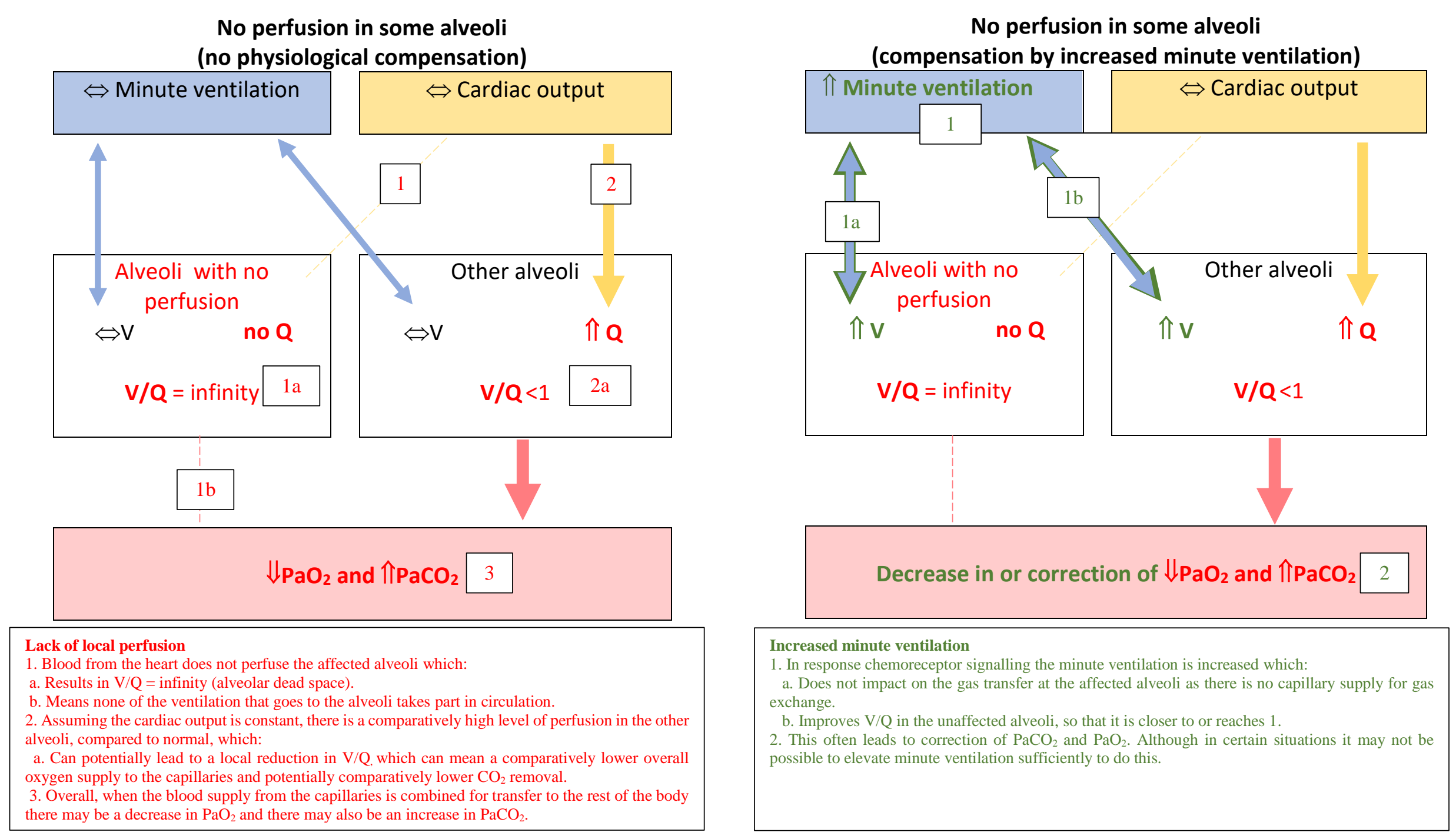

Figure 1.5 Description of areas of dead space with and without physiological compensation Legend overleaf. 
Figure 1.5 Description of areas of dead space with and without physiological compensation continued

$\mathrm{CO}_{2}$ : Carbon dioxide, $\mathrm{PaCO}_{2}$ : Arterial partial pressure of carbon dioxide, $\mathrm{PaO}_{2}$ : Arterial partial pressure of oxygen, Q: Perfusion, $\mathrm{V}$ : Ventilation.

Red text indicates changes that occur in relation to a lack of perfusion to alveoli. Green text indicates the effects of increased minute ventilation to improve $\mathrm{PaCO}_{2}$ and $\mathrm{PaO}_{2}$.

Figures 1.3 through 1.5 outline concepts based on information from reviews by Barberà et al in 1997, ${ }^{20}$ Naeije \& Brimioulle in 2001, ${ }^{21} \mathrm{O}^{\prime}$ Donnell \& Parker in 2006, ${ }^{22}$ Papi et al in $2006,{ }^{23}$ Cooper \& Celli in 2008, ${ }^{19}$ and Petersson \& Glenny in 2014. ${ }^{24}$ 
An additional aspect of gas exchange that may occur in patients with COPD is shunt. In this situation individual areas of the lung have no ventilation while perfusion is maintained (V/Q mismatch is zero). Similar to the situation in Figure 1.4, this can lead to a lower $\mathrm{PaO}_{2}$ and higher $\mathrm{PaCO}_{2}$. While shunt has been demonstrated to have almost no impact in the setting of AECOPD alone,$^{20}$ it could be of relevance in specific situations complicating COPD, such as pneumonia. ${ }^{24}$

Figures 1.4 and 1.5 are useful to demonstrate the concepts of V/Q mismatch in COPD, however they do not illustrate the complex relationships between the various factors that influence $\mathrm{PaO}_{2}$ and $\mathrm{PaCO}_{2}$. Firstly, the differing V/Q mismatch patterns and compensatory mechanisms illustrated in the figures do not occur independently. Interactions between the factors in each figure may lead to a wide variety of combinations of V/Q in different alveoli. These, in turn, may be affected by separate physiological processes, such as changes in minute ventilation, alterations in $\mathrm{VCO}_{2}$, and the Haldane effect (Textbox 1.1). Complicating the picture further, hypoxic pulmonary vasoconstriction is proposed to be affected by $\mathrm{pH}$ and $\mathrm{CO}_{2}$, as well as the extent of the lung that is hypoxic (if there are large areas of hypoxia, it is possible that there are limited alternative areas to redirect blood to for gas exchange). ${ }^{24,29}$ Additionally, changes in minute ventilation in response to hypoxaemia and/or hypercapnia can be influenced by chemoreceptor sensitivity, physical restrictions on tidal volume or limitations on expiratory flow. ${ }^{22}$ Lastly, and of specific relevance to this thesis, a number of factors mentioned above are thought to be modified by oxygen therapy, as outlined in the subsequent Sections of this Chapter. 


\subsection{Evidence for oxygen-induced elevations in $\mathrm{PaCO}_{2}$ and the benefits of titrated oxygen therapy in COPD}

\subsubsection{Overview}

Eighty years ago Barach published data demonstrating increased $\mathrm{CO}_{2}$ content in the blood following oxygen therapy, and noted that patients may become stuporous following high concentration oxygen administration. ${ }^{1} \mathrm{He}$ recommended that in clinical practice patients are not administered high concentration oxygen immediately, but are instead gradually exposed to increasing concentrations of oxygen therapy. Since then numerous studies have reported on the risks of oxygen therapy in patients with $\mathrm{COPD},{ }^{2,3}$ these include case reports, observational studies and interventional trials. Oxygen-induced hypercapnia has been demonstrated over a range of concentrations and durations of oxygen exposure. Significant $\mathrm{PaCO}_{2}$ increases have been reported to result from doses as low as $1 \mathrm{~L} / \mathrm{min}$ via nasal prongs, ${ }^{30}$ and from durations of exposure as short as 5 minutes. ${ }^{31}$ The phenomenon has been demonstrated in stable and acutely unwell patients, both with and without preexisting hypercapnia and hypoxaemia. The most clinically relevant study in this area is Austin et al's 2010 RCT which demonstrated significantly increased mortality in patients that received high concentration, rather than titrated, oxygen therapy. ${ }^{12}$

\subsubsection{Studies investigating the effects of oxygen on clinical outcomes in AECOPD}

\section{Case studies and observational studies}

Multiple reports have linked high concentration oxygen with significant elevations in blood $\mathrm{CO}_{2}$ and/or acidosis, and attributed these changes to coma, stupor or death. ${ }^{1,6-9,32,33}$ Observational studies support these findings by demonstrating oxygen therapy, or factors postulated to be altered by oxygen therapy $\left(\mathrm{PaO}_{2}, \mathrm{PaCO}_{2}\right.$, or $\left.\mathrm{pH}\right)$, to be associated with adverse clinical outcomes in patients with AECOPD. In 2000, Plant et al studied 983 
patients admitted to hospital for AECOPD. ${ }^{34}$ In the hypercapnic patients (47\% of the total sample), higher $\mathrm{PaO}_{2}$ levels were associated with worse acidosis $(\mathrm{r}=-0.214, \mathrm{P}<0.01)$. In turn, acidosis was positively associated with the likelihood of requirement for Intensive Care Unit (ICU) admission (odds ratio (OR) 6.10 (95\% CI 1.19 to 31.11), $\mathrm{P}=0.01$, for $\mathrm{pH}$ <7.25). In 2002, Denniston et al conducted an audit in 101 patients with AECOPD which found exposure to a fraction of inspired oxygen $\left(\mathrm{FiO}_{2}\right)>0.28$ was associated with a higher mortality rate compared to a $\mathrm{FiO}_{2} \leq 0.28$ (14\% versus $2 \%$, respectively, $\left.\mathrm{P}<0.05\right) .{ }^{35}$ In 2007 , Joosten et al presented data from 41 patients admitted to hospital for AECOPD. ${ }^{36}$ Patients that received oxygen at $>4 \mathrm{~L} /$ minute had a longer mean length of stay ( 8 versus 4 days, $\mathrm{P}=0.034)$, greater requirement for non-invasive ventilation (NIV) (39\% versus $23 \%$, $\mathrm{P}=0.033$ ), and increased high dependency unit (HDU) or ICU admissions (39\% versus $23 \%$, $\mathrm{P}=0.033$ ). In the same study, patients with $\mathrm{PaO}_{2} \geq 74.5 \mathrm{mmHg}$ also had longer lengths of hospital stay (11 versus 6 days, $\mathrm{P}=0.029$ ), greater requirement for NIV (55\% versus $14 \%$, $\mathrm{P}=0.012$ ), and increased risk of HDU or ICU admission (55\% versus $14 \%, \mathrm{P}=0.012$ ). In 2011, Wijesinghe et al reviewed the ambulance and hospital records for 250 patients with AECOPD and found that the flow of oxygen delivered was positively associated with poor outcome, defined as a composite of death, positive pressure ventilation or respiratory failure (OR 1.2 (95\% CI 1.0 to 1.4 ) per $1 \mathrm{~L} /$ min oxygen flow). ${ }^{37}$ Increased $\mathrm{PaO}_{2}$ was also associated with poor outcome (OR 1.1 (95\% CI 1.0 to 1.3 ) per $10 \mathrm{mmHg}$ increase). Recognising that low $\mathrm{PaO}_{2}$ values are also associated with worse outcomes in AECOPD, ${ }^{38}$ in 2012 Cameron et al categorised 254 patient presentations to hospital for AECOPD as hypoxaemic $\left(\mathrm{PaO}_{2}<60 \mathrm{mmHg}\right)$, hyperoxaemic $\left(\mathrm{PaO}_{2}>100 \mathrm{mmHg}\right)$ or normoxaemic, based on ABG values within four hours of triage. ${ }^{39}$ Both hyperoxaemia and hypoxaemia were associated with increased risk of hypercapnic respiratory failure, assisted ventilation or inpatient death (OR 9.17 (95\% CI 4.08 to 20.6) and 2.16 (1.11 to 4.20), respectively).

Both elevated $\mathrm{PaCO}_{2}$ and reduced $\mathrm{pH}$ have been linked to increased mortality in AECOPD in a number of observational studies. ${ }^{34,36,38,40}$ While both $\mathrm{PaCO}_{2}$ and $\mathrm{pH}$ are interrelated (Textbox 1.1), there appears to be a specific relationship between $\mathrm{pH}$ and adverse outcomes. Jeffrey et al's 1992 study provides an example of this. ${ }^{40}$ One hundred and thirty nine patients with AECOPD and a $\mathrm{PaCO}_{2}>49.5 \mathrm{mmHg}$ on room air were studied. $\mathrm{A} \mathrm{pH}<7.26$ was significantly associated with increased mortality risk compared to a $\mathrm{pH} \geq 7.26$ (26\% versus $7 \%$ of patients, $\mathrm{P}<0.05)$. However, there was no association found between $\mathrm{PaCO}_{2}$ and 
mortality. Joosten et al found the proportion of patients with a $\mathrm{pH}<7.25$ was significantly greater in hypercapnic patents that received oxygen at $>4 \mathrm{~L} / \mathrm{min}$, compared to hypercapnic patients that had received $\leq 4 \mathrm{~L} / \mathrm{min}$ (37\% versus $10 \%, \mathrm{P}=0.034) .{ }^{36}$ However, the mean highest $\mathrm{PaCO}_{2}$ was not statistically significantly different between the groups. Finally, Plant et al found acidosis, but not $\mathrm{PaCO}_{2}$, to be statistically significantly associated with subsequent admission to ICU (OR 6.10 (95\%CI 1.19 to 31.11 ) in patients with a $\mathrm{pH}<0.25$, compared to patients with a higher $\mathrm{pH} .{ }^{34}$ These findings suggest that rather than an absolute $\mathrm{PaCO}_{2}$ value, it is the acute increase in $\mathrm{PaCO}_{2}$ above a patient's chronic stable value, as reflected by change in $\mathrm{pH}$, which is an important determinant in AECOPD outcome.

While all of these studies are suggestive of clinical harm from oxygen therapy, their observational nature does not allow conclusions on causality. It could be argued that patients that are more likely to have a poor outcome have an increased likelihood of being supplied with more aggressive oxygen therapy by medical staff, whether it be in an attempt to follow guideline recommendations ${ }^{10,11,41}$ or based on a 'more is better' approach. ${ }^{12}$ This would mean increased likelihood of an adverse outcome leads to higher $\mathrm{FiO}_{2}$ and $\mathrm{PaO}_{2}$ values, rather than the other way around. Additionally, the relationship between poor outcome and high $\mathrm{PaCO}_{2}$ or low $\mathrm{pH}$ could be argued to be purely due to these factors being markers of disease severity, rather than them having a consequence for clinical outcomes.

However, the relationships outlined by these studies have supported the multiple calls made for an interventional study to investigate the clinical risks of high concentration oxygen in AECOPD. ${ }^{2,34,41,4243}$ 


\section{Interventional trials}

In 2002, Gomersall et al conducted a randomised pilot study in 34 patients admitted to ICU with AECOPD comparing oxygen titrated to maintain $\mathrm{PaO}_{2}>49.5 \mathrm{mmHg}$ and $\mathrm{pH} \geq 7.26$ (Group A) to oxygen titrated to maintain $\mathrm{PaO}_{2}>67.5 \mathrm{mmHg}$ (Group B). ${ }^{44}$ Patients had to have a $\mathrm{PaO}_{2}<49.5 \mathrm{mmHg}$ and $\mathrm{PaCO}_{2}>49.5 \mathrm{mmHg}$ on room air at study entry. The interventions differed by administration of doxapram (a respiratory stimulant). In Group A, doxapram was initiated if $\mathrm{pH}$ was $<7.26$ and it was titrated until $\mathrm{pH}$ was $\geq 7.26$ and $\mathrm{PaO}_{2}$ was $>49.5 \mathrm{mmHg}$. In Group B, doxapram was initiated if $\mathrm{pH}$ was $<7.26$ and mean arterial pressure was $<70 \mathrm{mmHg}$ or symptomatic cardiac arrhythmia occurred. It was then titrated until $\mathrm{pH}$ was $\geq 7.26$. While $\mathrm{PaO}_{2}$ was significantly higher in Group $\mathrm{B}$, there were no significant differences in mortality, hospital length of stay, $\mathrm{PaCO}_{2}$ or $\mathrm{pH}$ between the groups. Given the differing use of doxapram between the groups and small patient numbers, the impact of the differing oxygen regimens on clinical outcome was difficult to interpret.

It was not until 2010 that Austin et al performed the first RCT designed and powered to specifically investigate the clinical risks of high concentration oxygen in AECOPD. ${ }^{12}$ Paramedics were cluster randomised to deliver one of two different oxygen regimens to patients who had presumed AECOPD. They administered either high concentration oxygen (8-10 L/min via a mask and oxygen at 6-8 L/min to administer nebulised medication) or titrated oxygen (to maintain patient $\mathrm{SpO}_{2}$ values between $88-92 \%$ and use of compressed air to administer nebulised medication). Four percent of participants in the titrated arm died, compared with $9 \%$ in the high concentration arm (relative risk 0.42 (95\% CI 0.2 to 0.89 ), $\mathrm{P}=0.02$, on intention to treat analysis). When the analysis was performed in patients who were subsequently confirmed to have COPD through clinic record review, the mortality was $2 \%$ in the titrated arm and $9 \%$ in the high concentration arm (relative risk 0.22 (95\% CI 0.05 to 0.91$), \mathrm{P}=0.04)$. The number needed to harm was only 14 .

While the study was based on the concept that oxygen could cause harm by elevating $\mathrm{PaCO}_{2}$, there are conceivably other ways in which oxygen therapy could cause harm in AECOPD. Oxygen may impair respiratory function through atelectasis and exacerbation of ventilation-perfusion (V/Q) mismatch; it may also affect the cardiovascular system to reduce cardiac output as well as cerebral and renal blood flow, and can increase systemic 
vascular resistance; lastly it has been linked to the formation of potentially toxic reactive oxygen species. ${ }^{45-54}$ These factors could potentially lead to poor outcomes in patients with AECOPD by exacerbating respiratory failure or adversely impacting on co-morbid conditions, particularly as patients with COPD are more likely to have cardiovascular comorbidities. ${ }^{27}$ From a practical perspective, there is also the potential for oxygen to lead to delay in recognising patient deterioration by medical staff, leading to delays in implementation of appropriate therapy. ${ }^{55,56}$

Austin et al ${ }^{12}$ intended on collecting ABG data from participants on hospital arrival, which would have enabled interpretation as to whether increased mortality was related to oxygeninduced elevations in $\mathrm{PaCO}_{2}$. However, only $11 \%$ of $\mathrm{ABGs}$ were performed within 30 minutes of hospital arrival and it was not clear whether the randomised regimen had been continued up to the time ABGs were conducted. This was despite the study protocol having been discussed with emergency department (ED) hospital staff. When the ABG data that was taken was analysed by intention to treat in patients with confirmed COPD, the $\mathrm{PaCO}_{2}$ was $23 \mathrm{mmHg}$ lower in the titrated arm, compared to the high concentration arm $(n=40$ participants). The $\mathrm{pH}$ was 0.06 higher in the titrated arm, compared to the high concentration $\operatorname{arm}(n=38$ participants). However, these changes did not reach statistical significance. Noting that a high proportion of participants in the titrated arm received high concentration oxygen, despite protocol instructions, the authors performed a per protocol analysis in the subgroup of patients that had confirmed COPD. This did find a statistically significantly lower $\mathrm{PaCO}_{2}$, by $33.6 \mathrm{mmHg}(\mathrm{P}=0.02, \mathrm{n}=29)$, and higher $\mathrm{pH}$, by $0.12(\mathrm{P}=0.01, \mathrm{n}=28)$ in the titrated group. While limited, these data support the concept that oxygen causes clinical harm by inducing hypercapnia. This is further supported by a number of trials that have demonstrated clinically significant increases in $\mathrm{PaCO}_{2}$ in response to oxygen therapy in patients with COPD, as outlined in Section 1.3.3. 


\subsubsection{Studies investigating the effects of oxygen on $\mathrm{PaCO}_{2}$ in COPD}

\section{Overview}

A wide range of studies, including case reports, retrospective audits, and interventional trials have investigated the potential for oxygen to induce hypercapnia. The following is a systematic review performed with the purpose of evaluating the evidence for oxygeninduced hypercapnia in patients with COPD in trials other than Austin et al's 2010 RCT. ${ }^{12}$

\section{Systematic review methodology}

This systematic review was conducted in March 2018. The search strategy is summarised in Textbox 1.2. 


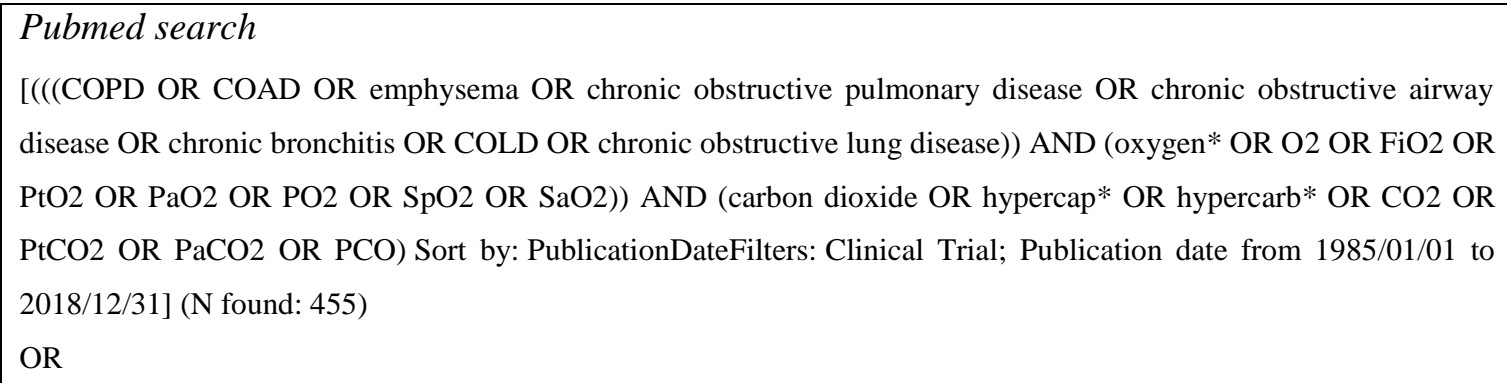

\section{Additional reference search}

References in the reviews by Murphy et al and Pilcher et al were reviewed as well as references from the papers identified above. Additionally, results from our study by Bardsley et $\mathrm{al}^{57}$ were included, despite not being published at the time of the search.

\section{Classification of eligible studies}

The abstract and, if applicable, full text were reviewed. While the term COPD is used throughout this review, eligible terms/diagnoses for inclusion included emphysema, chronic obstructive airway disease, chronic airflow obstruction, chronic bronchitis and chronic obstructive lung disease. Trials were eligible for inclusion if they directly compared the effects of oxygen delivery at a $\mathrm{FiO}_{2}>0.21$ (subsequently referred to as the 'oxygen' intervention(s)) with either oxygen at a lower $\mathrm{FiO}_{2}(>0.21)$ or room air (subsequently referred to as the 'control' intervention for randomised trials or baseline value for non-randomised trials). Trials had to report the numerical change in $\mathrm{PaCO}_{2}$ in response to oxygen delivery though comparison to either the control intervention or baseline value. Change in $\mathrm{PaCO}_{2}$ could be measured by $\mathrm{ABG}$, or the surrogate measures of capillary blood gas or transcutaneous measurement. Trials in which the full text was not available to me and/or the full text was not in English were excluded. To increase relevance to the acute clinical setting data were not included if during an intervention or baseline measurement the following factors occurred, which may alter $\mathrm{PaCO}_{2}$.

- $\quad$ Ventilation (invasive or non-invasive)

- $\quad$ High flow oxygen/air delivery (e.g. nasal high flow cannulae)

- Hyperbaric oxygen/air delivery

- $\quad$ Oxygen/air delivery with gases other than room air or nitrogen (e.g. helium or carbon dioxide above room air levels)

- $\quad$ Modification of oxygen delivery based on $\mathrm{PaCO}_{2}$ levels

- $\quad$ Sleep or exercise.

\section{Textbox 1.2 Search strategy}

ABG: Arterial blood gas, COPD: Chronic obstructive pulmonary disease, $\mathrm{FiO}_{2}$ : Fraction of inspired oxygen, $\mathrm{PaCO}_{2}$ : Arterial partial pressure of carbon dioxide. 
Studies are presented by 1) whether they recruited patients with AECOPD or stable COPD, and 2) whether they are of randomised design. The first distinction was made to address the possibility that results in stable patients may not necessarily reflect patient responses in the clinical setting. The second distinction recognises that without randomisation it is difficult to evaluate whether any observed changes in $\mathrm{PaCO}_{2}$ are due to oxygen delivery or other causes. Examples may include factors related to the oxygen intervention itself (for example breathing through a mouthpiece) or, in the case of patients with AECOPD, acute changes as part of the course of an exacerbation or improvements in response to other hospital therapies.

\section{Eligible studies}

Thirty-nine studies met the review criteria, the majority of which were performed in stable participants. Disease severity, as indicated by baseline $\mathrm{PaCO}_{2}$ and $\mathrm{PaO}_{2}$, varied widely.

\section{Studies in AECOPD}

Four of the 15 studies in AECOPD patients were randomised trials (Tables 1.1 and 1.2). Based on findings from the randomised trials, and supported by results from the nonrandomised trials, six key interpretations can be made. 


\begin{tabular}{|c|c|c|c|c|c|c|c|c|c|}
\hline \multirow[t]{2}{*}{ 1st author } & \multirow[t]{2}{*}{ Year } & \multirow[t]{2}{*}{$\mathbf{N}$} & \multicolumn{2}{|c|}{ Baseline values } & \multicolumn{3}{|c|}{ Interventions } & \multicolumn{2}{|c|}{$\mathrm{PaCO}_{2}$} \\
\hline & & & $\begin{array}{c}\text { Mean } \\
\mathrm{PaCO}_{2} \\
(\mathrm{mmHg})\end{array}$ & $\begin{array}{c}\text { Mean } \\
\mathrm{PaO}_{2} \\
(\mathrm{mmHg})\end{array}$ & Oxygen & Control & $\begin{array}{c}\text { Duration } \\
\text { (min) }\end{array}$ & $\begin{array}{c}\text { Mean } \\
\text { change from } \\
\text { baseline } \\
(\mathrm{mmHg})\end{array}$ & $\begin{array}{c}\text { Maximum } \\
\text { change from } \\
\text { baseline } \\
\text { (mmHg) }\end{array}$ \\
\hline Eldridge $^{58 *}$ & 1968 & 11 & 60 & 40 & $\begin{array}{c}2-3 \mathrm{~L} / \mathrm{min} \text { via } \\
\text { nasal cannula } \\
\text { or face mark }\end{array}$ & $\begin{array}{l}\text { 6-12 L/min via } \\
\text { nasal cannula or } \\
\text { face mark }\end{array}$ & $\geq 20$ & 5.3 & $\begin{array}{l}\text { Oxygen: } 25 \\
\text { Control: } 11\end{array}$ \\
\hline Gunawardena $^{31}$ & 1984 & 16 & 49 & 58 & $\begin{array}{c}8 \mathrm{~L} / \text { minute } \\
\text { oxygen-driven } \\
\text { nebuliser }\end{array}$ & $\begin{array}{l}8 \mathrm{~L} / \mathrm{minute} \text { air- } \\
\text { driven nebuliser }\end{array}$ & 15 & 6.0 & $\begin{array}{l}\text { Oxygen: } 22 \\
\text { Control: NR }\end{array}$ \\
\hline O’Donnell $^{59}$ & 1985 & 10 & 51 & 52 & $\begin{array}{c}7 \mathrm{~L} / \text { minute } \\
\text { oxygen-driven } \\
\text { nebuliser }\end{array}$ & $\begin{array}{l}7 \mathrm{~L} / \text { minute air- } \\
\text { driven nebuliser }\end{array}$ & 10 & $\begin{array}{c}6.9 \\
\text { (estimate) }^{* * *}\end{array}$ & $\begin{array}{l}\text { Oxygen: } 22.5 \\
\text { Control: NR }\end{array}$ \\
\hline Bardsley $^{57}$ & 2017 & 89 & 38 & NR** & $\begin{array}{c}8 \mathrm{~L} / \text { minute } \\
\text { oxygen-driven } \\
\text { nebuliser }\end{array}$ & $\begin{array}{l}8 \mathrm{~L} / \text { minute air- } \\
\text { driven nebuliser } \\
\text { with supplemental } \\
\text { nasal prong oxygen } \\
\text { titrated to maintain } \\
\mathrm{SpO}_{2} 88-92 \%\end{array}$ & $\begin{array}{c}35 \text { (two } 15 \\
\text { minute } \\
\text { interventions, } \\
\text { separated by } 5 \\
\text { min) }\end{array}$ & 3.3 & $\begin{array}{c}\text { Oxygen: } 10^{\wedge} \\
\text { Control: }<4\end{array}$ \\
\hline
\end{tabular}

Table 1.1 Randomised trials investigating the effects of oxygen therapy on mean $\mathrm{PaCO}_{2}$ in AECOPD

AECOPD: Acute exacerbation of chronic obstructive pulmonary disease, NR: Not reported, $\mathrm{PaCO}_{2}$ : Arterial partial pressure of carbon dioxide, PaO 2 : Arterial partial pressure of oxygen, $\mathrm{PcCO}_{2}$ : Capillary partial pressure of carbon dioxide, $\mathrm{PtCO}_{2}$ : Transcutaneous partial pressure of carbon dioxide, $\mathrm{SpO}$ : Oxygen saturation measured by pulse oximetry.

* Data have been combined into a high concentration 'oxygen' and low concentration 'control' group for comparability. If multiple FiO ${ }_{2}$ levels were available for each group the $\mathrm{PaCO}_{2}$ corresponding to the lowest $\mathrm{FiO}_{2}$ for the control group, and highest $\mathrm{FiO}_{2}$ for the oxygen group was selected. There were 8 patients who did not receive oxygen in these comparative groups. When instead the highest and lowest $\mathrm{FiO}_{2}$ values were compared for all 19 participants, the difference in $\mathrm{PaCO} 2$ was 4.8 mmHg. $\mathrm{Mean}$ change in $\mathrm{PaCO}_{2}$ from baseline is the differences at 20 minutes between interventions only, as baseline values prior to each intervention were not presented, maximum change values are calculated from initial value on air prior to interventions. Legend continued overleaf. 


\section{Table 1.1 Randomised trials investigating the effects of oxygen therapy on mean $\mathrm{PaCO}_{2}$ in $\mathrm{AECOPD}$ continued}

**Average $\mathrm{SpO}_{2}$ was $92.6 \%$.***Data derived from figures presented by the authors. ${ }^{\wedge}$ Maximum allowable change was $10 \mathrm{mmHg}$, as this was the criterion for participant withdrawal, which occurred in one participant.

All studies are cross over except Bardsley et al. ${ }^{57}$ Presented $\mathrm{PaCO}_{2}$ data are taken from the latest time point during the intervention. $\mathrm{Change} \mathrm{in} \mathrm{mean} \mathrm{PaCO}_{2}$ is the mean difference from baseline in the oxygen minus control intervention unless otherwise stated. $\mathrm{PaCO}_{2}$ measurements may be $\mathrm{PcCO}_{2}$ or $\mathrm{PtCO}_{2}$ values. With the exception of oxygen concentration, data presented in subgroups has been combined to present an overall value for all participants in each study. 
Please see the following page for Table 1.2. 


\begin{tabular}{|c|c|c|c|c|c|c|c|c|}
\hline \multirow[b]{2}{*}{ 1st author } & \multirow[b]{2}{*}{ Year } & \multirow[b]{2}{*}{$\mathbf{N}$} & \multicolumn{2}{|c|}{ Baseline } & \multicolumn{2}{|l|}{ Intervention } & \multicolumn{2}{|c|}{$\mathrm{PaCO}_{2}$} \\
\hline & & & $\begin{array}{c}\mathrm{PaCO}_{2} \\
(\mathrm{mmHg})\end{array}$ & $\begin{array}{c}\mathrm{PaO}_{2} \\
(\mathbf{m m H g})\end{array}$ & Delivery & $\begin{array}{c}\text { Duration } \\
\text { (min) }\end{array}$ & $\begin{array}{l}\text { Mean change from } \\
\text { baseline } \\
\text { (mmHg) }\end{array}$ & $\begin{array}{c}\text { Maximum change } \\
\text { from baseline } \\
(\mathrm{mmHg})\end{array}$ \\
\hline Comroe $^{60 *}$ & 1950 & 6 & 73 & $\mathrm{NR}^{* *}$ & $\begin{array}{l}100 \% \text { oxygen via unspecified } \\
\text { method }\end{array}$ & 10 to 240 & 16.7 & 34 \\
\hline \multirow{2}{*}{ Miller ${ }^{61 * * *}$} & \multirow{2}{*}{1968} & 7 & 52 & $\mathrm{NR} * *$ & $\begin{array}{l}30 \% \text { oxygen via unspecified } \\
\text { method }\end{array}$ & \multirow{2}{*}{$\geq 12$} & -0.3 & 6 \\
\hline & & 30 & 48 & $\mathrm{NR}^{* *}$ & $\begin{array}{l}100 \% \text { oxygen via unspecified } \\
\text { method }\end{array}$ & & 6.2 & 22 \\
\hline \multirow{3}{*}{ Smith $^{62 \wedge}$} & \multirow{3}{*}{1968} & 20 & \multirow{3}{*}{64} & \multirow{3}{*}{$\mathrm{NR} * *$} & $24 \%$ via 'ventimask' & 240 & -4.4 & \multirow{3}{*}{13} \\
\hline & & 2 & & & $24-28 \%$ via 'ventimask' & 240 & -4.5 & \\
\hline & & 3 & & & $28 \%$ via 'ventimask' & 240 & 2.0 & \\
\hline \multirow{2}{*}{ Warrell $^{63}$} & \multirow{2}{*}{1970} & \multirow{2}{*}{7} & \multirow{2}{*}{71} & \multirow{2}{*}{30} & $24.5 \%$ via 'ventimask' & 150 & 4.3 & $9^{\# \#}$ \\
\hline & & & & & $28 \%$ via 'ventimask' & $120^{\wedge \wedge}$ & 7.7 & 22.2 \\
\hline Rudolf ${ }^{64}$ & 1979 & 10 & 58 & 49 & $\begin{array}{l}4 \mathrm{~L} / \mathrm{min} \text { via medium } \\
\text { concentration mask }\end{array}$ & 60 & 8.8 & NR \\
\hline Degaute $^{65}$ & 1981 & 35 & 59 & 45 & $28 \%$ via 'ventimask' & 60 & 4 & NR \\
\hline Aubier ${ }^{66}$ & 1980 & 20 & 61 & 38 & $\begin{array}{c}5 \mathrm{~L} / \mathrm{min} \text { via mouthpiece, } \\
\text { minute ventilation was around } \\
10 \mathrm{~L} / \mathrm{min}\end{array}$ & 30 & 7.3 & NR \\
\hline Aubier ${ }^{67}$ & 1980 & 22 & 65 & 38 & Pure oxygen via mouthpiece & 13 to 15 & 23 & 76 \\
\hline
\end{tabular}

Table 1.2 Non-randomised trials investigating the effects of oxygen therapy on mean $\mathrm{PaCO}_{2}$ in $\mathrm{AECOPD}$

Table continues with legend overleaf. 


\begin{tabular}{|c|c|c|c|c|c|c|c|c|}
\hline \multirow[b]{2}{*}{ 1st author } & \multirow[b]{2}{*}{ Year } & \multirow[b]{2}{*}{$\mathbf{N}$} & \multicolumn{2}{|c|}{ Baseline } & \multicolumn{2}{|l|}{ Intervention } & \multicolumn{2}{|c|}{$\mathrm{PaCO}_{2}$} \\
\hline & & & $\begin{array}{c}\mathrm{PaCO}_{2} \\
(\mathrm{mmHg})\end{array}$ & $\begin{array}{c}\mathrm{PaO}_{2} \\
(\mathbf{m m H g})\end{array}$ & Delivery & $\begin{array}{c}\text { Duration } \\
\quad(\mathrm{min})\end{array}$ & $\begin{array}{c}\text { Mean change from } \\
\text { baseline } \\
(\mathrm{mmHg})\end{array}$ & $\begin{array}{c}\text { Maximum change } \\
\text { from baseline } \\
(\mathrm{mmHg})\end{array}$ \\
\hline \multirow{4}{*}{ Lejeune $^{68}$} & \multirow{4}{*}{1984} & \multirow{2}{*}{12} & \multirow{2}{*}{50} & \multirow{2}{*}{45} & $24 \%$ via 'mask' & 20 & 1 & \multirow{4}{*}{ NR } \\
\hline & & & & & $28 \%$ via 'mask' & $20^{\wedge \wedge}$ & 2 & \\
\hline & & \multirow{2}{*}{10} & \multirow{2}{*}{51} & \multirow{2}{*}{43} & $35 \%$ via 'mask' & 20 & 4 & \\
\hline & & & & & $40 \%$ via 'mask' & $20^{\wedge \wedge}$ & 5 & \\
\hline Robinson $^{69}$ & 2000 & 22 & 53 & 58 & $100 \%$ oxygen via nasal mask & $\geq 20$ & 3.9 & 19.6 \\
\hline Moloney $^{70 \#}$ & 2001 & 24 & 56 & 47 & $\begin{array}{l}\text { Titration to } \mathrm{SpO}_{2} 91-92 \% \text { via } \\
\text { Venturi mask }(24-40 \%)\end{array}$ & 120 & 0.7 & $25^{\# \#}$ \\
\hline
\end{tabular}

\section{Table 1.2 Non-randomised trials investigating the effects of oxygen therapy on mean $\mathrm{PaCO}_{2}$ in AECOPD continued}

AECOPD: Acute exacerbation of Chronic Obstructive Pulmonary Disease, NR: Not reported, $\mathrm{PaCO}_{2}$ : Arterial partial pressure of carbon dioxide, PaO ${ }_{2}$ : Arterial partial pressure of oxygen, $\mathrm{PcCO}_{2}$ : Capillary partial pressure of carbon dioxide, $\mathrm{PtCO}_{2}$ : Transcutaneous partial pressure of carbon dioxide, $\mathrm{SpO} 2$ : Arterial oxygen saturation.

* Two additional participants are not presented in the Table due to differing oxygen regimens: $45 \%$ oxygen for 17 hours corresponding to increased PaCO ${ }_{2}$ from baseline of $52 \mathrm{mmHg}$, and $100 \%$ oxygen for 90 minutes followed by 2 hours via a nasal catheter, which corresponded to increased PaCO $\mathrm{C}_{2}$ from baseline of $12 \mathrm{mmHg}$, data is a subset of the 65 participants studied that had mental changes with oxygen administration, an average from entire dataset was not presented. Participants assumed to be in acute setting, though not directly stated by authors. **Mean oxygen saturation values for Comroe, ${ }^{60}$ Miller $^{61} 30 \%$ group, Miller ${ }^{61} 100 \%$ group and Smith ${ }^{62}$ were 73.3 , 81.7, 83.2 and $60.8 \%$, respectively. $* * *$ Participants were not directly stated as acute or stable, however assumed AECOPD based on blood gas values at baseline, note that there was overlap between participants, with 5 in both the $30 \%$ and $100 \%$ groups. Legend continued overleaf. 


\section{Table 1.2 Non-randomised trials investigating the effects of oxygen therapy on mean $\mathrm{PaCO}_{2}$ in AECOPD continued}

$\wedge$ For this study: $\mathrm{N}$ is number of admissions, it is possible there were repeat participants, participants also demonstrated mean $\mathrm{PaCO} \mathrm{O}_{2}$ decreases on oxygen $\geq 8$ mmHg, with one decrease of $44 \mathrm{mmHg} .{ }^{\wedge}$ Immediately following intervention above. ${ }^{\wedge} \wedge$ Note it is not currently recommended to use flows as low as $4 \mathrm{~L} / \mathrm{min}$ with medium concentration masks due to risk of carbon dioxide retention through rebreathing. ${ }^{11,71,72}$ "Participants also demonstrated $\mathrm{PaCO}_{2}$ decrease from baseline of up to approximately 25 mmHg. \#\#) Data estimated from graphs.

Baseline values are mean values. Presented $\mathrm{PaCO}_{2}$ data are taken from the latest time point during the intervention. $\mathrm{Change}$ in mean $\mathrm{PaCO}$ is the mean difference from baseline. $\mathrm{PaCO}_{2}$ measurements may be $\mathrm{PcCO}_{2}$ or $\mathrm{PtCO}_{2}$ values. With the exception of oxygen concentration, data presented in subgroups has been combined to present an overall value for all participants in each study. 
1. $\mathrm{PtCO}_{2}$ changes in response to oxygen delivery can be physiologically and clinically significant.

Elbridge et $\mathrm{al}^{58}$ recruited 19 AECOPD patients with a baseline $\mathrm{PaCO}_{2}$ of at least $50 \mathrm{mmHg}$. Patients were administered oxygen at various flow rates in random order from 2 to $12 \mathrm{~L} / \mathrm{min}$, delivered for at least 20 minutes at a time via nasal cannula or oropharyngeal mask. Unfortunately, not all participants were given the same $\mathrm{FiO}_{2}$ levels and it is not stated how the $\mathrm{FiO}_{2}$ values were selected or whether washout periods were given between the differing flows. However, by analysing the individual data it can be seen that differences in $\mathrm{PaCO}_{2}$ in relation to oxygen delivery were physiologically and clinically significant. This was apparent in data from individual participants and by comparison of mean $\mathrm{PaCO}_{2}$ values at lower and higher oxygen flows. Nine participants had a difference of $\geq 4 \mathrm{mmHg}$ between a lower and higher flow, which can be considered a physiologically significant difference. ${ }^{13,14,73}$ In three of these participants the difference was $\geq 8 \mathrm{mmHg}$, which may be considered a clinically significant difference. ${ }^{13,14}$ The largest change in $\mathrm{PaCO}_{2}$ occurred between oxygen delivered at $2 \mathrm{~L} / \mathrm{min}$ and $12 \mathrm{~L} / \mathrm{min}$, which was associated with a $22 \mathrm{mmHg}$ increase in $\mathrm{PaCO}_{2}$ in one participant. This was associated with a 0.15 reduction in $\mathrm{pH}$, which is also a potentially clinically significant change, as outlined in Section 1.2.

Recognising that oxygen exposure during nebuliser administration might also result in clinically significant increases in $\mathrm{PaCO}_{2}$, Gunawardena et $\mathrm{al}^{31}$ and $\mathrm{O}^{\prime}$ Donnell et al ${ }^{59}$ performed cross over studies comparing the effects of oxygen-driven and air-driven nebulisation. Similar to Eldridge's study, the highest increase in a participant's $\mathrm{PaCO}_{2}$ from baseline during oxygen exposure was 22 and $22.5 \mathrm{mmHg}$, respectively. Overall Gunawardena et al found a mean $6 \mathrm{mmHg} \mathrm{PtCO}_{2}$ increase from baseline during oxygendriven nebulisation, when compared to air-driven nebulisation. In O'Donnell et al's study it was approximately $6.9 \mathrm{mmHg}$. Additionally, O’Donnell et al presented data in a subgroup of participants who were $\mathrm{CO}_{2}$ retainers at baseline $(\mathrm{n}=6)$, in which the mean $\mathrm{PaCO}_{2}$ increased $12.5 \mathrm{mmHg}$ on oxygen-driven nebulisers, compared to air-driven nebulisers. This was also accompanied by a reduction in $\mathrm{pH}$.

From 2015 I was involved in a study with Bardsley et al ${ }^{57}$ which further investigated the risks of oxygen-driven nebulisers in 89 patients with AECOPD (currently pending 
publication, for further details on involvement and registration see Appendix 1, Section A.4.4). Participants were randomised to receive either oxygen or air-driven nebulisation. Two nebulisers were delivered by the randomised gas over 15 minutes, separated by five minutes in between. Participants receiving air-driven nebulisation had oxygen titrated, if required, via nasal cannulae to $\mathrm{SpO}_{2}$ of 88-92\%, as was done in Austin et al's 2010 study. ${ }^{12}$ By the end of the second intervention the difference in $\mathrm{PtCO}_{2}$ for oxygen compared to airdriven nebulisations was $3.3 \mathrm{mmHg}$ (95\% CI 2.7 to 3.9), $\mathrm{P}<0.001$. Two participants had a $\mathrm{PtCO}_{2}$ increase $\geq 8 \mathrm{mmHg}$ from baseline, both during the oxygen-driven regimen. Eighteen participants had a $\mathrm{PtCO}_{2}$ increase $\geq 4 \mathrm{mmHg}$ from baseline, all in the oxygen-driven nebuliser group, risk difference $40 \%$ (95\% CI 25.7 to 54.3), $\mathrm{P}<0.001$. In patients that had capillary blood gas sampling done the mean pH changed by -0.015 (95\% CI -0.024 to $0.008), \mathrm{P}<0.001$ in the group randomised to oxygen-driven nebulisers, compared to the group that received air-driven nebulisers. This was associated with a mean increase in $\mathrm{PcCO}_{2}$ of $2.0 \mathrm{mmHg}(95 \% \mathrm{CI} 1.1$ to 2.8$), \mathrm{P}<0.001$. The participant with the largest reduction in $\mathrm{pH}$ from baseline, of 0.06 , had a rise in $\mathrm{PcCO}_{2}$ of $9 \mathrm{mmHg}$.

The non-randomised studies in AECOPD also support the potential for oxygen to cause physiological and clinically significant changes in $\mathrm{PaCO}_{2}$. Many of the studies reported large increases in $\mathrm{PaCO}_{2}$ from baseline in individual participants (Table 1.2), ${ }^{60,61,63,67,69,70}$ and all studies except three $e^{62,69,70}$ reported mean $\mathrm{PaCO}_{2}$ changes of $\geq 4$ or more from baseline at one or more of the oxygen flows delivered. Additionally, Aubier et $\mathrm{al}^{67}$ measured $\mathrm{pH}$ and found mean values decreased from baseline by 0.09 during $100 \%$ oxygen delivery $(\mathrm{P}<0.001)$, in conjunction with a mean $22 \mathrm{mmHg}$ increase in $\mathrm{PaCO}_{2}(\mathrm{P}<0.001)$. Lejeune et $\mathrm{al}^{68}$ also measured $\mathrm{pH}$, which decreased from baseline by $0.04(\mathrm{P}<0.001)$ on breathing $40 \%$ oxygen, associated with a mean $\mathrm{PaCO}_{2}$ increase of $5 \mathrm{mmHg}(\mathrm{P}<0.001)$.

2. Significant $\mathrm{PaCO}_{2}$ changes can occur in response to small changes in the concentration of oxygen delivery

Eldridge et al's study ${ }^{58}$ demonstrated that changes in $\mathrm{PaCO}_{2}$ could occur at flows as low as $2 \mathrm{~L} / \mathrm{min}$. After oxygen administration at $2 \mathrm{~L} / \mathrm{min}$ for 20 minutes in 17 participants there was an average $\mathrm{PaCO}_{2}$ increase of $5.2 \mathrm{mmHg}$ from baseline, with increases of $\geq 8 \mathrm{mmHg}$ in three participants. Similarly, the participants in Warrell et al's non-randomised study ${ }^{63}$ had a 
mean $\mathrm{PaCO}_{2}$ increase of $4.3 \mathrm{mmHg}$ during $24.5 \%$ oxygen delivery and $7.7 \mathrm{mmHg}$ during $28 \%$ oxygen delivery.

3. $\mathrm{PaCO}_{2}$ changes in response to oxygen delivery appear to have a positive dose dependent relationship with $\mathrm{FiO}_{2}$.

In 17 of the 19 participants in Eldridge et al's study, ${ }^{58}$ there was a sequential increase in $\mathrm{PaCO}_{2}$, for every increase in oxygen flow. The mean $\mathrm{PaCO}_{2}$ was $5.3 \mathrm{mmHg}$ higher after delivery of oxygen at a flow of $6 \mathrm{~L} / \mathrm{min}$ or more, compared to delivery at $3 \mathrm{~L} / \mathrm{min}$ or less (Table 1.1). The non-randomised trials by Lejeune et $\mathrm{al}^{68}$ and Warrell at al ${ }^{63}$ also demonstrated increases in mean $\mathrm{PaCO}_{2}$ with increased concentration of oxygen delivery (Table 1.2). An example of the clinical consequences of this relationship was presented by Campbell as a case study, in which a patient became semi-comatose on $34 \%$ oxygen administration with an increase in $\mathrm{PaCO}_{2}$ of $18 \mathrm{mmHg}$, and subsequently improved through the reduction of oxygen delivery to $28 \%{ }^{6}$

4. Changes in $\mathrm{PaCO}_{2}$ and $\mathrm{PaO}_{2} \underline{\text { in response to oxygen therapy can be variable, even at }}$ comparable $\mathrm{FiO}_{2}$ values

Variability in responses to oxygen have been observed both within individual studies and between them. For example, in the dataset from Eldridge et $\mathrm{al}^{58}$ there were three participants that were exposed to both $2 \mathrm{~L} / \mathrm{min}$ and $12 \mathrm{~L} / \mathrm{min}$ oxygen regimens. In one participant, the $\mathrm{PaCO}_{2}$ was $22 \mathrm{mmHg}$ higher at the end of $12 \mathrm{~L} / \mathrm{min}$ intervention compared to the $2 \mathrm{~L} / \mathrm{min}$ intervention. However, in the other two participants the difference in $\mathrm{PaCO}_{2}$ between the regimens was $\leq 3 \mathrm{mmHg}$. In the same three patients, the increase in $\mathrm{PaO}_{2}$ was also variable, ranging from 12 to $114 \mathrm{mmHg}$.

Similarly, there were individuals in each of the randomised trials by Gunawardena et al, ${ }^{31}$ O'Donnell et $\mathrm{al}^{59}$ and Bardsley et $\mathrm{al}^{57}$ that had no change in $\mathrm{PaCO}_{2}$ in response to oxygendriven nebulisers, yet other participants had significant changes of at least $10 \mathrm{mmHg}$ from baseline. Additionally, many of the non-randomised trials that reported individual participants had a change in $\mathrm{PaCO}_{2} \geq 8 \mathrm{mmHg}$ from baseline while receiving oxygen therapy 
also had participants in which there was no or a minimal increase in $\mathrm{PaCO}_{2}(\leq 1 \mathrm{mmHg})$ from baseline while on the same oxygen regimen. ${ }^{61-63}$

Figure 1.6 demonstrates that variability in $\mathrm{PaCO}_{2}$ response to oxygen is also apparent between studies, even when the delivered $\mathrm{FiO}_{2}$ is taken into account. Factors other than $\mathrm{FiO}_{2}$ must therefore be contributing to this variability. These may relate to participant factors (for example severity of disease) or methodological factors (such as the mode or duration of oxygen delivery). 


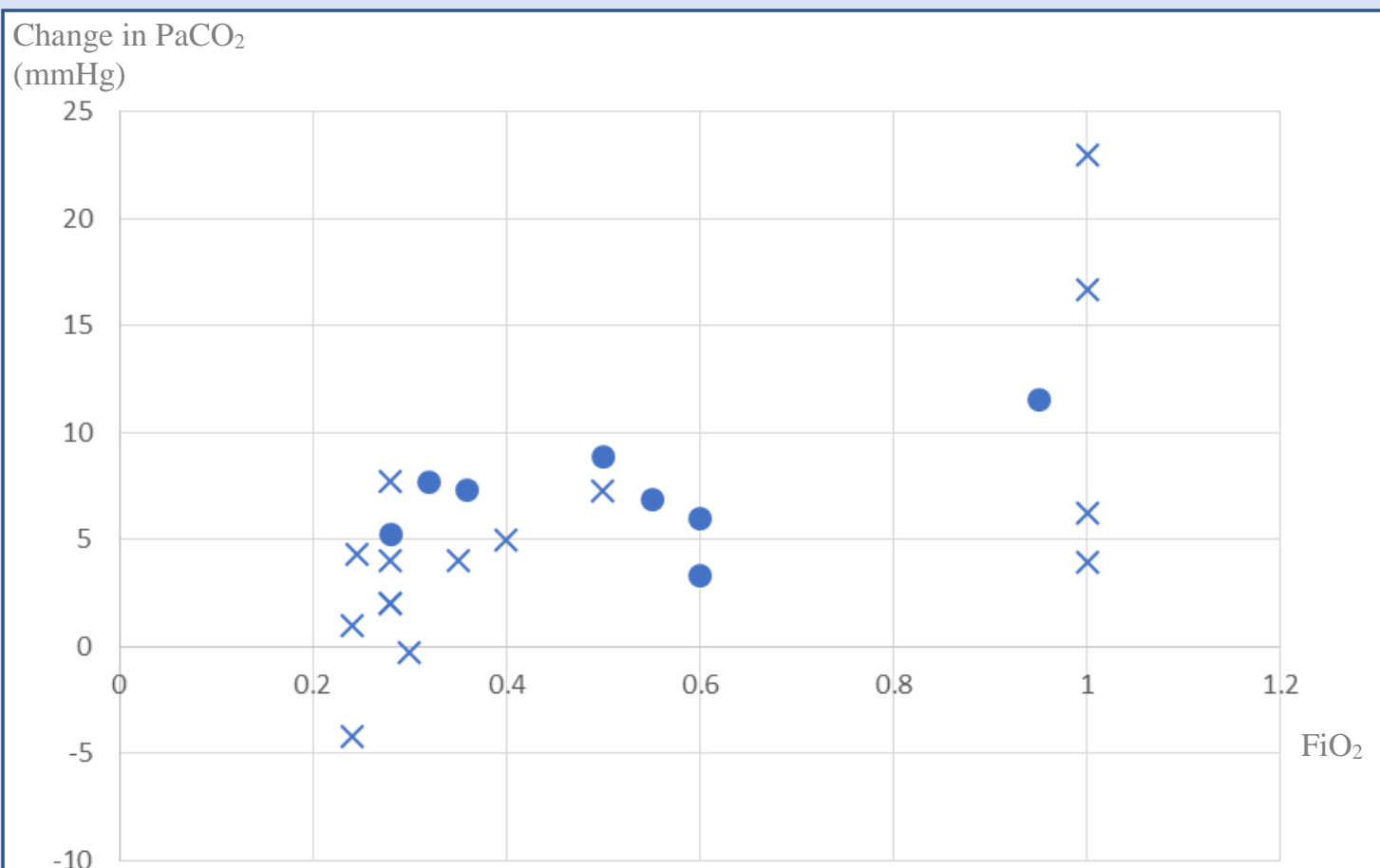

$-10$

Randomised trial in AECOPD $\quad \times$ Non-randomised trial in AECOPD

\begin{tabular}{|c|c|c|c|}
\hline & \multicolumn{4}{|c|}{ Randomised } \\
\hline \multirow{3}{*}{ 1st author } & $\mathbf{N}$ & $\begin{array}{c}\mathbf{F i O}_{2} \\
\text { estimate }\end{array}$ & $\begin{array}{c}\text { Change in } \\
\text { mean } \\
\mathbf{P a C O}_{2} \\
(\mathbf{m m H g})\end{array}$ \\
\hline \multirow{3}{*}{ Eldridge $^{58}$} & 17 & 0.28 & 5.2 \\
& 3 & 0.32 & 7.7 \\
\cline { 2 - 4 } & 7 & 0.36 & 7.3 \\
\cline { 2 - 4 } & 9 & 0.50 & 8.9 \\
\cline { 2 - 4 } & 4 & 0.95 & 11.5 \\
\hline Gunawardena $^{31}$ & 16 & 0.60 & 6.0 \\
\hline O'Donnell $^{59}$ & 10 & 0.55 & 6.9 \\
\hline Bardsley $^{57}$ & 89 & 0.60 & 3.3 \\
\hline
\end{tabular}

\begin{tabular}{|c|c|c|c|}
\hline \multicolumn{4}{|c|}{ Non-randomised } \\
\hline 1st author & $\mathbf{N}$ & $\underset{\text { estimate }}{\mathrm{FiO}_{2}}$ & $\begin{array}{c}\text { Change in } \\
\text { mean } \\
\mathrm{PaCO}_{2} \\
(\mathrm{mmHg})\end{array}$ \\
\hline Comroe $^{60}$ & 6 & 1 & 16.7 \\
\hline \multirow{2}{*}{ Miller $^{61}$} & 7 & 0.30 & -0.3 \\
\hline & 30 & 1 & 6.2 \\
\hline \multirow{2}{*}{ Smith $^{62 *}$} & 20 & 0.24 & -4.4 \\
\hline & 3 & 0.28 & 2 \\
\hline \multirow{2}{*}{ Warrell $^{63}$} & \multirow{2}{*}{7} & 0.245 & 4.3 \\
\hline & & 0.28 & 7.7 \\
\hline Degaute $^{65}$ & 35 & 0.28 & 4 \\
\hline Aubier $^{66}$ & 20 & 0.50 & 7.3 \\
\hline Aubier $^{67}$ & 22 & 1 & 23 \\
\hline \multirow{4}{*}{ Lejeune $^{68}$} & \multirow{2}{*}{12} & 0.24 & 1 \\
\hline & & 0.28 & 2 \\
\hline & \multirow{2}{*}{10} & 0.35 & 4 \\
\hline & & 0.40 & 5 \\
\hline Robinson $^{69}$ & 22 & 1 & 3.9 \\
\hline
\end{tabular}

\section{Figure 1.6 Mean $\mathrm{PaCO}_{2}$ changes compared to $\mathrm{FiO}_{2}$ in patients with $\mathrm{AECOPD}$}

AECOPD: Acute exacerbation of chronic obstructive pulmonary disease, $\mathrm{FiO}_{2}$ : Fraction of inspired oxygen, $\mathrm{PaCO}_{2}$ : Partial pressure of arterial carbon dioxide, $\mathrm{PcCO}_{2}$ : Capillary partial pressure of carbon dioxide.

$* \mathrm{~N}$ is number of admissions, it is possible there were repeat participants.

Note that data are not weighted by number of participants and $\mathrm{FiO}_{2}$ values are estimates based on descriptions of data in the Tables 1.1 and 1.2. For clarity these data are presented in the incorporated Table above. Legend continues overleaf. 
Figure 1.6 Mean $\mathrm{PaCO}_{2}$ changes compared to $\mathrm{FiO}_{2}$ in patients with AECOPD continued Change in mean $\mathrm{PaCO}_{2}$ is the mean difference from baseline in the oxygen minus control intervention in the randomised studies with the exception of Eldridge at al which is change from air at baseline. ${ }^{58}$ Change in mean $\mathrm{PaCO}_{2}$ is the mean difference from baseline in the non-randomised studies. Further details are provided in the legends of Tables 1.1 and 1.2. $\mathrm{PaCO}_{2}$ measurements may be $\mathrm{PcCO}_{2}$ or $\mathrm{PtCO}_{2}$ values. With the exception of $\mathrm{FiO}_{2}$, data presented in subgroups has been combined to present an overall value for all participants in each study. Data were included if $\mathrm{N}>2$ and an estimate was able to be made for $\mathrm{FiO}_{2}$. As such data from Moloney et $\mathrm{al}^{70}$ and Rudolf et $\mathrm{al}^{64}$ were not included, nor were data from $24-28 \%$ via 'ventimask' in Smith et al's study. ${ }^{62}$ Note that differing $\mathrm{FiO}_{2}$ 's from Eldridge et al ${ }^{58}$ and Warrell et al's ${ }^{63}$ studies were from the same participants. In Lejeune et al's study ${ }^{68}$ the 24 and $28 \%$ data were for the same participants, and the 35 and $40 \%$ were from the same participants. 
5. It is difficult to identify patient factors that predict the incidence and magnitude of $\underline{\mathrm{PaCO}_{2} \text { rise in response to oxygen }}$

A number of studies have attempted to identify whether certain baseline characteristics will predict whether a patient is at risk of oxygen-induced hypercapnia. However, the interpretation of the data available is limited.

Gunawardena et $\mathrm{al}^{31}$ and $\mathrm{O}^{\prime}$ Donnell et $\mathrm{al}^{59}$ each presented data from patients with baseline hypercapnia separately to patients without baseline hypercapnia. Significant increases in $\mathrm{PaCO}_{2}$ on oxygen compared to air-driven nebulisation were demonstrated only in the subgroups that had baseline hypercapnia. The increase was $7.7 \mathrm{mmHg}, \mathrm{P}<0.001$ in Gunawardena et al's study ( $\mathrm{N}=9)$ and $12.5 \mathrm{mmHg}, \mathrm{P}<0.001$ in O'Donnell's study (N=6). Compared to the other randomised trials, ${ }^{31,58,59}$ Bardsley et $\mathrm{al}^{57}$ recruited participants with a much lower mean baseline $\mathrm{PaCO}_{2}$ and demonstrated a smaller mean increase in $\mathrm{PaCO}_{2}$ during oxygen-driven nebulisation, compared to air-driven nebulisation. Of the 84 participants that had $\mathrm{PcCO}_{2}$ measured, 67 (80\%) were normocapnic $\left(\mathrm{PcCO}_{2} \leq 45 \mathrm{mmHg}\right)$ at baseline. Seven $(22 \%)$ of the normocapnic participants that received oxygen-driven nebulisation had a $\mathrm{PtCO}_{2}$ rise $\geq 4 \mathrm{mmHg}$ from baseline. In the hypercapnic participants, 7 (64\%) had a $\mathrm{PtCO}_{2}$ rise $\geq 4 \mathrm{mmHg}$ from baseline during oxygen-driven nebulisation. None of the participants in the study that received air-driven nebulisation had a $\mathrm{PtCO}_{2}$ rise $\geq 4$ $\mathrm{mmHg}$ from baseline. This suggests that while there may be a correlation between baseline $\mathrm{PaCO}_{2}$ and the likelihood or magnitude of an increase in $\mathrm{PaCO}_{2}$ in response to oxygen exposure, baseline hypercapnia is not a prerequisite for oxygen-induced elevations in $\mathrm{PaCO}_{2}$.

Contrasting data were gained in the two non-randomised studies that formally investigated predictors of a change in $\mathrm{PaCO}_{2}$ in response to oxygen. Moloney et $\mathrm{al}^{70}$ found no statistical relationship between baseline $\mathrm{PaO}_{2}, \mathrm{pH}$ or $\mathrm{PaCO}_{2}$ and likelihood of oxygen-induced elevations in $\mathrm{PaCO}_{2}$, however this may have been related to the overall mean increase in $\mathrm{PaCO}_{2}$ of only $0.7 \mathrm{mmHg}$ on oxygen in their participants. Robinson et al ${ }^{69}$ divided their participants into a 'retainer' subgroup (change in $\mathrm{PaCO}_{2} \geq 3 \mathrm{mmHg}$ from baseline in response to $100 \%$ oxygen) and non-retainer subgroup. There was no statistically significant 
difference in baseline $\mathrm{PaCO}_{2}$ between the subgroups, although the trend was towards a higher value in the retainers (56.3 versus $49.7 \mathrm{mmHg}$ ). The study investigators did, however, report $\mathrm{PaO}_{2}$ to be significantly lower in the retainer subgroup on room air, compared with the non-retainers $(54.5 \mathrm{mmHg}$ versus $62.6 \mathrm{mmHg}, \mathrm{P}=0.03)$.

\section{It is important to consider the impact of methodology on clinical applicability}

Oxygen delivery methods (including $\mathrm{FiO}_{2}$, delivery method and duration) and patient disease severity varied widely between the trials. This is likely to contribute to the variation in response to oxygen between the studies.

As an example, one factor which could account for variability observed between studies is the duration of oxygen administration. Gunawardena et al, ${ }^{31} \mathrm{O}^{\prime}$ Donnell et al ${ }^{59}$ and Bardsley et $\mathrm{al}^{57}$ all investigated the effects of oxygen over various time points and suggested that increases in $\mathrm{PaCO}_{2}$ are related to the length of time oxygen is administered. Elevations in $\mathrm{PaCO}_{2}$ were apparent within 5-6 minutes of oxygen exposure in all three studies, and $\mathrm{PaCO}_{2}$ continued to rise until the end of nebulisation. In a post hoc analysis, Bardsley et al demonstrated statistically significant differences in $\mathrm{PtCO}_{2}$ by time point, with an estimate of the time-related difference at 15 minutes minus six minutes, for oxygen compared to airdriven nebulisation, of $0.73 \mathrm{mmHg}$ (95\% CI 0.11 to 1.35 ), $\mathrm{P}=0.021$. However, the estimate for the difference between 35 minutes and 26 minutes was $0.43 \mathrm{mmHg}$ (95\% CI -0.19 to 1.06), $\mathrm{P}=0.17$. Data from Warrell et al, ${ }^{63}$ who presented $\mathrm{PaCO}_{2}$ values taken at 30 minute intervals during their oxygen regimens, were mixed. There was no evidence of an increasing $\mathrm{PaCO}_{2}$ with each time point over 150 minutes of $24.5 \%$ oxygen, but there was a trend towards an increase over time during $28 \%$ oxygen for 120 minutes. There were no comparative data on room air or oxygen delivery at a different $\mathrm{FiO}_{2}$, so it is difficult to evaluate the contribution of the participant's disease progression or response to other medical interventions over the study period. Overall the $\mathrm{PaCO}_{2}$ changes with time demonstrated in these studies are small and their contribution is unlikely to fully account for the variability in responses to oxygen between different studies. 


\section{Studies in stable COPD}

The trials in participants with stable COPD are presented in Tables 1.3 and 1.4. They tended to include patients with a lower mean baseline $\mathrm{PaCO}_{2}$ values compared to the trials in AECOPD. Mean changes in $\mathrm{PaCO}_{2}$ in response to oxygen at a given $\mathrm{FiO}_{2}$ also tended to be lower, with the majority sitting below $4 \mathrm{mmHg}$, as demonstrated in Figures $1.7 \mathrm{a}$ and $\mathrm{b}$. 


\begin{tabular}{|c|c|c|c|c|c|c|c|c|c|}
\hline \multirow[b]{2}{*}{ 1st author } & \multirow[b]{2}{*}{ Year } & \multirow[b]{2}{*}{$\mathbf{N}$} & \multicolumn{2}{|c|}{ Baseline values } & \multicolumn{3}{|c|}{ Interventions } & \multicolumn{2}{|c|}{$\mathrm{PaCO}_{2}$} \\
\hline & & & $\begin{array}{c}\text { Mean } \\
\mathrm{PaCO}_{2} \\
(\mathrm{mmHg})\end{array}$ & $\begin{array}{c}\text { Mean } \\
\mathrm{PaO}_{2} \\
(\mathbf{m m H g})\end{array}$ & Oxygen & Control & $\begin{array}{c}\text { Duration } \\
\text { (min) }\end{array}$ & $\begin{array}{c}\text { Mean } \\
\text { change } \\
\text { between } \\
\text { interventions } \\
(\mathrm{mmHg}) \\
\end{array}$ & $\begin{array}{c}\text { Maximum } \\
\text { change from } \\
\text { baseline } \\
\text { (mmHg) }\end{array}$ \\
\hline King $^{74}$ & 1973 & 10 & 52 & 49 & $\begin{array}{c}30 \% \text { oxygen via } \\
\text { mouthpiece* }\end{array}$ & $\begin{array}{l}\text { Room air via } \\
\text { mouthpiece* }\end{array}$ & 11 to 14 & 2.4 & NR \\
\hline Castaing $^{75}$ & 1985 & 14 & 51 & 55 & $\begin{array}{l}26 \% \text { oxygen via } \\
\text { mouthpiece }\end{array}$ & $\begin{array}{l}\text { Room air via } \\
\text { mouthpiece }\end{array}$ & 30 & 0.9 & NR \\
\hline Sassoon $^{76}$ & 1987 & 17 & 48 & $\mathrm{NR}^{* *}$ & $\begin{array}{l}\text { Oxygen via } \\
\text { mouthpiece } \\
\text { (mean 94\%) }\end{array}$ & $\begin{array}{l}\text { Room air via } \\
\text { mouthpiece }\end{array}$ & 15 & 4.4 & $15^{\wedge \wedge \wedge}$ \\
\hline \multirow{2}{*}{$\operatorname{Liss}^{77}$} & \multirow{2}{*}{1988} & \multirow{2}{*}{$8 * * *$} & \multirow{2}{*}{48} & \multirow{2}{*}{53} & $\begin{array}{l}2 \mathrm{~L} / \mathrm{min} \text { oxygen } \\
\text { via nasal prongs }\end{array}$ & $\begin{array}{l}2 \mathrm{~L} / \mathrm{min} \text { air via } \\
\text { nasal prongs }\end{array}$ & 5 & 2 & \multirow{2}{*}{ NR } \\
\hline & & & & & $\begin{array}{l}4 \mathrm{~L} / \mathrm{min} \text { oxygen } \\
\text { via nasal prongs }\end{array}$ & $\begin{array}{c}4 \mathrm{~L} / \mathrm{min} \text { air via } \\
\text { nasal prongs }\end{array}$ & 5 & 3 & \\
\hline Light $^{78}$ & 1989 & 17 & NR & NR & $\begin{array}{c}30 \% \text { oxygen via } \\
\text { mouthpiece* }\end{array}$ & $\begin{array}{l}\text { Room air via } \\
\text { mouthpiece* }\end{array}$ & 10 & 0.9 & NR \\
\hline \multirow{2}{*}{ Saadjian $^{79}$} & \multirow{2}{*}{1992} & \multirow{2}{*}{26} & \multirow{2}{*}{ NR } & \multirow{2}{*}{ NR } & $\begin{array}{c}30 \% \text { oxygen via } \\
\text { high } \\
\text { concentration } \\
\text { mask }\end{array}$ & $\begin{array}{c}21 \% \text { oxygen via } \\
\text { high concentration } \\
\text { mask }\end{array}$ & 20 & 1.95 & \multirow{2}{*}{ NR } \\
\hline & & & & & $\begin{array}{c}\text { 100\% oxygen via } \\
\text { high } \\
\text { concentration } \\
\text { mask }\end{array}$ & $\begin{array}{c}21 \% \text { oxygen via } \\
\text { high concentration } \\
\text { mask }\end{array}$ & 20 & 3.0 & \\
\hline
\end{tabular}

Table 1.3 Randomised trials investigating the effects of oxygen therapy on mean $\mathrm{PaCO}_{2}$ in stable COPD

Table continued overleaf. 


\begin{tabular}{|c|c|c|c|c|c|c|c|c|c|}
\hline \multirow[b]{2}{*}{ 1st author } & \multirow[b]{2}{*}{ Year } & \multirow[b]{2}{*}{$\mathbf{N}$} & \multicolumn{2}{|c|}{ Baseline values } & \multicolumn{3}{|c|}{ Interventions } & \multicolumn{2}{|c|}{$\mathrm{PaCO}_{2}$} \\
\hline & & & $\begin{array}{c}\text { Mean } \\
\mathrm{PaCO}_{2} \\
(\mathbf{m m H g})\end{array}$ & $\begin{array}{c}\text { Mean } \\
\mathrm{PaO}_{2} \\
(\mathbf{m m H g})\end{array}$ & Oxygen & Control & $\begin{array}{c}\text { Duration } \\
(\text { min) }\end{array}$ & $\begin{array}{c}\text { Mean } \\
\text { change } \\
\text { between } \\
\text { interventions } \\
\text { (mmHg) }\end{array}$ & $\begin{array}{c}\text { Maximum } \\
\text { change from } \\
\text { baseline } \\
(\mathrm{mmHg})\end{array}$ \\
\hline O'Donnell1 $^{73}$ & 1997 & 11 & 41 & 74 & $\begin{array}{c}60 \% \text { oxygen via } \\
\text { mouthpiece }\end{array}$ & $\begin{array}{c}\text { Room air via } \\
\text { mouthpiece }\end{array}$ & $\geq 5$ & 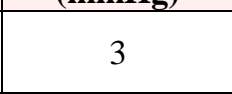 & NR \\
\hline $\mathrm{O}^{\prime}$ Donnell ${ }^{80}$ & 2002 & 20 & NR & $\mathrm{NR}^{* *}$ & $\begin{array}{l}60 \% \text { oxygen via } \\
\text { mouthpiece }\end{array}$ & $\begin{array}{c}\text { Room air via } \\
\text { mouthpiece }\end{array}$ & $\geq 10$ & 4.5 & $27^{\wedge \wedge \wedge}$ \\
\hline Edwards ${ }^{81}$ & 2011 & 18 & 48 & 62 & $\begin{array}{c}8 \mathrm{~L} / \text { minute } \\
\text { oxygen-driven } \\
\text { nebuliser }\end{array}$ & air-driven nebuliser & $\begin{array}{l}35 \text { (two } 15 \\
\text { minute } \\
\text { nebulisations } \\
\text { separated by } \\
5 \text { minutes) }\end{array}$ & $3.1^{\wedge}$ & $10^{\wedge \wedge}$ \\
\hline
\end{tabular}

Table 1.3 Randomised trials investigating the effects of oxygen therapy on mean $\mathrm{PaCO}_{2}$ in stable COPD continued

AECOPD: Acute exacerbation of Chronic Obstructive Pulmonary Disease, COPD: Chronic Obstructive Pulmonary Disease, NR: Not reported, PaCO 2 : Arterial partial pressure of carbon dioxide, $\mathrm{PaO}_{2}$ : Arterial partial pressure of oxygen, $\mathrm{PcCO}_{2}$ : Capillary partial pressure of carbon dioxide, $\mathrm{PtCO}_{2}$ : Transcutaneous partial pressure of carbon dioxide, $\mathrm{SpO}_{2}$ : Oxygen saturation measured by pulse oximetry.

*Assumed mouthpiece based on description of equipment, however not directly stated. ** Oxygen saturation at baseline $91.9 \%$ for Sassoon ${ }^{76}$ and $83 \%$ for O'Donnell. ${ }^{80}$ *** Two participants were hospital inpatients, reported to be clinically stable during interventions.

${ }^{\wedge}$ Change is change in $\mathrm{PaCO}_{2}$ from baseline in the oxygen minus air intervention. ${ }^{\wedge}$ Maximum allowable change was $10 \mathrm{mmHg}$, as this was a criterion for participant withdrawal, which occurred in one participant. ${ }^{\wedge \wedge}$ Estimated from graph.

All studies are cross over design. Presented $\mathrm{PaCO}_{2}$ data are taken from the latest time point during the intervention. Change in mean $\mathrm{PaCO}_{2}$ is the mean difference in the final $\mathrm{PaCO}_{2}$ in the oxygen minus control intervention unless otherwise stated. $\mathrm{PaCO}_{2}$ measurements may be $\mathrm{PcCO}_{2}$ or $\mathrm{PtCO}_{2}$ values. With the exception of oxygen concentration, data presented in subgroups has been combined to present an overall value for all participants in each study.

Legend continued overleaf. 


\section{Table 1.3 Randomised trials investigating the effects of oxygen therapy on mean $\mathrm{PaCO}_{2}$ in stable COPD continued}

A study of note not included in the Table was by Mithoefer et al in $1978^{82}$ as it was unclear whether participants had stable COPD or AECOPD. They were randomised to receive air, $24 \%$ oxygen, $28 \%$ oxygen, $35 \%$ oxygen and $40 \%$ oxygen each for 20 minutes in random order via a mouthpiece. $\mathrm{Mean}_{\mathrm{PaCO}}$ for each intervention was 37,39 , $39,39,39 \mathrm{mmHg}$, respectively in patients that were not hypercapnic at baseline. Mean $\mathrm{PaCO}_{2}$ for each intervention was 55, 56, 57, 57, 57 mmHg, respectively in patients that were hypercapnic at baseline. Another study of note not included in the Table was by Massaro et al in $1962,{ }^{83}$ as data were not presented in numerical form and it was unclear if participants were stable or had AECOPD. Participants were randomised to oxygen via a mask or nasal prongs and it appeared that in some participants there were physiologically significant increases in $\mathrm{PaCO}_{2}(\geq 4 \mathrm{mmHg})$ within 10 minutes of mask or nasal prong use, while with mask use there were clinically significant increases in $\mathrm{PaCO}_{2}(\geq 8 \mathrm{mmHg})$. A third study, by Richards et al in $1958^{84}$ was also omitted from the Table as it was unclear whether it was conducted in stable patients or those with AECOPD. Participants breathed air and 50\% oxygen in random order. Mean $\mathrm{PaCO}_{2}$ was $37 \mathrm{mmHg}$ on air and $39 \mathrm{mmHg}$ on 50\% oxygen in patients that were not hypercapnic at baseline. Mean $\mathrm{PaCO}_{2}$ was $50 \mathrm{mmHg}$ on air and $55 \mathrm{mmHg}$ on $50 \%$ oxygen in patients that were hypercapnic at baseline, one participant had an increase of $8 \mathrm{mmHg}$ on oxygen compared to air, another had an increase of $21 \mathrm{mmHg}$. 
Please see the following page for Table 1.4. 


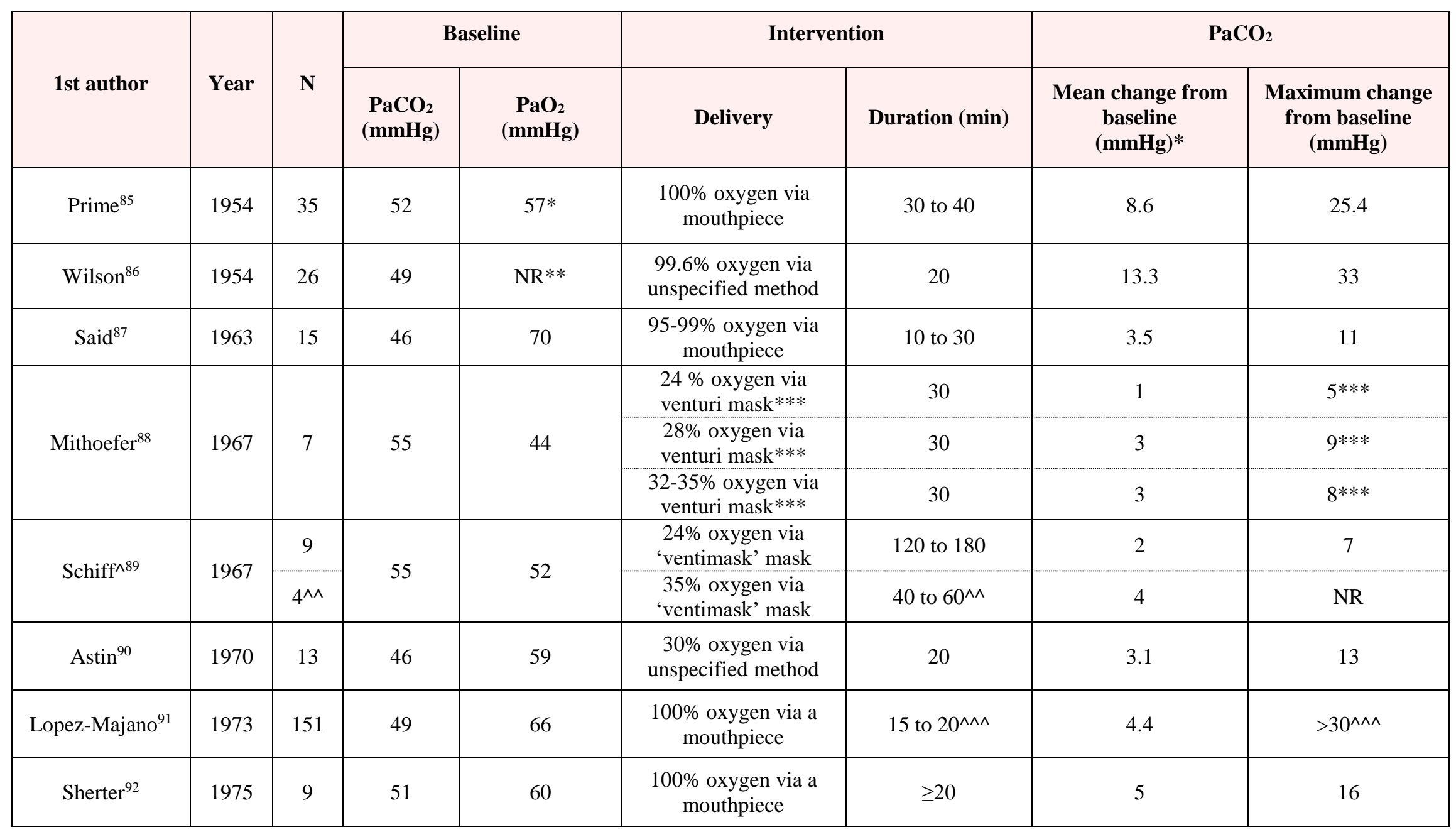

Table 1.4 Non-randomised trials investigating the effects of oxygen therapy on mean $\mathrm{PaCO}_{2}$ in stable COPD

Table Continued overleaf. 


\begin{tabular}{|c|c|c|c|c|c|c|c|c|}
\hline \multirow[b]{2}{*}{ 1st author } & \multirow[b]{2}{*}{ Year } & \multirow[b]{2}{*}{$\mathbf{N}$} & \multicolumn{2}{|c|}{ Baseline } & \multicolumn{2}{|c|}{ Intervention } & \multicolumn{2}{|c|}{$\mathrm{PaCO}_{2}$} \\
\hline & & & $\begin{array}{c}\mathrm{PaCO}_{2} \\
(\mathrm{mmHg})\end{array}$ & $\begin{array}{c}\mathrm{PaO}_{2} \\
(\mathbf{m m H g})\end{array}$ & Delivery & Duration (min) & $\begin{array}{c}\text { Mean change from } \\
\text { baseline } \\
(\mathrm{mmHg}) *\end{array}$ & $\begin{array}{c}\text { Maximum change } \\
\text { from baseline } \\
\text { (mmHg) }\end{array}$ \\
\hline Pietak $^{93}$ & 1975 & 12 & 41 & 74 & $\begin{array}{c}100 \% \text { humidified } \\
\text { oxygen via } \\
\text { mouthpiece } \\
\end{array}$ & 30 & 1 & NR \\
\hline \multirow{3}{*}{ Bone $^{94}$} & \multirow{3}{*}{1978} & \multirow{3}{*}{20} & \multirow{3}{*}{42} & \multirow{3}{*}{68} & $\begin{array}{l}28 \% \text { oxygen from } \\
\text { reservoir-two way } \\
\text { valve system }\end{array}$ & $\geq 30$ & 2 & 18 \\
\hline & & & & & $\begin{array}{l}35 \% \text { oxygen from } \\
\text { reservoir-two way } \\
\text { valve system }\end{array}$ & $\geq 30$ & 3.5 & 8 \\
\hline & & & & & $\begin{array}{c}40 \% \text { oxygen from } \\
\text { reservoir-two way } \\
\text { valve system }\end{array}$ & $\geq 30$ & 3.5 & 15 \\
\hline Aubier $^{66}$ & 1980 & 12 & 47 & 54 & $\begin{array}{c}5 \mathrm{~L} / \mathrm{min} \text { via } \\
\text { mouthpiece, minute } \\
\text { ventilation was around } \\
10 \mathrm{~L} / \mathrm{min} \\
\end{array}$ & 30 & 2.8 & NR \\
\hline Kawakami $^{95 \#}$ & 1983 & 28 & NR & NR & $\begin{array}{c}\text { 'Humidified pure } \\
\text { oxygen' }\end{array}$ & 60 & 1.4 & NR \\
\hline Dick $^{96}$ & 1997 & 11 & 53 & 62 & $\begin{array}{c}100 \% \text { oxygen via } \\
\text { mouthpiece }\end{array}$ & 15 & $6.6^{\# \#}$ & NR \\
\hline Chiang $^{97}$ & 2002 & 26 & 44 & 69 & $\begin{array}{c}2 \mathrm{~L} / \mathrm{min} \text { via nasal } \\
\text { cannula }\end{array}$ & 60 & 4.1 & NR \\
\hline Perrin $^{98}$ & 2010 & 18 & 40 & $\mathrm{NR}^{\# \# \#}$ & $\begin{array}{c}100 \% \text { via CPAP mask } \\
\text { without positive } \\
\text { pressure }\end{array}$ & 20 & 4.4 & NR \\
\hline
\end{tabular}

Table 1.4 Non-randomised trials investigating the effects of oxygen therapy on mean $\mathrm{PaCO}_{2}$ in stable COPD continued

Legend overleaf. 
COPD: Chronic Obstructive Pulmonary Disease, CPAP: Continuous positive airway pressure mask, NR: Not reported, $\mathrm{PaCO}_{2}$ : Arterial partial pressure of carbon dioxide, $\mathrm{PaO}_{2}$ : Arterial partial pressure of oxygen, $\mathrm{PcCO}_{2}$ : Capillary partial pressure of carbon dioxide, $\mathrm{PtCO}_{2}$ : Transcutaneous partial pressure of carbon dioxide, $\mathrm{SpO}$ : Oxygen saturation measured by pulse oximetry.

* Data available for 31 participants only. ** Mean oxygen saturation was $83.0 \%$.*** Order of the interventions was randomised, however the comparison to room air was by comparison to baseline (not randomised) so the study was included in this Table for simplicity, values for maximum change from baseline were estimated from graphs. $\wedge$ Some participants were reported to be convalescing from acute respiratory failure, but were considered to be in a stable state. ${ }^{\wedge}$ Four of the nine participants went on to receive the $35 \%$ intervention following the $24 \%$ intervention. ${ }^{\wedge} \wedge$ In participants with baseline $\mathrm{PaCO}_{2}>60 \mathrm{mmHg}$ data from 15 minutes time point was included instead of 20 minutes, as at 20 minutes 7 participants had no data due to having been withdrawn due to excessive ventilatory depression, the maximum change from baseline value for this study was estimated from a graph. \# Participants attended study visit 2 weeks after hospital admission. \#\# This study was of randomised design, and reported no significant change in $\mathrm{PaCO}_{2}$ on room air, however presented $\mathrm{PaCO}_{2}$ values are only reported for oxygen, therefore it is reported in this Table for non-randomised data. ${ }^{\# \#} \mathrm{SpO}_{2}$ was $95.8 \%$.

Presented $\mathrm{PaCO}_{2}$ data are taken from the latest time point during the intervention. Change in mean $\mathrm{PaCO}_{2}$ is the mean difference from baseline. $\mathrm{PaCO}_{2}$ measurements may be $\mathrm{PcCO}_{2}$ or $\mathrm{PtCO}_{2}$ values. With the exception of oxygen concentration, data presented in subgroups has been combined to present an overall value for all participants in each study.

A study of note that was not included in the Table above was by Kawakami et al in 1982, ${ }^{99}$ which did not give numerical $\mathrm{PaCO}_{2}$ results. Participants breathed $100 \%$ oxygen at rest for 20 minutes, while some patients appeared to have increases in $\mathrm{PaCO}_{2}$, the precise magnitude of the change was unclear. 


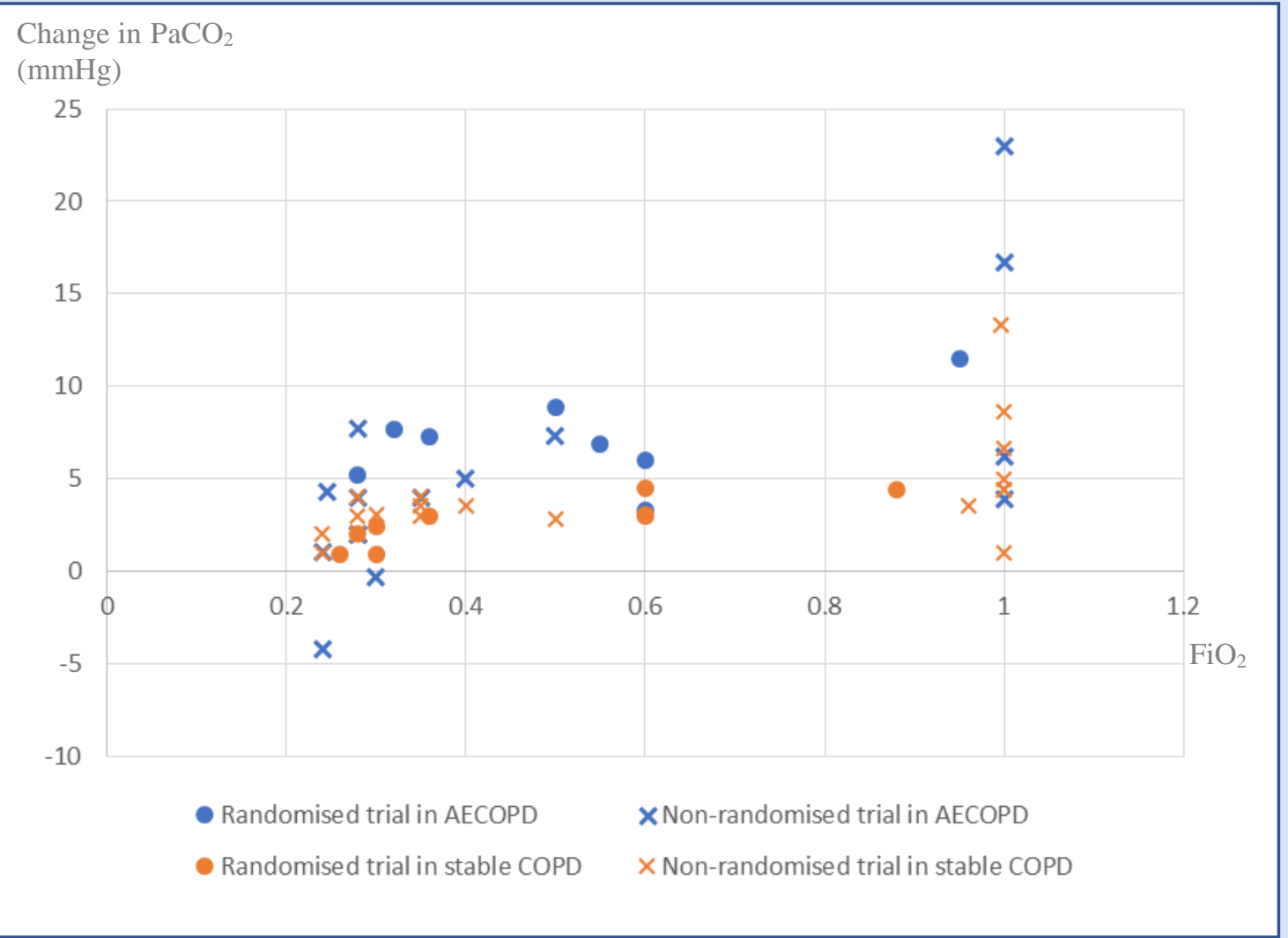

Figure 1.7a Graph of mean $\mathrm{PaCO}_{2}$ changes compared to $\mathrm{FiO}_{2}$ in patients with $\mathrm{AECOPD}$ and stable COPD

AECOPD: Acute exacerbation of chronic obstructive pulmonary disease, COPD: Chronic obstructive pulmonary disease, $\mathrm{FiO}_{2}$ : Fraction of inspired oxygen, $\mathrm{PaCO}_{2}$ : Arterial partial pressure of carbon dioxide, $\mathrm{PcCO}_{2}$ : Capillary partial pressure of carbon dioxide.

Note that data are not weighted by number of participants and $\mathrm{FiO}_{2}$ values are only estimates based on descriptions of data in the Tables 1.1 to 1.4. For clarity these data are presented in the Table in 1.7b. Change in mean $\mathrm{PaCO}_{2}$ is the mean difference from baseline in the oxygen minus control intervention in the randomised studies in AECOPD, with the exception of Eldridge at al which is change from air at baseline. ${ }^{58}$ Change in mean $\mathrm{PaCO}_{2}$ is the mean difference in the final $\mathrm{PaCO}_{2}$ in the oxygen minus control intervention in the randomised studies in stable COPD, with the exception of Edwards et al. ${ }^{81}$ Change in mean $\mathrm{PaCO}_{2}$ is the mean difference from baseline in the non-randomised studies in stable COPD and AECOPD. Further study details are provided in the legends of Tables 1.1 to 1.4. $\mathrm{PaCO}_{2}$ measurements may be $\mathrm{PcCO}_{2}$ or $\mathrm{PtCO}_{2}$ values. With the exception of $\mathrm{FiO}_{2}$, data presented in subgroups has been combined to present an overall value for all participants in each study. Data were included if $\mathrm{N}>2$ and an estimate was able to be made for $\mathrm{FiO}_{2}$. As such data from Moloney et al, ${ }^{70}$ Rudolf et al, ${ }^{64}$ and Saadjian et al, ${ }^{79}$ were not included, nor were data from 24-28\% via 'ventimask' in Smith et al's study. ${ }^{62}$ Note that data from differing $\mathrm{FiO}_{2}$ 's from Eldridge et al ${ }^{58}$ Warrell et al, ${ }^{63}$ Liss et al,${ }^{77}$ Mithoefer et al ${ }^{88}$ and Bone et al's ${ }^{94}$ studies were from the same participants. In Lejeune et al's study ${ }^{68}$ the 24 and $28 \%$ data were for the same participants, and the 35 and $40 \%$ were from the same participants. In Schiff et al's study ${ }^{89}$ four of the nine participants that received a $\mathrm{FiO}_{2}$ at $24 \%$ subsequently received $35 \%$. 


\begin{tabular}{|c|c|c|c|c|c|c|c|}
\hline \multicolumn{4}{|c|}{ AECOPD randomised } & \multicolumn{4}{|c|}{ AECOPD non-randomised } \\
\hline 1st author & $\mathbf{N}$ & $\begin{array}{c}\stackrel{\mathrm{FiO}_{2}}{\text { estimate }}\end{array}$ & $\begin{array}{c}\text { Change in } \\
\text { mean } \\
\mathrm{PaCO}_{2} \\
(\mathrm{mmHg}) \\
\end{array}$ & 1st author & $\mathbf{N}$ & $\begin{array}{c}\stackrel{\mathrm{FiO}_{2}}{\text { estimate }}\end{array}$ & $\begin{array}{c}\text { Change in } \\
\text { mean } \\
\mathrm{PaCO}_{2} \\
(\mathrm{mmHg}) \\
\end{array}$ \\
\hline \multirow{5}{*}{ Eldridge $^{58}$} & 17 & 0.28 & 5.2 & Comroe $^{60}$ & 6 & 1 & 16.7 \\
\hline & 3 & 0.32 & 7.7 & \multirow{2}{*}{ Miller $^{61}$} & 7 & 0.30 & -0.3 \\
\hline & 7 & 0.36 & 7.8 & & 30 & 1 & 6.2 \\
\hline & 9 & 0.50 & 8.9 & \multirow{2}{*}{ Smith $^{62 * *}$} & 20 & 0.24 & -4.4 \\
\hline & 3 & 0.95 & 13.3 & & 3 & 0.28 & 2 \\
\hline Gunawardena $^{31}$ & 16 & 0.60 & 6.0 & \multirow{2}{*}{ Warrell $^{63}$} & \multirow{2}{*}{7} & 0.245 & 4.3 \\
\hline O’Donnell $^{59}$ & 10 & 0.55 & 6.9 & & & 0.28 & 7.7 \\
\hline \multirow{3}{*}{ Bardsley $^{57}$} & 89 & 0.60 & 3.3 & Degaute $^{65}$ & 35 & 0.28 & 4 \\
\hline & & & & Aubier $^{66}$ & 20 & 0.50 & 7.3 \\
\hline & & & & Aubier $^{67}$ & 22 & 1 & 23 \\
\hline \multicolumn{4}{|c|}{ Stable COPD randomised } & \multirow{4}{*}{ Lejeune $^{68}$} & \multirow{2}{*}{12} & 0.24 & 1 \\
\hline \multirow{4}{*}{$1^{\text {st }}$ author } & \multirow{4}{*}{$\mathbf{N}$} & \multirow{4}{*}{$\begin{array}{c}\mathrm{FiO}_{2} \\
\text { estimate }\end{array}$} & \multirow{4}{*}{$\begin{array}{c}\text { Change in } \\
\text { mean } \\
\mathrm{PaCO}_{2} \\
(\mathrm{mmHg})\end{array}$} & & & 0.28 & 2 \\
\hline & & & & & \multirow{2}{*}{10} & 0.35 & 4 \\
\hline & & & & & & 0.40 & 5 \\
\hline & & & & Robinson $^{69}$ & 22 & 1 & 3.9 \\
\hline $\mathrm{King}^{74}$ & 10 & 0.30 & 2.4 & \multirow{2}{*}{\multicolumn{4}{|c|}{ Stable COPD non-randomised }} \\
\hline Castaing $^{75}$ & 14 & 0.26 & 0.9 & & & & \\
\hline Sassoon $^{76}$ & 17 & 0.94 & 4.4 & \multirow{4}{*}{$1^{\text {st }}$ author } & \multirow{4}{*}{$\mathbf{N}$} & \multirow{4}{*}{$\begin{array}{c}\mathrm{FiO}_{2} \\
\text { estimate }\end{array}$} & \multirow{4}{*}{$\begin{array}{c}\text { Change in } \\
\text { mean } \\
\mathrm{PaCO}_{2} \\
(\mathrm{mmHg}) \\
\end{array}$} \\
\hline \multirow{2}{*}{$\mathrm{Liss}^{77}$} & \multirow{2}{*}{8} & 0.28 & 2 & & & & \\
\hline & & 0.36 & 3 & & & & \\
\hline Light $^{78}$ & 17 & 0.30 & 0.9 & & & & \\
\hline O'Donnell $^{73}$ & 11 & 0.60 & 3 & Prime $^{85}$ & 35 & 1 & 8.6 \\
\hline O’Donnell $^{80}$ & 20 & 0.60 & 4.5 & Wilson $^{86}$ & 26 & 0.996 & 13.3 \\
\hline Edwards $^{81}$ & 18 & 0.60 & $3.1^{*}$ & Said $^{87}$ & 15 & 0.96 & 3.5 \\
\hline & & & & \multirow{3}{*}{ Mithoefer $^{88}$} & & 0.24 & 1 \\
\hline & & & & & 7 & 0.28 & 3 \\
\hline & & & & & & 0.35 & 3 \\
\hline & & & & & 9 & 0.24 & 2 \\
\hline & & & & Schiff $^{\circ \infty}$ & 4 & 0.35 & 4 \\
\hline & & & & Astin $^{90}$ & 13 & 0.3 & 3.1 \\
\hline & & & & Lopez-Majano $^{91}$ & 151 & 1 & 4.4 \\
\hline & & & & Sherter $^{92}$ & 9 & 1 & 5 \\
\hline & & & & Pietak $^{93}$ & 12 & 1 & 1 \\
\hline & & & & & & 0.28 & 2 \\
\hline & & & & Bone $^{94}$ & 20 & 0.35 & 3.5 \\
\hline & & & & & & 0.40 & 3.5 \\
\hline & & & & Aubier $^{66}$ & 12 & 0.50 & 2.8 \\
\hline & & & & Dick $^{96}$ & 11 & 1 & 6.6 \\
\hline & & & & Chiang $^{97}$ & 26 & 0.28 & 4.1 \\
\hline & & & & Perrin $^{98}$ & 18 & 1 & 4.4 \\
\hline
\end{tabular}

Figure 1.7b Tables of mean $\mathrm{PaCO}_{2}$ changes compared to $\mathrm{FiO}_{2}$ in patients with $\mathrm{AECOPD}$ and stable COPD

AECOPD: Acute exacerbation of chronic obstructive pulmonary disease, COPD: Chronic obstructive pulmonary disease, $\mathrm{FiO}_{2}$ : Fraction of inspired oxygen, $\mathrm{PaCO}_{2}$ : Arterial partial pressure of carbon dioxide.

* Value compared between randomised groups, taken as difference from baseline during oxygen intervention minus difference from baseline during air intervention. $* * \mathrm{~N}$ is number of admissions, it is possible there were repeat participants. For further detail see legend for Figure 1.7a. 
Aubier et al ${ }^{66}$ performed the only study which measured $\mathrm{PaCO}_{2}$ during an oxygen regimen in the same patients during AECOPD and then when stable. In 12 participants with AECOPD oxygen was administered via a mouthpiece for 30 minutes, and was associated with a mean $\mathrm{PaCO}_{2}$ increase of $10.1 \mathrm{mmHg}$. When the same participants were stable, the same oxygen regimen resulted in a $\mathrm{PaCO}_{2}$ change that was significantly smaller at only 2.8 mmHg $(\mathrm{P}<0.01)$. In 1977, Rudolf et al ${ }^{100}$ examined the effects of oxygen in patients with respiratory failure. While the cause of the respiratory failure was not identified as COPD (meaning the study was not eligible for inclusion in this systematic review), the findings are noted here as another example of the effects of oxygen on the same patients when in an acute exacerbation and when stable. $\mathrm{A} \mathrm{FiO}_{2}$ of up to 0.28 for 1 hour increased $\mathrm{PaCO}_{2}$ values by 9,15 and $31 \mathrm{mmHg}$ compared with air in three patients with an exacerbation of chronic respiratory failure. However, the same oxygen regimen did not alter $\mathrm{PaCO}_{2}$ more than 3 mmHg when the same three patients were stable. The possible mechanisms behind these differences are discussed in Section 1.3.4.

Despite the lower mean changes in $\mathrm{PaCO}_{2}$ in response to oxygen in the stable studies, the results reinforced the key messages from the studies in AECOPD. Firstly, the studies in stable participants demonstrated physiologically and clinically significant changes in $\mathrm{PtCO}_{2}$ could occur in individuals in response to oxygen. ${ }^{76,80,92,94,96-98,81,85-91}$ As demonstrated in the acute setting, significant increases in $\mathrm{PaCO}_{2}$ were reported following comparatively low concentrations of delivered oxygen, such as the participant with an $18 \mathrm{mmHg}^{\mathrm{maCO}} 2$ increase after delivery of $28 \%$ oxygen for $\geq 30$ minutes in Bone et al's study. ${ }^{94}$

In the trials that compared differing concentrations of oxygen delivery, the difference in the changes in $\mathrm{PaCO}_{2}$ between the highest and lowest $\mathrm{FiO}_{2}$ was small $(\leq 3.5 \mathrm{mmHg}) .{ }^{77,79,88,89,94}$ Despite this, in each of the randomised studies every increase in $\mathrm{FiO}_{2}$ was associated with a small increase in mean $\mathrm{PaCO}_{2},{ }^{77,79}$ reflecting the dose response relationship demonstrated in the studies in AECOPD. Additionally, in all three non-randomised studies in stable COPD, the mean change in $\mathrm{PaCO}_{2}$ on the highest $\mathrm{FiO}_{2}$ was slightly higher than the $\mathrm{PaCO}_{2}$ on the lowest $\mathrm{FiO}_{2}{ }^{88,89,94}$

Variability in response to oxygen was also apparent in the studies in patients with stable COPD, especially at a $\mathrm{FiO}_{2}$ of $100 \%$ (Figure 1.7a and 1.7b). A number of the studies in 
stable COPD attempted to identify predictors of a $\mathrm{PaCO}_{2}$ increase in response to oxygen. Similar to the findings in AECOPD, there were mixed results. Sassoon et $\mathrm{al}^{76}$ found a significant correlation between forced expiratory volume in 1 second $\left(\mathrm{FEV}_{1}\right)$ and change in $\mathrm{PtCO}_{2}$ on oxygen $(\mathrm{r}=-0.50, \mathrm{P}<0.05)$; however no correlation was found with baseline $\mathrm{PtCO}_{2}$ or arterial oxygen saturation $\left(\mathrm{SaO}_{2}\right)$. When O'Donnell et al ${ }^{80}$ categorised their participants as retainers (change in $\mathrm{PaCO}_{2} \geq 3 \mathrm{mmHg}$ on oxygen) and non-retainers, they found no significant difference in baseline $\mathrm{PaCO}_{2}$ values between the groups; however baseline $\mathrm{PaO}_{2}$ was significantly lower in the retainer group $(\mathrm{P}<0.05)$. Lopez-Majano et $\mathrm{al}^{91}$ found statistically significant associations between oxygen-induced elevations in $\mathrm{PaCO}_{2}$ and baseline $\mathrm{PaCO}_{2}(\mathrm{r}=0.41, \mathrm{P}<0.01), \mathrm{PaO}_{2}(\mathrm{r}=0.45, \mathrm{P}<0.01), \mathrm{pH}(\mathrm{r}=0.19, \mathrm{P}, 0.01)$ and bicarbonate $(\mathrm{r}=0.26, \mathrm{P}<0.001)$. Bone et $\mathrm{al}^{94}$ reported the effects of varying $\mathrm{FiO}_{2}$ levels in a subgroup of patients with hypercapnia and a subgroup without. While they did not provide statistical analysis comparing the groups, the mean changes in $\mathrm{PaCO}_{2}$ at each $\mathrm{FiO}_{2}$ were similar (within $1 \mathrm{mmHg}$ ) between hypercapnic and non-hypercapnic participants. However, in a retrospective study in patients with AECOPD in the same manuscript the authors report an association between admission $\mathrm{PaO}_{2}$ and $\mathrm{pH}$ and the likelihood of somnolence developing on oxygen therapy. Finally, Chiang et al ${ }^{97}$ reported oxygen at $2 \mathrm{~L} / \mathrm{min}$ resulted in statistically significant increases in mean $\mathrm{PaCO}_{2}$ in both normocapnic and hypercapnic patients. While the mean change in $\mathrm{PaCO}_{2}$ associated with oxygen administration was greater in the patients who were hypercapnic at baseline $(5.4 \mathrm{mmHg}$ compared to 2.9 $\mathrm{mmHg}$ ), data were not formally analysed to determine if the difference was statistically significant.

\section{Overall conclusions}

Findings 1 through 5 generated by the studies in AECOPD, and supported by the studies in stable COPD, provide evidence for oxygen-induced hypercapnia and support the rationale behind the titration of oxygen therapy to avoid both hypoxaemia and hyperoxaemia.

The clinically significant increases in $\mathrm{PaCO}_{2}$ and decreases in $\mathrm{pH}$ associated with oxygen delivery, combined with the results from Austin et al's 2010 RCT, ${ }^{12}$ support the use of titrated oxygen therapy to improve patient outcomes in AECOPD. The studies demonstrating clinically significant increases in $\mathrm{PaCO}_{2}$ can occur during oxygen-driven 
nebuliser delivery suggest that clinical improvements are contributed to by the avoidance of oxygen-driven nebulisers.

The dose response relationships between $\mathrm{FiO}_{2}$ and change in $\mathrm{PaCO}_{2}$, and the clinically significant elevations in $\mathrm{PaCO}_{2}$ reported after exposure to relatively low $\mathrm{FiO}_{2}$ levels, demonstrate the utility of an upper $\mathrm{SpO}_{2}$ titration limit to prevent the unnecessary initiation of oxygen therapy or delivery of oxygen at concentrations higher than required to relieve hypoxaemia. This in turn has the potential to decrease the risk of oxygen-induced hypercapnia and improve clinical outcomes.

The variability in the changes in $\mathrm{PaCO}_{2}$ and $\mathrm{PaO}_{2}$ in response to oxygen therapy demonstrate why titration to each patient's oxygen saturations is essential to avoid the risks of hypoxaemia and hypercapnia, rather than the alternative of prescribing a set 'one size fits all' oxygen concentration. Overall, it appears that while many studies suggest that elevated baseline $\mathrm{PaCO}_{2}$ and/or decreased baseline blood oxygen levels may relate to the risk of oxygen-induced hypercapnia, neither appear to be a prerequisite. The inability to predict which COPD patients are at risk of oxygen-induced hypercapnia further illustrates the importance of titrating oxygen in all patients with COPD, rather than assuming how a patient will respond to oxygen therapy.

Additionally, data from these studies have demonstrated that it is likely that the variability in response to oxygen is partly related to study methodology. This is supported by the data suggesting that changes in $\mathrm{PaCO}_{2}$ in response to delivery are dependent on factors such as $\mathrm{FiO}_{2}$, length of oxygen exposure, and whether a patient is stable or has AECOPD. These findings highlight the importance of carefully considering the applicability of study findings in the acute clinical setting. 


\subsubsection{Mechanisms behind oxygen-induced hypercapnia in COPD}

\section{Proposed mechanisms}

Despite the number of trials demonstrating $\mathrm{PaCO}_{2}$ rises in response to oxygen delivery, the mechanism or mechanisms behind oxygen-induced hypercapnia are still debated. ${ }^{42,101,102}$ The four main theories are summarised in Figure 1.8. Oxygen administration has been suggested to impact on the Haldane effect by displacing $\mathrm{CO}_{2}$ bound to haemoglobin to increase dissolved levels in the blood, elevating $\mathrm{PaCO}_{2}$. Oxygen therapy has also been suggested to result in absorption atelectasis, which could lead to shunt and V/Q mismatch. ${ }^{67}$ The most commonly quoted mechanism, however, is a decrease in the hypoxic drive to breathe. As outlined in Textbox 1.1 and Figure 1.5, minute ventilation is influenced by feedback from chemoreceptors which detect oxygen, $\mathrm{CO}_{2}$ and $\mathrm{pH}$ in the blood. Many patients with COPD are thought to have reduced responsiveness to $\mathrm{CO}_{2}$ levels and instead rely on hypoxic drive to breathe. Administration of oxygen may reduce hypoxic drive, resulting in decreased ventilation and increased $\mathrm{PaCO}_{2}$. The reversal of hypoxic pulmonary vasoconstriction has also been postulated as a key mechanism. As outlined in Textbox 1.1 and Figure 1.4, hypoxic pulmonary vasoconstriction causes local decreases in blood flow to poorly ventilated alveoli, and results in increased flow to other alveoli with better ventilation. Oxygen administration is thought to increase oxygen in the areas of low ventilation, reversing the local pulmonary vasoconstriction. The resulting increase in blood flow to the poorly ventilated areas worsens V/Q mismatch, while the decreased blood flow to the well-ventilated areas leads to increased dead space. 


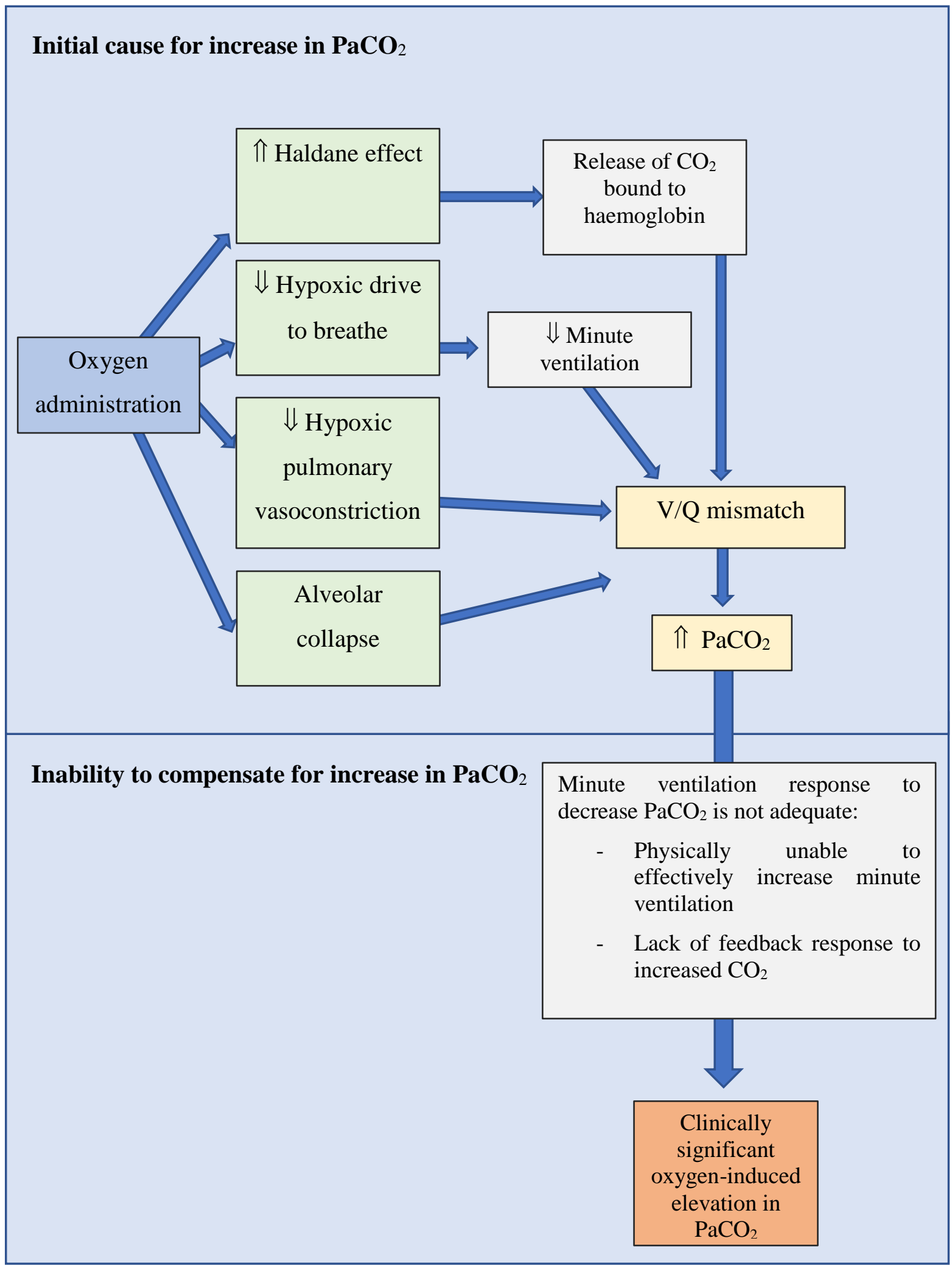

Figure 1.8 Main mechanisms proposed to account for oxygen-induced hypercapnia

$\mathrm{PaCO}_{2}$ : Arterial partial pressure of carbon dioxide, $\mathrm{CO}_{2}$ : Carbon dioxide, V/Q: Ventilation-perfusion ratio. Figure is based on reviews/discussion by Rudolf $1977,{ }^{100}$ Stradling 1986, ${ }^{103}$ New 2006, ${ }^{42}$ Brill \& Wedzicha 2014, ${ }^{102}$ and Abdo \& Heunks 2012. ${ }^{101}$ 
An essential aspect of oxygen-induced hypercapnia is the inability to compensate for the degree of $\mathrm{PaCO}_{2}$ elevation. ${ }^{100}$ It may be that the increase in $\mathrm{PaCO}_{2}$ is of such a magnitude that it is not physically possible to increase minute ventilation to counteract it, or that the ability to increase minute ventilation is affected by an aspect of the pathophysiology of COPD, such as decreased chemoreceptor responsiveness to $\mathrm{PaCO}_{2}$ or physical changes that impair the ability to increase minute ventilation.

It is plausible that a combination of each of the initial causes increased $\mathrm{PaCO}_{2}$ presented in Figure 1.8 contribute to the overall $\mathrm{PaCO}_{2}$ response to oxygen therapy in an individual patient. Each of the proposed mechanisms may impact on each other and be dependent on a number of other physiological factors that affect $\mathrm{PaCO}_{2}$ (as outlined at the end of Section 1.2.2). This may go some way to explaining the variability in responses to oxygen outlined in Section 1.3.3, as well as the observation that patients with AECOPD tend to have a greater $\mathrm{PaCO}_{2}$ increase in response to oxygen compared to stable patients. For example, in patients with a lower tidal volume, a smaller absolute decrease in tidal volume (which could occur due to loss of hypoxic drive) can cause a comparatively larger reduction in alveolar ventilation. ${ }^{103}$ Additionally, it has been suggested that patients with a higher initial $\mathrm{PaCO}_{2}$ require smaller reductions in alveolar ventilation to increase $\mathrm{PaCO}_{2} \cdot{ }^{103}$ The magnitude of minute ventilation changes and/or hypoxic pulmonary constriction to counter V/Q mismatch prior to the administration of oxygen therapy, could relate to a greater potential for their reversal (through loss of hypoxic drive and/or loss of hypoxic pulmonary vasoconstriction), which may result in a greater effect on $\mathrm{PaCO}_{2}$. Finally, lower oxygen saturations prior to oxygen therapy could mean that the amount of $\mathrm{CO}_{2}$ bound to haemoglobin is higher, so that when oxygen is delivered, a greater amount of bound $\mathrm{CO}_{2}$ is able to be displaced via the Haldane effect to increase $\mathrm{PaCO}_{2} .{ }^{103}$ Each of these examples includes factors which are associated with AECOPD (decreased tidal volume, elevated $\mathrm{PaCO}_{2}$, requirement of compensation for $\mathrm{V} / \mathrm{Q}$ mismatch and low $\mathrm{PaO}_{2}$ ). Additionally, a multitude of other factors, such as levels of $\mathrm{CO}_{2}$ production by metabolism, alterations in cardiac output, and co-morbidities, may complicate the picture further.

Difficulty in identifying and untangling the potential contributions of these factors is likely to contribute to the ongoing difficulty in assessing the proposed mechanisms behind oxygen-induced hypercapnia. 


\section{Assessing the proposed mechanisms behind oxygen-induced hypercapnia}

Reduction of hypoxic drive to breathe

This has been assessed by measuring minute ventilation (the volume of air transferred over 1 minute), which is the product of tidal volume (volume per breath) and respiratory rate (breaths per unit of time):

[minute ventilation $]=[$ tidal volume $] \times$ [respiratory rate $]$

Release of hypoxic pulmonary vasoconstriction

A key measurement that has been used to imply the release of hypoxic pulmonary vasoconstriction is the dead space to tidal volume ratio (VD/VT). As outlined previously, total VD (physiological dead space) is composed of anatomical dead space (portions of the airway that are not involved in gas transfer) and alveolar dead space (portions of the alveoli which do not take place in respiration as there is no blood supply for gas transfer). Expired $\mathrm{CO}_{2}\left(\mathrm{PECO}_{2}\right)$ represents the mixed gas from physiological dead space (where no perfusion takes place) and the gas from the alveoli participating in gas exchange $\left.\left(\mathrm{P}_{\mathrm{A}} \mathrm{CO}_{2}\right)\right)$. As a result, VD/VT can be calculated by the Bohr equation:

$[\mathrm{VD} / \mathrm{VT}]=\left[\mathrm{P}_{\mathrm{A}} \mathrm{CO}_{2}-\mathrm{PECO}_{2}\right] /\left[\mathrm{P}_{\mathrm{A}} \mathrm{CO}_{2}\right]$

This equation was subsequently modified by Engoff to:

$[\mathrm{VD} / \mathrm{VT}]=\left[\mathrm{PaCO}_{2}-\mathrm{PECO}_{2}\right] /\left[\mathrm{PaCO}_{2}\right]$

For practical purposes $\mathrm{P}_{\mathrm{A}} \mathrm{CO}_{2}$ was assumed to equal $\mathrm{PaCO}_{2}$ (measurable by blood gas or estimated via transcutaneous monitoring). However, it should be noted that this change limits the distinction between an increase in $\mathrm{PaCO}_{2}$ due to increased dead space or due to shunt (in which $\mathrm{P}_{\mathrm{A}} \mathrm{CO}_{2}$ will not match $\mathrm{PaCO}_{2}$ ). ${ }^{104,105}$ A further point to consider in the evaluation of VD/VT is that values may be influenced by loss of hypoxic drive, as 
reductions in tidal volume are not linear to reductions in dead space, and so are capable of altering the VD/VT ratio. ${ }^{103}$

Another measurement used to evaluate release of hypoxic pulmonary vasoconstriction is the multiple inert gas elimination technique (MIGET). This involves the intravenous infusion of six inert gases of differing solubility, which are subsequently measured from expiration, mixed venous blood and arterial blood. Calculation of ventilation and perfusion is via the Fick principle (that blood flow to an organ can be calculated by measuring the concentration of a substance entering and leaving that organ, and accounting for use of the substance by the organ). This allows assessment of dead space, V/Q distribution and shunt.

\section{Evidence for the proposed mechanisms behind oxygen-induced hypercapnia}

A number of the trials from the systematic review in Section 1.3.3 have investigated the proposed mechanisms for oxygen-induced hypercapnia. However, methodology has been variable and the interpretation of results a source of debate. Breaking the results into their most simplistic form, Tables 1.5 to 1.7 demonstrate the effects of oxygen administration on measures used to represent reduction of hypoxic drive to breathe and measures used to represent release of hypoxic pulmonary vasoconstriction. 


\begin{tabular}{|c|c|c|c|c|c|c|}
\hline 1st author & Year & $\mathbf{N}$ & $\begin{array}{c}\mathrm{PaCO}_{2} \\
\text { mean } \\
\text { change } \\
\text { from } \\
\text { baseline } \\
(\mathrm{mmHg})\end{array}$ & $\begin{array}{l}\text { Measures of } \\
\text { reduction in } \\
\text { hypoxic drive to } \\
\text { breathe }\end{array}$ & $\begin{array}{c}\text { Measures of } \\
\text { release of hypoxic } \\
\text { pulmonary } \\
\text { vasoconstriction }\end{array}$ & $\begin{array}{c}\text { Relationship between } \\
\text { change in measure and } \\
\text { change in } \mathrm{PaCO}_{2}\end{array}$ \\
\hline Aubier ${ }^{66}$ & 1980 & 20 & 7.3 & $\begin{array}{l}\downarrow \text { Minute } \\
\text { ventilation } \\
\downarrow \text { Respiratory rate } \\
\leftrightarrow \text { Tidal volume }\end{array}$ & Not assessed & $\begin{array}{l}\text { No correlation between } \\
\text { magnitude of } \mathrm{PaCO}_{2} \\
\text { change and minute } \\
\text { ventilation or } \\
\text { respiratory rate. }\end{array}$ \\
\hline Aubier $^{67}$ & 1980 & 22 & 23 & $\begin{array}{l}\downarrow \text { Minute } \\
\text { ventilation* } \\
\leftrightarrow \text { Respiratory } \\
\text { rate } \\
\leftrightarrow \text { Tidal volume } \\
\end{array}$ & $\begin{array}{l}\uparrow \mathrm{VD} / \mathrm{VT} \text { (Bohr } \\
\text { Engoff equation) }\end{array}$ & $\begin{array}{l}\text { No correlation between } \\
\text { magnitude of } \mathrm{PaCO}_{2} \\
\text { change and minute } \\
\text { ventilation, respiratory } \\
\text { rate or tidal volume. }\end{array}$ \\
\hline \multirow{2}{*}{ Robinson ${ }^{69}$} & \multirow{2}{*}{2000} & $\begin{array}{l}10 \text { non- } \\
\text { retainers** }\end{array}$ & -1.3 & $\begin{array}{l}\leftrightarrow \text { Minute } \\
\text { ventilation }\end{array}$ & $\begin{array}{l}\text { MIGET: } \\
\uparrow \mathrm{V} / \mathrm{Q} \\
\text { heterogeneity } \\
\uparrow \text { Dispersion of } \\
\text { perfusion } \\
\text { distribution^ } \\
\leftrightarrow \text { Dispersion of } \\
\text { alveolar } \\
\text { ventilation- } \\
\text { perfusion } \\
\text { (excluding dead } \\
\text { space)^ } \\
\leftrightarrow \text { Dead space*** } \\
\leftrightarrow \text { VD/VT (Bohr } \\
\text { equation) } \\
\leftrightarrow \text { Shunt }\end{array}$ & \multirow{2}{*}{$\begin{array}{l}\text { No statistically } \\
\text { significant difference in } \\
\text { any of these changes } \\
\text { between retainers and } \\
\text { non-retainers. }\end{array}$} \\
\hline & & $\begin{array}{c}12 \\
\text { retainers** }\end{array}$ & 8.3 & $\begin{array}{l}\downarrow \text { Minute } \\
\text { ventilation }\end{array}$ & $\begin{array}{l}\text { MIGET: } \\
\uparrow \mathrm{V} / \mathrm{Q} \\
\text { heterogeneity } \\
\uparrow \text { Dispersion of } \\
\text { perfusion } \\
\text { distribution^ }^{\wedge} \text { Dispersion of } \\
\text { alveolar } \\
\text { ventilation- } \\
\text { perfusion } \\
\text { (excluding dead } \\
\text { space)^ } \\
\leftrightarrow \text { Dead space*** } \\
\uparrow \mathrm{VD} / \mathrm{VT} \text { (Bohr } \\
\text { equation) } \\
\leftrightarrow \text { Shunt }\end{array}$ & \\
\hline
\end{tabular}

Table 1.5 Studies investigating mechanisms behind oxygen-induced hypercapnia in patients with AECOPD

MIGET: Multiple Inert Gas Elimination Technique, $\mathrm{PaCO}_{2}$ : Arterial partial pressure of arterial carbon dioxide, VD/VT: Dead space to tidal volume, V/Q: Ventilation-Perfusion ratio. *Note there was an initial decrease in minute ventilation within 5 minutes of oxygen delivery, however the decrease was smaller by the end of the intervention. **Retainers were defined as participants who had a $>3 \mathrm{mmHg}$ increase in $\mathrm{PaCO}_{2}$ during oxygen administration. ${ }^{* * *}$ Units with $\mathrm{V} / \mathrm{Q}$ ratio $>100$. $^{\wedge}$ i.e. increase in perfusion to lung units with low V/Q. ^ i.e. increase in alveolar dead space. None of the studies were randomised. A change is depicted as an increase $(\uparrow)$ or decrease $(\downarrow)$ if the difference on oxygen compared to baseline was $\mathrm{P}<0.05$. 


\begin{tabular}{|c|c|c|c|c|c|c|}
\hline 1st author & Year & $\mathbf{N}$ & $\begin{array}{c}\mathrm{PaCO}_{2} \\
\text { mean } \\
\text { change } \\
\text { from } \\
\text { baseline } \\
(\mathrm{mmHg}) \\
\end{array}$ & $\begin{array}{l}\text { Measures of } \\
\text { reduction in } \\
\text { hypoxic drive to } \\
\text { breathe }\end{array}$ & $\begin{array}{c}\text { Measures of } \\
\text { release of hypoxic } \\
\text { pulmonary } \\
\text { vasoconstriction }\end{array}$ & $\begin{array}{l}\text { Relationship between } \\
\text { change in measure and } \\
\text { change in } \mathrm{PaCO}_{2}\end{array}$ \\
\hline Castaing $^{75}$ & 1985 & 14 & 0.9 & $\begin{array}{l}\leftrightarrow \text { Minute } \\
\text { ventilation } \\
\leftrightarrow \text { Respiratory } \\
\text { rate }\end{array}$ & $\begin{array}{l}\text { MIGET } \\
\leftrightarrow \text { V/Q } \\
\text { heterogeneity } \\
\leftrightarrow \text { Dispersion of } \\
\text { perfusion } \\
\text { distribution } \\
\leftrightarrow \text { Dispersion of } \\
\text { alveolar } \\
\text { ventilation- } \\
\text { perfusion } \\
\text { (excluding dead } \\
\text { space) } \\
\uparrow \text { Dead space* } \\
\leftrightarrow \text { Shunt fraction }\end{array}$ & Not assessed \\
\hline Sassoon $^{76}$ & 1987 & 17 & 4.4 & $\begin{array}{l}\leftrightarrow \text { Minute } \\
\text { ventilation } \\
\leftrightarrow \text { Respiratory } \\
\text { rate } \\
\leftrightarrow \text { Tidal volume } \\
\end{array}$ & $\begin{array}{l}\uparrow \mathrm{VD} / \mathrm{VT} \text { (Bohr } \\
\text { Engoff equation) }\end{array}$ & Not assessed \\
\hline $\operatorname{Light}^{78 * *}$ & 1989 & 17 & 0.9 & $\begin{array}{l}\downarrow \text { Minute } \\
\text { ventilation } \\
\leftrightarrow \text { Respiratory } \\
\text { rate } \\
\leftrightarrow \text { Tidal volume } \\
\end{array}$ & $\begin{array}{l}\leftrightarrow \mathrm{VD} / \mathrm{VT} \\
(\text { Undefined } \\
\left.\text { method }^{* * *}\right)\end{array}$ & Not assessed \\
\hline $\begin{array}{c}\text { O'Donnell } \\
80\end{array}$ & 1997 & 11 & 3 & Not assessed & $\begin{array}{l}\uparrow \mathrm{VD} / \mathrm{VT} \\
\text { (Undefined } \\
\text { method }^{* * *} \text { ) }\end{array}$ & Not assessed \\
\hline \multirow{2}{*}{$\begin{array}{l}\text { O'Donnell } \\
73\end{array}$} & \multirow{2}{*}{2002} & $\begin{array}{l}11 \text { non- }^{-} \\
\text {retainers^ }\end{array}$ & 0 & $\begin{array}{l}\leftrightarrow \text { Minute } \\
\text { ventilation } \\
\leftrightarrow \text { Respiratory } \\
\text { rate } \\
\leftrightarrow \text { Tidal volume } \\
\leftrightarrow \text { Alveolar } \\
\text { ventilation^^} \\
\end{array}$ & $\begin{array}{l}\leftrightarrow \text { VD/VT } \\
\text { (Undefined } \\
\text { method } * * * \text { ) } \\
\leftrightarrow \text { Arterial-end } \\
\text { tidal difference } \\
\text { in } \mathrm{CO}_{2}\end{array}$ & \multirow[t]{2}{*}{$\begin{array}{l}\mathrm{VD} / \mathrm{VT} \text { and alveolar } \\
\text { ventilation were both } \\
\text { significantly associated } \\
\text { with } \mathrm{PaCO}_{2}\end{array}$} \\
\hline & & $\begin{array}{c}9 \\
\text { retainers }^{\wedge}\end{array}$ & 10 & $\begin{array}{l}\leftrightarrow \text { Minute } \\
\text { ventilation } \\
\leftrightarrow \text { Respiratory } \\
\text { rate } \\
\leftrightarrow \text { Tidal volume } \\
\downarrow \text { Alveolar } \\
\text { ventilation^^}\end{array}$ & $\begin{array}{l}\uparrow \mathrm{VD} / \mathrm{VT} \\
\text { (Undefined } \\
\text { method***) } \\
\uparrow \text { Arterial-end tidal } \\
\text { difference } \\
\text { in } \mathrm{CO}_{2}\end{array}$ & \\
\hline
\end{tabular}

Table 1.6 Randomised studies investigating mechanisms behind oxygen-induced hypercapnia in patients with stable COPD

$\mathrm{CO}_{2}$ : Carbon dioxide, MIGET: Multiple Inert Gas Elimination Technique, $\mathrm{PaCO}_{2}$ : Arterial partial pressure of carbon dioxide, VD/VT: Dead space to tidal volume, V/Q: Ventilation-Perfusion ratio.

*Units with V/Q ratio $>100$. **Data refers to data from patients at rest only. ***VD/VT assumed to be taken from Bohr Engoff equation, though not directly stated in methods. ${ }^{\wedge}$ Retainers were defined as participants who had a $>3 \mathrm{mmHg}$ increase in $\mathrm{PaCO}_{2}$ during oxygen administration. ${ }^{\wedge} \wedge$ Alveolar ventilation is related to both minute ventilation and dead space. A change is depicted as an increase $(\uparrow)$ or decrease $(\downarrow)$ if the difference on oxygen compared to baseline was $\mathrm{P}<0.05$. 


\begin{tabular}{|c|c|c|c|c|c|c|}
\hline $\begin{array}{c}1^{\text {st }} \\
\text { author }\end{array}$ & Year & $\mathbf{N}$ & $\begin{array}{c}\mathrm{PaCO}_{2} \\
\text { Mean } \\
\text { change } \\
\text { from } \\
\text { baseline } \\
(\mathrm{mmHg})\end{array}$ & $\begin{array}{l}\text { Measure of } \\
\text { reduction in } \\
\text { hypoxic drive to } \\
\text { breathe }\end{array}$ & $\begin{array}{c}\text { Measures of } \\
\text { release of hypoxic } \\
\text { pulmonary } \\
\text { vasoconstriction }\end{array}$ & $\begin{array}{l}\text { Relationship between } \\
\text { change in measure and } \\
\text { change in } \mathrm{PaCO}_{2}\end{array}$ \\
\hline Prime $^{85}$ & 1954 & 35 & 8.6 & $\begin{array}{l}\text { Decreased } \\
\text { minute } \\
\text { ventilation } \\
\text { (no statistical } \\
\text { comparison } \\
\text { presented) } \\
\end{array}$ & Not assessed & Not assessed \\
\hline Wilson $^{86}$ & 1954 & 26 & 13.3 & $\begin{array}{l}\downarrow \text { Minute } \\
\text { ventilation } \\
\downarrow \text { Alveolar } \\
\text { ventilation* }\end{array}$ & Not assessed & $\begin{array}{l}\text { No correlation } \\
\text { between magnitude of } \\
\mathrm{PaCO}_{2} \text { change and } \\
\text { minute ventilation } \\
\text { Changes alveolar } \\
\text { ventilation were } \\
\text { significantly } \\
\text { associated change in } \\
\mathrm{PaCO}_{2}\end{array}$ \\
\hline Aubier ${ }^{66}$ & 1980 & 12 & 2.8 & $\begin{array}{l}\downarrow \text { Minute } \\
\text { ventilation } \\
\leftrightarrow \text { Respiratory } \\
\text { rate } \\
\leftrightarrow \text { Tidal } \\
\text { volume }\end{array}$ & Not assessed & Not assessed \\
\hline Dick $^{96}$ & 1997 & 11 & 6.6 & $\begin{array}{l}\leftrightarrow \text { Minute } \\
\text { ventilation }\end{array}$ & Not assessed & $\begin{array}{l}\text { No correlation } \\
\text { between magnitude of } \\
\mathrm{PaCO}_{2} \text { change and } \\
\text { minute ventilation. }\end{array}$ \\
\hline \multirow{2}{*}{ Chiang $^{97}$} & \multirow{2}{*}{2002} & $\begin{array}{c}14 \\
\text { normo- } \\
\text { capnic at } \\
\text { baseline }\end{array}$ & 2.9 & $\begin{array}{l}\leftrightarrow \text { Minute } \\
\text { ventilation }\end{array}$ & \multirow{2}{*}{ Not assessed } & \multirow{2}{*}{ Not assessed } \\
\hline & & $\begin{array}{c}12 \\
\text { hyper- } \\
\text { capnic at } \\
\text { baseline }\end{array}$ & 5.4 & $\begin{array}{l}\leftrightarrow \text { Minute } \\
\text { ventilation }\end{array}$ & & \\
\hline
\end{tabular}

Table 1.7 Non-randomised studies investigating mechanisms behind oxygen-induced hypercapnia in patients with stable COPD

$\mathrm{PaCO}_{2}$ : Arterial partial pressure of carbon dioxide, VD/VT: Dead space to tidal volume.

* Alveolar ventilation may be relevant to both the minute ventilation and hypoxic pulmonary vasoconstriction columns.

A change is depicted as an increase $(\uparrow)$ or decrease $(\downarrow)$ if the difference on oxygen compared to baseline was $\mathrm{P}<0.05$. Note Perrin ${ }^{98}$ did measure minute ventilation, respiratory rate and VD/VT, however data are not included in the Table above as they were not presented as compared to baseline, it was noted that VD/VT in the COPD participants did increase compared to healthy participants, when on oxygen, however there was no difference in values for minute ventilation or respiratory rate compared to healthy participants. 
There were no RCTs in patients with AECOPD in which the potential mechanisms of oxygen-induced hypercapnia were investigated. Three non-randomised trials were conducted in patients with AECOPD,${ }^{66,67,69}$ all of which demonstrated reductions in minute ventilation in response to oxygen administration (Table 1.5). In stable patients changes in minute ventilation were more variable (Tables 1.6 to 1.7). In the studies which demonstrated increases in $\mathrm{PaCO}_{2}$ on oxygen administration, there were only three which reported a decrease in minute ventilation. ${ }^{66,85,86}$

Aubier et $\mathrm{al}^{67}$ and Robinson et $\mathrm{al}^{69}$ were the only studies to assess change in VD/VT in response to oxygen in patients with AECOPD. Aubier et al used the Bohr-Engoff equation to calculate VD/VT. Robinson used MIGET to assess V/Q relationship and calculate VD/VT via the Bohr equation. Both studies reported an association between oxygen administration and increased VD/VT. While Robinson et al reported change in VD/VT to be significant in retainers only, overall there was no significant difference in VD/VT change between retainers and non-retainers. The use of MIGET also allowed evaluation of heterogeneity in V/Q matching, and demonstrated increased distribution of perfusion (in other words, increase in perfusion to lung units with low V/Q). This occurred in both the retainer and non-retainer subgroups.

Several studies in stable COPD measured VD/VT. In the studies that demonstrated an increase in $\mathrm{PaCO}_{2}$ with oxygen administration there was also an increase in VD/VT. ${ }^{73,76}$ Conversely, in two of the patient groups with no physiologically significant change in $\mathrm{PaCO}_{2}$ in response to oxygen (the non-retainer subgroup in O'Donnell et al's study ${ }^{73}$ and the participants in Light et al's study ${ }^{78}$ ) there was no change in VD/VT (Table 1.6).

While the results point to the involvement of both a reduction in hypoxic drive to breathe and release of hypoxic pulmonary vasoconstriction as mechanisms behind oxygen-induced hypercapnia, interpretation of their relative contributions is a source of debate. Aubier et $\mathrm{al}^{67}$ interpreted the small reductions in minute ventilation they observed as insufficient to account for changes in $\mathrm{PaCO}_{2}$, and concluded that altered gas exchange was the dominant mechanism. This was backed up by the absence of a statistical relationship between change in minute ventilation and change in $\mathrm{PaCO}_{2}$, however no results as to the relationship between changes in VD/VT and $\mathrm{PaCO}_{2}$ were presented. In contrast, Robinson et al ${ }^{69}$ came 
to the conclusion that it was changes in ventilation that were responsible for their observed increases in $\mathrm{PaCO}_{2}$ during oxygen administration. This was based on the similarity in changes in perfusion in both their retainer and non-retainer subgroups. The conclusion was reached despite failing to demonstrate a statistically significant difference in minute ventilation between retainers and non-retainers. Both interpretations have subsequently been questioned..$^{98,101,103,106,107}$ Interestingly, on interpreting Aubier et al's results, Stradling et $\mathrm{al}^{103}$ came to the opposite conclusion of the authors, suggesting a reduction in hypoxic drive to breathe was capable of explaining the observed change in $\mathrm{PaCO}_{2}$. Similarly, FellerKopman and Schwartzstein ${ }^{106}$ came to the opposite conclusion to Robinson et al regarding their results, and suggested that release of hypoxic pulmonary constriction could explain them. These discrepancies demonstrate how variability in results and their interpretation contribute to the difficulty in evaluating the physiological mechanisms behind oxygeninduced hypercapnia. 


\subsection{Evidence for oxygen-induced elevations in $\mathrm{PaCO}_{2}$ and the benefits of titrated oxygen therapy in conditions other than COPD}

\subsubsection{Asthma and pneumonia}

As outlined previously, V/Q mismatch is a key factor in AECOPD and potentially a mechanism through which oxygen-induced hypercapnia occurs. Recognising that ventilation-perfusion mismatch occurs in both pneumonia and asthma, RCTs were conducted to investigate the effects of high concentration oxygen on $\mathrm{PaCO}_{2}$ in these conditions.

In 2012, Wijesinghe et $\mathrm{al}^{14}$ conducted a parallel RCT comparing the effects of high concentration oxygen ( $8 \mathrm{~L} /$ minute via Hudson mask) and titrated oxygen (to $\mathrm{SpO}_{2}$ 93-95\%) for 60 minutes, in 150 patients presenting to hospital with suspected community acquired pneumonia. Patients with COPD were excluded. Over $90 \%$ of the participants that received high concentration therapy had a $\mathrm{SpO}_{2} \geq 99 \%$ by the end of the intervention, and it was over 93\% in the remainder. The mean difference in $\mathrm{PtCO}_{2}$ from baseline was $2.7 \mathrm{mmHg}$ higher in the high concentration oxygen group (95\% CI 1.5 to $3.9 \mathrm{mmHg}, \mathrm{P}<0.001$ ). An increase in $\mathrm{PtCO}_{2} \geq 8 \mathrm{mmHg}$ occurred in $15 \%$ of the participants that received high concentration oxygen and $2 \%$ of the participants that received titrated oxygen (relative risk $5.7, \mathrm{P}=0.007$ ).

In 2003, Rodrigo et al ${ }^{108}$ randomised 74 patients with an acute asthma exacerbation to receive either $28 \%$ oxygen via a Hudson mask or $100 \%$ oxygen via a non-rebreathing mask for 20 minutes. At the end of the intervention the participants in the $100 \%$ oxygen group had a significantly higher mean $\mathrm{PaCO}_{2}$ (38 mmHg versus $35.4 \mathrm{mmHg}, \mathrm{P}=0.03$ ). This was followed by Perrin et al's RCT in 2011, ${ }^{13}$ which compared the effects of high concentration oxygen ( $8 \mathrm{~L} /$ minute via Hudson mask) and titrated oxygen (to $\mathrm{SpO}_{2}$ 93-95\%) for 60 minutes in 106 patients presenting to hospital with an exacerbation of asthma. At the end of the study period $78 \%$ of the participants that received high concentration oxygen therapy had a $\mathrm{SpO}_{2}$ 
$\geq 99 \%$, and it was $\geq 95 \%$ in the remainder. The mean difference in $\mathrm{PtCO}_{2}$ from baseline was $2.6 \mathrm{mmHg}$ higher in the high concentration oxygen group (95\% CI 0.9 to $4.3 \mathrm{mmHg}$, $\mathrm{P}<0.003)$. An increase in $\mathrm{PtCO}_{2} \geq 8 \mathrm{mmHg}$ occurred in $22 \%$ of the participants that received high concentration oxygen and $6 \%$ of participants that received titrated oxygen (relative risk 3.9, $\mathrm{P}=0.016$ ). The results are supported by non-randomised trial data in acute ${ }^{109}$ and stable asthma, ${ }^{98}$ in which oxygen was demonstrated to increase $\mathrm{PaCO}_{2}$ and $\mathrm{PtCO}_{2}$, respectively.

These studies all support the concept that oxygen administration might lead to clinically significant elevations in $\mathrm{PaCO}_{2}$ across a range of respiratory disorders with abnormal gas exchange.

\subsubsection{Obesity}

Obesity affects more than 650 million adults worldwide, and is a major risk factor for a number of diseases that could result in patient hospitalisation, including cardiovascular diseases, diabetes and cancers. ${ }^{110}$ In New Zealand obesity affects one in three adults, and rates are highest in Māori and Pacific adults (50\% and 69\%, respectively). ${ }^{11}$

Obesity affects respiratory physiology by reducing lung volume, decreasing compliance, and causing V/Q mismatch and hypoventilation. ${ }^{112,113}$ Changes in physiology can lead to OHS, a triad of obesity (body mass index $(\mathrm{BMI}) \geq 30 \mathrm{~kg} / \mathrm{m}^{2}$ ), awake chronic hypercapnia $\left(\mathrm{PaCO}_{2} \geq 45 \mathrm{mmHg}\right)$ and sleep disordered breathing (usually obstructive sleep apnoea). ${ }^{114,115} \mathrm{OHS}$ is thought to be present in around a third of obese hospital inpatients. ${ }^{116}$

These changes in respiratory function may place patients at risk of oxygen-induced elevations in $\mathrm{PaCO}_{2}$. Given the number of obesity-associated co-morbidities that may lead to hospitalisation and the administration of oxygen therapy, it is clinically important to assess the risk of oxygen-induced hypercapnia in these patients.

A systematic review of the studies that have investigated the effect of oxygen on $\mathrm{PaCO}_{2}$ in people with obesity was conducted in March 2018 (methodology in Textbox 1.3). Four eligible studies were identified, two of which are randomised trials. 


\begin{abstract}
Search
Pubmed search:

[(obesity OR obese OR Pickwickian syndrome Or Obesity hypoventilation syndrome OR OHS) AND ((oxygen* OR O2 OR FiO2 OR PtO2 OR PaO2 OR PO2 OR SpO2 OR SaO2) AND (carbon dioxide OR hypercap* OR hypercarb* OR CO2 OR PtCO2 OR PaCO2 OR PCO)) (N found: 695)
\end{abstract}

Additional reference search:

References from the papers identified above were also reviewed.

\title{
Classification of eligible studies
}

The abstract and, if applicable, full text were reviewed.

Trials were eligible for inclusion if they included participants with obesity and evaluated the effects of oxygen delivery at a $\mathrm{FiO}_{2}>0.21$ on $\mathrm{PaCO}_{2} \cdot \mathrm{PaCO}_{2}$ could be measured by $\mathrm{ABG}$, or surrogate measures such as capillary blood gas or transcutaneous measurement. Trials in which the full text was not available to me and/or the full text was not in English were excluded.

To increase relevance to the acute clinical setting, data were not included if during an intervention or baseline measurement the following factors occurred, which may alter $\mathrm{PaCO}_{2}$.

- Ventilation (invasive or non-invasive)

- High flow delivery (e.g. nasal high flow cannulae)

- Hyperbaric delivery

- Delivery with gases other than room air or nitrogen (e.g. helium or carbon dioxide above room air levels)

- Modification of oxygen delivery based on $\mathrm{PaCO}_{2}$ levels

Textbox 1.3 Search strategy for studies investigating the effects of oxygen therapy on $\mathrm{PaCO}_{2}$ in obesity

ABG: Arterial blood gas, $\mathrm{FiO}_{2}$ : Fraction of inspired oxygen, $\mathrm{PaCO}_{2}$ : Arterial partial pressure of carbon dioxide. 
In 1963, Said et al ${ }^{87}$ investigated the effects of 'nearly pure' oxygen via a mouthpiece in 11 obese patients, with a mean $\mathrm{PaO}_{2}$ of $77.3 \mathrm{mmHg}$ and mean $\mathrm{PaCO}_{2}$ of $39 \mathrm{mmHg}$ on room air. Following oxygen administration for at least 10 minutes, the mean $\mathrm{PaCO}_{2}$ increased by $4 \mathrm{mmHg}$, with a $\geq 8 \mathrm{mmHg}$ increase in two participants, only one of which was hypercapnic at baseline. Of note, in 1969, Calzavara et al ${ }^{117}$ investigated the effects of oxygen in 12 patients with obesity. The manuscript was written in Italian, however data from each of the participants was demonstrated in table form. Average baseline $\mathrm{SpO}_{2}$ on air was $86 \%$ and $\mathrm{PaCO}_{2}$ was $46.7 \mathrm{mmHg}$. The mean $\mathrm{PaCO}_{2}$ increase was $6.2 \mathrm{mmHg}$ on oxygen with increases of $\geq 8 \mathrm{mmHg}$ in five participants, only one of which was hypercapnic at baseline. The author's reported an associated decrease in respiratory rate and tidal volume. In 1973, Barrera et $\mathrm{al}^{118}$ studied 10 obese patients, four of which were thought to have OHS. In these four participants the average $\mathrm{PaCO}_{2}$ on room air was $58.3 \mathrm{mmHg}$, which increased to 63.2 mmHg on $31 \%$ oxygen, and to $63.4 \mathrm{mmHg}$ on $100 \%$ oxygen. There did not appear to be similar changes in the other participants.

In 2011 Wijesinghe et al ${ }^{15}$ investigated the effects of room air and 100\% oxygen delivery for 20 minutes in a randomised cross over trial in 24 outpatients with OHS. In keeping with their diagnosis, all participants were hypercapnic at baseline. Change in mean $\mathrm{PtCO}_{2}$ from baseline was $5 \mathrm{mmHg}$ higher during 100\% oxygen compared to room air. Three of the 24 participants were withdrawn early due to $\mathrm{PtCO}_{2}$ increases of $>10 \mathrm{mmHg}$ from baseline. Similar to changes observed in COPD patients, the increase in $\mathrm{PtCO}_{2}$ was associated with a reduction in minute ventilation and increase in VD/VT. Patients at greatest risk of worsening hypercapnia were those with the lowest oxygen saturations at baseline, that is, those more likely to receive oxygen therapy in the hospital setting.

In 2013, Hollier et $\mathrm{al}^{16}$ recruited 14 outpatients with OHS to a randomised cross over study comparing 28 and 50\% oxygen administration, each for 20 minutes. They used arterialised venous partial pressure of carbon dioxide $\left(\mathrm{PavCO}_{2}\right)$ as an outcome measure, and reported it to increase by $2.3 \mathrm{mmHg}$ from baseline during $28 \%$ oxygen $(\mathrm{P}=0.013)$ and $3.8 \mathrm{mmHg}$ from baseline during $50 \%$ oxygen $(\mathrm{P}=0.012)$. The latter increase was associated with a 0.3 decrease in $\mathrm{pH}$. 
Overall, the results of these studies demonstrate high concentration oxygen administration can result in rapid and clinically significant increases in $\mathrm{PaCO}_{2}$ in patients with obesity. Results from the earlier studies suggest that oxygen-induced elevations in $\mathrm{PaCO}_{2}$ may occur in patients with and without baseline hypercapnia. The two randomised trials provide an evidence base for the Thoracic Society of Australia and New Zealand (TSANZ) ${ }^{11}$ and British Thoracic Society (BTS $)^{10}$ guideline recommendations to titrate oxygen therapy in patients with OHS. However, the data are limited in their application to all obese patients in the clinical setting, due to the restriction of recruitment to patients with OHS. The RCT in Chapter 4 of this thesis was performed to investigate the effects of high concentration compared to titrated oxygen in medical inpatients with morbid obesity, who were not selected for a pre-existing diagnosis of OHS.

\subsubsection{Bronchiectasis}

Bronchiectasis is a disease of airflow obstruction, hypoventilation and V/Q mismatch. Obstruction is mainly due to wall thickening of the small airways, while the larger airways are permanently dilated, resulting in chronic cough, increased sputum production and recurrent infections, which may require hospitalisation. ${ }^{119-121}$ While many patients have idiopathic disease, there are a number of other etiologies that cause bronchiectasis, including damage from infection, ciliary dysfunction, cystic fibrosis, aspiration and immune deficiency. ${ }^{120}$ The reported rates of bronchiectasis worldwide are variable, with increases in populations with poor access to healthcare and high childhood disease rates. ${ }^{120}$ In New Zealand the prevalence of bronchiectasis is estimated at around 158 per 100,000, with Pacific and Māori disproportionately affected (at 686 and 368 per 100,000, respectively). ${ }^{122}$ Bronchiectasis is an important cause of hospitalisation in New Zealand, leading to 29 hospitalisations per 100,000 in $2015 .^{122}$

Given the similarities in respiratory pathology between bronchiectasis and COPD, it is possible that clinically significant oxygen-induced hypercapnia may also occur in patients with bronchiectasis.

A systematic review of the studies that have investigated the effect of oxygen on $\mathrm{PaCO}_{2}$ in patients with bronchiectasis was conducted in February 2018 (methodology in Textbox 1.4). 
Two small sleep studies ${ }^{123,124}$ and one exercise study ${ }^{125}$ have been performed in patients with cystic fibrosis. No eligible studies were identified in patients with non-cystic fibrosis bronchiectasis. 


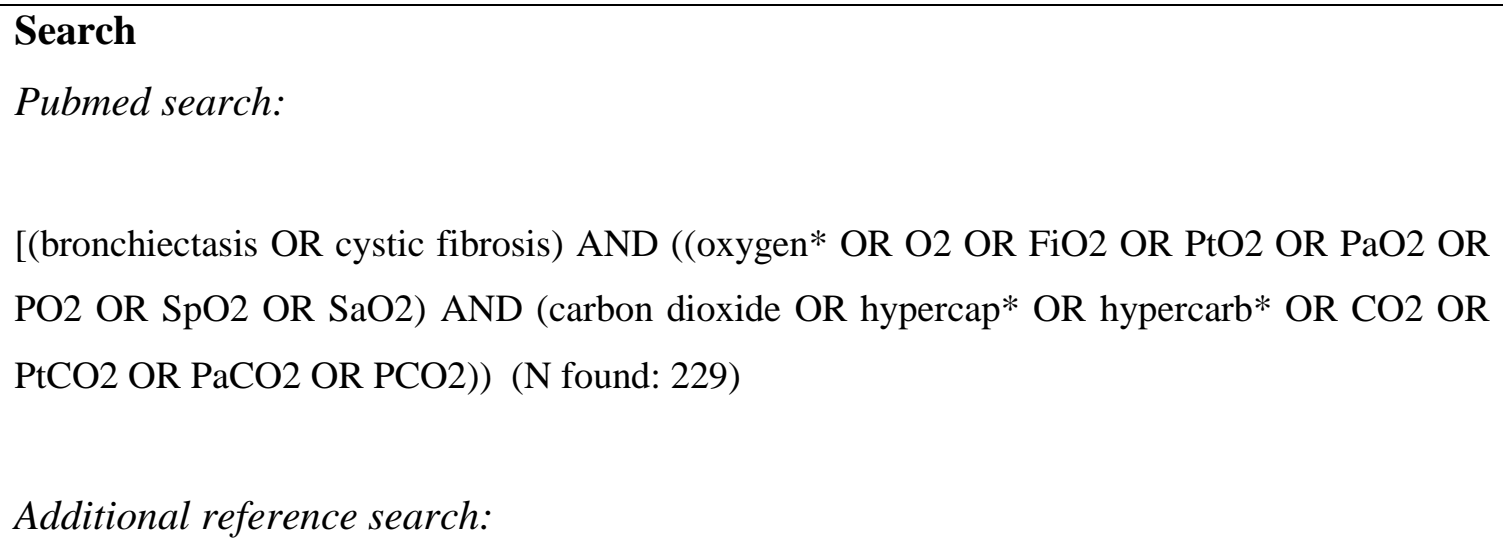

Pubmed search:

[(bronchiectasis OR cystic fibrosis) AND ((oxygen* OR O2 OR FiO2 OR PtO2 OR PaO2 OR PO2 OR SpO2 OR SaO2) AND (carbon dioxide OR hypercap* OR hypercarb* OR CO2 OR $\mathrm{PtCO} 2$ OR PaCO2 OR PCO2)) (N found: 229)

Additional reference search:

References from the papers identified above were also reviewed.

\section{Classification of eligible studies}

The abstract and, if applicable, full text were reviewed.

Trials were eligible for inclusion if they included participants with cystic fibrosis or bronchiectasis and evaluated the effects of oxygen delivery at a $\mathrm{FiO}_{2}>0.21$ on $\mathrm{PaCO}_{2}$. $\mathrm{PaCO}_{2}$ could be measured by $\mathrm{ABG}$, or surrogate measures such as capillary blood gas or transcutaneous measurement. Trials in which the full text was not available to me and/or the full text was not in English were excluded.

To increase relevance to the acute clinical setting, data were not included if during an intervention or baseline measurement the following factors occurred, which may alter $\mathrm{PaCO}_{2}$.

- Ventilation (invasive or non-invasive)

- High flow delivery (e.g. nasal high flow cannulae)

- Hyperbaric delivery

- Delivery with gases other than room air or nitrogen (e.g. helium or carbon dioxide above room air levels)

- Modification of oxygen delivery based on $\mathrm{PaCO}_{2}$ levels

Textbox 1.4 Search strategy for studies investigating the effects of oxygen therapy on $\mathrm{PaCO}_{2}$ in bronchiectasis

ABG: Arterial blood gas, $\mathrm{FiO}_{2}$ : Fraction of inspired oxygen, $\mathrm{PaCO}_{2}$ : Arterial partial pressure of carbon dioxide. 
In 1984, Spier et al ${ }^{123}$ recruited 10 patients with stable cystic fibrosis, severe airway obstruction and $\mathrm{SaO}_{2}<92 \%$. They were randomised to the order they received oxygen and air overnight, via nasal prongs at $2 \mathrm{~L}$ /minute. While sleep itself increased the maximal $\mathrm{PtCO}_{2}$ values by between 6.3 and $6.5 \mathrm{mmHg}$ on room air, the addition of oxygen at 2 $\mathrm{L} /$ minute increased these values by a further 2 to $4 \mathrm{mmHg}(\mathrm{P}<0.005)$. There was no association between these changes and minute ventilation measures. In 1997 Gozal et al ${ }^{124}$ also studied the effects of nocturnal oxygen in cystic fibrosis patients. Six patients received air overnight and then subsequently spent a night on low flow supplemental oxygen, the exact flow determined during afternoon naps when $\mathrm{PtCO}_{2}$ and $\mathrm{SpO}_{2}$ were measured. Sleep was also found to increase $\mathrm{PtCO}_{2}$ on air, however there was a further increase in $\mathrm{PtCO}_{2}$ during oxygen delivery, resulting in the mean $\mathrm{PtCO}_{2}$ being $7.5 \mathrm{mmHg}$ higher in patients during low flow oxygen compared to room air $(\mathrm{P}<0.02)$.

Lastly, in 1992 Marcus et al ${ }^{125}$ measured $\mathrm{PtCO}_{2}$ values during exercise testing in 22 patients with cystic fibrosis. Room air and 30\% oxygen were administered in random order. Exercise on room air increased mean $\mathrm{PtCO}_{2}$ by $6 \mathrm{mmHg}$ from baseline at rest. The increase was greater during $30 \%$ oxygen, at $10 \mathrm{mmHg}(\mathrm{P}=0.02)$. There was no difference in minute ventilation between the regimens.

Overall, these studies indicate the potential for oxygen therapy to increase $\mathrm{PaCO}_{2}$ in patients with bronchiectasis, however their applicability to clinical practice is severely limited by the restriction of recruitment to cystic fibrosis patients and the conduct of studies in the settings of sleep and exercise, which themselves consistently altered $\mathrm{PtCO}_{2}$ levels on room air. The randomised cross over study in Chapter 5 of this thesis was performed to estimate the effect of high concentration oxygen compared to room air on $\mathrm{PaCO}_{2}$ in patients with bronchiectasis while awake and at rest.

\subsubsection{Neuromuscular disease and kyphoscoliosis}

The term 'neuromuscular disease' encompasses a broad range conditions, some of which can result in skeletal muscle and diaphragmatic weakness, leading to hypoventilation. ${ }^{113,126}$ Muscle weakness can also lead to reduced functional residual capacity and increased work 
of breathing. ${ }^{126}$ Kyphoscoliosis also impacts on respiratory physiology, by resulting in reduced chest wall compliance, leading to hypoventilation and respiratory failure. ${ }^{113}$ While these conditions are less common causes of respiratory failure than the diseases outlined previously, acute respiratory illnesses can cause serious complications that can result in severe hypoxaemia and the need for oxygen therapy. It is therefore important to establish whether these patients are at risk of oxygen-induced hypercapnia.

A systematic review of the studies that have investigated the effect of oxygen on $\mathrm{PaCO}_{2}$ in neuromuscular disease and/or kyphoscoliosis patients was conducted in February 2018 (methodology in Textbox 1.5). There was only one trial ${ }^{127}$ and two observational studies $^{128,129}$ in neuromuscular disease patients which were eligible for inclusion. No eligible studies were found in kyphoscoliosis patients. 


\section{Search}

Pubmed search:

[(neuromuscular OR motor neuron disease OR amyotrophic lateral sclerosis OR dystrophy OR palsy OR kyphoscoliosis) AND ((oxygen* OR O2 OR FiO2 OR PtO2 OR PaO2 OR PO2 OR SpO2 OR SaO2) AND (carbon dioxide OR hypercap* OR hypercarb* OR CO2 OR PtCO2 OR $\mathrm{PaCO} 2$ OR PCO2)) (N found: 895)

\section{Additional reference search:}

References from the papers identified above were also reviewed.

\section{Classification of eligible studies}

The abstract and, if applicable, full text were reviewed. Trials were eligible for inclusion if they included participants with neuromuscular disease or kyphoscoliosis and evaluated the effects of oxygen delivery at a $\mathrm{FiO}_{2}>0.21$ on $\mathrm{PaCO}_{2} \cdot \mathrm{PaCO}_{2}$ could be measured by $\mathrm{ABG}$, or surrogate measures such as capillary blood gas or transcutaneous measurement. Trials in which the full text was not available to me and/or the full text was not in English were excluded

To increase relevance to the acute clinical setting, data were not included if during an intervention or baseline measurement the following factors occurred, which may alter $\mathrm{PaCO}_{2}$.

- Ventilation (invasive or non-invasive)

- High flow delivery (e.g. nasal high flow cannulae)

- Hyperbaric delivery

- Delivery with gases other than room air or nitrogen (e.g. helium or carbon dioxide above room air levels)

- Modification of oxygen delivery based on $\mathrm{PaCO}_{2}$ levels

Textbox 1.5 Search strategy for studies investigating the effects of oxygen therapy on $\mathrm{PaCO}_{2}$ in neuromuscular disease and/or kyphoscoliosis

ABG: Arterial blood gas, $\mathrm{FiO}_{2}$ : Fraction of inspired oxygen, $\mathrm{PaCO}_{2}$ : Arterial partial pressure of carbon dioxide. 
In 1984, Walshaw et al ${ }^{127}$ recruited 16 patients with acute hemiplegia (onset within previous 24 hours) due to cerebrovascular accident. At baseline patients had mean values for $\mathrm{PaO}_{2}$ of $66 \mathrm{mmHg}, \mathrm{PaCO}_{2}$ of $33.8 \mathrm{mmHg}$ and $\mathrm{pH}$ of 7.37. After 15 minutes of 59-65\% oxygen via a ventimask, mean $\mathrm{PaCO}_{2}$ increased by $2.2 \mathrm{mmHg}(\mathrm{P}<0.01)$. As recognised by the authors, the participants' respiratory responses could have been altered centrally by their cerebrovascular accident, so it is difficult to evaluate the contribution of hemiplegia to the change in $\mathrm{PaCO}_{2}$.

In 1995, Gay and Edmonds ${ }^{128}$ retrospectively reviewed the medical records of eight patients with a range of neuromuscular diseases and diaphragm dysfunction (polymyositis, motor neuron disease, inflammatory motor neuropathy or chronic poliomyelitis). Blood gas values before and after the administration of low flow oxygen therapy at 0.5 to $2 \mathrm{~L} /$ minute were compared. Mean $\mathrm{PaCO}_{2}$ after oxygen administration was observed to increase by 28.2 $\mathrm{mmHg}$; however, measurements were made up to six days following oxygen therapy.

In 2016, Chiou et al ${ }^{129}$ presented case studies on a series of patients with neuromuscular disease who received oxygen. One of the cases meet the criteria in Textbox 1.5, in which a 32 year old with Becker muscular dystrophy was placed on $100 \%$ oxygen and obtunded over the next 20 minutes, $\mathrm{PaCO}_{2}$ was measured as $177 \mathrm{mmHg}$.

Overall, it is difficult to interpret whether the data from these studies suggest oxygeninduced hypercapnia occurs in patients with neuromuscular disease and/or kyphoscoliosis. The randomised cross over study in Chapter 5 of this thesis was performed to estimate the effect of high concentration oxygen compared to room air on $\mathrm{PaCO}_{2}$ in patients with neuromuscular disease or kyphoscoliosis. 


\subsection{Practical considerations in the titration of oxygen}

therapy

\subsubsection{Translating evidence into clinical practice}

Prior to 2010, many guidelines recommended the avoidance of high concentration oxygen, particularly in patients with AECOPD. Suggested regimens for delivery tended to focus on the provision of oxygen at low flows, ${ }^{130-132}$ or the titration of therapy to patient oxygen saturations. ${ }^{41}$ These recommendations were supported by case studies and trials that demonstrated increases in $\mathrm{PaCO}_{2}$ in response to oxygen, as well as observational studies suggesting worse clinical outcomes on higher concentrations of oxygen, as outlined in Sections 1.2 and 1.3. However, a number of audits have suggested that guideline recommendations had not been followed. In 2002, Denniston et $\mathrm{al}^{35}$ reported the use of oxygen in excess of $28 \%$ in well over half of the 101 hospital admissions for AECOPD studied, contrary to recommendations of the local guidelines at the time. ${ }^{130}$ Similarly, in 2007, Joosten et al ${ }^{36}$ found uncontrolled oxygen therapy was common in their review of 65 patients presenting to hospital for AECOPD, despite guideline recommendations against it. ${ }^{131,132}$ Wijesinghe et al's 2011 study $^{37}$ (with data collected from patient presentations prior to 2008), showed 90 of the 250 hospital presentations studied received oxygen at $\geq 8$ $\mathrm{L} /$ minute, and $\mathrm{PaO}_{2}$ values in hospital reached up to $300 \mathrm{mmHg}$, indicating controlled therapy had not been followed as per local guidelines available at the time. ${ }^{132}$

One factor which might explain why oxygen guidelines were not followed in these studies was the lack of RCT data for clinical harm available at the time. Some publications during this period still suggested that the risks of high concentration oxygen may have been overstated $^{44}$ and that hypoxaemia may be inadequately corrected due to excessive fears of $\mathrm{CO}_{2}$ retention. ${ }^{70}$ However, the trend to deliver high concentration oxygen continued after Austin et al's $2010 \mathrm{RCT}^{12}$ demonstrated increased mortality in patients that received high concentration instead of titrated oxygen therapy. ${ }^{133,134}$ Interestingly, despite specific staff protocol training, there was an unexpectedly high rate of high concentration oxygen administration in the titrated arm of Austin et al's study; ${ }^{12} 56 \%$ of participants with 
confirmed AECOPD received high concentration oxygen at some point during titrated therapy. On discussion with the staff involved, many reported they were concerned about "insufficient oxygen delivery in distressed patients". This highlights how difficult it can be to change practice away from the belief that 'more is better' ${ }^{12,135}$

At a local level the Wellington Free Ambulance (WFA) integrated an education program in 2009 to educate staff on the potential risks of oxygen therapy and current guideline recommendations for the titration of oxygen therapy to achieve oxygen saturations between $88-92 \%$ in patients with AECOPD. ${ }^{41}$ This target saturation range was the same as what was administered in the titrated regimen in Austin et al's 2010 study. ${ }^{12}$ Prior to 2013 WFA staff only had oxygen-driven nebulisers available, so high concentration oxygen exposure was unavoidable in patients that received nebulised medication. This was in contrast to the titrated regimen in Austin et al's study, ${ }^{12}$ where delivery of nebulisers was by air. The audit in Chapter 2 was conducted with the aims of assessing whether the education intervention reduced exposure to high concentration oxygen in patients with AECOPD, and to quantify exposure to high concentration oxygen that could have been avoided if air-driven nebulisers were available.

\subsubsection{The optimal target saturation range for oxygen titration and the impact of pulse oximeter accuracy}

Current guidelines recommend the titration of oxygen therapy to a $\mathrm{SpO}_{2}$ between $88-92 \%$ in patients with AECOPD and other conditions at risk of hypercapnia. ${ }^{10,11}$ The evidence base for the use of this range is provided by Austin et al's 2010 RCT. ${ }^{12}$ In patients without COPD or another respiratory condition associated with hypercapnia, oxygen titration is also recommended. ${ }^{10,11}$ However, evidence for the optimal target $\mathrm{SpO}_{2}$ range is less clear. The 2017 BTS Guidelines ${ }^{10}$ recommend $94-98 \%$ as a target $\mathrm{SpO}_{2}$ range. However the TSANZ Guidelines ${ }^{11}$ recommend a slightly lower range, at 92-96\%. Beasley et al justified the lower target range by considering the evidence to support low risk of harm at a $\mathrm{SaO}_{2}$ of at least $90 \%{ }^{136}$ Additionally, the lower range was considered to potentially reduce unnecessary oxygen use as health professionals often administer oxygen well in excess of recommended target ranges, as outlined in Section 1.5.1.136 
A practical consideration that is essential to the recommended $\mathrm{SpO}_{2}$ targets in both of the guidelines is the accuracy of the pulse oximeters used to assess $\mathrm{SaO}_{2}$. Pulse oximeter measured $\mathrm{SpO}_{2}$ values have been found to both over and underestimate $\mathrm{SaO}_{2}$ values from ABG measurement, with wide limits of agreement. ${ }^{137-164}$ Additionally, oximeter accuracy may change with evolving sensor technology and software algorithms, which means previous studies may not be directly relevant to the sensors currently used in Australia and New Zealand. The multicentre study in Chapter 3 was conducted to investigate the agreement between $\mathrm{SpO}_{2}$ and $\mathrm{SaO}_{2}$ in a range of oximeters in clinical use in Australian and New Zealand hospitals, and evaluate whether a $\mathrm{SpO}_{2}$ of $92 \%$ (the lower limit of the TSANZ guideline's recommended titration range) was able to rule out hypoxaemia $\left(\mathrm{SaO}_{2}<90 \%\right)$. 


\subsection{Summary, gaps in knowledge and the studies in this thesis}

Austin et al's 2010 study $^{12}$ demonstrated a significant reduction in mortality in patients with AECOPD who received titrated oxygen therapy, compared to those that received high concentration oxygen therapy. It provides RCT level evidence for guideline recommendations to titrate oxygen therapy in the acute clinical setting. The clinical trials investigating the effects of oxygen on $\mathrm{PaCO}_{2}$ support the rationale for titrated therapy and demonstrate that oxygen-induced hypercapnia may occur in a wide range of respiratory conditions.

The studies in the following chapters are all aimed at addressing gaps in knowledge which may have practical implications for oxygen therapy and/or the identification of patients at risk of oxygen-induced hypercapnia in the acute clinical setting.

There is limited data on the risks of oxygen therapy in patients with obesity, bronchiectasis, neuromuscular disease or kyphoscoliosis. A number of audits have highlighted concerns that health professionals administer oxygen therapy at levels in excess of guideline recommendations, demonstrating the need for practical strategies to improve the safety of clinical practice. Another practical issue affecting the administration of titrated oxygen therapy is the need to understand how discrepancies between $\mathrm{SpO}_{2}$ and $\mathrm{SaO}_{2}$ may impact on the ability to accurately avoid both hypoxaemia and hyperoxaemia. To further extend knowledge in these areas the following studies are included in this thesis:

An observational study comparing oxygen delivery to patients with AECOPD during ambulance journey to hospital in 2005 and 2010 (Chapter 2), to determine:

- Whether oxygen delivery practices differed before and after the local ambulance service delivered an education program to staff on the potential harms of high concentration oxygen therapy in 2009 
- The incidence of exposure to high concentration oxygen via oxygen-driven nebulisers in patients that would otherwise not have been exposed to high concentration oxygen delivery.

A multicentre study to compare ABG measured and pulse oximeter measured oxygen saturations using currently available pulse oximeters in Australian and New Zealand hospitals (Chapter 3), to determine:

- The level of agreement between $\mathrm{SaO}_{2}$ and $\mathrm{SpO}_{2}$ values

- The diagnostic performance of $\mathrm{SpO}_{2}$ to detect hypoxaemia $\left(\mathrm{SaO}_{2}<90 \%\right)$

- Factors affecting oximeter accuracy.

A RCT investigating the effect of high concentration oxygen therapy in patients with obesity presenting to hospital (Chapter 4), to determine:

- The effects of oxygen therapy on $\mathrm{PaCO}_{2}$.

A series of three randomised cross over trials investigating the effects of high concentration oxygen therapy in patients with neuromuscular disease or kyphoscoliosis, bronchiectasis, and COPD (Chapter 5), to determine:

- The effects of oxygen therapy on $\mathrm{PaCO}_{2}$

- The mechanisms behind any change in $\mathrm{PaCO}_{2}$, through the evaluation of changes to minute ventilation, VD/VT and other respiratory parameters

- If $\mathrm{FEV}_{1}$ is a predictor of the risk and magnitude of oxygen-induced hypercapnia in patients with COPD and bronchiectasis.

Original studies using TOSCA data (Appendix 1):

- The studies in Chapters 4 and 5 were originally conducted using a TOSCA transcutaneous monitor (Radiometer). However, concerns regarding probe accuracy meant that all TOSCA data were considered unusable.

- Data from these original studies using the TOSCA are presented and compared to the data in Chapters 4 and 5.

- Steps taken to assess accuracy of data collected using the replacement transcutaneous monitor (SenTec) are presented. 
Chapter 2: Audit of oxygen use in AECOPD 


\subsection{Overview}

\section{Audit of oxygen use in AECOPD}

\section{AIM}

In 2009 the Wellington Free Ambulance implemented an education program to reduce high concentration oxygen delivery to patients with an acute exacerbation of chronic obstructive pulmonary disease (AECOPD). The aim of this audit was to compare prehospital oxygen delivery to patients with AECOPD before and after the program.

\section{METHODS}

An audit of patients who presented to Wellington Regional Hospital by ambulance with an AECOPD in 2005 and then in 2010, after implementation of the education program. Oxygen therapy was categorised as: HIGH, supplemental high concentration oxygen therapy $\geq 3 \mathrm{~L} / \mathrm{min}$ and/or delivery via high concentration mask; NEB, high concentration oxygen only during nebuliser use; or LOW, neither of these.

\section{KEY RESULTS}

In 2005 those in the HIGH, NEB and LOW categories were $81(75.0 \%), 18$ $(16.7 \%)$ and $9(8.3 \%)$ of 108 identified patients. In 2010 those in the HIGH, NEB and LOW categories were 80 $(44.0 \%), 61(33.5 \%)$ and $41(22.5 \%)$ of 182 identified patients. The proportions of patients in the three oxygen groups were significantly different between 2005 and $2010(\mathrm{P}<0.001)$.

\section{CONCLUSIONS}

The proportion of patients administered supplemental high concentration oxygen therapy markedly decreased between 2005 and 2010 following implementation of the education program. However, in 2010 more than half of the patients not managed with high concentration oxygen therapy were still exposed to high concentration oxygen through the use of oxygen-driven nebulisers. To reduce exposure to high concentration oxygen in AECOPD the use of air-driven nebulisers or metered dose inhalers with spacers is required.

\section{CO-INVESTIGATORS AND PUBLICATION}

Pilcher J, Cameron L, Braithwaite I, Bowles D, Swain A, Bailey M, Weatherall M, Beasley R, Perrin K. Comparative audit of oxygen use in the prehospital setting, in acute COPD exacerbation, over 5 years. Emerg Med J. 2013 Nov 15:emermed-2013.

Reproduced with permission (see Appendix). Some changes have been made from the above publication. Section 2.6 is additional to the publication.

\section{Textbox 2.0 Overview}




\subsection{Rationale}

The routine administration of high concentration oxygen therapy to patients with AECOPD leads to worse outcomes including increased risk of mortality. 2,12,34,35,37,39,165,166 However, high concentration oxygen therapy is commonly administered in the pre-hospital management of AECOPD. ${ }^{34,35,37,39,165,166}$ This has led to consideration of the reasons for the divergence of recommended and actual practice, and strategies that might change practice. $^{42,167}$

Wellington Free Ambulance (WFA) is a charitable trust which provides services to a population of 475,000 people, operating from eleven ambulance stations in the greater Wellington region. All paramedics are trained to administer oxygen and all vehicles are equipped with pulse oximeters but end tidal carbon dioxide $\left(\mathrm{ETCO}_{2}\right)$ monitoring is designed mainly for post-intubation use. Paramedic guidelines advise that oxygen administration should be restricted in patients with AECOPD and that the target oxygen saturation for this group is $88-92 \%$. To ensure management of COPD patients according to their guidelines ${ }^{168}$ WFA developed an integrated education program in 2009.

To investigate the effect of the education program on oxygen administration by paramedics, we audited pre-hospital oxygen delivery to WFA patients with an AECOPD in 2005 and 2010. Our hypothesis was that the program would reduce the use of supplemental high concentration oxygen therapy but that the use of oxygen-driven nebulisers to administer bronchodilators would result in exposure to high concentration oxygen in an important proportion of patients not otherwise exposed. 


\subsection{Methods}

A retrospective audit of patients admitted to Wellington Regional Hospital (WRH) by ambulance with an AECOPD in 2005 and 2010 was carried out. Patients were identified by the WRH Decision Support Unit using the primary discharge diagnosis of COPD (ICD Code J440 or J441). Presentations were excluded if the ambulance record was missing or if the patient was transferred from another hospital. If patients presented more than once during either 2005 or 2010 , only the first documented presentation was used.

Oxygen therapy administered by the WFA service prior to presentation at WRH was categorised as HIGH, NEB, or LOW (Figure 2.1). The HIGH category included patients who received supplementary oxygen therapy at high concentrations with documented oxygen flow of $\geq 3 \mathrm{~L} / \mathrm{min}$ and/or oxygen delivered by a high concentration mask. The NEB category included patients, not classified in the HIGH category, who received high concentration oxygen solely due to the administration of bronchodilator therapy through an oxygen-driven nebuliser and not otherwise exposed to oxygen therapy. LOW included the remainder of patients in whom either 'room air' or a flow rate of $<3 \mathrm{~L} / \mathrm{min}$ was documented, or if there was no mention of any oxygen therapy. Patients for whom oxygen delivery was documented but where there was no record of the flow rate or whether a high concentration mask was used were not analysed. For patients categorised into HIGH, NEB or LOW groups, who had more than one oxygen saturation documented in the WFA patient record, the final recorded oxygen saturation before hospital arrival was documented. 


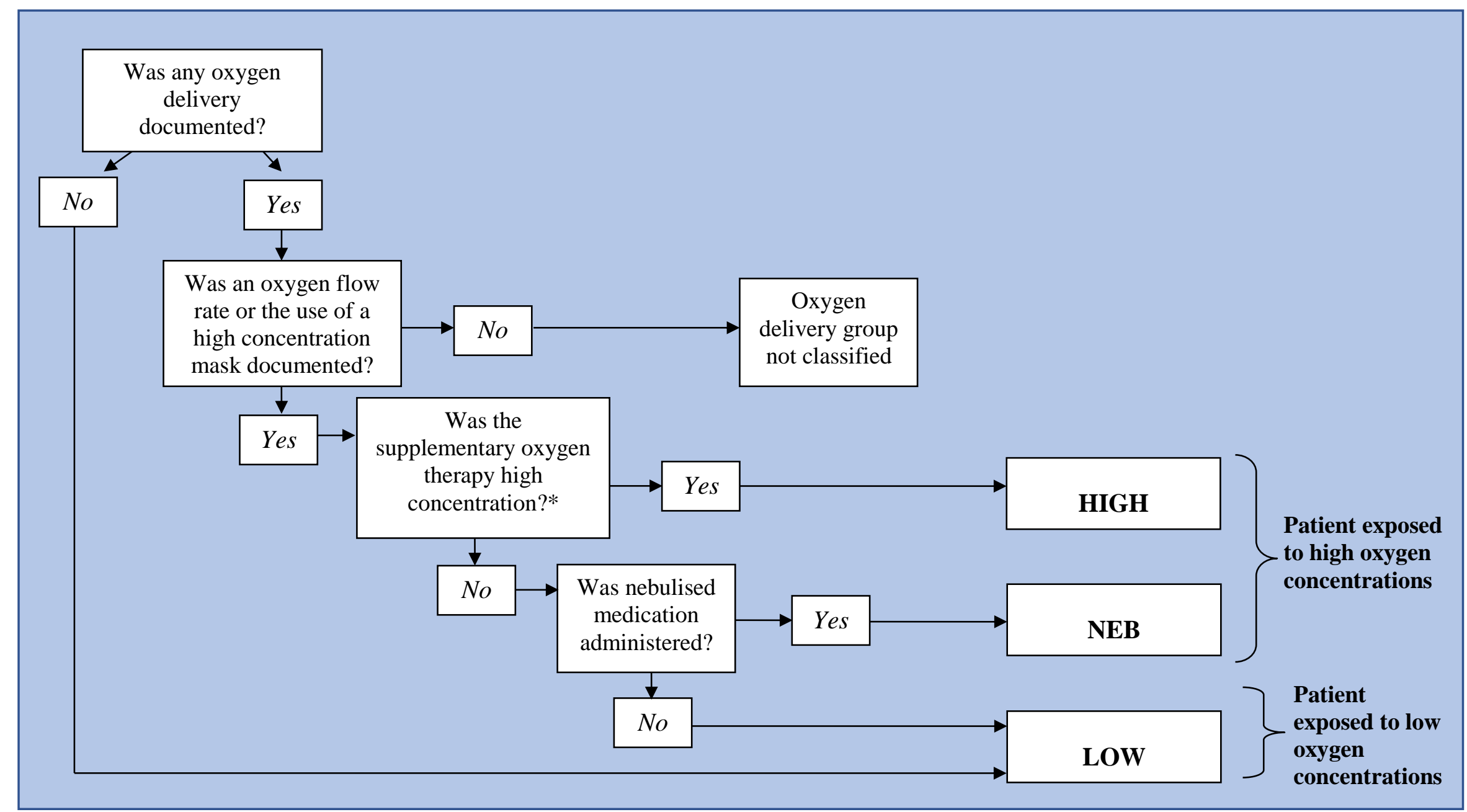

Figure 2.1 Oxygen therapy classification

* Supplementary oxygen therapy is defined as administration of oxygen via nasal prongs or a mask for the sole purpose of the provision of oxygen therapy (as opposed to oxygen administered to assist in the delivery of nebulised medication). High concentration supplementary oxygen therapy is a documented flow $\geq 3$ L/min and/or oxygen delivered via a high concentration mask. 
In WFA nasal prongs are used to deliver oxygen at 1-4 L/min, medium concentration masks to deliver oxygen at 6-8 L/min and reservoir masks are used with an oxygen flow rate of 10-15 L/min. Venturi masks are not used. All nebulisers (Hudson RCI Micro Mist) are oxygen-driven, with a recommended flow rate of $8 \mathrm{~L} / \mathrm{min}$.

The WFA integrated education program started in 2009. It focused on titrating oxygen therapy to a target patient oxygen saturation of $88-92 \%$, rather than using a predetermined flow rate. The program had: face-to-face training updates, clinical notices to paramedics, audit of clinical records and reminders in staff newsletters. The training coincided with the release of COPD Alert cards to patients with known $\mathrm{CO}_{2}$ retention. Oxygen administration in AECOPD was also included in the list of key Clinical Performance Indicators in October 2010 .

A Chi-square test examined if different proportions of patients were in the oxygen administration categories of: HIGH, NEB or LOW, by year, 2005 versus 2010. The relative risk of death or assisted ventilation by year, 2005 versus 2010, with appropriate confidence intervals, was estimated by logistic regression, both unadjusted and adjusted for confounding by oxygen administration category and a past history of type II respiratory failure.

Final oxygen saturation values were described numeric summaries and by the proportion of patients with an oxygen saturation of $\leq 87 \%, 88-92 \%, 93-96 \%$ and $\geq 97 \%$. Comparison of median was by a Wilcoxon two-sample test with Hodges-Lehman estimation of the difference. SAS version 9.2 was used.

This study, as a clinical audit, met Capital and Coast District Health Board policy requirements of prospective registration and maintenance of patient confidentiality. 


\subsection{Results}

There were 119 admissions in 2005 and 190 in 2010 eligible for inclusion in the analysis (Figure 2.2). The age and physiological measurements, taken on ambulance arrival, were similar in 2005 and 2010, and are shown in Table 2.1. The proportions of patients with home nebuliser use, home oxygen prescription, long term oral steroids, a history of assisted ventilation, and previous type II respiratory failure were higher in the 2005 group. 


\section{Admissions for an acute exacerbation of}

COPD identified from WRH

2005: $\mathrm{n}=238$

2010: $n=398$

\section{Exclusions}

- Not brought in by ambulance from the community $(2005: \mathrm{n}=39,2010: \mathrm{n}=53)$

- Unable to obtain notes or Incomplete data in notes (2005: $n=21,2010: n=38$ )

- Repeat admission (2005: $\mathrm{n}=59,2010$ : $\mathrm{n}=117$ )

Figure 2.2 Patient inclusion/exclusion pathway

COPD: Chronic obstructive pulmonary disease, WRH: Wellington Regional Hospital. 


\begin{tabular}{|c|c|c|}
\hline & 2005 & 2010 \\
\hline & \multicolumn{2}{|c|}{$\mathbf{n} / \mathbf{N}(\%)$} \\
\hline Male & $60 / 119(50.4)$ & $102 / 190(53.7)$ \\
\hline Home nebuliser use & 36/119 (30.3) & 29/190 (15.3) \\
\hline Home oxygen use & 23/119 (19.3) & 27/190 (14.2) \\
\hline $\begin{array}{l}\text { Long term oral steroid } \\
\text { prescription }\end{array}$ & $15 / 118(12.7)$ & $15 / 190(7.9)$ \\
\hline $\begin{array}{l}\text { Previous assisted } \\
\text { ventilation }\end{array}$ & $15 / 119(12.6)$ & 22/190 (11.6) \\
\hline \multirow[t]{2}{*}{$\begin{array}{l}\text { Previous type II } \\
\text { respiratory failure }\end{array}$} & 43/119 (36.1) & $41 / 190(21.6)$ \\
\hline & \multicolumn{2}{|c|}{ Mean (SD) } \\
\hline Age (years) & $\begin{array}{c}74.9(8.6) \\
\mathrm{N}=119\end{array}$ & $\begin{array}{l}72.2(10.5) \\
\mathrm{N}=190\end{array}$ \\
\hline Glasgow Coma Scale* & $\begin{array}{c}14.7(1.5) \\
\mathrm{N}=116\end{array}$ & $\begin{array}{c}14.9(0.73) \\
\mathrm{N}=185\end{array}$ \\
\hline $\begin{array}{l}\text { Heart rate* } \\
\text { (beats per minute) }\end{array}$ & $\begin{array}{l}103.7(22.6) \\
\mathrm{N}=119\end{array}$ & $\begin{array}{c}102.8(21.8) \\
\mathrm{N}=184\end{array}$ \\
\hline $\begin{array}{l}\text { Respiratory rate (breaths } \\
\text { per minute)* }\end{array}$ & $\begin{array}{c}29.4(8.3) \\
\mathrm{N}=110\end{array}$ & $\begin{array}{l}29.1(7.8) \\
\mathrm{N}=173\end{array}$ \\
\hline $\begin{array}{l}\text { Oxygen saturation } \\
\text { recorded on room air } \\
(\%)^{*}\end{array}$ & $\begin{array}{l}85.4(9.5) \\
\mathrm{N}=30\end{array}$ & $\begin{array}{c}88.7(8.7) \\
\mathrm{N}=77\end{array}$ \\
\hline $\begin{array}{l}\text { Systolic blood pressure } \\
(\mathrm{mmHg})^{*}\end{array}$ & $\begin{array}{l}159.9(35.0) \\
\mathrm{N}=101\end{array}$ & $\begin{array}{l}153.6(30.6) \\
\mathrm{N}=166\end{array}$ \\
\hline
\end{tabular}

\section{Table 2.1 Patient characteristics}

*First ambulance measurement recorded. 
There were 108 and 182 admissions in 2005 and 2010 respectively that were able to be categorised in the HIGH, NEB and LOW oxygen treatment groups for analysis. Nebulised medication was administered to just over half of the patients in both 2005 and 2010. The mean number of nebulisers administered to patients given at least one nebulisation was 1.6 in 2005 and 1.7 in 2010. The proportions of patients in the three oxygen groups are shown in Table 2.2. These were significantly different between 2005 and 2010; Chi-square=26.8, $2 \mathrm{df}, \mathrm{P}<0.001$. There was a marked reduction in the proportion in the HIGH category, falling from $75 \%$ to $44 \%$. 


\begin{tabular}{|lcc|}
\hline & $\mathbf{2 0 0 5}$ & $\mathbf{2 0 1 0}$ \\
\hline Any nebuliser use, n/N (\%) & $65 / 116(56.0)$ & $103 / 190(54.2)$ \\
\hline $\begin{array}{l}\text { Nebulisations in patients administered a } \\
\text { nebuliser, Median (range) }\end{array}$ & $1(1$ to 6$)$ & $2(1$ to 5) \\
\hline $\begin{array}{l}\text { Ambulance transit time in minutes, } \\
\text { Mean (SD) }\end{array}$ & $42.8(22.2)$ & $48.1(26.7)$ \\
& $\mathrm{N}=119$ & $\mathrm{~N}=190$ \\
\hline Oxygen treatment group, n/N (\%) & & $80 / 182(44.0)$ \\
HIGH & $81 / 108(75.0)$ & $61 / 182(33.5)$ \\
NEB & $18 / 108(16.7)$ & $41 / 182(22.5)$ \\
LOW & $9 / 108(8.3)$ & \\
\hline $\begin{array}{l}\text { Outcomes, } \mathrm{n} / \mathrm{N}(\%) \\
\text { Any assisted ventilation during hospital } \\
\text { admission }\end{array}$ & $30 / 119(25.2)$ & $25 / 190(13.2)$ \\
In hospital death & & $7 / 190(3.7)$ \\
\hline
\end{tabular}

Table 2.2 Ambulance treatment and patient outcomes

See Figure 2.1 for definitions of HIGH, NEB and LOW. 
The unadjusted odds ratio for risk for assisted ventilation for 2010 versus 2005 was 0.71 (0.52 to 0.98$), P=0.003$. The association between the year for 2010 versus 2005 and need for assisted ventilation was weaker and not statistically significant after adjustment for a past history of type II respiratory failure and oxygen administration type 0.76 (0.53 to 1.09), $\mathrm{P}=0.14$. A history of type II respiratory failure significantly influenced the risk of assisted ventilation $(\mathrm{P}<0.001)$ in the multivariate analysis, however oxygen administration type did not, (HIGH versus LOW, $\mathrm{P}=0.69$ and $\mathrm{NEB}$ versus $\mathrm{LOW}, \mathrm{P}=0.54$ ). The unadjusted odds ratio for risk for death for 2010 versus 2005 was 1.10 (95\% CI 0.31 to 3.84), $\mathrm{P}=0.88$.

There were 84 and 147 admissions in 2005 and 2010 respectively that had more than one oxygen saturation documented in their ambulance record and were able to be categorised into a HIGH, NEB or LOW group. The final oxygen saturations recorded by the ambulance staff are shown in Table 2.3. There was a statistically significant difference in median oxygen saturations, 98\% (IQR 95 to 99) in 2005 and 96\% (IQR 94 to 98) in 2010, difference $1.5 \%$ (95\% CI 1.0 to 2.0 ), $\mathrm{P}<0.001$. There were only $1 / 84$ and $4 / 147$ patients with final oxygen saturations less than the lower limit of the recommended oxygen saturation target range (88 to 92\%) in 2005 and 2010 respectively. There were no patients with an oxygen saturation $\leq 88 \%$ in the LOW oxygen group in either year. The majority of patients had saturations over $92 \%$, regardless of year or oxygen regimen. The proportion of patients with an oxygen saturation $\geq 97 \%$ was 58/84 (69\%) in 2005 and 69/147 (47\%) in 2010. In both years the majority of patients in the NEB group had a final oxygen saturation $\geq 97 \%$ (Table 2.3). ABG samples were taken within the first 30 minutes of arrival to the ED in $9 \%(10 / 108)$ and $5 \%(9 / 182)$ of patients in 2005 and 2010, respectively. 


\begin{tabular}{|c|c|c|c|}
\hline & \multicolumn{3}{|c|}{2005} \\
\hline & HIGH & NEB & LOW \\
\hline Median (range) & $\begin{array}{c}98(88 \text { to } 100) \\
N=63\end{array}$ & $\begin{array}{c}99(86 \text { to } 100) \\
N=16\end{array}$ & $\begin{array}{c}95(91 \text { to } 100) \\
\mathrm{N}=5\end{array}$ \\
\hline$<87, \mathrm{n}(\%)$ & $0(0)$ & $1(6.3)$ & $0(0)$ \\
\hline $88-92, \mathrm{n}(\%)$ & $5(7.9)$ & $0(0)$ & $1(20.0)$ \\
\hline 93-96, n (\%) & $16(25.4)$ & $1(6.3)$ & $2(40.0)$ \\
\hline \multirow[t]{3}{*}{$>97, \mathrm{n}(\%)$} & $42(66.7)$ & $14(87.5)$ & $2(40.0)$ \\
\hline & \multicolumn{3}{|c|}{2010} \\
\hline & HIGH & NEB & LOW \\
\hline Median (range) & $\begin{array}{c}96(77 \text { to } 100) \\
\mathrm{N}=67\end{array}$ & $\begin{array}{c}97(78 \text { to } 100) \\
\mathrm{N}=51\end{array}$ & $\begin{array}{c}96(90 \text { to } 100) \\
\mathrm{N}=29\end{array}$ \\
\hline$<87, \mathrm{n}(\%)$ & $3(4.5)$ & $1(2.0)$ & $0(0)$ \\
\hline 88-92, n (\%) & $6(9.0)$ & $11(21.6)$ & $4(13.8)$ \\
\hline 93-96, n (\%) & $26(38.8)$ & $11(21.6)$ & $16(55.1)$ \\
\hline$>97, \mathrm{n}(\%)$ & $32(47.8)$ & $28(54.9)$ & $9(31.0)$ \\
\hline
\end{tabular}

\section{Table 2.3 Last oxygen saturation before hospital arrival}

Values are $\mathrm{SpO}_{2}(\%)$.

$\mathrm{SpO}_{2}$ : Oxygen saturation measured by standard pulse oximeter.

See Figure 2.1 for definitions of HIGH, NEB and LOW. 


\subsection{Discussion}

This audit shows that the proportion of patients with AECOPD managed with supplemental high concentration oxygen therapy, the HIGH group, markedly decreased after implementation of an education program which involved verbal and written instruction, audit of clinical records, and monitoring of relevant clinical performance indicators. The change in practice was associated with a reduction in the proportion of patients presenting to hospital with oxygen saturations $\geq 97 \%$. However, in 2010 more than half of the patients that were not managed with supplemental high concentration therapy were still exposed to high concentration oxygen through the use of oxygen-driven nebulisers. These findings suggest that to future limit exposure to high concentration oxygen therapy and risk of inappropriately high oxygen saturations, the use of alternative pre-hospital methods to deliver bronchodilator medication, other than oxygen-driven nebulisers, are required. ${ }^{167}$

The potential risks of oxygen-driven nebulisers in the setting of AECOPD are shown by the progressive increase in $\mathrm{PaCO}_{2}$ that occurs during the period of a single or repeated nebulisation. ${ }^{31,81}$ The risk is greater in patients with previous hypercapnia, ${ }^{41}$ and the magnitude of the increase in $\mathrm{PaCO}_{2}$ is unpredictable. Some patients experience an increase of $>10 \mathrm{mmHg}$ within the period required to deliver a single nebulisation, whereas others show no response. ${ }^{31,81}$ During prolonged ambulance transfers, repeat administration of nebulised bronchodilators in critically ill patients has the potential to deliver almost continuous high concentration therapy. In this regard, the ambulance transit times of at least 30 minutes in this and other audits ${ }^{35,37}$ are relevant.

A recent RCT provided proof of concept evidence that air-driven nebulisers could be used to titrate oxygen therapy in AECOPD. ${ }^{12}$ In that study of titrated versus high concentration oxygen therapy, the titrated regimen involved administration of supplementary oxygen as required to achieve an oxygen saturation of 88 to $92 \%$, with bronchodilator medications administered via an air-driven nebuliser. This approach resulted in a $78 \%$ reduction in mortality compared with the high concentration oxygen regimen in which patients received 8-10 litres per minute of oxygen and were administered bronchodilator medication via oxygen-driven nebulisers. As a result this titrated regimen which incorporates air-driven 
nebulisers can be recommended as the optimal management approach in the pre-hospital treatment of AECOPD.

Although the first physiological measurements taken by ambulance staff were similar in 2005 and 2010, in 2010 patients had lower rates of home nebuliser use, home oxygen prescription, long-term oral steroid use and past type II respiratory failure. This suggests that the audit in 2010 included patients with less severe disease and that the lower rates of assisted ventilation in 2010 may not result solely from the changes in the approach to oxygen therapy between the two periods. This is supported by our observation that the association with assisted ventilation by year was much weaker when adjusted for a history of type II respiratory failure.

With regard to the final oxygen saturation recorded before hospital arrival there are a number of important observations that can be made. Firstly less than $3 \%$ of patients had a final oxygen saturation of $\leq 87 \%$ on their ambulance record consistent with administration of oxygen appropriately avoiding hypoxaemia in almost all patients. Secondly there were no patients who received low flow or no oxygen therapy that had an oxygen saturation of $\leq 87 \%$, indicating that a proportion of patients with an AECOPD can be safely managed with this therapeutic approach. Thirdly, the reduced use of supplemental high concentration oxygen in 2010 translated to only a modest reduction in the proportion of patients with oxygen saturations above the upper limit of the target saturation range 88-92\%. Finally, the proportion of patients with an oxygen saturation of $\geq 97 \%$ was similar in the NEB group compared to the HIGH group. This illustrates the risk of inappropriately high oxygen saturations associated with bronchodilator nebuliser therapy administered by high concentration oxygen.

This study was not powered to detect the impact of oxygen exposure on the need for assisted ventilation or mortality. The mortality rates were lower than reported in previous studies, ${ }^{12,166}$ which might suggest that, despite the high rates of high concentration oxygen use, patients in this study may have had milder disease.

This study was retrospective and this caused some limitations. While patients were classified as having exposure to high concentrations of oxygen, we are not able to report on 
the duration of exposure or whether this was part of a titrated regimen. In addition, we were unable to determine with certainty the oxygen flow at the time oxygen saturations were measured and few patients had an ABG measurement within 30 minutes of hospital arrival. We are also unable to ascertain the duration of each nebuliser use as these data were not recorded in clinical records. While our data confirmed that some patients with severe AECOPD do require high concentrations of oxygen to reach an oxygen saturation target of 88 to $92 \%$ it is demonstrated that this is likely to represent a minority. The changes in practice observed between 2005 and 2010 are unlikely to have been solely due to the education program. Rather than having a control group unexposed to the program, it was delivered to all staff to ensure the most widespread uptake of recommended practice possible.

Alternatives to oxygen-driven nebulisers include ultrasonic or standard air-driven nebulisers ${ }^{41}$ and the delivery of bronchodilators via metered dose inhaler and spacer. The latter is shown to provide equivalent bronchodilator efficacy to a nebuliser in AECOPD. ${ }^{169}$ Both of these options allow oxygen titration via nasal prongs during their use. In 2005 and 2010 the WFA only had oxygen-driven nebulisers available for use. Following this audit the WFA is implementing the use of portable, ultrasonic nebulisers (Aeroneb-Go) which are designed for use in ambulances. The nebulisers are lightweight $(60 \mathrm{~g})$, battery powered and almost silent. Nebulised drugs are administered either through a mouthpiece or a facemask and supplementary nasal oxygen can be given simultaneously as necessary. They have advantages over standard air-driven nebulisers that present ambulance installation difficulties due to the weight and size of the cylinders. The WFA will continue educational training focussed on use of the new nebulisers and appropriate oxygen administration as required, titrated to achieve an oxygen saturation of $88-92 \%$.

In conclusion, there was a marked decrease in the use of supplemental high concentration oxygen therapy in patients with AECOPD over a five year period within a regional ambulance service. However, about half of the patients not managed with high concentration oxygen therapy were still exposed to high concentration oxygen solely through the use of oxygen-driven nebulisers to deliver bronchodilator therapy. It is therefore recommended that an air-driven nebuliser device, or a metered dose inhaler with a spacer, is used to deliver bronchodilator therapy in pre-hospital care. 


\title{
2.6 Audit following study publication
}

\begin{abstract}
After the publication of this study an audit was performed by WFA staff comparing oxygen saturation values in 200 patients with suspected AECOPD prior to and after the introduction of Aeroneb-Go nebulisers. ${ }^{170}$ Prior to the introduction of Aeroneb-Go nebulisers $100 \%$ of the patients had been exposed to oxygen, either as supplementary oxygen or via oxygendriven nebuliser. Following introduction of Aeroneb-Go nebulisers, this dropped to $72 \%$ $(\mathrm{P}<0.001)$, indicating decreased unnecessary oxygen exposure. In patients that arrived at hospital with a $\mathrm{SpO}_{2}>92 \%, 33 \%$ had received air nebulisers and no oxygen therapy. These figures suggest that the introduction of air-driven nebulisers significantly reduced the rate of unnecessary oxygen exposure in AECOPD patients.
\end{abstract}


Chapter 3: Multicentre study comparing ABG values to those obtained by pulse oximeters used in Australian and New Zealand Hospitals 


\subsection{Overview}

\section{Multicentre study comparing arterial blood gas}

values to those obtained by pulse oximeters used in Australian and New Zealand Hospitals

\section{AIM}

To investigate the level of agreement between oxygen saturations measured by pulse oximeter $\left(\mathrm{SpO}_{2}\right)$ and arterial blood gas $\left(\mathrm{SaO}_{2}\right)$ in a range of oximeters currently in clinical use in Australian and New Zealand hospitals.

\section{METHODS}

Paired $\mathrm{SpO}_{2}$ and $\mathrm{SaO}_{2}$ measurements were collected from 400 patients in one Australian and two New Zealand hospitals. The bias and limits of agreement were calculated, as well as the sensitivity and specificity for detecting hypoxia (defined as $\mathrm{SaO}_{2}<90 \%$ ).

\section{KEY RESULTS}

Bias for oximeter measured minus arterial blood gas measured oxygen saturation was $-1.2 \%$, with limits of agreement $-4.4 \%$ to 2.0\%. In 10/400 participants the $\mathrm{SpO}_{2}$ was at least $4 \%$ lower than $\mathrm{SaO}_{2}$, and in $3 / 400$ participants it was at least $4 \%$ higher than the $\mathrm{SaO}_{2}$. None of the participants with a $\mathrm{SpO}_{2} \geq 92 \%$ were hypoxaemic $\left(\mathrm{SaO}_{2}\right.$ $<90 \%)$.

\section{CONCLUSIONS}

In the majority of the study participants pulse oximetry was an accurate method to assess $\mathrm{SaO}_{2}$ and had good performance in detecting hypoxaemia. However, in a small proportion of participants, differences between $\mathrm{SaO}_{2}$ and $\mathrm{SpO}_{2}$ could have clinical significance in terms of patient monitoring and management. $\mathrm{SpO}_{2} \geq 92 \%$ indicates that hypoxia $\left(\mathrm{SaO}_{2}\right.$ $<90 \%)$ is not present.

\section{CO-INVESTIGATORS AND PUBLICATION}

Janine Pilcher, Laura Ploen, Steve McKinstry, George Bardsley, Jimmy Chien, Lesley Howard, Lutz Beckert, Maureen Swanney, Sharon Lee, Mark Weatherall, Richard Beasley, for the TSANZ Oxygen Guidelines Group (See Appendix).

Journal submission for publication in progress at the time of thesis submission. 


\subsection{Rationale}

Pulse oximetry provides a non-invasive approximation of $\mathrm{SaO}_{2}$, and is considered the fifth vital sign in clinical assessment. ${ }^{10,11,171}$ Monitoring of $\mathrm{SpO}_{2}$ values is required to titrate oxygen therapy to avoid the risks of hypoxaemia and hyperoxaemia. ${ }^{10,11}$

Assessment of the degree of agreement between the gold standard ABG measurement of $\mathrm{SaO}_{2}$ and $\mathrm{SpO}_{2}$ is essential for the interpretation and use of pulse oximetry values by health care workers. It is also essential for the development of safe and practical recommendations for $\mathrm{SpO}_{2}$ targets for the titration of oxygen therapy. Overestimation of $\mathrm{SaO}_{2}$ may result in clinically relevant hypoxaemia being undetected or untreated. Conversely, underestimation may result in unnecessary oxygen therapy with the associated risks of hyperoxaemia.

The United States regulatory body, the Food and Drug Administration (FDA) centre, requires the accuracy of pulse oximeters to be tested against $\mathrm{SaO}_{2}$, in healthy adults in laboratory settings. ${ }^{172}$ In clinical practice a number of factors have been demonstrated to influence oximeter accuracy including hypoxaemia, hypercapnia, glycosylated haemoglobin (HbA1c), skin pigmentation, and use of nail polish or acrylic nails. ${ }^{137,140,143,150,151,154,155,159,171}$

A number of clinical studies have shown $\mathrm{SpO}_{2}$ to both over and underestimate $\mathrm{SaO}_{2}$, and may have wide limits of agreement. ${ }^{137-164}$ However, oximeter accuracy has been demonstrated to differ by the model used, ${ }^{140,151,155,162,163}$ and manufacturers are continuously evolving sensor technology and software algorithms. ${ }^{171}$ This means previous studies may not be directly relevant to the Australian or New Zealand clinical settings, having assessed a different population group and different models of pulse oximeters.

The main objective of this study was to investigate the level of agreement between $\mathrm{SaO}_{2}$ and $\mathrm{SpO}_{2}$ measurement using pulse oximeters currently available in Australian and New Zealand hospitals. Secondary objectives were to evaluate the diagnostic performance of $\mathrm{SpO}_{2}$ to detect hypoxia, and investigate factors affecting oximeter accuracy. 


\subsection{Methods}

This multicentre prospective non-experimental observational study compared simultaneous $\mathrm{SpO}_{2}$ and $\mathrm{SaO}_{2}$ measurements in inpatients and outpatients at Westmead Hospital in Sydney, Australia, and Wellington and Christchurch Hospitals in New Zealand.

Patients aged 16 years or older requiring an $\mathrm{ABG}$ measurement as part of clinical care were recruited. Participants or their next of kin were required to provide full written informed consent in New Zealand. Participants were excluded if they had a diagnosis of sickle cell anaemia, methaemoglobinemia, carbon monoxide poisoning, or were previously recruited to the study with paired $\mathrm{SpO}_{2}$ and $\mathrm{SaO}_{2}$ values successfully recorded. They could also be excluded for any other condition which, at the investigator's discretion, was believed may present a safety risk or impact upon the feasibility of the study or the interpretation of the study results.

Participants were identified in hospital wards and outpatient clinics. Demographic data were recorded. Skin colour was assessed using the Fitzpatrick scale. ${ }^{173}$

$\mathrm{SpO}_{2}$ was measured during a clinically indicated $\mathrm{ABG}$. The oximeter probe was put in place for at least 10 seconds prior to the $\mathrm{ABG}$, or longer if indicated by the manufacturer instructions. $\mathrm{SpO}_{2}$ was measured from an earlobe or finger probe, depending on departmental policies and what the staff member responsible for performing oximetry would usually use to monitor that patient. If a finger probe was used, it was placed on the index finger on the contra-lateral side to $\mathrm{ABG}$ sampling. Where possible, nail polish was removed prior to measurement.

The $\mathrm{SpO}_{2}$ value recorded was the first value following visualisation of blood entering the collection vial for the $\mathrm{ABG}$ analysis. If the participant was on oxygen at the time of the $\mathrm{ABG}$, this was also recorded. Measurements paired with $\mathrm{ABG}$ samples subsequently identified to be venous or unusable (e.g. sample too small for analysis) were excluded. The models of oximeter and ABG analyser were recorded. Data recorded from the ABG were $\mathrm{SaO}_{2}, \mathrm{PaO}_{2}, \mathrm{PaCO}_{2}$, Carboxyhaemoglobin ( $\left.\mathrm{CoHb}\right)$, Methaemoglobin (MetHb) and $\mathrm{HbA1c}$, if measured as part of clinical practice. Investigators were asked to record whether they had 
any concerns with oximeter accuracy, such as nail polish that was not removed, poor oximeter signal or patient movement.

Bland-Altman plots, estimation of bias and limits of agreement were used to describe the agreement between $\mathrm{SpO}_{2}$ and $\mathrm{SaO}_{2}$ measurement.

The diagnostic performance of $\mathrm{SpO}_{2}<90 \%$ to detect hypoxia, defined as $\mathrm{SaO}_{2}<90 \%$ and defined as $\mathrm{PaO}_{2}<60 \mathrm{mmHg}$, was evaluated using contingency tables, with sensitivities and specificities estimated by an exact binomial method for proportions. A post hoc analysis of the ability for $\mathrm{SaO}_{2}<90 \%$ to detect a $\mathrm{PaO}_{2}<90 \%$ was performed using the same methods.

Associations with mean bias were illustrated by a scatter plot with a scatter plot smoother and a Spearman rank-correlation coefficient for $\mathrm{SaO}_{2}$, and ANOVA for categorical variables in Textbox 3.1, with the mean difference between categories assessed with an F-test. Where a categorical variable only had one observation it was not used in the ANOVA. BlandAltman methods were planned to be used, should important predictors of bias be identified, to determine whether there was also an effect on limits of agreement.

To estimate the difference between $\mathrm{SpO}_{2}$ and $\mathrm{SaO}_{2}$ due to different oximetry devices, estimation of variance components and associated intra-class correlation coefficients for the effect of oximeters as well as best linear unbiased predictors of the effect of individual oximeters were assessed by mixed linear models and estimation by restricted maximum likelihood.

SAS Version 9.4 was used. 
○ Location of measurement (ED, HDU, ward, or outpatient department)

- Position of the oximeter probe (finger or ear)

- Doctor's diagnosis of recognised condition associated with chronic respiratory failure (chronic obstructive pulmonary disease, obesity hypoventilation syndrome, bronchiectasis, cystic fibrosis, neuromuscular disease and chest wall deformities such as severe kyphoscoliosis)

- Current tobacco smoking status (current versus ex or non smoker)

- Skin pigmentation (based on modified Fitzpatrick scale with patient skin colour classified as either: Light (Type I to Type II), Medium (Type III to Type IV) or Dark (Type V to Type VI))

- A doctor's diagnosis of Diabetes Mellitus 
The planned sample size of 400 was based on three considerations. Firstly, for the analysis of variables that predict the size of the bias we sought to have between 20 and 40 participants for each degree of freedom in the ANOVA. Based on the six variables, some of which have multiple levels, this required between 200 and 400 participants. Secondly the estimates of paired $\mathrm{SD}$ for the $\mathrm{SpO}_{2}$ to $\mathrm{SaO}_{2}$ difference from patients in a range of clinical settings were $0.55 \%,{ }^{137} 2.1 \%,{ }^{161}$ and $2.2 \% .{ }^{160}$ There is $80 \%$ power, with a type I error rate of $5 \%$, to detect a $\mathrm{SpO}_{2}$ to $\mathrm{SaO}_{2}$ difference of $2 \%$ for any of the variables that might predict bias, if there were two equal sized groups of 42 participants, 21 in each group. For estimation of variance of components for the different pulse oximeters by Best Unbiased Linear Predictors between 20 and 25 participants per oximeter brand were required and it was estimated that between 10 and 20 oximeter brands would be used.

The study was prospectively registered on the Australian New Zealand Clinical Trials Registry (ANZCTR) (ACTRN12614001257651). Ethical approval was obtained from the Northern B Ethics Committee in New Zealand and the Western Sydney Local Health District Human Research Ethics Committee in Australia. 


\subsection{Results}

Four-hundred patients were included; 253 from Christchurch, 103 from Wellington and 44 Westmead Hospital (Figure 3.1). Participant characteristics and details of the pulse oximeters and $\mathrm{ABG}$ analysers are presented in Tables 3.1 and 3.2. $\mathrm{SaO}_{2}$ values ranged from 72 to $100 \%$. The majority of samples were taken in the Outpatient Department. Only one participant was recruited from $\mathrm{ED}$. All $\mathrm{SpO}_{2}$ samples were taken from the finger except one. 


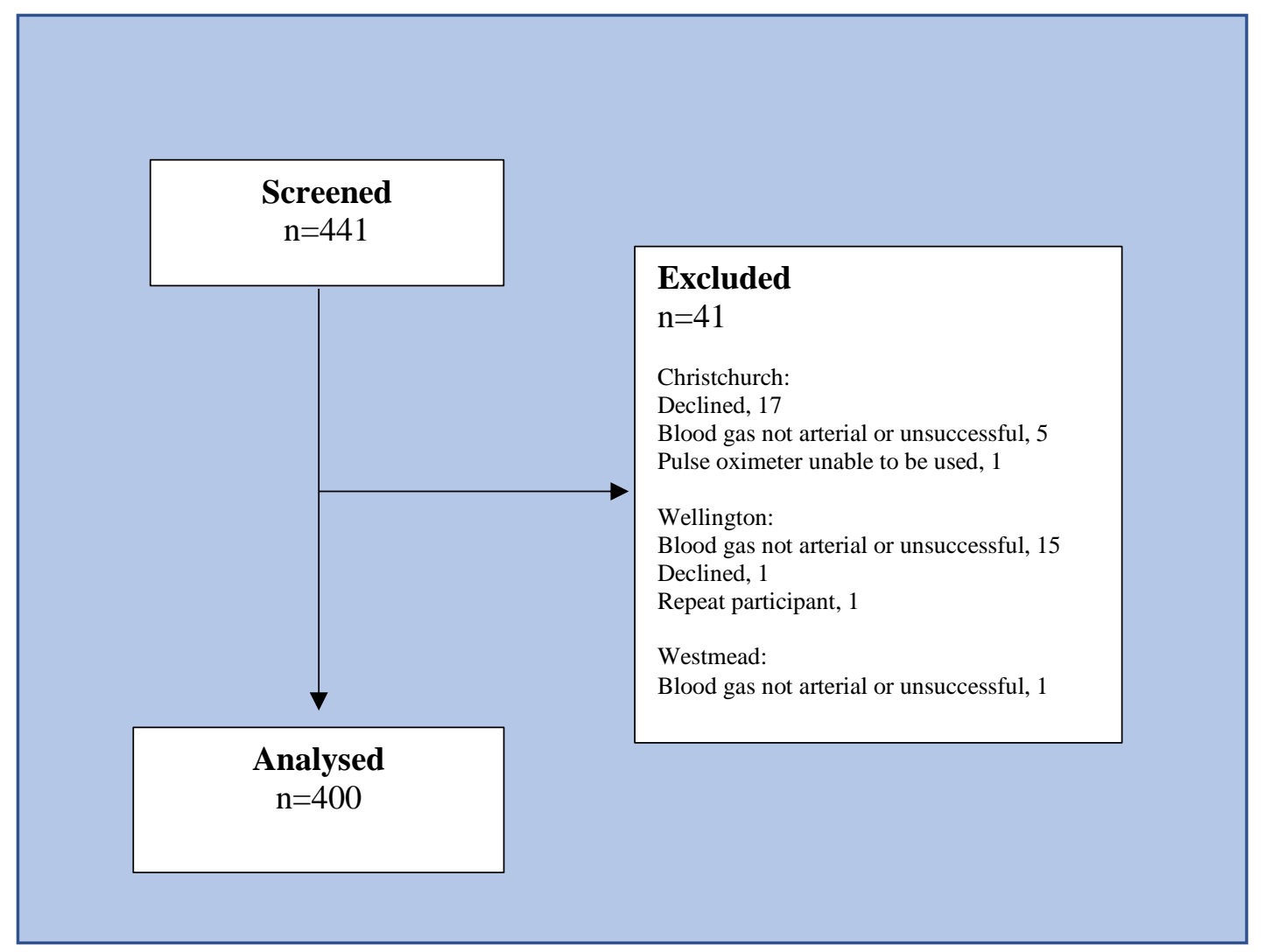

Figure 3.1 Flow of participants 


\begin{tabular}{|lc|}
\hline \multicolumn{2}{|c|}{ General characteristics, $\mathbf{n}(\boldsymbol{\%})^{* \wedge}$} \\
\hline Age, years & \\
- Mean (SD) & $64.2(15.2)$ \\
- Min to max & 18.7 to 95.1 \\
\hline Male gender & $212(53)$ \\
\hline Smoking status (n = 399) & \\
- Current & $43(10.8)$ \\
- Ex & $203(50.9)$ \\
- Never & $153(38.5)$ \\
\hline Fitzpatrick Score & \\
I & $44(11)$ \\
II & $198(49.5)$ \\
III & $127(31.8)$ \\
IV & $30(7.5)$ \\
V & $1(0.3)$ \\
VI & $0(0)$ \\
\hline Conditions associated with chronic respiratory failure \\
- None & $229(57.3)$ \\
- Hypercapnia** on ABG & 16 \\
- At least one & $171(42.8)$ \\
- Hypercapnia** on ABG & 57 \\
\hline Individual conditions associated with chronic respiratory failure \\
- COPD & $113(28.3)$ \\
- Obesity hypoventilation syndrome & $30(7.5)$ \\
- Bronchiectasis & $19(4.8)$ \\
- Cystic fibrosis & $1(0.3)$ \\
- Neuromuscular disease & $24(6)$ \\
- Chest wall deformity & $11(2.8)$ \\
& \\
\hline Peripheral vascular disease & $11(2.8)$ \\
\hline Diabetes & $18(4.5)$ \\
\hline Oxygen administration & $25(6.3)$ \\
\hline Hospital location & \\
- Outpatient & \\
- Ward & \\
- HDU & \\
- ED & \\
\hline
\end{tabular}

\section{Table 3.1 Participant characteristics}

Table continued overleaf. 


\begin{tabular}{|c|c|}
\hline \multicolumn{2}{|c|}{ General characteristics, $n(\%) * \wedge$} \\
\hline \multicolumn{2}{|c|}{ Ethnicity, New Zealand } \\
\hline $\begin{array}{l}\text { - NZ European } \\
\text { - Māori } \\
\text { - Samoan } \\
\text { - Chinese } \\
\text { - Indian } \\
\text { - Cook Island Māori } \\
\text { - Tongan } \\
\text { - Other }\end{array}$ & $\begin{array}{l}280(70.0) \\
26(6.5) \\
13(3.3) \\
1(0.3) \\
4(1.0) \\
1(0.3) \\
3(0.8) \\
28(7.0)\end{array}$ \\
\hline \multicolumn{2}{|l|}{ Ethnicity, Australia } \\
\hline $\begin{array}{l}\text { - Caucasian } \\
\text { - Middle Eastern } \\
\text { - Other }\end{array}$ & $\begin{array}{l}34(8.5) \\
6(1.5) \\
5(1.3)\end{array}$ \\
\hline \multicolumn{2}{|c|}{ ABG and oximetry data, mean (SD), $\min$ to $\max ^{\wedge}$} \\
\hline $\mathrm{SpO}_{2}, \%$ & $93.5(3.8), 72$ to 100 \\
\hline $\begin{array}{l}\text { - Participants with } \mathrm{SpO}_{2}<90 \% \\
(\mathrm{n},(\%))\end{array}$ & $49(12.3)$ \\
\hline $\begin{array}{l}\text { Concern with } \mathrm{SpO}_{2} \text { data accuracy } \\
\text { recorded by investigator } \\
(\mathrm{n},(\%))^{* * *}\end{array}$ & $16(4.0)$ \\
\hline $\mathrm{SaO}_{2}, \%$ & $94.7(3.8), 72.1$ to 100 \\
\hline $\begin{array}{l}\text { - Participants with } \mathrm{SaO}_{2}<90 \% \\
(\mathrm{n},(\%))\end{array}$ & $35(8.8)$ \\
\hline $\mathrm{PaO}_{2}, \mathrm{mmHg}$ & $74.8(21.3), 37.9$ to 396 \\
\hline $\begin{array}{l}\text { - Participants with } \mathrm{PaO}_{2}<60 \mathrm{mmHg} \\
(\mathrm{n},(\%))\end{array}$ & $61(15.3)$ \\
\hline $\mathrm{PaCO}_{2}, \mathrm{mmHg}$ & $40.3(7.2), 25.4$ to 87.2 \\
\hline $\mathrm{Hb}, \mathrm{g} / \mathrm{L}$ & 136.7 (18.8), 67 to 192 \\
\hline \multicolumn{2}{|l|}{$\mathrm{CoHb}, \%$} \\
\hline $\begin{array}{l}\text { All participants }(n=358) \\
\text { - Current smokers }(n=40) \\
\text { - Ex smokers }(n=183) \\
\text { - Never smokers }(n=135)\end{array}$ & $\begin{array}{l}2.1(1.2), 0 \text { to } 7 \\
3.9(1.7), 0.9 \text { to } 6.7 \\
1.9(0.9), 0.0 \text { to } 7.0 \\
1.9(0.7), 0.0 \text { to } 4.2\end{array}$ \\
\hline
\end{tabular}

Table 3.1 Participant characteristics continued

ABG: Arterial blood gas, CoHb: Carboxyhaemoglobin, COPD: Chronic Obstructive Pulmonary Disease, ED: Emergency Department, HDU: High Dependency Unit, Hb: Haemoglobin, NZ: New Zealand, $\mathrm{PaO}_{2}$ : Arterial partial pressure of oxygen, $\mathrm{PaCO}_{2}$ : Arterial partial pressure of carbon dioxide, $\mathrm{SaO}_{2}$ : Oxygen saturation measured by arterial blood gas sample, $\mathrm{SpO}_{2}$ : Oxygen saturation measured by standard pulse oximeter.

$* \mathrm{~N}=400$, unless otherwise stated. $* * \mathrm{PaCO}_{2}>45 \mathrm{mmHg}$. $* * *$ For example nail polish, acrylic nail, nail pathology, low perfusion or variability noted on monitor. ^ Unless otherwise stated 


\begin{tabular}{|c|c|c|c|}
\hline & $\begin{array}{c}\text { Christchurch } \\
\text { Hospital } \\
\text { N=253 } \\
\end{array}$ & $\begin{array}{c}\text { Wellington } \\
\text { Hospital } \\
\mathbf{N}=\mathbf{1 0 3} \\
\end{array}$ & $\begin{array}{c}\text { Westmead } \\
\text { Hospital } \\
\mathrm{N}=44 \\
\end{array}$ \\
\hline \multicolumn{4}{|l|}{ Oximeter brand (n, \%) } \\
\hline \multicolumn{4}{|l|}{ Nonin } \\
\hline - Avant 9700 & $103(40.9)$ & & \\
\hline - Avant 4000 & $76(30.2)$ & & \\
\hline - Avant Unspecified* & $1(0.4)$ & & \\
\hline - Lifesense Medair & $48(19)$ & & \\
\hline-2120 & & $8(7.8)$ & \\
\hline-2140 & & $1(1)$ & \\
\hline \multicolumn{4}{|l|}{ Masimo } \\
\hline - Masimoset Quartz Q400 & $23(9.1)$ & & \\
\hline - Masimoset Quartz Unspecified* & $1(0.4)$ & & \\
\hline - Rainbow Radical 7 & & $91(88.4)$ & $1(2.3)$ \\
\hline \multicolumn{4}{|l|}{ Other } \\
\hline - Novametrix Model 512 & & $1(1)$ & \\
\hline - GE Dash 3000 & & $2(1.9)$ & \\
\hline - Welch Allyn monitors** & & & $19(43.2)$ \\
\hline - Philips Intellivue MP70 monitor** & & & $16(36.4)$ \\
\hline - Ohmeda Biox 3700E monitor** & & & $7(15.9)$ \\
\hline - Carescape Monitor B450** & & & $1(2.3)$ \\
\hline \multicolumn{4}{|c|}{ Concerns with $\mathrm{SpO}_{2}$ data accuracy as recorded by the investigator (n) } \\
\hline - Nail polish, acrylic nail or double nail & 4 & 4 & 1 \\
\hline - Variability in displayed $\mathrm{SpO}_{2}$ & 1 & 0 & 2 \\
\hline - Low perfusion noted on $\mathrm{SpO}_{2}$ monitor & 0 & 1 & 0 \\
\hline - Other & $1 *$ & $1 * * *$ & $1^{*}$ \\
\hline \multicolumn{4}{|l|}{ ABG analyser } \\
\hline & $\begin{array}{c}\text { Radiometer } \\
\text { ABL800 }\end{array}$ & $\begin{array}{c}\text { Radiometer } \\
\text { ABL800 }\end{array}$ & $\begin{array}{c}\text { Radiometer } \\
\text { ABL800 }\end{array}$ \\
\hline
\end{tabular}

\section{Table 3.2 Oximeter and ABG analyser details by hospital}

ABG: Arterial blood gas, $\mathrm{SpO}_{2}$ : Oxygen saturation measured by standard pulse oximeter.

*Unspecified by investigator. **Monitors used one of the following probes: Nellcor DuraSensor Adult Oxygen Transducer, GE TruSignal $\mathrm{SpO}_{2}$ Finger Sensor, LNCS Reusable Sensors or Philips Compatible Direct-Connect $\mathrm{SpO}_{2}$ Sensor. *** $\mathrm{SpO}_{2}$ probe had to be applied to same hand as $\mathrm{ABG}$ taken from due to medical condition affecting contralateral side. Note: Oximeter monitor type not available for 1 participant from Christchurch. 
The bias for $\mathrm{SpO}_{2}$ minus $\mathrm{SaO}_{2}$ was $-1.2 \%$, with limits of agreement $-4.4 \%$ to $2.0 \%$. The Bland-Altman plot is presented in Figure 3.2. There were 10/400 participants in whom the $\mathrm{SpO}_{2}$ was at least $4 \%$ lower than $\mathrm{SaO}_{2}$. In one of these participants the investigator reported concern with the oximeter accuracy. There were 3/400 participants in which the $\mathrm{SpO}_{2}$ was at least $4 \%$ higher than the $\mathrm{SaO}_{2}$. In one of these participants the investigator reported concern with the oximeter accuracy. Characteristics of these participants are shown in Table 3.3 . 


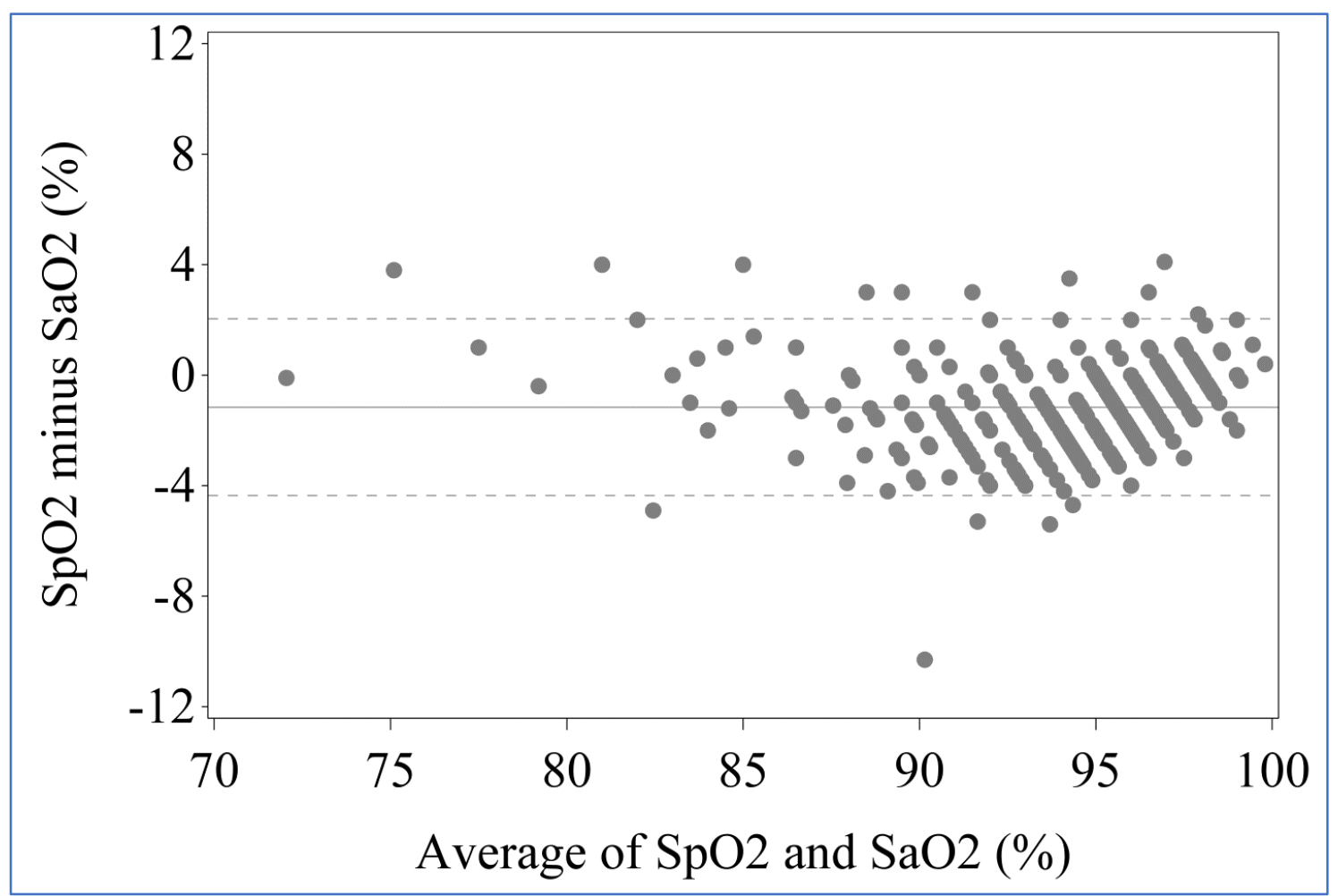

Figure 3.2 Bland-Altman plot for $\mathrm{SpO}_{2}$ versus average of $\mathrm{SpO}_{2}$ and $\mathrm{SaO}_{2}$

$\mathrm{SaO}_{2}$ : Oxygen saturation measured by arterial blood gas sample, $\mathrm{SpO}_{2}$ : Oxygen saturation measured by standard pulse oximeter. 


\begin{tabular}{|c|c|c|c|c|c|c|c|c|c|}
\hline Patient & $\begin{array}{c}\text { Condition with } \\
\text { risk of } \\
\text { hypercapnia }\end{array}$ & $\begin{array}{l}\text { Hospital and } \\
\text { location }\end{array}$ & $\begin{array}{l}\text { Presenting } \\
\text { diagnosis }\end{array}$ & $\begin{array}{l}\text { Oxygen } \\
\text { delivery* }\end{array}$ & Oximeter model & $\begin{array}{l}\mathrm{PaO}_{2} \\
(\mathrm{mmHg})\end{array}$ & $\begin{array}{c}\mathrm{SaO}_{2} \\
(\%)\end{array}$ & $\begin{array}{c}\mathrm{SpO}_{2} \\
(\%)\end{array}$ & $\begin{array}{c}\mathrm{SpO}_{2}- \\
\mathrm{SaO}_{2} \\
(\%)\end{array}$ \\
\hline 1 & \multirow{5}{*}{ None } & Wellington Outpatients & Interstitial lung disease & No & Masimo Radical 7 & 65 & 94 & 90 & -4 \\
\hline 2 & & Christchurch Outpatients & Work up & No & Nonin Avant 9700 & 78.2 & 96.2 & 92 & -4.2 \\
\hline 3 & & $\begin{array}{c}\text { Christchurch } \\
\text { Ward }\end{array}$ & Work up & No & Nonin Avant 9700 & 77.5 & 96.4 & 91 & -5.4 \\
\hline 4 & & Christchurch Outpatients & Work up & No & Nonin Avant 9700 & 74.2 & 96.7 & 92 & -4.7 \\
\hline 5 & & $\begin{array}{c}\text { Westmead } \\
\text { HDU }\end{array}$ & Heart failure & Yes & Philips Intellivue MP70 & 80 & 98 & 94 & -4 \\
\hline 6 & Cystic fibrosis & $\begin{array}{l}\text { Christchurch } \\
\text { Ward } \\
\end{array}$ & Fitness to fly test & See note** & Nonin Avant 9700 & 47.2 & 84.9 & 80 & -4.9 \\
\hline 7 & COPD & $\begin{array}{c}\text { Westmead } \\
\text { HDU }\end{array}$ & COPD & Yes & Philips Intellivue MP70 & 55.5 & 91.2 & 87 & -4.2 \\
\hline 8 & COPD & Westmead Outpatients & Heart failure & No & Ohmeda Biox 3700e & 63.7 & 94.3 & 89 & -5.3 \\
\hline 9 & COPD & Wellington Outpatients & COPD & No & Masimo Radical 7 & 74 & 95 & 91 & -4 \\
\hline 10 & Chest wall disease & Westmead Outpatients & $\begin{array}{c}\text { Chronic respiratory } \\
\text { failure }\end{array}$ & Yes & Masimo Radical 7 & 71.6 & 95.3 & 85 & -10.3 \\
\hline 11 & COPD & $\begin{array}{c}\text { Wellington } \\
\text { Ward }\end{array}$ & COPD & No & Nonin 2120 & 44 & 79 & 83 & 4 \\
\hline 12 & COPD & Wellington Outpatients & Other- not documented & No & Masimo Radical 7 & 46 & 83 & 87 & 4 \\
\hline 13 & $\begin{array}{c}\text { Neuromuscular } \\
\text { disease }\end{array}$ & Westmead Outpatients & Neuromuscular disease & No & Welch Allyn & 65.8 & 94.9 & 99 & 4.1 \\
\hline
\end{tabular}

Table 3.3 Participants with discrepancy of at least $4 \%$ between $\mathrm{SpO}_{2}$ and $\mathrm{SaO}_{2}$

COPD: Chronic Obstructive Pulmonary Disease, $\mathrm{FiO}_{2}$ : Fraction of inspired oxygen, $\mathrm{HDU}$ : High dependency unit, $\mathrm{SaO}_{2}$ : Oxygen saturation measured by arterial blood gas sample, $\mathrm{SpO}_{2}$ : Oxygen saturation measured by standard pulse oximeter, $\mathrm{PaO}_{2}$ : Arterial partial pressure of oxygen. Blue cells are participant $\mathrm{SpO}_{2}$ and $\mathrm{SaO}_{2}$ values which indicate oxygen therapy should be started or increased based on TSANZ Guidelines (i.e saturation value $<88 \%$ in participants at risk of hypercapnia and $<92 \%$ in participants not at risk of hypercapnia). *At time of paired $\mathrm{SpO}_{2} / \mathrm{SaO}_{2}$ recording. **Hypoxic gas $\left(\mathrm{FiO}_{2} 0.15\right)$ administered as part of a flight test. All $\mathrm{SpO}_{2}$ values were taken from the finger. Participants 8 and 13 had documented investigator concern over accuracy of the $\mathrm{SpO}_{2}$. In Participant 8 this was noted instability of $\mathrm{SpO}_{2}$ values between 89 to $95 \%$, despite trace appearing satisfactory. In Participant 13 the reason was not documented by the investigator. Participant 5 had peripheral vascular disease. 
Sensitivity and specificity for the ability of $\mathrm{SpO}_{2}<90 \%$ to detect $\mathrm{SaO}_{2}<90 \%, \mathrm{SpO}_{2}<90 \%$ to detect $\mathrm{PaO}_{2}<60 \mathrm{mmHg}$ and $\mathrm{SaO}_{2}<90 \%$ to detect $\mathrm{PaO}_{2}<60 \mathrm{mmHg}$ are presented in Table 3.4. $\mathrm{SpO}_{2}<92 \%$ had $100 \%$ sensitivity and $84.4 \%$ specificity for detecting $\mathrm{SaO}_{2}<90 \%$ and $95.1 \%$ sensitivity and $90.0 \%$ specificity for detecting $\mathrm{PaO}_{2}<60 \mathrm{mmHg}$ (Tabulated data in Tables 3.5 and 3.6, ROC curves presented in Figures 3.3 and 3.4). Participants tended to sit to the left of the predicted oxygen haemoglobin dissociation curve (Figure 3.5). ${ }^{18}$ There were $13 / 400$ participants $(3 \%)$ in whom the $\mathrm{PaO}_{2}$ was $>100 \mathrm{mmHg}$. Twelve of these participants had an oximetry value $>96 \%$. One had an oximetry value of $96 \%$; their $\mathrm{PaO}_{2}$ was $142 \mathrm{mmHg}$ and $\mathrm{SaO}_{2}$ was $99 \%$. 


\begin{tabular}{|c|c|c|c|}
\hline \multicolumn{4}{|c|}{ Ability for $\mathrm{SpO}_{2}<90 \%$ to detect $\mathrm{SaO}_{2}<90 \%$} \\
\hline \multicolumn{3}{|c|}{$\mathrm{SaO}_{2}<90 \%$} & \multirow{5}{*}{$\begin{array}{l}\text { Sensitivity: } 88.6 \% \\
\text { Specificity: } 95.1 \%\end{array}$} \\
\hline $\mathrm{SpO}_{2}<90 \%$ & Yes & No & \\
\hline Yes & 31 & 18 & \\
\hline No & 4 & 347 & \\
\hline Total & 35 & 365 & \\
\hline \multicolumn{4}{|c|}{ Ability for $\mathrm{SpO}_{2}<90 \%$ to detect $\mathrm{PaO}_{2}<60 \mathrm{mmHg}$} \\
\hline & \multicolumn{2}{|c|}{$\mathrm{PaO}_{2}<60 \mathrm{mmHg}$} & \multirow{5}{*}{$\begin{array}{l}\text { Sensitivity: } 70.5 \% \\
\text { Specificity: } 98.2 \%\end{array}$} \\
\hline $\mathrm{SpO}_{2}<90 \%$ & Yes & No & \\
\hline Yes & 43 & 6 & \\
\hline No & 18 & 333 & \\
\hline Total & 61 & 339 & \\
\hline \multicolumn{4}{|c|}{ Ability for $\mathrm{SaO}_{2}<90 \%$ to detect $\mathrm{PaO}_{2}<60 \mathrm{mmHg}$} \\
\hline & \multicolumn{2}{|c|}{$\mathrm{PaO}_{2}<60 \mathrm{mmHg}$} & \multirow{5}{*}{$\begin{array}{l}\text { Sensitivity: } 54.1 \% \\
\text { Specificity: } 99.4 \%\end{array}$} \\
\hline $\mathrm{SaO}_{2}<90 \%$ & Yes & No & \\
\hline Yes & 33 & 2 & \\
\hline No & 28 & 337 & \\
\hline Total & 61 & 339 & \\
\hline
\end{tabular}

Table 3.4 Diagnostic performance of $\mathrm{SpO}_{2}$ and $\mathrm{SaO}_{2}$

$\mathrm{PaO}_{2}$ : Arterial partial pressure of oxygen, $\mathrm{SaO}_{2}$ : Oxygen saturation measured by arterial blood gas sample, $\mathrm{SpO}_{2}$ : Oxygen saturation measured by standard pulse oximeter. 


\begin{tabular}{|c|c|c|}
\hline $\mathrm{SpO}_{2}$ & Sensitivity & Specificity \\
\hline 72 & 2.9 & 100 \\
\hline 77 & 5.7 & 100 \\
\hline 78 & 8.6 & 100 \\
\hline 79 & 11.4 & 100 \\
\hline 80 & 14.3 & 100 \\
\hline 83 & 28.6 & 100 \\
\hline 84 & 34.3 & 100 \\
\hline 85 & 40.0 & 99.7 \\
\hline 86 & 57.1 & 99.7 \\
\hline 87 & 71.4 & 99.5 \\
\hline 88 & 88.6 & 98.1 \\
\hline 89 & 88.6 & 95.1 \\
\hline 90 & 97.1 & 89.0 \\
\hline 91 & 100 & 84.4 \\
\hline 92 & 100 & 75.9 \\
\hline 93 & 100 & 61.6 \\
\hline 94 & 100 & 53.7 \\
\hline 95 & 100 & 35.9 \\
\hline 96 & 100 & 22.7 \\
\hline 97 & 100 & 11.0 \\
\hline 98 & 100 & 2.7 \\
\hline 99 & 100 & 0.8 \\
\hline 100 & 100 & 0.0 \\
\hline
\end{tabular}

Table 3.5 Sensitivity and specificity for $\mathrm{SpO}_{2}$ less than or equal to the nominated level for $\mathrm{SaO}_{2}<90 \%$

$\mathrm{SaO}_{2}$ : Oxygen saturation measured by arterial blood gas sample, $\mathrm{SpO}_{2}$ : Oxygen saturation measured by standard pulse oximeter.

All values are \%. 


\begin{tabular}{|c|c|c|}
\hline $\mathrm{SpO}_{2}$ & Sensitivity & Specificity \\
\hline 72 & 1.6 & 100 \\
\hline 77 & 3.3 & 100 \\
\hline 78 & 4.9 & 100 \\
\hline 79 & 6.6 & 100 \\
\hline 80 & 8.2 & 100 \\
\hline 83 & 16.4 & 100 \\
\hline 84 & 19.7 & 100 \\
\hline 85 & 23.0 & 99.7 \\
\hline 86 & 31.1 & 99.4 \\
\hline 87 & 41.0 & 99.4 \\
\hline 88 & 57.4 & 99.1 \\
\hline 89 & 70.5 & 98.2 \\
\hline 90 & 90.2 & 94.4 \\
\hline 91 & 95.1 & 90.0 \\
\hline 92 & 98.4 & 81.4 \\
\hline 93 & 100 & 66.4 \\
\hline 94 & 100 & 57.8 \\
\hline 95 & 100 & 38.6 \\
\hline 96 & 100 & 24.5 \\
\hline 97 & 100 & 11.8 \\
\hline 98 & 100 & 3.0 \\
\hline 99 & 100 & 0.9 \\
\hline 100 & 100 & 0.0 \\
\hline
\end{tabular}

Table 3.6 Sensitivity and specificity for $\mathrm{SpO}_{2}$ less than or equal to the nominated level for $\mathrm{PaO}_{2}<60 \mathrm{mmHg}$

$\mathrm{PaO}_{2}$ : Arterial partial pressure of oxygen, $\mathrm{SpO}_{2}$ : Oxygen saturation measured by standard pulse oximeter.

All values are \%. 


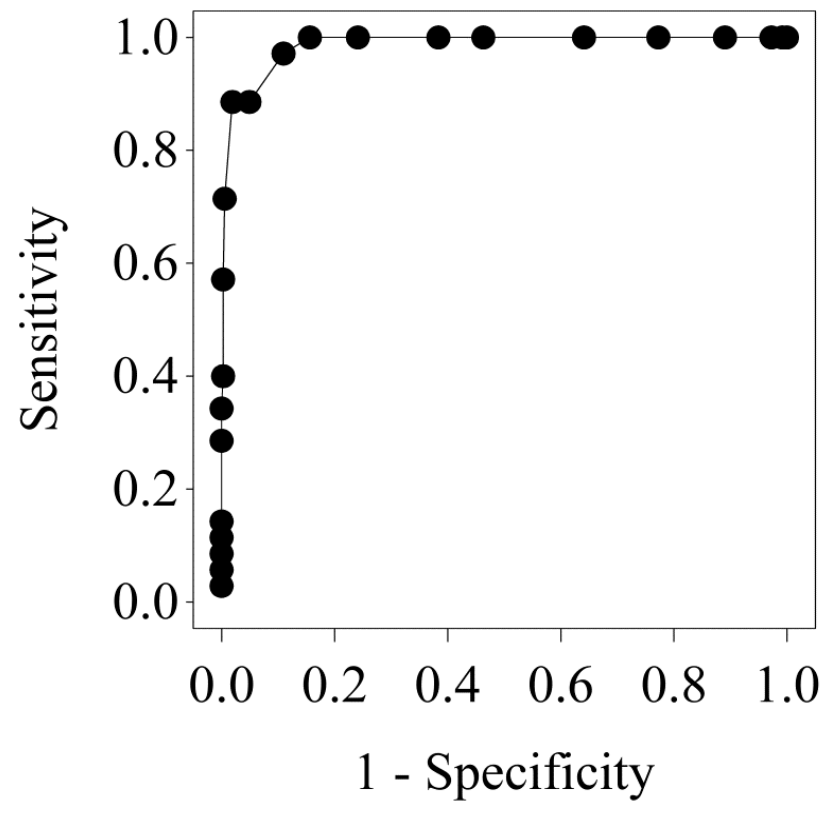

Figure 3.3 ROC curve for $\mathrm{SpO}_{2}$ to predict $\mathrm{SaO}_{2}<90 \%$

$\mathrm{SaO}_{2}$ : Oxygen saturation measured by arterial blood gas sample, $\mathrm{SpO}_{2}$ : Oxygen saturation measured by standard pulse oximeter.

The c-statistic for the logistic regression, representing the area under the ROC curve, was 0.986. 


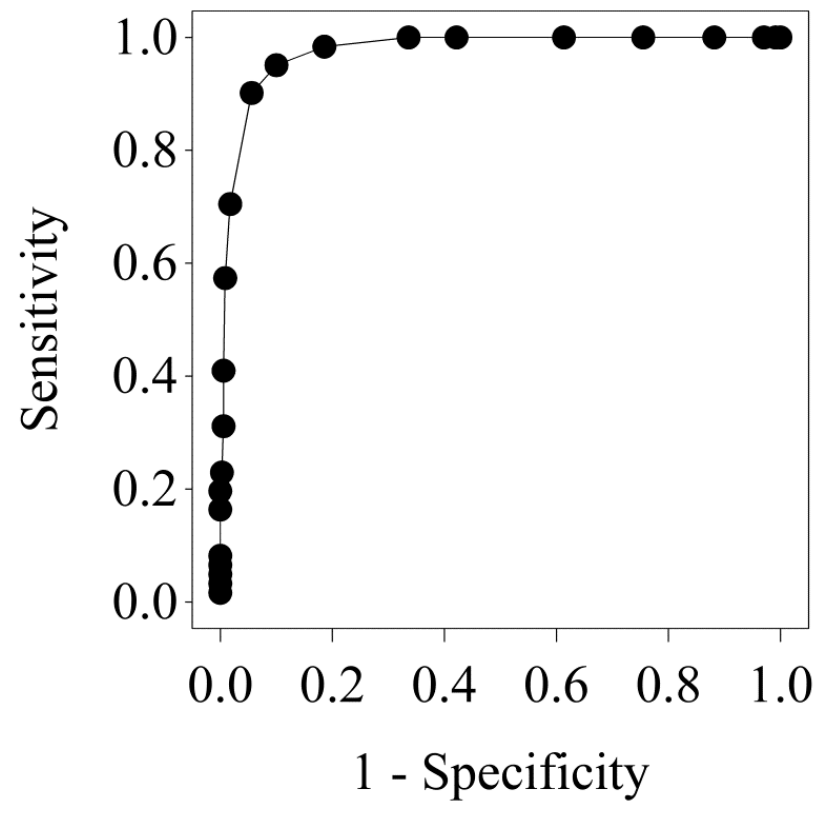

Figure 3.4 ROC curve for $\mathrm{SpO}_{2}$ to predict $\mathrm{PaO}_{2}<60 \mathrm{mmHg}$ $\mathrm{PaO}_{2}$ : Arterial partial pressure of oxygen, $\mathrm{SpO}_{2}$ : Oxygen saturation measured by standard pulse oximeter.

The c-statistic for the logistic regression, representing the area under the ROC curve, was 0.976. 


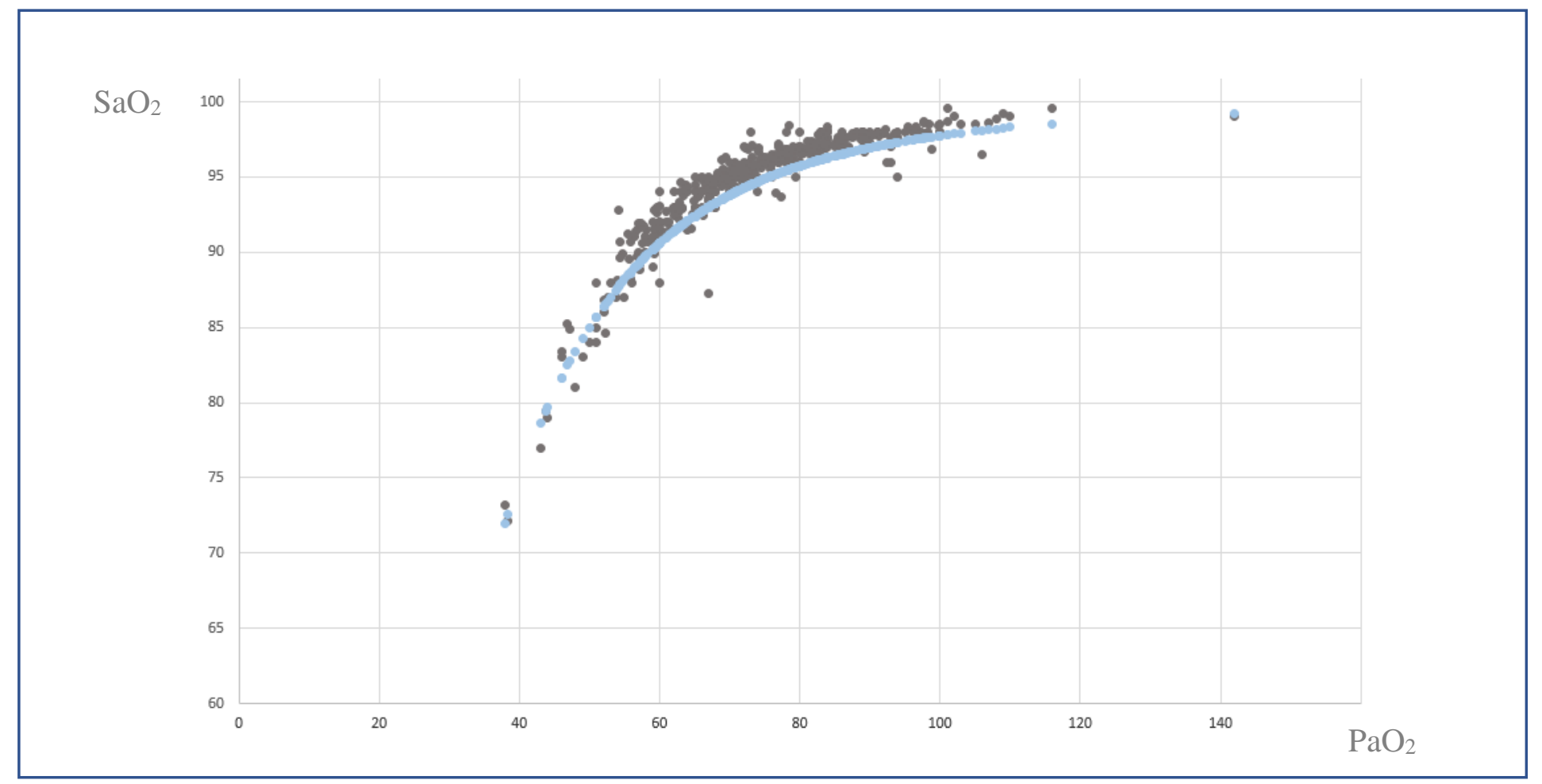

Figure 3.5 Predicted oxygen haemoglobin dissociation curve and data from ABG samples taken in this study

$\mathrm{PaO}_{2}$ : Arterial partial pressure of oxygen, $\mathrm{SaO}_{2}$ : Oxygen saturation measured by arterial blood gas sample.

Blue data points are predicted values calculated from $\mathrm{PaO}_{2}$ values obtained in this study using the simplified Severinghaus equation. ${ }^{18}$ Grey data points are data from participants in this study. One participant's data omitted $\left(\mathrm{PaO}_{2}\right.$ was $396 \mathrm{mmHg}, \mathrm{SaO}_{2}$ was $\left.100 \%\right)$ to retain graph axis limit formatting. 
There was no statistical evidence of an association between $\mathrm{SaO}_{2}$ and bias between $\mathrm{SpO}_{2}$ and $\mathrm{SaO}_{2}$; Spearman coefficient $0.003, \mathrm{P}=0.94$ (Figure 3.6). Of the other factors from Textbox 3.1, only a diagnosis of diabetes was identified as a predictor of bias $(\mathrm{P}=0.05)$ (Table 3.7). In diabetics it was -0.8 (limits of agreement -4.4 to 2.8 ), in non-diabetics it was $-1.2(-4.4$ to 2.0$)$. 


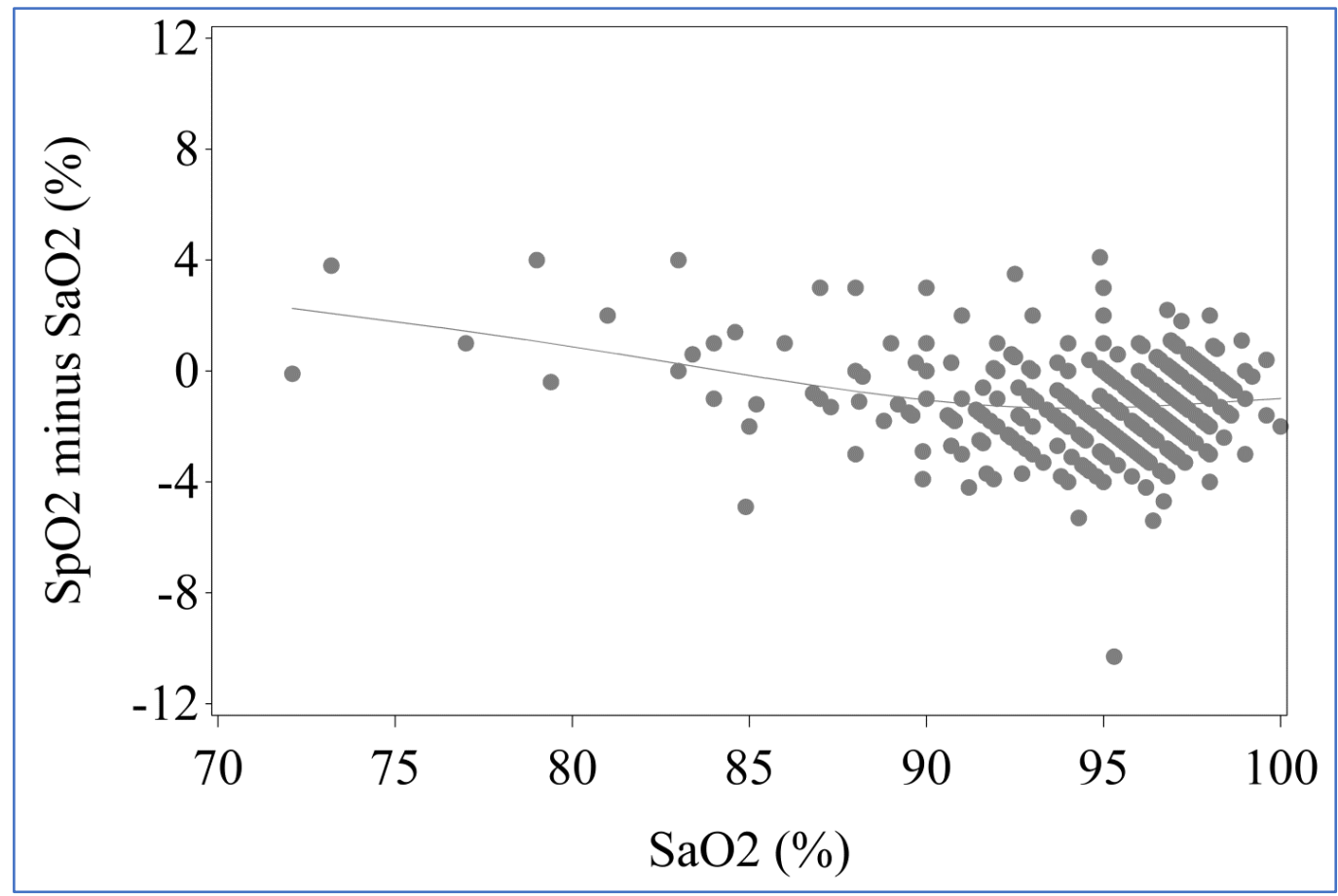

Figure 3.6 Plot for bias versus $\mathrm{SaO}_{2}$

$\mathrm{SaO}_{2}$ : Oxygen saturation measured by arterial blood gas sample, $\mathrm{SpO}_{2}$ : Oxygen saturation measured by standard pulse oximeter. 


\begin{tabular}{|c|c|}
\hline Diabetes & $\mathrm{SpO}_{2}$ minus $\mathrm{SaO}_{2}$ Mean (SD) \\
\hline No $N=320$ & $-1.2(1.6)$ \\
\hline Yes $\mathrm{N}=80$ & $-0.8(1.8)$ \\
\hline \multicolumn{2}{|c|}{$\begin{array}{l}\text { The ANOVA based F-test for evidence in difference in mean bias by diabetes: } \mathrm{F}(1,398 \\
\text { DF) } 3.84, \mathrm{P}=0.05 \text { : difference }-0.4 \text { ( } 95 \% \text { CI }-0.08 \text { to } 0.001) \text {. Given that the difference was } \\
\text { not of clinical significance a Bland-Altman plot was not performed. }\end{array}$} \\
\hline Location & $\mathrm{SpO}_{2}$ minus $\mathrm{SaO}_{2}$ Mean (SD) \\
\hline Emergency Department $\mathrm{N}=1$ & $-0.6(\mathrm{NA})$ \\
\hline High Dependency Unit $\mathrm{N}=18$ & $-1.1(1.6)$ \\
\hline Outpatient department $\mathrm{N}=341$ & $-1.2(1.6)$ \\
\hline Ward $\mathrm{N}=40$ & $-1.3(1.6)$ \\
\hline \multicolumn{2}{|c|}{$\begin{array}{l}\text { ANOVA based F-test for evidence in difference in mean bias: } \mathrm{F}(2,396 \mathrm{DF}) 0.10, \mathrm{P}=0.91 \text {. } \\
\text { Note: Emergency Department category was excluded from analysis as } \mathrm{N}=1 \text {, as per } \\
\text { methods. }\end{array}$} \\
\hline Position of oximeter probe & $\mathrm{SpO}_{2}$ minus $\mathrm{SaO}_{2}$ Mean (SD) \\
\hline Ear $\mathrm{N}=1$ & $-2.5(\mathrm{NA})$ \\
\hline Finger $\mathrm{N}=399$ & $-1.2(1.6)$ \\
\hline \multicolumn{2}{|c|}{ ANOVA results not reported due to result of $\mathrm{N}=1$ for ear subgroup, as per methods. } \\
\hline $\begin{array}{l}\text { Doctor's diagnosis of recognised } \\
\text { condition associated with chronic } \\
\text { respiratory failure* }\end{array}$ & $\mathrm{SpO}_{2}$ minus $\mathrm{SaO}_{2}$ Mean (SD) \\
\hline No N=229 & $-1.3(1.3)$ \\
\hline Yes $\mathrm{N}=171$ & $-1.0(1.9)$ \\
\hline \multicolumn{2}{|c|}{ ANOVA based F-test for evidence in difference in mean bias: $\mathrm{F}(1,398 \mathrm{DF}) 2.53, \mathrm{P}=0.11$} \\
\hline Current tobacco smoking status & $\mathrm{SpO}_{2}$ minus $\mathrm{SaO}_{2}$ Mean (SD) \\
\hline Current $\mathrm{N}=43$ & $-1.1(1.6)$ \\
\hline $\mathrm{Ex} \mathrm{N}=203$ & $-1.2(1.7)$ \\
\hline Never $\mathrm{N}=153$ & $-1.1(1.5)$ \\
\hline \multicolumn{2}{|c|}{ ANOVA based F-test for evidence in difference in mean bias: $\mathrm{F}(2,396 \mathrm{DF}) 0.15, \mathrm{P}=0.86$. } \\
\hline Skin pigmentation** & $\mathrm{SpO}_{2}$ minus $\mathrm{SaO}_{2}$ Mean (SD) \\
\hline Dark $\mathrm{N}=1$ & $0.1(\mathrm{NA})$ \\
\hline Medium N=157 & $-1.1(1.6)$ \\
\hline Light $\mathrm{N}=242$ & $-1.2(1.7)$ \\
\hline $\begin{array}{l}\text { ANOVA based F-test for evidence in } \mathrm{d} \\
\text { Note Dark category was excluc }\end{array}$ & $\begin{array}{l}\text { mean bias: } \mathrm{F}(1,397 \mathrm{DF}) 0.42, \mathrm{P}=0.52 \text {. } \\
\text { alysis as } \mathrm{N}=1 \text {, as per methods. }\end{array}$ \\
\hline
\end{tabular}

\section{Table 3.7 Contingency tables and ANOVA results for factors from Textbox 3.1}

NA: Not applicable, $\mathrm{SaO}_{2}$ : Oxygen saturation measured by arterial blood gas sample, $\mathrm{SpO}_{2}$ : Oxygen saturation measured by standard pulse oximeter. $\mathrm{SpO}_{2}$ minus $\mathrm{SaO}_{2}$ values are \%.

* Chronic obstructive pulmonary disease, obesity hypoventilation syndrome, bronchiectasis, cystic fibrosis, neuromuscular disease and chest wall deformities such as severe kyphoscoliosis. **Skin pigmentation codes are as per the Fitzpatrick scale outlined in Textbox 3.1. 
The most common oximeter models used were the Nonin Avant 9700 in 103 participants (26\%), Massimo Rainbow Radical 7 in 92 participants (23\%) and the Nonin Avant 4000 in 76 participants (19\%) (Table 3.2). The difference in the estimation of variance components was 0.16 for oximeter brand and 2.48 for residual, resulting in an intra-class correlation coefficient of 0.94 . This can be interpreted as approximately $6 \%$ of variation in the relationship between $\mathrm{SpO}_{2}$ versus $\mathrm{SaO}_{2}$ being due to oximeter brand. Detailed results by oximeter are presented in Table 3.8 . 


\begin{tabular}{|lcc|}
\hline Oximeter & $\begin{array}{c}\mathrm{SpO}_{2} \text { minus SaO } \\
\text { Mean (SD) }\end{array}$ & $\begin{array}{c}\text { Estimates of SpO minus } \mathrm{SaO}_{2} \\
(\mathbf{9 5 \%} \text { CI) by broad best linear } \\
\text { unbiased prediction }\end{array}$ \\
\hline Carescape Monitor B450* & $-1.5(\mathrm{NA})$ & $-1.2(-2.3$ to -0.03$)$ \\
\hline GE Dash 3000 & $-2(0)$ & $-1.2(-2.3$ to -0.2$)$ \\
\hline Masimo Radical 7 & $-0.5(1.9)$ & $-0.6(-0.9$ to -0.3$)$ \\
\hline Masimoset Quartz Unspecified** & -0.5 (NA) & $-1.1(-2.2$ to 0.03$)$ \\
\hline Masimoset Quartz Q400 & $-1.0(1.3)$ & $-1.1(-1.7$ to -0.5$)$ \\
\hline Nonin 2120 & $-0.4(2.3)$ & $-0.9(-1.7$ to -0.03$)$ \\
\hline Nonin 2140 & $-2(\mathrm{NA})$ & $-1.2(-2.3$ to -0.1$)$ \\
\hline Nonin Avant Unspecified** & -2.4 (NA) & $-1.2(-2.3$ to -0.1$)$ \\
\hline Nonin Avant 4000 & $-1.5(1.2)$ & $-1.5(-1.8$ to -1.1$)$ \\
\hline Nonin Avant 9700 & $-1.4(1.4)$ & $-1.4(-1.7$ to -1.1$)$ \\
\hline Nonin Lifesense Medair & $-1.5(1.5)$ & $-1.4(-1.9$ to -1.0$)$ \\
\hline Novametrix Model 512 & 0 (NA) & $-1.1(-2.2$ to 0.1$)$ \\
\hline Ohmeda Biox 3700E Monitor* & $-2.0(2.0)$ & $-1.4(-2.3$ to -0.5$)$ \\
\hline Philips Intellivue MP70 Monitor* & $-1.1(1.6)$ & $-1.1(-1.8$ to -0.5$)$ \\
\hline Welch Allyn Monitor* & $-0.3(2.0)$ & $-0.7(-1.3$ to -0.04$)$ \\
\hline
\end{tabular}

\section{Table 3.8 Variation due to oximeter}

NA: Not applicable (as $\mathrm{N}=1$ ), $\mathrm{SaO}_{2}$ : Oxygen saturation measured by arterial blood gas sample, $\mathrm{SpO}_{2}$ : Oxygen saturation measured by standard pulse oximeter. Values are \%.

*Monitors used one of the following probes: Nellcor DuraSensor Adult Oxygen Transducer, GE TruSignal $\mathrm{SpO}_{2}$ Finger Sensor, LNCS Reusable Sensors or Philips Compatible Direct-Connect SpO2 Sensor. **Unspecified by investigator.

The machine by machine estimates are all very similar, consistent with the high value of the intra-class correlation coefficient. 


\subsection{Discussion}

The bias and limits of agreement between $\mathrm{SpO}_{2}$ and $\mathrm{SaO}_{2}$ in this study suggest that pulse oximetry is an accurate method to assess $\mathrm{SaO}_{2}$ in most patients in the clinical setting. However, in a small number of participants potentially clinically important differences between $\mathrm{SpO}_{2}$ and $\mathrm{SaO}_{2}$ could affect patient assessment and management. A practical guide that can be derived from data is that a $\mathrm{SpO}_{2} \geq 92 \%$ effectively ruled out presence of hypoxia (indicated by a $\mathrm{SaO}_{2}<90 \%$ ). There were no clinically significant differences in oximeter accuracy based on absolute level of $\mathrm{SaO}_{2}$, numerous clinical characteristics or oximeter brand.

The magnitude of bias and associated limits of agreement from the range of oximeters in this study suggested that overall they perform at a similar level or better than oximeters used in many of the clinical studies performed in the last 10 years. ${ }^{137,139-142,144-146,148,150,153-}$ 156,159,162-164 This is in keeping with constant oximeter sensor technology and software improvements by manufacturers over time. ${ }^{171}$

The negative bias, albeit small, meant that the oximeters tended to under, rather than over estimate $\mathrm{SaO}_{2}$. Such underestimation has the potential to result in a conservative estimate of risk of hypoxia and may lead to more liberal oxygen therapy than might be required. $\mathrm{SpO}_{2}$ underestimated $\mathrm{SaO}_{2}$ by at least $4 \%$ in around $3 \%$ of participants, and overestimated it by at least $4 \%$ in less than $1 \%$ of participants. These findings mean that while the oximeters performed well overall, there were still potentially clinically relevant differences in $\mathrm{SpO}_{2}$ and $\mathrm{SaO}_{2}$ in a small proportion of the participants. In the majority of the participants with $\mathrm{SpO}_{2}$ and $\mathrm{SaO}_{2}$ values differing by at least $4 \%$ the investigators did not state they had any concerns with oximeter accuracy. This highlights potential difficulty in identifying when an oximetry value is incorrect and emphasises the importance of guideline recommendations to consider oximetry values in clinical context. ${ }^{171}$

The TSANZ ${ }^{11}$ and BTS ${ }^{10}$ guidelines for acute oxygen therapy both recommend the use of pulse oximetry as a vital sign and a tool to titrate oxygen therapy to a target oxygen saturation range. The TSANZ recommend oxygen is delivered to a $\mathrm{SpO}_{2}$ target range of 92 
to $96 \%$ in patients not at risk of hypercapnic respiratory failure. ${ }^{11}$ This range was developed to reduce the risks of both hyperoxaemia and hypoxaemia, while recognising potential oximeter accuracy limitations. ${ }^{174}$ The lower limit of $92 \%$ is supported by a $\mathrm{SpO}_{2}$ saturation of $\geq 92 \%$ indicating that hypoxia $\left(\mathrm{SaO}_{2}<90 \%\right)$ is not present. The recommended upper $\mathrm{SpO}_{2}$ limit of $96 \%$, aimed at avoiding hyperoxaemia, is supported by the finding that 12 of the 13 participants with a $\mathrm{PaO}_{2}$ of greater than $100 \mathrm{mmHg}$ had a $\mathrm{SpO}_{2}$ value of over $96 \%$.

A $\mathrm{SpO}_{2}<90 \%$ had a specificity of only $70.5 \%$ in identifying a $\mathrm{PaO}_{2}<60 \mathrm{mmHg}$, while for $\mathrm{SaO}_{2}$ it was only $54.1 \%$. These values are in keeping with the majority of participants being positioned to the left of the predicted dissociation curve in this study. In keeping with recommendations by the TSANZ Oximetry Guidelines, ${ }^{171}$ these findings highlight the limitations of estimating $\mathrm{PaO}_{2}$ from saturation values, and vice versa.

Patients with sickle cell anaemia, methaemoglobinemia, or carbon monoxide poisoning we excluded from the study and nail polish was removed where possible as these factors are well established to impact on oximeter results. ${ }^{171} \mathrm{SaO}_{2}$, oximeter model and the numerous clinical variables were not found to significantly impact on oximeter accuracy. However, it was not possible to evaluate the effect of earlobe oximetry, Fitzpatrick scale V or VI, or ED location on accuracy due to there being only one participant in each of these categories.

This study had the advantage of a multicentre design and use of a range of oximeters routinely available to clinical staff in a variety of hospital settings. A wide range of patients were included, both in terms of presenting diagnosis and illness severity. These factors make the results directly applicable to a wide range of hospital settings in New Zealand and Australia.

While there was a range of $\mathrm{SaO}_{2}$ values between 72 and $100 \%$, the results cannot be applied to patients with $\mathrm{SaO}_{2}$ of under $70 \%$, at which oximeter inaccuracy is well recognised. ${ }^{171}$ Having only one participant with a Fitzpatrick score of V, and none with VI, meant study findings may not be applicable to patients with higher skin pigmentation. This is especially important as oximeter accuracy has been demonstrated to decrease as pigmentation increases, particularly at lower $\mathrm{SaO}_{2}$ levels and in oximeters of the same brand as some of those used in our study (Massimo Radical and Nonin 9700). ${ }^{151}$ Unexpectedly, all except one 
of the oximeter measurements were taken from the finger, limiting the application of the findings to sensors applied to the earlobe. Additionally, results may not be applicable to patients in theatre, ICU or ED, especially as a variety of factors specific to these settings have been identified as affecting oximeter accuracy previously. ${ }^{145,147,148,153,156,158,159,161}$

Single oximeter and blood gas measurement pairing from each participant were used, which has the advantage of removing potential bias from repeated measures. However, this did mean that we could not specifically assess the accuracy of $\mathrm{SpO}_{2}$ to detect changes in $\mathrm{SaO}_{2}$ over time.

Overall, the oximeters used in this study had good accuracy in determining both individual $\mathrm{SaO}_{2}$ values and detecting hypoxia in a range of clinical settings. The use of $\mathrm{SpO}_{2}$ of $92 \%$ as the lower boundary for the titration of oxygen therapy was supported by $100 \%$ sensitivity for $\mathrm{SpO}_{2}<92 \%$ in identifying hypoxia $\left(\mathrm{SaO}_{2}<90 \%\right)$. In a small number of participants discrepancies between $\mathrm{SpO}_{2}$ and $\mathrm{SaO}_{2}$ could have implications for patient assessment and management. This highlights the importance of recognising that clinically relevant inaccuracies in oximetry values can occur, and that $\mathrm{SpO}_{2}$ is interpreted within clinical context. 
Chapter 4: Randomised controlled trial of oxygen in obese hospital inpatients 


\subsection{Overview}

\section{Randomised controlled trial of oxygen in obese hospital inpatients}

\section{AIM}

To investigate the effect of oxygen therapy on transcutaneous partial pressure of carbon dioxide $\left(\mathrm{PtCO}_{2}\right)$ in morbidly obese adults.

\section{METHODS}

A randomised controlled crossover trial of 24 adult medical inpatients with a body mass index $>40 \mathrm{~kg} / \mathrm{m}^{2}$ comparing two 60 minute interventions: i) 'titrated' oxygen; oxygen, if required, via nasal prongs to achieve an oxygen saturation $\left(\mathrm{SpO}_{2}\right)$ between $88-92 \%$; and ii) 'high concentration' oxygen; $8 \mathrm{~L} / \mathrm{min}$ via Hudson mask. $\mathrm{PtCO}_{2}$ was measured at 10 minute intervals.

\section{KEY RESULTS}

The baseline $\mathrm{PtCO}_{2}$ was $\leq 45 \mathrm{mmHg}$ in $16 / 22(72.7 \%)$ participants with full data. The mean difference $(95 \% \mathrm{CI})$ in $\mathrm{PtCO}_{2}$ was $3.2 \mathrm{mmHg}$ (1.3 to 5.2), $\mathrm{P}=0.002$, higher at 60 minutes following high concentration compared with titrated oxygen.

\section{CONCLUSIONS}

High concentration oxygen therapy increases $\mathrm{PtCO}_{2}$ in morbidly obese patients. These findings support the guideline recommendation to titrate oxygen, if required, to achieve a target oxygen saturation of $88-92 \%$ in adults with morbid obesity.

\section{CO-INVESTIGATORS AND PUBLICATION}

Pilcher J, Richards M, Eastlake L, McKinstry SJ, Bardsley G, Jefferies S, Braithwaite I, Weatherall M, Beasley R. High flow or titrated oxygen for obese medical inpatients: a randomised crossover trial. The Medical journal of Australia. 2017 Nov 20;207(10):4304. (C) Copyright 2017. The Medical Journal of Australia - adapted and reproduced with permission. See Appendix for reproduction permission and further investigator details. 


\subsection{Rationale}

As outlined in Chapter 1, oxygen therapy increases $\mathrm{PaCO}_{2}$ in patients with stable and AECOPD. ${ }^{2,3}$ The hypercapnia and associated respiratory acidosis can be marked, and contribute to mortality being more than twice as high among patients with AECOPD who receive high concentration oxygen therapy than among those for whom oxygen administration is titrated to achieve a target oxygen saturation of $88-92 \%$, as measured by pulse oximetry. ${ }^{12}$

There is also evidence that administering high concentration oxygen may increase $\mathrm{PaCO}_{2}$ in patients with other respiratory conditions, such as acute asthma, ${ }^{13,108,109}$ communityacquired pneumonia, ${ }^{14}$ and stable OHS. ${ }^{15,16,87,117,118}$ Guidelines therefore recommend that oxygen therapy be titrated to a target $\mathrm{SpO}_{2}$ range to avoid the risks of both hypoxaemia and hyperoxaemia. $^{10,11}$

In an earlier randomised cross over trial of the effects of $100 \%$ oxygen therapy in patients with OHS, three of 24 participants were withdrawn early because $\mathrm{PaCO}_{2}$ increased by more than $10 \mathrm{mmHg}$ in less than 20 minutes, indicating that high concentration oxygen administration can result in rapid, clinically significant increases in the $\mathrm{PaCO}_{2} \cdot{ }^{15}$ Patients at greatest risk of worsening hypercapnia were those with the most marked hypoxaemia; that is, those most likely to receive oxygen therapy. The generalisability of our findings to patients with morbid obesity was limited by the requirement that participants had chronic respiratory failure, in accordance with the definition of OHS. ${ }^{116}$ Generalisability to clinical practice was also limited by administering $100 \%$ oxygen for 20 minutes rather than lower concentrations for longer periods, which is more likely in clinical settings.

The aim of our study was to compare the effects on $\mathrm{PaCO}_{2}$ of high concentration and titrated oxygen in medical inpatients with morbid obesity who were not selected for a pre-existing diagnosis of OHS. To assess the physiological response, we continuously monitored $\mathrm{PtCO}_{2}$, a non-invasive validated measure of $\mathrm{PaCO}_{2} \cdot{ }^{175-177}$ The hypothesis was that high concentration oxygen therapy would increase $\mathrm{PtCO}_{2}$ to a significantly greater extent than an oxygen regimen in which administration, if required, is titrated to achieve a $\mathrm{SpO}_{2}$ target of 
88 to $92 \%$, as recommended when treating patients with conditions associated with chronic respiratory failure. ${ }^{10,11}$ 


\subsection{Methods}

This randomised controlled cross over trial recruited 24 adult patients with a BMI exceeding $40 \mathrm{~kg} / \mathrm{m}^{2}$ who had been admitted under General Medicine to WRH, New Zealand. Patients were identified by Hospital staff while on the ward and were excluded if they were under 16 years of age, had been diagnosed with COPD or a condition associated with restriction of chest wall expansion other than obesity, unstable angina or recent myocardial infarction (MI), had a baseline $\mathrm{PtCO}_{2}$ greater than $65 \mathrm{mmHg}$, or were currently receiving NIV. Investigators could also exclude patients for any condition that might represent a safety risk or affect the feasibility of the study or its results.

After written informed consent had been provided, demographic and clinical data were collected. Spirometry was performed according to American Thoracic Society/European Respiratory Society guidelines ${ }^{178}$ with a handheld spirometer (CareFusion). Transcutaneous monitors on the earlobe measured $\mathrm{SpO}_{2}, \mathrm{PtCO}_{2}$ and heart rate. Measurements for the first 12 participants were recorded with the TOSCA 500 monitor (Radiometer); as this was not available for the second 12, their data were collected with a SenTec monitor (SenTec). Respiratory rate was measured at each time point over 60 seconds by direct observation.

An overview of study procedures is presented in Figure 4.1. Participants were randomised to the order in which they received 60 minutes of titrated oxygen therapy (oxygen delivered, if required, via nasal prongs to achieve $\mathrm{SpO}_{2}$ of 88-92\%) or high concentration oxygen therapy (delivered via Hudson mask at $8 \mathrm{~L} / \mathrm{min}$, without regard to $\mathrm{SpO}_{2}$ ). The randomisation schedule was generated by the study statistician; the intervention order for each participant was sealed in an opaque envelope and opened by the study investigator at randomisation. The washout period between the two interventions was at least 30 minutes. If participants were receiving oxygen at the start of the study, it was titrated for 30 minutes to achieve a $\mathrm{SpO}_{2}$ of $88-92 \%$ before the first intervention, and for a minimum of 30 minutes during the washout period before the second intervention; this was undertaken to standardise baseline conditions. $\mathrm{PtCO}_{2}, \mathrm{SpO}_{2}$, respiratory rate, and heart rate were recorded at baseline, and every 10 minutes during the interventions. $\mathrm{PtCO}_{2}$ was monitored continuously; if it increased by more than $10 \mathrm{mmHg}$ from baseline, the intervention was ended. The primary outcome 
variable was $\mathrm{PtCO}_{2}$ at 60 minutes, adjusted for baseline. Secondary outcome variables included the proportion of participants at each time point with a change in $\mathrm{PtCO}_{2}$ from baseline of least $4 \mathrm{mmHg}$; the proportion with this change at at least one time point; and $\mathrm{PtCO}_{2}, \mathrm{SpO}_{2}$, heart rate, and respiratory rate at all time points, adjusted for baseline. Differences in outcome variables according to treatment were estimated by mixed linear models with fixed effects for all the baseline measurements of the particular outcome variables, intervention order, and intervention. A random effect for participants accounted for the cross over design. These estimates are presented as differences between the high concentration oxygen and titrated oxygen interventions, with $95 \%$ confidence intervals. The difference (with 95\% CI) in the proportion of participants with a $\mathrm{PtCO}_{2}$ rise of at least 4 $\mathrm{mmHg}$ was assessed in a McNemar test. Whether the change in monitor affected the differences between randomised treatments was explored by post hoc addition of fixed effects for a main effect and an interaction effect. In a further simple post hoc analysis, the difference between the oxygen intervention types in two subgroups was compared in $t$ tests: participants who had a baseline $\mathrm{PtCO}_{2}$ greater than $45 \mathrm{mmHg}$, and those admitted with a respiratory diagnosis. All analyses were conducted in SAS 9.3 (SAS Institute). A sample size of 24 was calculated to have $80 \%$ power (type I error rate $5 \%$ ) to detect a difference in $\mathrm{PtCO}_{2}$ of $2.4 \mathrm{mmHg}$ between the groups, half the mean difference found by a study of participants with OHS (5 mmHg; standard deviation, $4 \mathrm{mmHg}) .{ }^{15}$ 


\begin{tabular}{|c|c|c|c|c|c|c|}
\hline & & \multicolumn{2}{|c|}{ Intervention 1} & & \multicolumn{2}{|c|}{ Intervention 2} \\
\hline & & & $\begin{array}{l}\text { Administration } \\
\text { of high } \\
\text { concentration or } \\
\text { titrated oxygen }\end{array}$ & $\begin{array}{c}\text { Washout } \\
\text { period }\end{array}$ & & $\begin{array}{c}\text { Administration } \\
\text { of high } \\
\text { concentration or } \\
\text { titrated oxygen }\end{array}$ \\
\hline \multicolumn{2}{|l|}{ Time } & $\begin{array}{l}\text { Time } \\
\text { zero }\end{array}$ & $0-60$ minutes & $\begin{array}{c}\geq 30 \\
\text { minutes }\end{array}$ & $\begin{array}{l}\text { Time } \\
\text { zero }\end{array}$ & 0-60 minutes \\
\hline $\begin{array}{l}\text { Recording } \\
\text { - Heart rate } \\
\text { - Respiratory } \\
\text { rate } \\
\text { - } \mathrm{PtCO}_{2} \\
\text { - Oxygen } \\
\text { saturation }\end{array}$ & $\begin{array}{l}\text { Method } \\
\text { SenTec } \\
\text { Investigator } \\
\text { observation } \\
\text { SenTec } \\
\text { SenTec }\end{array}$ & $X$ & $\begin{array}{c}\mathrm{X} \\
\text { (every } 10 \\
\text { minutes) }\end{array}$ & & $\mathrm{X}$ & $\begin{array}{c}\mathrm{X} \\
\text { (every } 10 \\
\text { minutes) }\end{array}$ \\
\hline \multicolumn{2}{|c|}{$\begin{array}{l}\text { Continuous monitoring } \\
-\mathrm{PtCO}_{2} \\
\text { - Oxygen saturation }\end{array}$} & & $X$ & & & $X$ \\
\hline
\end{tabular}

Figure 4.1 Overview of study procedures and measurements

$\mathrm{PtCO}_{2}$ : Transcutaneous partial pressure of carbon dioxide. 
The study was prospectively approved by the New Zealand Health and Disability Ethics Committee Central (reference, CEN/10/03/08) and was registered with the ANZCTR (ACTRN12610000522011). 


\subsection{Results}

Participants were recruited from February to September 2015. Eighty inpatients were screened, and 24 were randomised to treatment (Figure 4.2). One participant withdrew after randomisation when given the opportunity to be discharged home, and one participant was randomised in error a second time during a subsequent admission; both were excluded from the analysis. The remaining 22 patients were studied at a median 0.9 days (range, 0.2 to 6.5 days) after admission. 


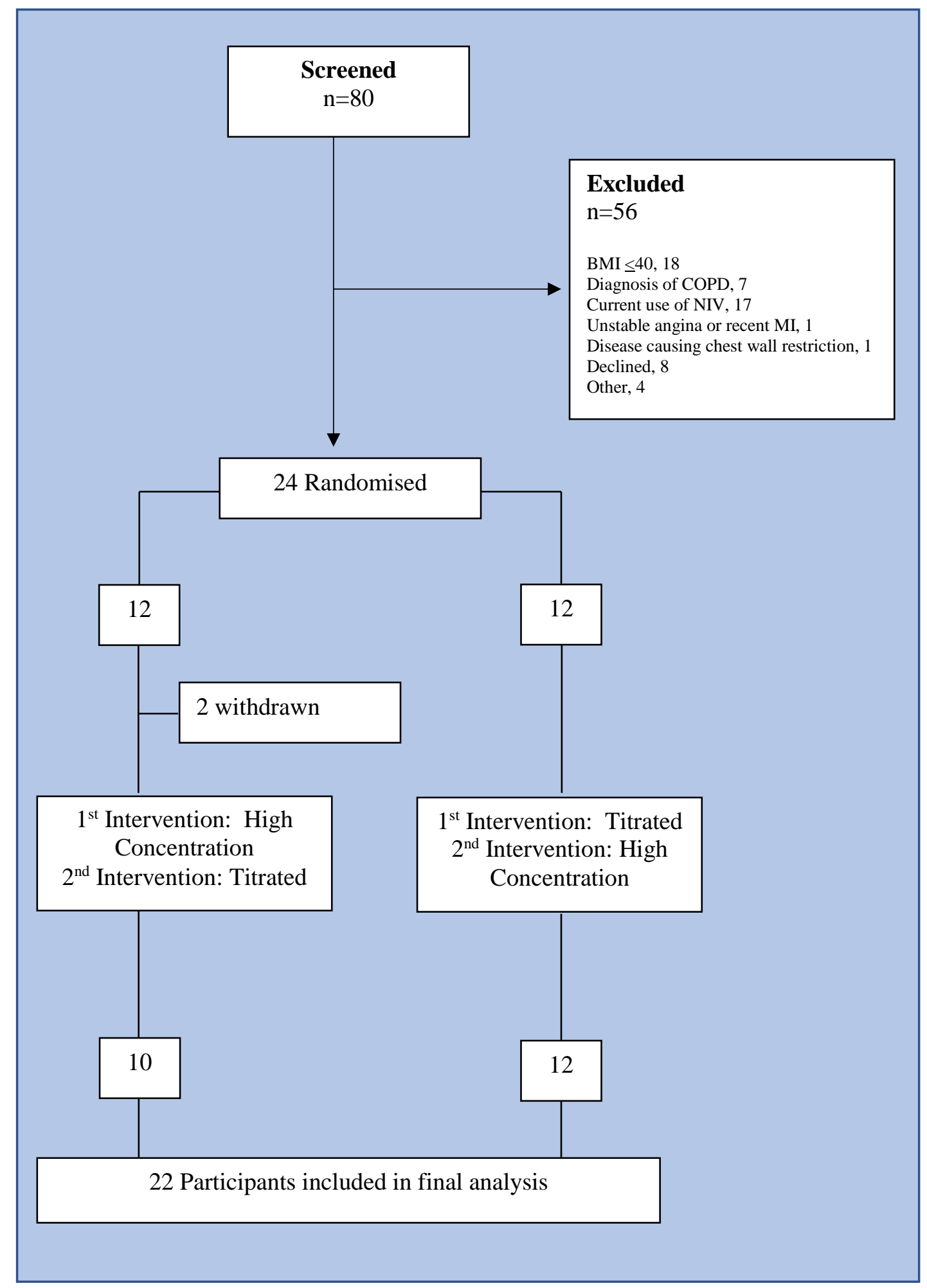

\section{Figure 4.2 Flow of participants through the study}

BMI: Body mass index, COPD: Chronic obstructive pulmonary disease, MI: Myocardial infarction, NIV: noninvasive ventilation. 
The baseline characteristics of the participants are summarised in Table 4.1. The median $\mathrm{SpO}_{2}$ was $97 \%$ (range, 89 to $100 \%$ ); the mean $\mathrm{PtCO}_{2}$ was $41.7 \mathrm{mmHg}$, and 16 participants (73\%) had a baseline $\mathrm{PtCO}_{2}$ of $45 \mathrm{mmHg}$ or less. No participant had a previous diagnosis of OHS; six participants reported a history of witnessed apnoea and snoring, but none had been diagnosed with obstructive sleep apnoea. Seven participants had an admission diagnosis of asthma, and two were admitted with a lower respiratory tract infection. Three participants (two with asthma, one with heart failure) required up to $1 \mathrm{~L} / \mathrm{min}$ oxygen via nasal cannulae during the titration intervention to maintain $\mathrm{SpO}_{2}$ at 88 to $92 \%$. 


\begin{tabular}{|c|c|}
\hline Characteristic & Mean (SD) \\
\hline Age (years) & $53.5(16.1)$ \\
\hline $\operatorname{BMI}\left(\mathrm{kg} / \mathrm{m}^{2}\right)$ & $50.4(9.2)$ \\
\hline $\mathrm{FEV}_{1} / \mathrm{FVC}^{*}$ & $0.75(0.08)$ \\
\hline $\mathrm{PtCO}_{2}(\mathrm{mmHg})$ & $41.7(5.8)$ \\
\hline \multirow[t]{2}{*}{ Oxygen saturation (\%) } & $96.1(2.6)$ \\
\hline & n (\%) \\
\hline Male sex & $7(31.8)$ \\
\hline \multicolumn{2}{|l|}{ Ethnicity } \\
\hline Māori & $3(13.6)$ \\
\hline NZ European & $8(36.4)$ \\
\hline Pacific Island & $11(50.0)$ \\
\hline \multicolumn{2}{|l|}{ Days since admission } \\
\hline 1 & $13(59.1)$ \\
\hline 2 & $5(22.7)$ \\
\hline 3 or more & $4(18.2)$ \\
\hline \multicolumn{2}{|l|}{ Diagnosis } \\
\hline Cellulitis & $6(27.3)$ \\
\hline Asthma exacerbation & $7(31.8)$ \\
\hline Lower respiratory tract infection & $2(9.1)$ \\
\hline Other & $7(31.8)$ \\
\hline \multicolumn{2}{|l|}{ Smoking status } \\
\hline Current & $1(4.5)$ \\
\hline Ex smoker & $12(54.5)$ \\
\hline Never smoker & $9(40.9)$ \\
\hline
\end{tabular}

\section{Table 4.1 Baseline characteristics}

BMI: Body mass index, $\mathrm{FEV}_{1}$ : Forced expiratory volume in one second, $\mathrm{FVC}$ : Forced vital capacity, $\mathrm{PtCO}_{2}$ :

Transcutaneous partial pressure of carbon dioxide.

$* \mathrm{~N}=19$.

$\mathrm{N}=22$ unless otherwise stated. 
All 22 participants completed both interventions, although high concentration oxygen was interrupted for 3 minutes for one participant at 32 minutes while they visited the bathroom. The baseline $\mathrm{PtCO}_{2}$ values for all but two participants were within $4 \mathrm{mmHg}$ of each other for both interventions; the mean baseline $\mathrm{PtCO}_{2}$ before intervention was $41.8 \mathrm{mmHg}$ for titrated oxygen and $41.7 \mathrm{mmHg}$ for high concentration oxygen. The effect of randomisation order was not statistically significant for any of the $\mathrm{PtCO}_{2}$ analyses.

The mean difference in $\mathrm{PtCO}_{2}$ at 60 minutes, adjusted for baseline, between the high concentration oxygen and titrated oxygen interventions was $3.2 \mathrm{mmHg}(95 \% \mathrm{CI}, 1.3$ to 5.2; $\mathrm{P}=0.002$ ) (Table 4.2). The increase in $\mathrm{PtCO}_{2}$ with high concentration oxygen therapy and the difference between the two interventions were evident as early as 10 minutes after commencing the interventions (Table 4.3). 


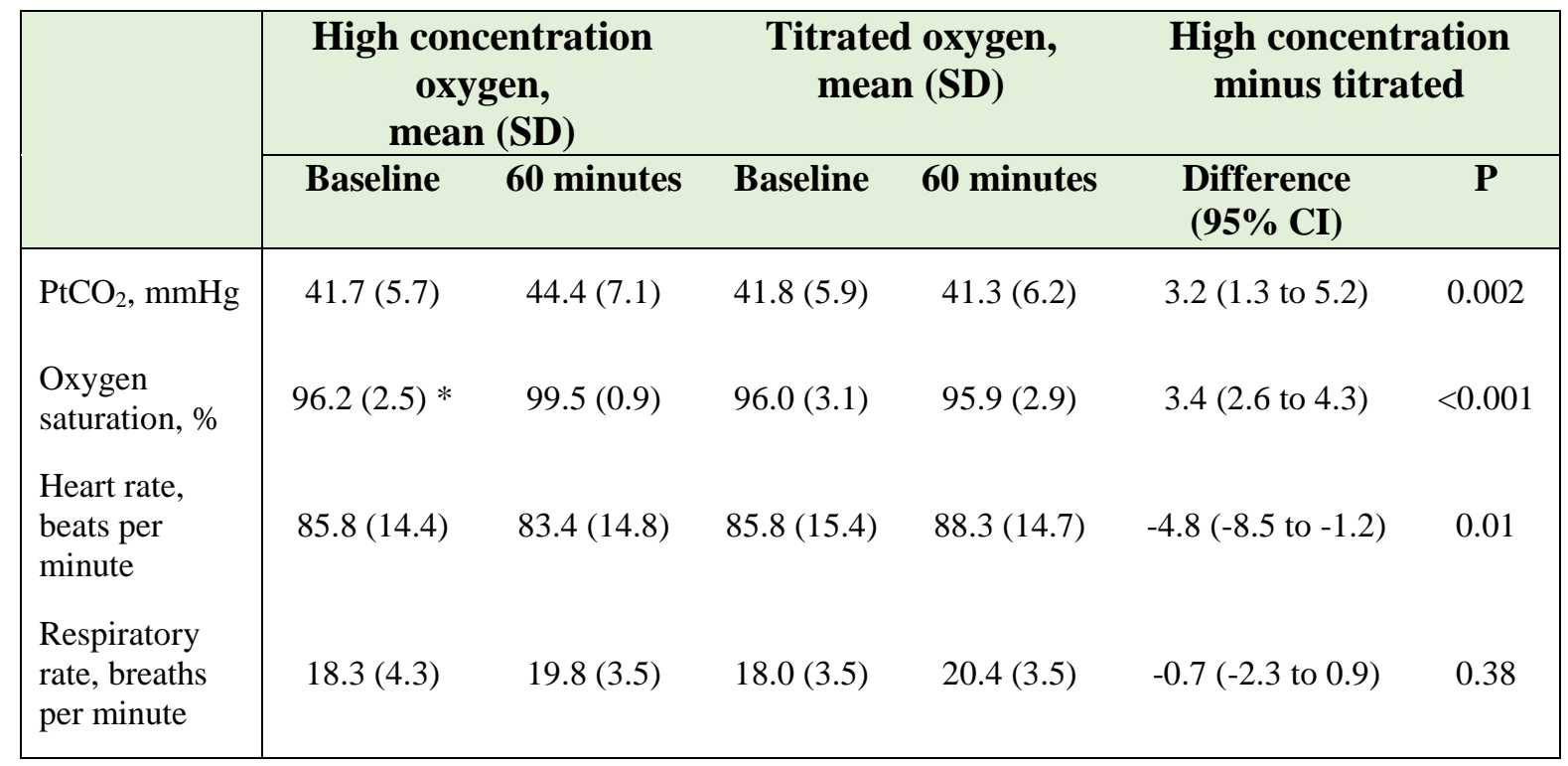

Table 4.2 Differences in outcomes at 60 minutes, for high concentration vs titrated oxygen therapy, adjusted for baseline.

$\mathrm{PtCO}_{2}$ : Transcutaneous partial pressure of carbon dioxide.

$* \mathrm{~N}=21$ due to error in recording baseline data.

$\mathrm{N}=22$ unless otherwise stated. 


\begin{tabular}{|c|c|c|c|c|}
\hline \multirow[b]{2}{*}{ Variable } & \multicolumn{2}{|c|}{ Mean (SD) } & \multirow{2}{*}{$\begin{array}{l}\text { High concentration minus } \\
\text { titrated oxygen therapy, } \\
(95 \% \mathrm{CI})\end{array}$} & \multirow[b]{2}{*}{$\mathbf{P}$} \\
\hline & $\begin{array}{c}\text { High } \\
\text { concentration }\end{array}$ & Titrated & & \\
\hline \multicolumn{5}{|c|}{$\mathrm{PtCO}_{2}, \mathbf{m m H g}$} \\
\hline 0 & $41.7(5.7)$ & $41.8(5.9)$ & & \\
\hline 10 & $44.3(6.5)$ & $41.6(6.2)$ & 2.8 (1.8 to 3.8$)$ & $<0.001$ \\
\hline 20 & $44.7(6.6)$ & $41.8(6.5)$ & $3.0(1.8$ to 4.3$)$ & $<0.001$ \\
\hline 30 & $44.8(6.3)$ & $41.9(6.4)$ & $3.0(-1.7$ to 4.3$)$ & $<0.001$ \\
\hline 40 & $44.9(6.4)$ & $42.0(6.4)$ & $3.0(1.6$ to 4.4$)$ & $<0.001$ \\
\hline 50 & $44.9(6.9)$ & $41.4(6.4)$ & $3.6(1.6$ to 5.6$)$ & 0.001 \\
\hline 60 & $44.4(7.1)$ & $41.3(6.2)$ & $3.2(1.3$ to 5.2$)$ & 0.002 \\
\hline \multicolumn{5}{|l|}{$\mathrm{SpO}_{2}, \%$} \\
\hline 0 & $96.2(2.5)^{*}$ & $96.0(3.1)$ & & \\
\hline 10 & $99.5(0.8)$ & $95.6(3.1)$ & $3.7(2.9$ to 4.5$)$ & $<0.001$ \\
\hline 20 & $99.4(0.8)$ & $96.1(2.9)$ & $3.1(2.2$ to 4.0$)$ & $<0.001$ \\
\hline 30 & $99.4(0.8)$ & $95.8(2.5)$ & $3.4(2.6$ to 4.2$)$ & $<0.001$ \\
\hline 40 & $99.4(0.7)$ & $95.7(3.5)$ & $3.6(-2.5$ to 4.6$)$ & $<0.001$ \\
\hline 50 & $99.4(0.9)$ & $96.2(2.8)$ & $3.0(2.2$ to 3.9$)$ & $<0.001$ \\
\hline 60 & $99.5(0.9)$ & $95.9(2.9)$ & $3.4(2.6$ to 4.3$)$ & $<0.001$ \\
\hline \multicolumn{5}{|c|}{ Heart Rate, beats per minute } \\
\hline 0 & $85.8(14.4)$ & $85.8(15.4)$ & & \\
\hline 10 & $82.6(14.6)$ & $87.9(14.1)$ & $-5.3(-8.8$ to -1.8$)$ & 0.004 \\
\hline 20 & $82.5(15.1)$ & $88.0(14.5)$ & $-5.4(-9.3$ to -1.4$)$ & 0.009 \\
\hline 30 & $83.4(16.5)$ & $86.9(14.4)$ & $-3.5(-7.7$ to 0.7$)$ & 0.10 \\
\hline 40 & $82.1(16.1)$ & $88.7(15.0)$ & $-6.5(-10.9$ to -2.1$)$ & 0.005 \\
\hline 50 & $81.7(15.5)$ & $89.0(15.6)$ & $-7.2(-10.3$ to -4.1$)$ & $<0.001$ \\
\hline 60 & $83.4(14.8)$ & $88.3(14.7)$ & $-4.8(-8.5$ to -1.2$)$ & 0.01 \\
\hline \multicolumn{5}{|c|}{ Respiratory Rate, breaths per minute } \\
\hline 0 & $18.3(4.3)$ & $18.0(3.5)$ & & \\
\hline 10 & $18.7(4.6)$ & $19.0(3.5)$ & $-0.5(-2.3$ to 1.3$)$ & 0.60 \\
\hline 20 & $18.0(4.1)$ & $18.5(2.8)$ & $-0.7(-2.1$ to 0.8$)$ & 0.35 \\
\hline 30 & $19.0(2.7)$ & $19.1(3.6)$ & $-0.3(-1.9$ to 1.4$)$ & 0.74 \\
\hline 40 & $19.0(2.7)$ & $19.6(5.0)$ & $-0.8(-3.0$ to 1.5$)$ & 0.50 \\
\hline 50 & $19.4(3.8)$ & $20.2(4.2)$ & $-0.9(-3.1$ to 1.2$)$ & 0.39 \\
\hline 60 & $19.8(3.5)$ & $20.4(3.5)$ & $-0.7(-2.3$ to 0.9$)$ & 0.38 \\
\hline
\end{tabular}

Table 4.3 Mean values and mixed linear model differences for $\mathrm{PtCO}_{2}$, heart rate, respiratory rate and oxygen saturations

$\mathrm{SpO}_{2}$ : Oxygen saturation, $\mathrm{PtCO}_{2}$ : Transcutaneous partial pressure of carbon dioxide.

$* \mathrm{~N}=21$

$\mathrm{N}=22$ for all unless stated. 
The difference in $\mathrm{PtCO}_{2}$ at 60 minutes was greater for participants with a baseline $\mathrm{PtCO}_{2}$ exceeding $45 \mathrm{mmHg}(\mathrm{P}=0.043)$ (Table 4.4), but admission diagnosis (respiratory $\mathrm{v}$ non respiratory) did not affect this outcome (Table 4.4). 


\begin{tabular}{|c|c|c|c|c|}
\hline \multicolumn{5}{|c|}{ Baseline $\mathrm{PtCO}_{2}>45 \mathrm{mmHg}$} \\
\hline & \multicolumn{2}{|c|}{ Mean (SD) } & \multirow{2}{*}{$\begin{array}{c}\text { Difference* }^{*} \\
(95 \% \text { CI })\end{array}$} & \multirow[t]{2}{*}{$\mathbf{P}$} \\
\hline & No $(n=16)$ & Yes $(n=6)$ & & \\
\hline $\begin{array}{l}\text { High concentration } \\
\text { oxygen }\end{array}$ & $2.4(2.7)$ & $3.8(1.7)$ & $-1.4(-3.9$ to 1.0$)$ & 0.24 \\
\hline Titrated oxygen & $0.2(2.0)$ & $-2.4(6.2)$ & $2.7(-3.8$ to 9.1$)$ & 0.13 \\
\hline $\begin{array}{l}\text { High concentration minus } \\
\text { titrated }\end{array}$ & $2.1(3.3)$ & $6.2(5.6)$ & $-4.1(-8.1$ to -0.1$)$ & 0.043 \\
\hline \multicolumn{5}{|c|}{ Admission was for a respiratory disorder } \\
\hline & \multicolumn{2}{|c|}{ Mean (SD) } & Difference* & $\mathbf{P}$ \\
\hline & No $(n=13)$ & Yes $(n=9)$ & $(95 \% \mathrm{CI})$ & \\
\hline $\begin{array}{l}\text { High concentration } \\
\text { oxygen }\end{array}$ & $2.8(2.7)$ & $2.6(2.3)$ & $0.2(-2.1$ to 2.5$)$ & 0.85 \\
\hline Titrated oxygen & $0.0(4.5)$ & $-1.2(1.8)$ & $1.2(-2.1$ to 4.5$)$ & 0.46 \\
\hline $\begin{array}{l}\text { High concentration minus } \\
\text { titrated }\end{array}$ & $2.8(5.1)$ & $3.8(3.1)$ & $-1.0(-5.0$ to 3.0$)$ & 0.61 \\
\hline
\end{tabular}

Table 4.4 Change in $\mathrm{PtCO}_{2}$ from baseline at 60 minutes, stratified by baseline values and by admission diagnosis

$\mathrm{PtCO}_{2}$ : Transcutaneous partial pressure of carbon dioxide.

* No minus yes. 
The increase in $\mathrm{PtCO}_{2}$ from baseline was $4 \mathrm{mmHg}$ or more for 14 participants during the high concentration intervention and for two during the titrated intervention (Table 4.5). The proportion of participants in whom $\mathrm{PtCO}_{2}$ increased by $4 \mathrm{mmHg}$ or more from baseline was significantly greater for the high concentration intervention than for the titration intervention (Table 4.6). For one participant, an increase in $\mathrm{PtCO}_{2}$ of $9.7 \mathrm{mmHg}$ during the high concentration intervention was measured during continuous monitoring; they were sleepy but rousable. For nine of the 14 participants in whom $\mathrm{PtCO}_{2}$ increased by at least 4 mmHg over baseline with high concentration oxygen, baseline $\mathrm{PtCO}_{2}$ had been below 45 $\mathrm{mmHg}$. For one participant, $\mathrm{PtCO}_{2}$ was reduced by $13 \mathrm{mmHg}$ at 50 minutes and by 14 $\mathrm{mmHg}$ at 60 minutes during the titrated intervention, associated with movement to a more upright position; $\mathrm{PtCO}_{2}$ was not reduced by $4 \mathrm{mmHg}$ or more from baseline for any other participant during either intervention. 


\begin{tabular}{|c|c|c|c|c|c|c|c|c|c|c|c|}
\hline \multirow{2}{*}{ ID } & \multirow{2}{*}{$\begin{array}{l}\text { Admission } \\
\text { diagnosis }\end{array}$} & \multirow{2}{*}{ Intervention } & \multirow{2}{*}{$\begin{array}{l}\text { BMI, } \\
\mathrm{kg} / \mathrm{m}^{2}\end{array}$} & \multicolumn{2}{|c|}{$\begin{array}{l}\text { Baseline value prior to } \\
\text { intervention }\end{array}$} & \multicolumn{6}{|c|}{ Change in $\mathrm{PtCO}_{2}$ from baseline $(\mathrm{mmHg})$} \\
\hline & & & & $\begin{array}{l}\mathrm{PtCO}_{2}, \\
\mathrm{mmHg}\end{array}$ & $\begin{array}{c}\text { Oxygen } \\
\text { saturation, } \%\end{array}$ & $10 \mathrm{~min}$ & $20 \mathrm{~min}$ & $30 \mathrm{~min}$ & $40 \mathrm{~min}$ & $50 \mathrm{~min}$ & $60 \mathrm{~min}$ \\
\hline 02 & Cellulitis & Titrated & 45.5 & 51 & 98 & 1 & 2 & 4 & 4 & 4 & 4 \\
\hline 13 & Diabetes & Titrated & 53.2 & 43 & 96 & 3 & 4 & 4 & 4 & 5 & 5 \\
\hline 02 & Cellulitis & High concent. & 45.5 & 46 & 97 & 3 & 3 & 3 & 4 & 6 & 5 \\
\hline 03 & Cellulitis & High concent. & 52.3 & 44 & 99 & 2 & 4 & 5 & 4 & 3 & 4 \\
\hline 04 & LRTI & High concent. & 41.0 & 43 & 94 & 6 & 9 & 8 & 9 & 7 & 5 \\
\hline 06 & Asthma & High concent. & 62.4 & 48 & NA & 1 & 2 & 2 & 4 & 3 & 4 \\
\hline 07 & Asthma & High concent. & 51.7 & 43 & 98 & 3 & 5 & 6 & 4 & 5 & 4 \\
\hline 08 & Cellulitis & High concent. & 56.0 & 38 & 97 & 3 & 3 & 4 & 4 & 3 & 4 \\
\hline 09 & Cellulitis & High concent. & 45.2 & 47 & 96 & 3 & 2 & 2 & 3 & 4 & 3 \\
\hline 11 & Asthma & High concent. & 56.6 & 40 & 98 & 4 & 4 & 3 & 2 & 3 & 3 \\
\hline 13 & Diabetes & High concent. & 53.2 & 41 & 97 & 4 & 5 & 5 & 6 & 6 & 6 \\
\hline 17 & Testicular infarction & High concent. & 59.5 & 33 & 94 & 6 & 6 & 5 & 6 & 6 & 5 \\
\hline 19 & Asthma & High concent. & 49.2 & 43 & 98 & 1 & 1 & 2 & 4 & 5 & 2 \\
\hline 20 & Heart failure & High concent. & 47.7 & 57 & 92 & 6 & 6 & 6 & 5 & 8 & 7 \\
\hline 21 & Asthma & High concent. & 55.1 & 31 & 98 & 2 & 4 & 8 & 8 & 8 & 3 \\
\hline 24 & LRTI & High concent. & 40.0 & 44 & 93 & 6 & 7 & 3 & 3 & 3 & 4 \\
\hline
\end{tabular}

Table 4.5 Characteristics $\mathrm{PtCO}$ in participants with an increase from baseline $\geq 4 \mathrm{~mm} \mathrm{Hg}$

BMI: Body mass index, ID: Participant Identification number, LRTI: Lower respiratory tract infection, NA: Not available, PtCO 2 : Transcutaneous partial pressure of carbon dioxide; Titrated: Titrated oxygen regimen; High Concent: High concentration oxygen regimen. Values in red meet criteria for $\geq 4$ mmHg cut off. Note that data for participant 17 onwards was from the SenTec and available to $1 \mathrm{dp}$, however have been rounded to the nearest whole number for this Table. 


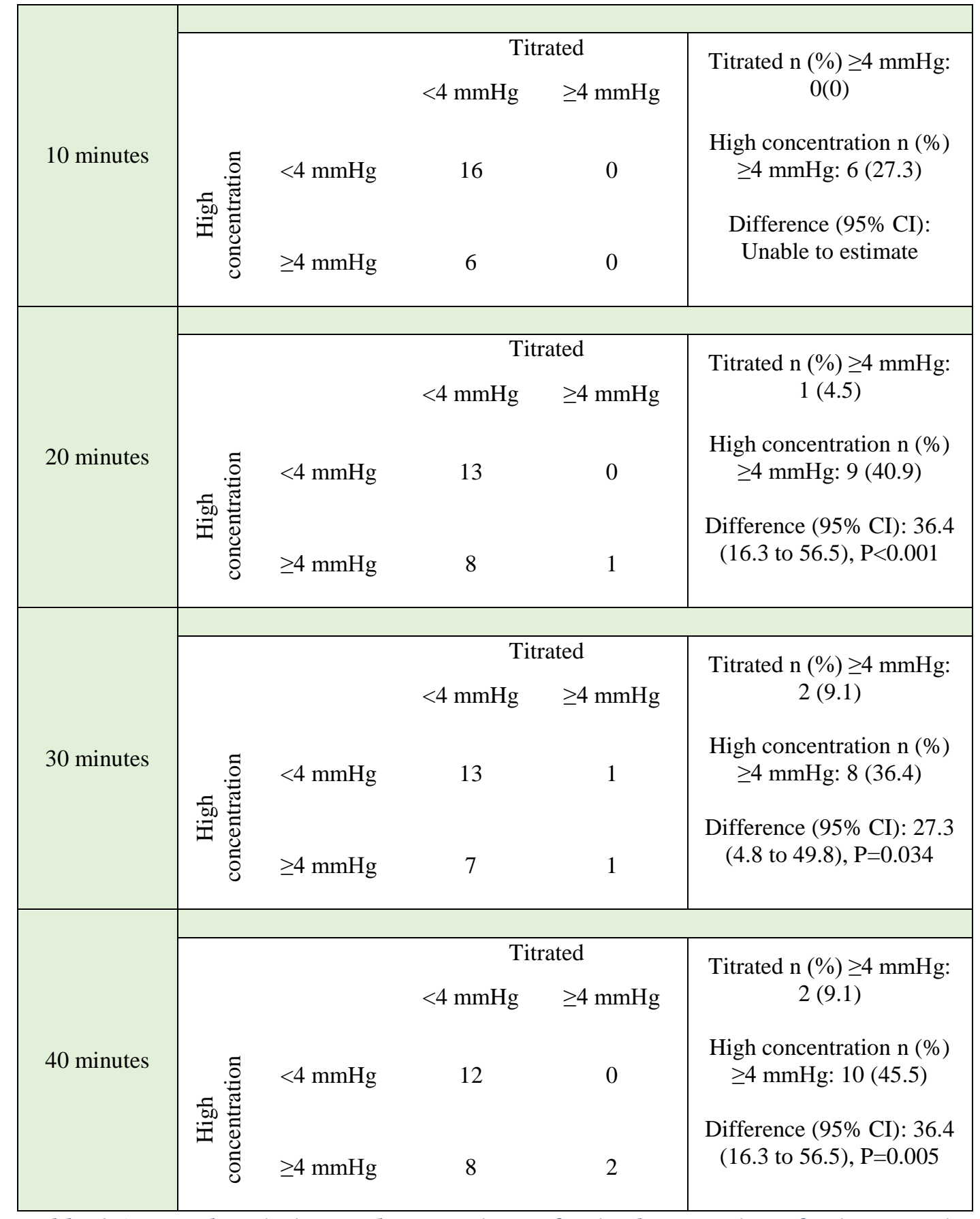

Table 4.6 Data description and comparison of paired proportions for increase in $\mathrm{PtCO}_{2}$ $\geq 4 \mathrm{mmHg}$ from baseline Continued overleaf. 


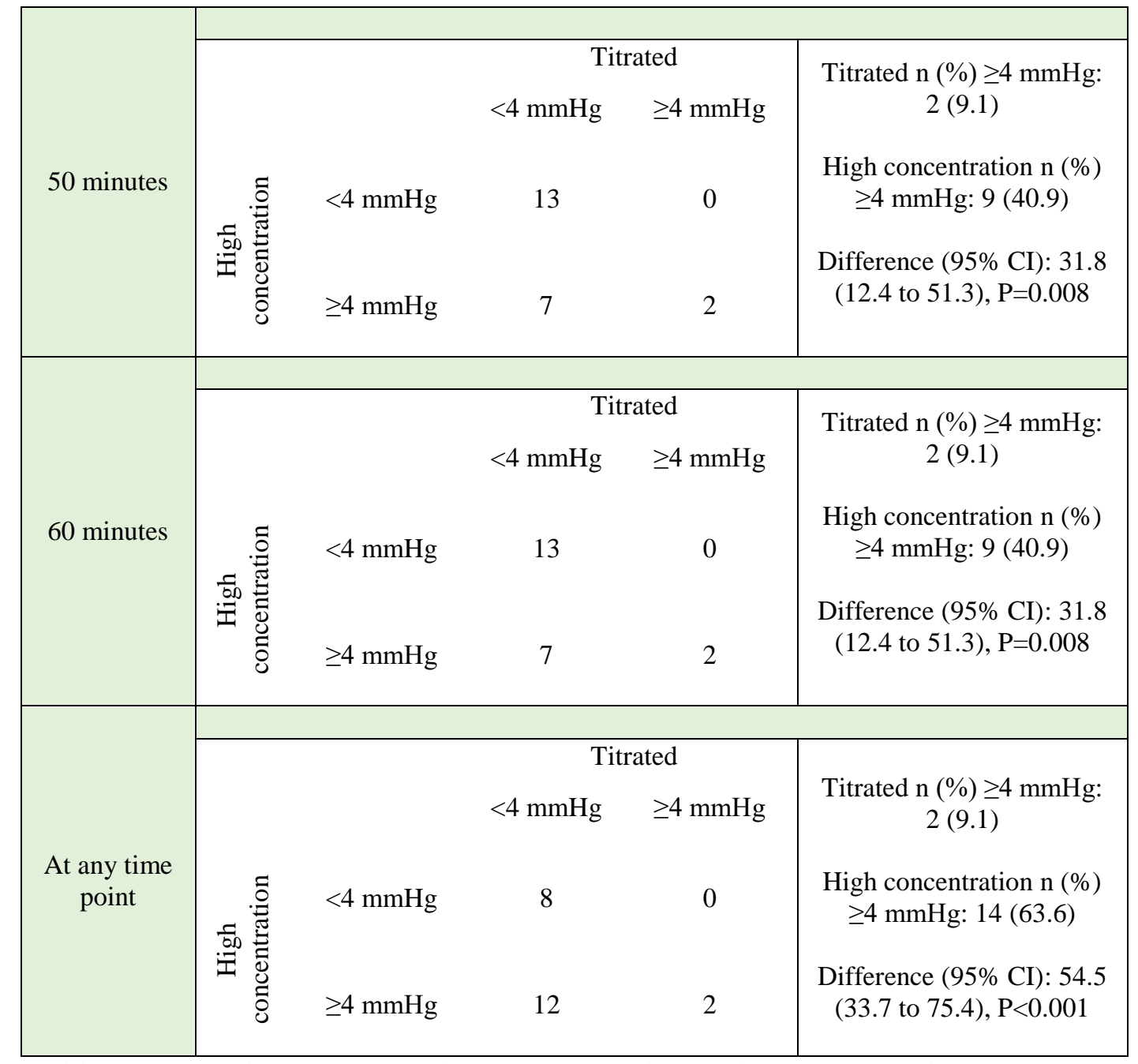

Table 4.6 Data description and comparison of paired proportions for increase in $\mathrm{PtCO}_{2}$ $\geq 4 \mathrm{mmHg}$ from baseline continued

$\mathrm{PtCO}_{2}$ : Transcutaneous partial pressure of carbon dioxide.

Note TOSCA data available to $0 \mathrm{dp}$ (4 $\mathrm{mmHg}$ and above used as the cut off) and SenTec data available to $1 \mathrm{dp}$ (4.0 $\mathrm{mmHg}$ and above used as the cut off). 
There was no interaction between treatment and transcutaneous monitor type (for interaction, $\mathrm{P}=0.50$ ). In a model that incorporated a fixed effect for the monitor type, the estimate of the differences between titrated and high concentration oxygen was the same.

The change in $\mathrm{SpO}_{2}$ from baseline was significantly greater at all time points for high concentration oxygen than for titrated oxygen treatment. The change in heart rate was significantly lower with high concentration oxygen at most time points. The respiratory rate did not differ between the two interventions (Table 4.3). 


\subsection{Discussion}

High concentration oxygen therapy increased $\mathrm{PtCO}_{2}$ in morbidly obese hospital inpatients to a significantly greater degree than titrating oxygen to achieve a target $\mathrm{SpO}_{2}$ of 88 to $92 \%$, regardless of whether hypercapnia was present at baseline or the patient had an acute respiratory disorder. These observations support guidelines that recommend titrated oxygen rather than unrestricted high concentration therapy in patients with conditions associated with chronic respiratory failure, such as morbid obesity ${ }^{10}$ and OHS. ${ }^{11}$ Further, these results build on earlier observations that oxygen increases $\mathrm{PtCO}_{2}$ in patients with $\mathrm{OHS}^{15,16}$ by reporting a similar physiological response in patients with simple morbid obesity, without a diagnosis of OHS. About two-thirds of the participants with rises in $\mathrm{PtCO}_{2}$ of at least 4 $\mathrm{mmHg}$ were not hypercapnic at baseline, indicating that hypercapnia is not a prerequisite for oxygen-induced elevations in $\mathrm{PaCO}_{2}$ in patients with obesity, as is also the case for patients with respiratory conditions. . $^{2,13,14,108,109}$

For the high concentration oxygen intervention, we administered oxygen at $8 \mathrm{~L} / \mathrm{min}$ through a Hudson mask. It is reasonable to assume that such a regimen may be employed in an acute medical setting in breathless, morbidly obese patients, regardless of the presence of hypoxaemia; it has been reported that high concentration oxygen is commonly administered to COPD patients without evidence of hypoxaemia..$^{35,39,179}$

The mean increase in $\mathrm{PtCO}_{2}$ of $3.2 \mathrm{mmHg}$ after $8 \mathrm{~L} / \mathrm{min}$ oxygen through a Hudson mask (equivalent to a $\mathrm{FiO}_{2}$ of at least 0.5$)^{180}$ we measured was similar to the $3.8 \mathrm{mmHg}$ increase in $\mathrm{PavCO}_{2}$ in the study by Hollier and colleagues, in which a $\mathrm{FiO}_{2}$ of 0.50 was administered to stable OHS patients. ${ }^{16}$ The authors reported that this level of $\mathrm{PavCO}_{2}$ increase was associated with a fall in blood $\mathrm{pH}$ from 7.373 to $7.346,{ }^{16}$ resulting in respiratory acidosis likely to be clinically significant; $\mathrm{pH}$ below 7.35 is associated with increased mortality and a greater need for intubation in patients with COPD. ${ }^{40,181}$ Importantly, the severity of an exacerbation is indicated not by the absolute level of hypercapnia, but rather by the increase above the chronic stable $\mathrm{PaCO}_{2}$ value, as reflected by increased acidosis. ${ }^{40}$ In Hollier et al's study, a $\mathrm{FiO}_{2}$ of 0.28 increased $\mathrm{PavCO}_{2}$ by $2.3 \mathrm{mmHg}$ and a $\mathrm{FiO}_{2}$ of 0.50 increased $\mathrm{PavCO}_{2}$ by $3.8 \mathrm{mmHg}$ in patients with OHS respectively, ${ }^{16}$ whereas in the earlier study delivering a 
$\mathrm{FiO}_{2}$ of 1.0 in OHS patients $\mathrm{PtCO}_{2}$ increased by $5.0 \mathrm{mmHg} .{ }^{15}$ Recognising that both $\mathrm{PtCO}_{2}{ }^{175-177}$ and $\mathrm{PavCO}_{2}{ }^{182}$ are validated indirect measures of $\mathrm{PaCO}_{2}$, this dose response relationship between $\mathrm{PaCO}_{2}$ and $\mathrm{FiO}_{2}$ supports the use of titrated oxygen, with reduced exposure to higher oxygen concentrations reducing the risk of oxygen-induced hypercapnia.

The physiological response to high concentration oxygen was variable, with an increase in $\mathrm{PtCO}_{2}$ of at least $8 \mathrm{mmHg}$ from baseline in three of 22 participants during 60 minutes of oxygen therapy. Such variability has been noted previously, ${ }^{15,16,87,117,118}$ suggesting it might be clinically useful to be able to identify adverse responders. In keeping with the relationships demonstrated in Chapter 1 , the rise in $\mathrm{PtCO}_{2}$ with high concentration oxygen therapy was greater in those with hypercapnia at baseline. This indicates that those with chronic respiratory failure were at greater risk of life-threatening hypercapnia during oxygen therapy, as reported earlier. ${ }^{16}$ This is relevant, as about one-third of patients with morbid obesity also have chronic respiratory failure. ${ }^{15,116}$

A diagnosis of OHS or hypercapnia at baseline were not prerequisites for oxygen-induced elevations in $\mathrm{PtCO}_{2}$ in this study. Obesity can have a range of effects on respiratory physiology, which may occur in patients with or without OHS. These include atelectasis and abnormalities in V/Q mismatch, ${ }^{183}$ which could contribute to the proposed mechanisms behind oxygen-induced elevations in carbon dioxide outlined in Chapter 1.

The characteristics of the participants are relevant to the external validity of our findings. Our recruitment method resulted in participants with a range of medical conditions who were morbidly obese, with a mean BMI of $50.4 \mathrm{~kg} / \mathrm{m}^{2}$. None had been diagnosed with OHS, and only six had baseline $\mathrm{PtCO}_{2}$ values greater than $45 \mathrm{mmHg}$, indicating that most participants did not have chronic respiratory failure at baseline. This proportion is similar to the one in three patients with morbid obesity in whom awake hypercapnia was observed during screening for the previous study, ${ }^{15}$ and with estimates of the prevalence of OHS among hospitalised obese inpatients. ${ }^{116}$ The co-morbidities reflect the range of acute medical conditions of patients admitted to internal medicine departments, apart from COPD. Seven participants had an admission diagnosis of acute exacerbation of asthma, and two had lower respiratory tract infections. To ensure generalisability to medical inpatients with obesity, patients with these conditions were not excluded, despite previous work 
demonstrating $\mathrm{PaCO}_{2}$ may rise in patients with these acute respiratory conditions during oxygen therapy. ${ }^{13,14,108,109}$ On further analysis, whether participants were admitted with a respiratory diagnosis had no effect on the magnitude of the $\mathrm{PtCO}_{2}$ change in our study.

$\mathrm{PtCO}_{2}$ was used as a painless, non-invasive and validated measure for continuously monitoring changes in $\mathrm{PaCO}_{2}$ in response to oxygen, ${ }^{13-15,176,177}$ and which can be used to accurately estimate changes in $\mathrm{PcCO}_{2}$ from baseline ${ }^{175}$ (for further detail see Appendix 1). Neither arterial nor capillary blood gas sampling was attempted, as these invasive methods do not allow continuous assessment of partial pressure of carbon dioxide $\left(\mathrm{PCO}_{2}\right)$. The $\mathrm{PtCO}_{2}$ monitor employed (TOSCA or SenTec) had no effect on the observed differences between the two treatments. A cross over design was employed, with adequate washout between interventions. ${ }^{64}$ The nature of the interventions did not allow blinding of investigators or participants. The study was not designed to assess why high concentration oxygen increased $\mathrm{PtCO}_{2}$ in people with morbid obesity; reduced minute ventilation ${ }^{15}$ reduced tidal volume, ${ }^{16}$ and absorption atelectasis ${ }^{87}$ have been proposed as possible mechanisms, as outlined in Chapter 1.

In conclusion, it was found that high concentration oxygen therapy increases $\mathrm{PtCO}_{2}$ in patients with morbid obesity with or without hypercapnia at baseline. This finding extends previous observations that this response is seen in a range of respiratory conditions, including COPD, ${ }^{2,3,12}$ asthma, ${ }^{13,108,109}$ pneumonia, ${ }^{14}$ and OHS. ${ }^{15,16}$ The findings support guideline recommendations that oxygen be titrated to a target $\mathrm{SpO}_{2}$ of 88 to $92 \%$ in patients with conditions associated with hypercapnic respiratory failure, such as morbid obesity. ${ }^{10,11}$ 
Chapter 5: Randomised cross over trials on the effect of $50 \%$ oxygen on $\mathrm{PtCO}_{2}$ in patients with stable

COPD, bronchiectasis, and neuromuscular disease or kyphoscoliosis 


\subsection{Overview}

\section{Randomised cross over trials on the effect of $50 \%$}

oxygen on $\mathrm{PtCO}_{2}$ in patients with stable COPD, bronchiectasis, and neuromuscular disease or kyphoscoliosis

\section{AIM}

To investigate whether increases in arterial partial pressure of carbon dioxide $\left(\mathrm{PaCO}_{2}\right)$ occur in response to oxygen therapy in stable patients with neuromuscular disease or kyphoscoliosis, and bronchiectasis.

\section{METHODS}

Three randomised cross over trials recruited stable patients with neuromuscular disease or kyphoscoliosis $(\mathrm{N}=20)$, bronchiectasis $(\mathrm{N}=24)$, and COPD $(\mathrm{N}=24)$. Participants received 50\% oxygen and $21 \%$ oxygen (air), each for 30 minutes, in randomly assigned order. The primary outcome was transcutaneous partial pressure of carbon dioxide $\left(\mathrm{PtCO}_{2}\right)$ at 30 minutes.

\section{KEY RESULTS}

The intervention baseline adjusted $\mathrm{PtCO}_{2}$ difference $(95 \% \mathrm{CI})$ between oxygen and air after 30 minutes was $0.2 \mathrm{mmHg}(-0.4$ to 0.9$), \mathrm{P}=0.40$; $0.5 \mathrm{mmHg}(-0.2$ to 1.2$), \mathrm{P}=0.18$; and $1.3 \mathrm{mmHg}$ (0.7 to 1.8$), \mathrm{P}<0.001$, in the neuromuscular disease/kyphoscoliosis, bronchiectasis and COPD participants respectively.

\section{CO-INVESTIGATORS AND}

\section{PUBLICATION}

Janine Pilcher, Darmiga Thayabaran, Stefan Ebmeier, Mathew Williams, Geraldine Back, Hamish Collie, Michael Richards, Susan Bibby, Ruth Semprini, Mark Weatherall and Richard Beasley. Journal submission for publication in progress at the time of thesis submission. See Appendix for further investigator details.

\section{CONCLUSIONS}

The small increase in $\mathrm{PtCO}_{2}$ in the stable COPD patients with high concentration oxygen therapy contrasts with the marked increases in $\mathrm{PaCO}_{2}$ seen in the setting of acute exacerbations of COPD. This suggests that the model of studying the effects of high concentration oxygen therapy in patients with stable respiratory disease is not generalisable to the use of oxygen therapy in the acute clinical setting. Appropriate studies of high concentration compared to titrated oxygen in acute clinical settings are needed to determine if there is a risk of oxygen-induced hypercapnia in patients with neuromuscular disease, kyphoscoliosis or bronchiectasis. 


\subsection{Rationale}

As outlined in Chapter 1, oxygen-induced hypercapnia has been demonstrated in a range of respiratory conditions with abnormal gas exchange and/or reduced ventilation with respiratory failure. ${ }^{13-16,184}$ Neuromuscular disease and kyphoscoliosis can lead to hypoventilation and chronic respiratory failure, while airflow obstruction and ventilationperfusion mismatch are both features of bronchiectasis. As acute respiratory illnesses complicate both of these conditions and can result in hypoxia and the need for oxygen therapy, it is important to establish whether these patients are at risk of oxygen-induced hypercapnia.

Previous studies investigating the effects of oxygen on $\mathrm{PaCO}_{2}$ in these conditions are limited and detailed in Chapter 1. Briefly, two small sleep studies ${ }^{123,124}$ and one exercise study ${ }^{125}$ have been performed in patients with cystic fibrosis, which demonstrated average $\mathrm{PtCO}_{2}$ increases between $4^{125}$ and $7.5 \mathrm{mmHg}^{124}$ during oxygen therapy compared to room air. In patients with neuromuscular disease data are limited to retrospective case examples ${ }^{129}$ and a case series which found low-flow oxygen $(0.5-2 \mathrm{~L} / \mathrm{min})$ elevated $\mathrm{PaCO}_{2}$ by an average 28 $\mathrm{mmHg},{ }^{128}$ however the measurements were made up to six days after oxygen therapy.

The purpose of the randomised cross over trials in this Chapter was to investigate the effects of $50 \%$ oxygen compared to $21 \%$ oxygen in patients with stable neuromuscular disease or kyphoscoliosis and patients with stable bronchiectasis. To assess the applicability of the results to the clinical setting, stable COPD patients were also studied, matched by severity of airflow obstruction to the bronchiectasis patients. To assess the accuracy of the use of transcutaneous monitoring in this setting arterialised capillary blood gases and $\mathrm{PtCO}_{2}$ readings were taken simultaneously at the end of the COPD study. The main hypothesis was that oxygen therapy would increase $\mathrm{PtCO}_{2}$ in all three trials. 


\subsection{Methods}

This series of three double-blind cross over trials randomised patients to the order they received 50\% oxygen ("oxygen" intervention) and medical grade air containing $21 \%$ oxygen ("air" intervention). The trials recruited 20 patients with neuromuscular disease or kyphoscoliosis (neuromuscular disease/kyphoscoliosis study), 24 patients with bronchiectasis (bronchiectasis study) and 24 patients with COPD (COPD study). Inclusion and exclusion criteria are presented in Table 5.1, including the criteria by which bronchiectasis and COPD participants were matched by airflow obstruction severity.

Potentially eligible patients were recruited through Hutt Valley Hospital (neuromuscular disease/kyphoscoliosis study only), WRH and the Medical Research Institute of New Zealand (MRINZ) patient lists, as well as newsletters (neuromuscular disease/kyphoscoliosis study only) and posters (COPD study only). 


\begin{tabular}{|c|c|c|c|}
\hline Study & $\begin{array}{c}\text { Neuromuscular disease/ } \\
\text { kyphoscoliosis }\end{array}$ & Bronchiectasis & COPD \\
\hline \multicolumn{4}{|c|}{ Inclusion criteria } \\
\hline & $\begin{array}{l}\text { Neuromuscular disease with } \\
\geq 10 \% \text { drop VC from sitting to } \\
\text { lying or SNIP <95\% limit* } \\
\text { and/or } \\
\text { Kyphoscoliosis with an FVC } \\
<65 \% \text { predicted }^{185 * *}\end{array}$ & $\begin{array}{l}\text { Bronchiectasis as } \\
\text { diagnosed by a doctor and } \\
\text { confirmed with CT scan } \\
\text { and/or } \\
\text { Cystic fibrosis as } \\
\text { diagnosed by a doctor }\end{array}$ & $\begin{array}{l}\text { COPD, as diagnosed by a } \\
\text { doctor }\end{array}$ \\
\hline \multicolumn{4}{|c|}{ Exclusion $_{\text {criteria }} * * *$} \\
\hline $\begin{array}{l}\text { Study } \\
\text { Baseline } \\
\mathrm{PtCO}_{2}\end{array}$ & $\geq 60 \mathrm{mmHg}$ & $\geq 60 \mathrm{mmHg}$ & $\geq 60 \mathrm{mmHg}$ \\
\hline Age & $<14$ years old & $<14$ years old & $<16$ years old \\
\hline $\begin{array}{l}\text { Co- } \\
\text { morbidities }\end{array}$ & $\begin{array}{l}\text { COPD } \\
\text { Morbid obesity^ }\end{array}$ & $\begin{array}{l}\text { COPD } \\
\text { Morbid obesity^ }\end{array}$ & $\begin{array}{l}\text { Bronchiectasis } \\
\text { Morbid obesity^ }\end{array}$ \\
\hline Spirometry & $\begin{array}{l}\mathrm{FEV}_{1}: \mathrm{FVC} \text { ratio } \leq 0.7, \text { if } \\
\text { participant is able to complete } \\
\text { forced spirometry }\end{array}$ & & $\begin{array}{l}\mathrm{FEV}_{1}: \mathrm{FVC} \text { ratio }>0.7 \\
\text { Inability to match } \mathrm{FEV}_{1} \\
\text { percentage predicted with } \\
\text { a Bronchiectasis study } \\
\text { participant }^{\wedge \wedge}\end{array}$ \\
\hline Other & & $\begin{array}{l}\text { Infection with } \\
\text { Burkholderia } \\
>10 \text { pack year smoking } \\
\text { history }\end{array}$ & \\
\hline
\end{tabular}

\section{Table 5.1 Inclusion/Exclusion criteria}

BMI: Body mass index, COPD: Chronic Obstructive Pulmonary Disease, CT: computerised tomography, $\mathrm{FEV}_{1}$ : Forced expiratory volume in 1 second, FVC: Forced vital capacity, $\mathrm{PtCO}_{2}$ : Transcutaneous partial pressure of carbon dioxide, SNIP: Sniff nasal inspiratory pressure, VC: Vital capacity (slow).

*This is the limit under which $95 \%$ of healthy subjects are as based on work by Uldry \& Fitting. ${ }^{186} * *$ Note that this may be calculated using arm span as per European Respiratory Society guidelines. ${ }^{187} * * *$ All studies also excluded participants for any other condition which, at the investigator's discretion, was believed may present a safety risk or impact the feasibility of the study or the study results. ${ }^{\wedge} \mathrm{BMI} \geq 40 \mathrm{~kg} / \mathrm{m}^{2}$. ${ }^{\wedge}$ To be a match, the COPD participant must have an $\mathrm{FEV}_{1}$ percentage predicted within an absolute value of $5 \%$ of the $\mathrm{FEV}_{1}$ percentage predicted for the bronchiectasis study participant (values inclusive). An exception to this was for the three bronchiectasis participants that had $\mathrm{FEV}_{1}$ percentage predicted values of $109 \%$ or higher, who were matched with COPD participants with an $\mathrm{FEV}_{1}$ percent predicted of $80 \%$ or over (i.e. participants in the mildest COPD severity category based on $\left.\mathrm{FEV}_{1}\right) .{ }^{188}$ The exception was made as it was not feasible to recruit matching COPD participants with $\mathrm{FEV}_{1}$ values within $5 \%$ and the required obstruction $\left(\mathrm{FEV}_{1} / \mathrm{FVC}\right.$ $\leq 0.7$ ), as this would require them to have an FVC well in excess of their predicted value. 
Participants attended a single study visit at the MRINZ. Spirometry was performed to ATS/ERS criteria $^{178}$ using a handheld spirometer (Masterscreen non-heated pneumotach, CareFusion Germany 234 GmbH, Leibnizstrasse 7, 97204 Hoechberg, Germany). Sniff nasal inspiratory pressure (SNIP) testing (neuromuscular disease participants only) was performed on a handheld device (MicroRPM CareFusion Germany 234 GmbH, Leibnizstrasse 7, 97204 Hoechberg, Germany). After confirming eligibility, the SenTec was attached with a V-Sign Sensor, with single use clips. The arterialisation temperature was set at 42 degrees. Maintenance and stabilisation are presented in Textbox 5.1. An overview of study procedures and measurements is presented in Figure 5.1. 


\section{SenTec maintenance and calibration}

Prior to each use the SenTec probe was checked for damage and underwent system calibration. Maintenance was as per SenTec manufacturer's instructions (General (HB-005771-h) and Technical (HB-005752-g) manuals). Probe membranes were replaced every 28 days. An exception to this was a period where the SenTec had both quarterly maintenance and membrane replacement overdue due to investigator error. Three participants were recruited during this time. It resulted in withdrawal of one Chronic Obstructive Pulmonary Disease (COPD) study participant during their study visit when it was realised data values were inaccurate, and removal of SenTec data from the dataset (see Textbox 5.2). Prior to this one participant in the COPD study and one in the neuromuscular disease/kyphoscoliosis study had data recorded when the procedures were overdue. Data were retained for analysis based on minor probe drift on review of subsequent drift corrected data, which suggested ongoing of probe accuracy.

\section{SenTec Stabilisation}

To ensure that the probe had stabilised prior to any data collection there was a stabilisation period following placement of the probe on the participant's ear. At 28 minutes and 30 minutes the transcutaneous partial pressure of carbon dioxide $\left(\mathrm{PtCO}_{2}\right)$ was recorded. If the values were within $1 \mathrm{mmHg}$ of each other the study commenced. If not, stabilisation was continued until values were within $1 \mathrm{mmHg}$ of each other over a 2 minute period. The time period for stabilisation was based on previous work assessing time to probe stabilisation. ${ }^{189,190}$

\section{Mask stabilisation}

The mask was fitted while the participant was seated comfortably. Small, medium and large masks were available and fitted as appropriate. Once the mask was fitted with no evidence of leaks around the seal the participant breathed room air from the mask. $\mathrm{PtCO}_{2}$ was recorded at 4 minutes and 5 minutes after fitting. If the $\mathrm{PtCO}_{2}$ values were within $1 \mathrm{mmHg}$ of each other, the $\mathrm{T}=0$ measures were taken and the Intervention commenced. If values were not within $1 \mathrm{mmHg}$ of each other the stabilisation period was continued until two measures taken 1 minute apart were within $1 \mathrm{mmHg}$. 


\begin{tabular}{|c|c|c|c|c|c|c|c|c|}
\hline & & \multirow{3}{*}{$\begin{array}{c}\text { Study } \\
\text { baseline }\end{array}$} & \multicolumn{3}{|c|}{ Intervention 1} & \multicolumn{3}{|c|}{ Intervention 2} \\
\hline & & & & $\begin{array}{l}\text { Administration of } \\
50 \% \text { oxygen or } \\
\text { room air }\end{array}$ & $\begin{array}{l}\text { Washout } * / \\
\text { rest period with } \\
\text { observation }\end{array}$ & & $\begin{array}{l}\text { Administration of } \\
50 \% \text { oxygen or } \\
\text { room air }\end{array}$ & $\begin{array}{l}\text { Rest period with } \\
\text { observation }\end{array}$ \\
\hline \multicolumn{2}{|l|}{ Time } & & & & 30-60 minutes & & 0-30 minutes & 30-60 minutes \\
\hline \multicolumn{2}{|l|}{ Application of mask } & & \multicolumn{2}{|r|}{$X$} & & \multicolumn{2}{|r|}{$\mathrm{X}$} & \\
\hline $\begin{array}{l}\text { Recording: } \\
-\mathrm{PtCO}_{2}\end{array}$ & $\begin{array}{l}\text { Method: } \\
\text { SenTec }\end{array}$ & $X$ & $X$ & $\begin{array}{c}\mathrm{X} \\
\text { (every } 10 \text { minutes) }\end{array}$ & $\begin{array}{c}\mathrm{X} \\
\text { (every } \\
10 \text { minutes) }\end{array}$ & $X$ & $\begin{array}{c}\mathrm{X} \\
\text { (every } 10 \text { minutes) }\end{array}$ & $\begin{array}{c}\mathrm{X} \\
\text { (every } \\
10 \text { minutes) }\end{array}$ \\
\hline $\begin{array}{l}\text { Recording: } \\
\text { - Heart rate } \\
\text { - Respiratory rate }\end{array}$ & $\begin{array}{l}\text { Method: } \\
\text { SenTec } \\
\text { Investigator observation }\end{array}$ & $X$ & & $X$ & & & $X$ & \\
\hline $\begin{array}{l}\text { - Respiratory rate } \\
\text { - ETCO } \\
\text { - Minute ventilation } \\
\text {-VD/VT }\end{array}$ & $\begin{array}{l}\mathrm{CO}_{2} \mathrm{SMO} \\
\mathrm{CO}_{2} \mathrm{SMO} \\
\mathrm{CO}_{2} \mathrm{SMO} \\
\mathrm{CO}_{2} \mathrm{SMO}^{* *} \\
\end{array}$ & & $\mathrm{X}$ & (every 10 minutes) & & $X$ & (every 10 minutes) & \\
\hline $\begin{array}{l}\text { Calculation: } \\
\text { - Tidal Volume } \\
\text { - Dead space } \\
\text { - Alveolar volume } \\
\text { - Alveolar minute } \\
\text { ventilation }\end{array}$ & $\begin{array}{l}\text { Method:*** } \\
\text { [minute ventilation] / [respiratory rate] } \\
\text { [tidal volume] X [VD/VT**] } \\
\text { [tidal volume] - [dead space volume] } \\
\text { [alveolar volume] X [respiratory rate] }\end{array}$ & & $\mathrm{X}$ & $\begin{array}{c}\mathrm{X} \\
\text { (every } 10 \text { minutes) }\end{array}$ & & $\mathrm{X}$ & $\begin{array}{c}\mathrm{X} \\
\text { (every } 10 \text { minutes) }\end{array}$ & \\
\hline $\begin{array}{l}\text { Calculation: } \\
\text { - Drift corrected } \\
\mathrm{PtCO}_{2}\end{array}$ & $\begin{array}{l}\text { Method: } \\
\text { SenTec data upload to V-Stats (V3.2) software }\end{array}$ & & $\mathrm{X}$ & $\begin{array}{c}\mathrm{X} \\
\text { (at } 30 \text { minutes) }\end{array}$ & & $\mathrm{X}$ & $\begin{array}{c}\mathrm{X} \\
\text { (at } 30 \text { minutes) }\end{array}$ & \\
\hline $\begin{array}{l}\text { Recording: } \\
\text { - Oxygen } \\
\text { saturation^ }\end{array}$ & $\begin{array}{l}\text { Method: } \\
\text { SenTec V-Stats (V3.2) software }\end{array}$ & & & & $\mathrm{X}$ & & & \\
\hline
\end{tabular}

Figure 5.1 Overview of study procedures and measurements

$\mathrm{ETCO}_{2}$ : End tidal carbon dioxide. $\mathrm{PtCO}_{2}$ : Transcutaneous partial pressure of carbon dioxide. VD/VT: Dead space to tidal volume ratio.

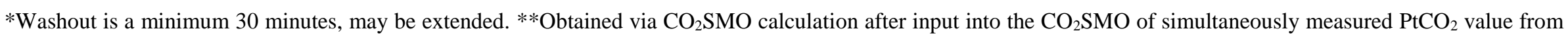
the SenTec. ***Based on recordings from the row above. ${ }^{\wedge}$ Continuous recording made for visual inspection for rebound hypoxia. During the study oxygen saturation values were covered on SenTec display to ensure investigator blinding. 
The study was conducted while the participants were at rest and sitting at approximately 90 degrees. Study baseline $\mathrm{PtCO}_{2}$, heart rate, and $\mathrm{SpO}_{2}$ were recorded via a SenTec transcutaneous monitor (SenTec AG, Switzerland), and respiratory rate by investigator observation.

Participants were then fitted with a full-face positive airway pressure mask (Respironics), attached to a Douglas Bag (Hans Rudolph) via $\mathrm{CO}_{2} \mathrm{SMO}$ adapter (Novametrix Medical Systems), one-way T valve, respiratory filter (Microgard II, Carefusion), tubing and three-way tap, all connected in series (Figure 5.2). Participants breathed room air for at least five minutes to adjust to breathing through the equipment (Textbox 5.1), and then breathed the intervention gas for 30 minutes. After each intervention, the mask was removed and there was a 30 minute observation period breathing room air. 


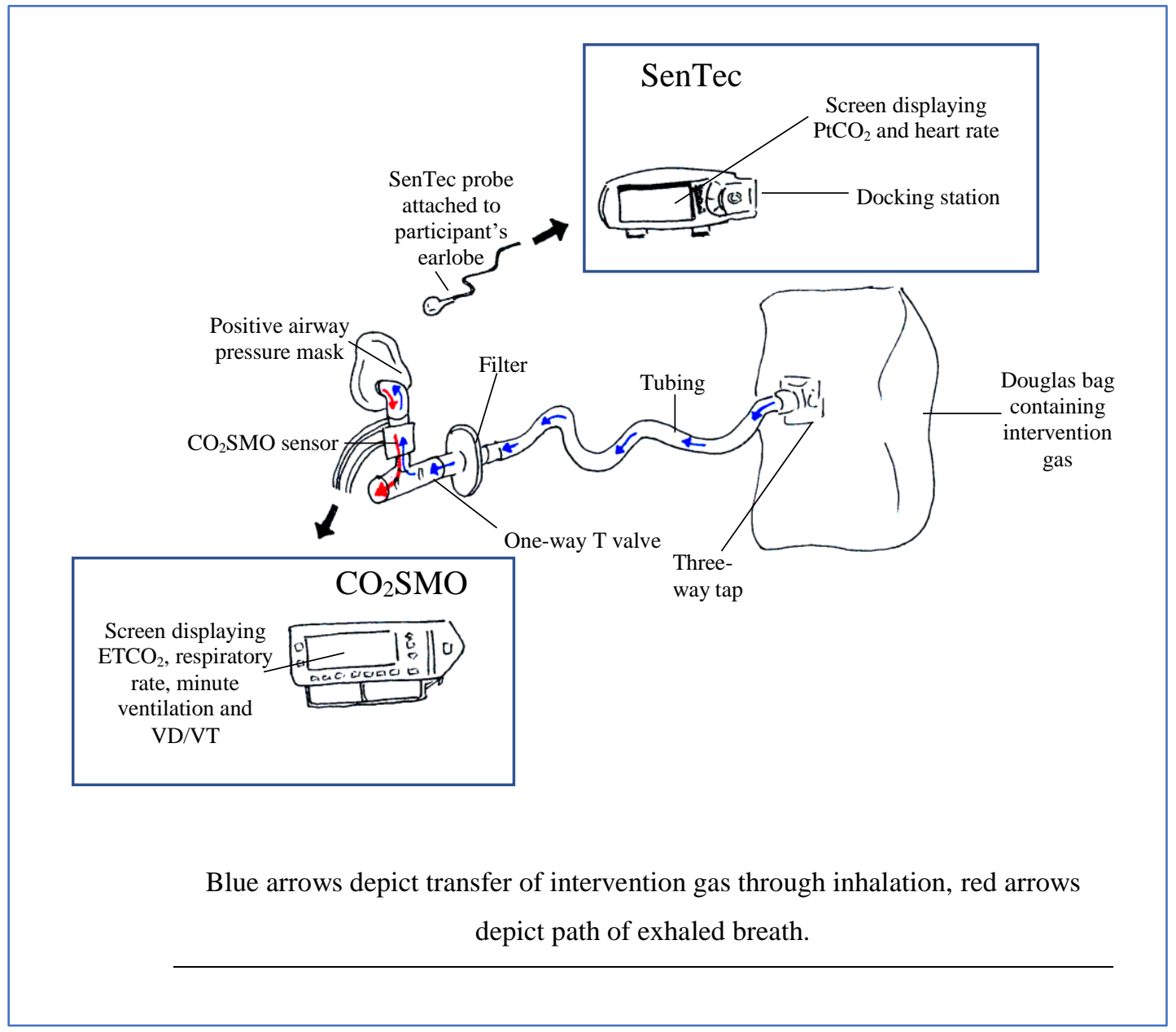

Figure 5.2 Equipment diagram

$\mathrm{ETCO}_{2}$ : End tidal carbon dioxide, $\mathrm{PtCO}_{2}$ : Transcutaneous partial pressure of carbon dioxide, VD/VT: Dead space to tidal volume. 
Heart rate and $\mathrm{PtCO}_{2}$ were measured via SenTec. Respiratory rate, $\mathrm{ETCO}_{2}$, minute ventilation and dead space to tidal volume (VD/VT) were measured via $\mathrm{CO}_{2} \mathrm{SMO}$ (Model 8100 ), from which the tidal volume, volume of dead space, alveolar volume and alveolar minute ventilation were calculated. Measurements were taken at $\mathrm{T}=0$ (following mask stabilisation and immediately prior to intervention), and at 10 minute intervals during the intervention and observation periods. $\mathrm{SpO}_{2}$ on the SenTec display was covered during the intervention and washout periods to maintain investigator blinding. $\mathrm{PtCO}_{2}$ was monitored continuously; the intervention was stopped if values rose by $\geq 10 \mathrm{mmHg}$ from $\mathrm{T}=0$.

At the end of the COPD study arterialised capillary blood gas samples were taken from the ear or finger and $\mathrm{PtCO}_{2}$ was recorded at the time blood was first visualised. SenTec data were uploaded to V-Stats (V3.2) software to obtain drift corrected $\mathrm{PtCO}_{2}$ and oxygen saturation.

The study statistician, who was not involved in study recruitment or visits, created computerised 1:1 randomisation sequences for each study. Randomisation codes were placed in sealed opaque envelopes and opened by the unblinded investigator following $\mathrm{T}=0$ measurements. The blinded investigator recorded all measurements from this point onwards.

The study outcomes are summarised in Figure 5.1. The primary outcome was $\mathrm{PtCO}_{2}$ after 30 minutes. The primary analysis was a mixed linear model with fixed effects for the $\mathrm{T}=0$ measurements, intervention, and randomisation order, and a random effect for participants to take into account the cross over design. For all measures an interaction term was tested first to see if there was any difference between the interventions that depended on the time of measurement. As secondary analyses for all outcomes, the differences between interventions at each measurement time were analysed by similarly structured models, with addition of the fixed effect of the time of measurement and a random effect for each participant using a spatial exponential in time repeated measures variance-covariance matrix to account for the cross over design. The results of this model for $\mathrm{PtCO}_{2}$ were compared between the COPD and bronchiectasis study participants (as fixed effects), and were also adjusted for $\mathrm{FEV}_{1}$ percentage predicted. Finally, the difference in proportions of participants with a change in $\mathrm{PtCO}_{2}$ of $\geq 4 \mathrm{mmHg}$ and $\geq 10 \mathrm{mmHg}$ from $\mathrm{T}=0$ were also 
estimated, as physiologically and clinically significant differences, respectively. ${ }^{13,14,73}$ All estimates of differences are shown as oxygen minus room air. The uploaded oxygen saturation data were visually reviewed for evidence of rebound hypoxia.

SAS version 9.4 was used.

The intended sample size for each cross over study was 24 based on $80 \%$ power and a type I error rate of 5\%, to detect a difference of $2.4 \mathrm{mmHg}$. This is half the difference found in a study of participants with OHS which reported a mean (SD) paired difference of 5(4) mmHg. ${ }^{15}$

Each trial was prospectively registered on ANZCTR and had Health and Disability Ethics Committee approval (Table 5.2). Māori consultation and approval took place through the Capital and Coast District Health Board Regional Advisory Group Māori (RAG-M 2012/166 (neuromuscular disease/kyphoscoliosis study), RAG-M 2012/166b (bronchiectasis study) and RAG-M 203/297 (COPD study). Additionally the Hutt Valley District Health Board Māori Health Unit was consulted prior to recruitment at Hutt Valley Hospital (neuromuscular disease/kyphoscoliosis study). 


\begin{tabular}{|l|l|l|}
\hline Study & Registration Number & Ethical Approval Details \\
\hline $\begin{array}{l}\text { Neuromuscular disease/ } \\
\text { kyphoscoliosis }\end{array}$ & ACTRN12615000970549 & $\begin{array}{l}\text { Submission number: } \\
\text { CEN/11/11/065 } \\
\text { Committee: Central Health } \\
\text { and Disability Ethics } \\
\text { Committee New Zealand }\end{array}$ \\
\hline Bronchiectasis & ACTRN12615000971538 & $\begin{array}{l}\text { Submission number: } \\
\text { CEN/11/12/075 } \\
\text { Committee: Central Health } \\
\text { and Disability Ethics } \\
\text { Committee New Zealand }\end{array}$ \\
\hline COPD & ACTRN12615001056583 & $\begin{array}{l}\text { Submission number: } \\
13 / \text { STH/200 } \\
\text { Committee: Southern Health } \\
\text { and Disability Ethics } \\
\text { Committee New Zealand }\end{array}$ \\
\hline & & \\
\hline
\end{tabular}

Table 5.2 Ethical approval and trial registration details

COPD: Chronic Obstructive Pulmonary Disease. 


\subsection{Results}

Participants were recruited between October 2015 and May 2017 (Figure 5.3). The neuromuscular disease/kyphoscoliosis study recruitment was stopped at 20 participants due to difficulty in recruitment. Participant characteristics are summarised in Tables 5.3 to 5.5. The COPD group had higher smoking rates than the other two groups, and had similar severity of airflow obstruction as the bronchiectasis group. One participant in the COPD study had a $\mathrm{SpO}_{2}$ of $87 \%$ at study baseline, all other participants had a $\mathrm{SpO}_{2}$ of $\geq 91 \%$. All study baseline $\mathrm{PtCO}_{2}$ values were $<45 \mathrm{mmHg}$, with the exception of two participants in the neuromuscular disease/kyphoscoliosis group. Textbox 5.2 summarises the data that were not included in the analysis. 

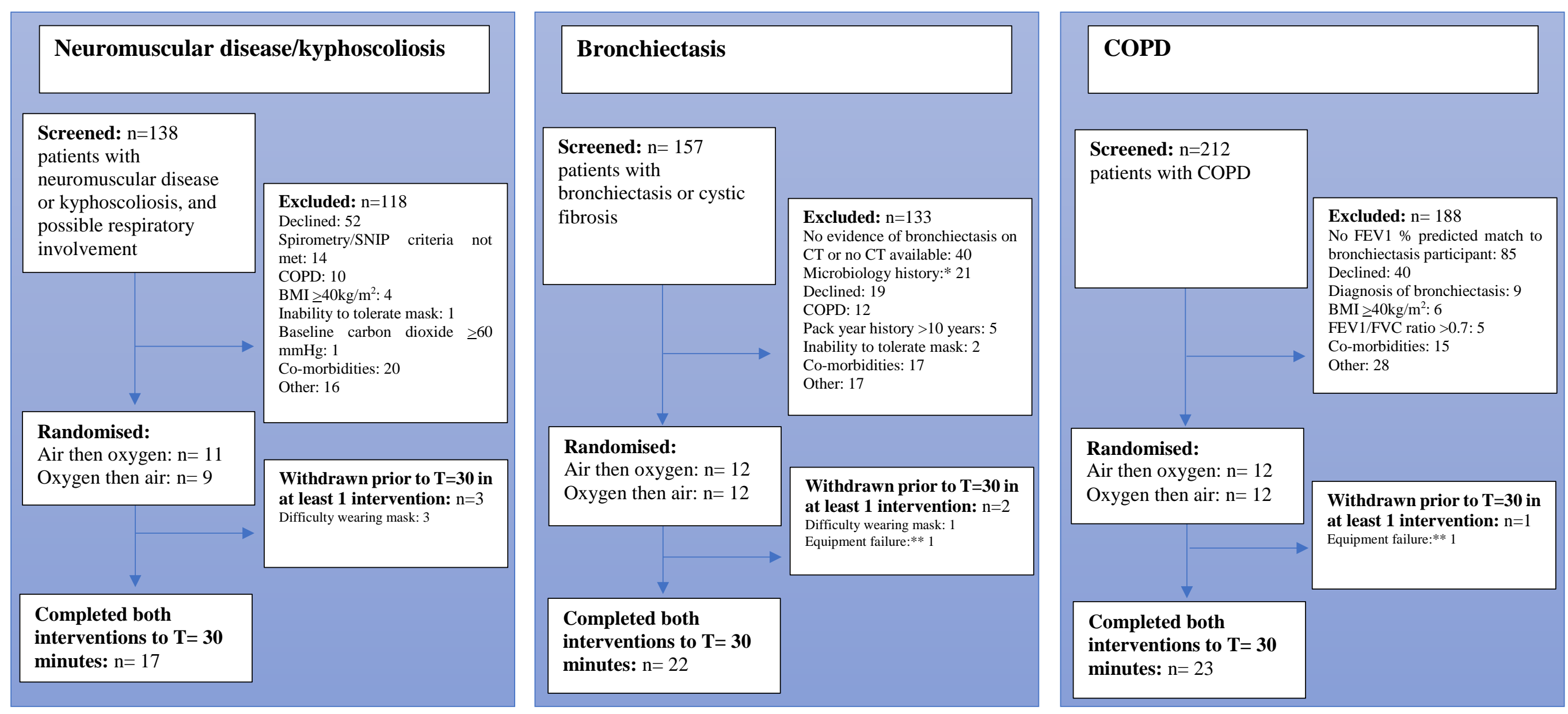

\section{Figure 5.3 Flow of participants through studies}

BMI: Body mass index, COPD: Chronic obstructive pulmonary disease, CT: Computerised tomography, FEV 1 : Forced expiratory volume in 1 second, FVC: Forced vital capacity, SNIP: Sniff nasal inspiratory pressure. *Burkholderia or other result at the investigator's discretion. **T valve tubing malfunction for 1 participant in the bronchiectasis study and SenTec maintenance error for 1 participant in the COPD study. See Textbox 5.2 for detail on participants and data included/excluded. 


\begin{tabular}{|c|c|c|c|}
\hline & 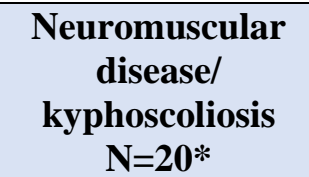 & $\begin{array}{l}\text { Bronchiectasis } \\
\qquad \mathrm{N}=\mathbf{2 4}^{*}\end{array}$ & $\begin{array}{l}\text { COPD } \\
\text { N=24* }\end{array}$ \\
\hline \multicolumn{4}{|l|}{$\mathbf{N}(\%)$} \\
\hline Diagnosis & $\begin{array}{c}\text { Neuromuscular } \\
\text { disease: } 19 \\
\text { Kyphoscoliosis: } 2^{* *}\end{array}$ & $\begin{array}{l}\text { Bronchiectasis: } 24 \\
\text { Cystic Fibrosis: } 0\end{array}$ & COPD: 24 \\
\hline Male & $8(40 \%)$ & $7(29 \%)$ & $12(50 \%)$ \\
\hline Home NIV & $4(20 \%)$ & $2(8 \%)$ & $1(4 \%)$ \\
\hline Home oxygen & $1(5 \%)$ & $0(0 \%)$ & $0(0 \%)$ \\
\hline $\begin{array}{l}\text { Smoking status } \\
\text { - Current } \\
\text { - Ex } \\
\text { - Never }\end{array}$ & $\begin{array}{c}\text { Total } \mathrm{N}=18 * * * \\
1(6 \%) \\
7(39 \%) \\
10(56 \%)\end{array}$ & $\begin{array}{c}\text { Total } \mathrm{N}=23 * * * \\
0(0 \%) \\
3(13 \%) \\
20(87 \%)\end{array}$ & $\begin{array}{c}\text { Total } \mathrm{N}=18 * * * \\
3(17 \%) \\
15(83 \%) \\
0(0 \%)\end{array}$ \\
\hline $\begin{array}{l}\text { Other respiratory diagnoses } \\
\text { - Asthma } \\
\text { - Sleep apnoea }\end{array}$ & $\begin{array}{l}2(10 \%) \\
3(15 \%)\end{array}$ & $\begin{array}{l}15(63 \%) \\
2(8.3 \%) \\
\end{array}$ & $\begin{array}{l}8(33 \%) \\
1(4 \%) \\
\end{array}$ \\
\hline \multicolumn{4}{|l|}{ Mean (SD)* } \\
\hline Age (years) & $52.2(14.9)$ & $63.0(12.0)$ & $69.4(7.3)$ \\
\hline BMI $\left(\mathrm{kg} / \mathrm{m}^{2}\right)$ & $25.3(7.2)$ & $27.1(4.7)$ & $27.9(4.8)$ \\
\hline Smoking pack years & $4.2(9.1)$ & $0.6(2.2)$ & $35.5(22.9)$ \\
\hline $\mathrm{FEV}_{1}$ percentage predicted $(\%)$ & $57.6(20.5)$ & $69.9(22.4)$ & $65.7(17.3)$ \\
\hline FVC percentage predicted $(\%)$ & $57.7(20.5)$ & $87.4(21.5)$ & $97.5(17.9)$ \\
\hline $\mathrm{FEV}_{1} / \mathrm{FVC}$ ratio $(\%)$ & $83.0(7.3)$ & $64.6(12.2)$ & $53.5(11.1)$ \\
\hline $\begin{array}{l}\mathrm{PtCO}_{2}(\mathrm{mmHg}) \\
\text { - Min to max }\end{array}$ & $\begin{array}{c}38.7(4.8) \\
27.8 \text { to } 48.6\end{array}$ & $\begin{array}{c}36.6(3.4) \\
29.3 \text { to } 42.8\end{array}$ & $\begin{array}{l}35.7(3.5)^{\wedge} \\
29.8 \text { to } 42.1\end{array}$ \\
\hline Oxygen saturation (\%) & $95.7(2.4)$ & $96.3(1.3)$ & $95.4(2.5)^{\wedge}$ \\
\hline - Min to max & 91 to 100 & 93 to 99 & 87 to 99 \\
\hline Respiratory rate (breaths/min) & $18.8(4.5)$ & $16.8(3.2)$ & $17.0(3.9)$ \\
\hline \multicolumn{4}{|c|}{ Neuromuscular disease entry criteria $\mathbf{N}(\%)$} \\
\hline $\begin{array}{l}\text { Participants with SNIP }<95 \% \\
\text { range }\end{array}$ & $\begin{array}{c}12(63 \%) \\
(\text { Total } \mathrm{N}=19)\end{array}$ & NA & NA \\
\hline $\begin{array}{l}\text { Participants with VC drop } \\
\geq 10 \% \text { sitting to lying }\end{array}$ & $\begin{array}{c}13(72 \%) \\
\text { (Total N=18) }\end{array}$ & NA & NA \\
\hline
\end{tabular}

\section{Table 5.3 Participant characteristics and study baseline measurements}

COPD: Chronic Obstructive Pulmonary Disease, BMI: Body mass index, FEV $\mathrm{F}_{1:}$ Forced expiratory volume in 1 second, FVC: Forced vital capacity, NA: Not applicable, NIV: Non-invasive ventilation, $\mathrm{PtCO}_{2}$ : Transcutaneous partial pressure of carbon dioxide, SNIP: Sniff nasal inspiratory pressure, VC: Vital capacity (slow). *Unless otherwise stated. **One participant was eligible on neuromuscular disease and kyphoscoliosis criteria. $* * *$ Data unavailable from some participants. In the COPD study six participants did not report whether they were current or ex smokers, however all had pack year histories of at least 19 years. ${ }^{\wedge} \mathrm{N}=23$, data unavailable due to SenTec failure. See Textbox 5.2 for detail on participants and data included/excluded. 


\begin{tabular}{|lccc|}
\hline \multicolumn{1}{|c|}{ Ethnicity } & $\begin{array}{c}\text { Neuromuscular } \\
\text { disease/ } \\
\text { kyphoscoliosis } \\
\mathbf{N = 2 0}\end{array}$ & $\begin{array}{c}\text { Bronchiectasis } \\
\mathbf{N = 2 4}\end{array}$ & $\begin{array}{c}\text { COPD } \\
\mathbf{N = 2 4}\end{array}$ \\
\hline NZ European & 16 & 18 & 19 \\
Māori & 0 & 1 & 3 \\
Chinese & 0 & 2 & 0 \\
Samoan & 1 & 1 & 0 \\
Indian & 0 & 0 & 1 \\
Other & 3 & 2 & 1 \\
\hline
\end{tabular}

Table 5.4 Participant ethnicity

COPD: Chronic Obstructive Pulmonary Disease, NZ: New Zealand.

Values are $\mathrm{n}$ values. 


\begin{tabular}{|ll|}
\hline \multicolumn{1}{|c|}{ Diagnosis } & N \\
\hline Charcot Marie Tooth & 3 \\
Ehlers Danlos* & 1 \\
Facioscapulohumeral muscular dystrophy & 2 \\
Limb girdle muscular dystrophy & 1 \\
Motor neuron disease & 5 \\
Multiple sclerosis & 1 \\
Myotonic dystrophy & 4 \\
Phrenic nerve palsy & 1 \\
Tetraplegia & 1 \\
Nil (entry to study under kyphoscoliosis criteria) & 1 \\
Table 5.5 Neuromuscular disease diagnoses for neuromuscular disease/ kyphoscoliosis \\
study \\
* This participant had kyphoscoliosis and Ehlers-Danlos Syndrome. They meet the spirometry entry \\
criteria for kyphoscoliosis, was well as the spirometry and SNIP entry criteria for neuromuscular \\
disease.
\end{tabular}




\section{Neuromuscular disease/kyphoscoliosis study:}

The following participants withdrew due to inability to tolerate the mask:

- 1 Participant: Withdrew from study after $\mathrm{T}=0$ Intervention 1 , all subsequent data points not collected.

- 1 Participant: Withdrew from study after $\mathrm{T}=10$ Intervention 1 , all subsequent data points not collected.

- 1 Participant: Withdrew from Intervention 1 after $\mathrm{T}=20$ due to cough, resulting in Intervention $1 \mathrm{~T}=30$ and washout data not being collected.

Individual data unavailable:

- 1 Participant: at $\mathrm{T}=60$ during Intervention 1 data not recorded as required restroom.

\section{Bronchiectasis study:}

The following participant withdrew due to inability to tolerate the mask:

- 1 Participant: Withdrew from study after T=20 Intervention 1, all subsequent data points not collected.

Individual data unavailable:

- 1 Participant: At $\mathrm{T}=10$ during Intervention 1 data not recorded as tubing failed, all subsequent data points for Intervention 1 not collected.

- 1 Participant: At $\mathrm{T}=60$ during Intervention 1 ear clip for SenTec disconnected with no SenTec data.*

\section{COPD study:}

Participant data withdrawal:

- 1 Participant: All SenTec data had to be discarded due to SenTec maintenance error. No SenTec data was used. $* \mathrm{CO}_{2} \mathrm{SMO}$ data** was recorded until $\mathrm{T}=10 \mathrm{~min}$ for Intervention 2 only, when participant withdrawn based on identification of inability to rely on SenTec data.

Individual data unavailable:

- 1 Participant: At $\mathrm{T}=10$ during Intervention 1 there was a mask leak and resulting $\mathrm{CO}_{2} \mathrm{SMO}$ inaccuracy. No $\mathrm{CO}_{2} \mathrm{SMO}$ data** was used for this time point.

- 1 Participant: At T=20 during Intervention 2 the $\mathrm{CO}_{2} \mathrm{SMO}$ did not report dead space to tidal volume ratio (VD/VT). This meant that volume of dead space, alveolar minute ventilation and alveolar volume also could not be calculated.

- 1 Participant: At T=30 during Intervention 2 heart rate was not recorded due to investigator error.

*SenTec data: Transcutaneous partial pressure of carbon dioxide $\left(\mathrm{PtCO}_{2}\right)$ and heart rate. Note VD/VT measurement requires $\mathrm{PtCO}_{2}$ to be available from SenTec. Note calculation of volume of dead space, alveolar minute ventilation and alveolar volume requires $\mathrm{PtCO}_{2}$ to be available from SenTec.

** $\mathrm{CO}_{2} \mathrm{SMO}$ data: End tidal carbon dioxide $\left(\mathrm{ETCO}_{2}\right)$, minute ventilation, VD/VT and respiratory rate. Note calculation of tidal volume, volume of dead space, alveolar minute ventilation and alveolar volume require data from $\mathrm{CO}_{2} \mathrm{SMO}$.

Textbox 5.2 Summary of participant and individual data not included in analyses. 
$\mathrm{PtCO}_{2}$ rose after the mask was applied in both interventions, returning to study baseline within 10 minutes of removal. At $\mathrm{T}=0$, (i.e. after placement and stabilisation of the mask, but prior to receiving the intervention) the average $\mathrm{PtCO}_{2}$ increase was at least $1.3 \mathrm{mmHg}$ higher than the last $\mathrm{PtCO}_{2}$ measurement prior to mask placement (Table 5.6). The difference $(95 \% \mathrm{CI})$ in $\mathrm{PtCO}_{2}$ at 30 minutes between oxygen and room air, adjusted for $\mathrm{T}=0 \mathrm{PtCO}_{2}$, was $0.2 \mathrm{mmHg}$ (-0.4 to 0.9$), \mathrm{P}=0.40 ; 0.5 \mathrm{mmHg}$ (-0.2 to 1.2$), \mathrm{P}=0.18$; and $1.3 \mathrm{mmHg}$ (0.7 to 1.8), $\mathrm{P}<0.001$, in the neuromuscular disease/kyphoscoliosis, bronchiectasis and COPD participants respectively (Table 5.6). The mixed linear model estimates for the differences in $\mathrm{PtCO}_{2}$ across all time points and adjusted for $\mathrm{T}=0$ were higher during the oxygen intervention compared to room air in the bronchiectasis and COPD studies (Table 5.6). 


\begin{tabular}{|c|c|c|c|}
\hline & $\begin{array}{l}\text { Neuromuscular } \\
\text { disease/ } \\
\text { kyphoscoliosis } \\
\mathrm{N}=20^{*}\end{array}$ & $\begin{array}{c}\text { Bronchiectasis } \\
\qquad \mathrm{N}=\mathbf{2 4}^{*}\end{array}$ & $\begin{array}{l}\text { COPD } \\
\mathrm{N}=\mathbf{2 4} *\end{array}$ \\
\hline \multicolumn{4}{|c|}{$\begin{array}{l}\text { Change in } \mathrm{PtCO}_{2} \text { on placement of mask** } \\
\text { Mean (SD), } \mathrm{mmHg}\end{array}$} \\
\hline Intervention 1 & $1.8(2.8)$ & $1.3(1.7)$ & $1.3(1.4)^{\wedge \wedge \wedge}$ \\
\hline Intervention 2 & $1.3(1.1)^{\wedge}$ & $2.0(1.4)^{\wedge \wedge \wedge}$ & $1.8(1.4)^{\wedge \wedge \wedge}$ \\
\hline \multicolumn{4}{|c|}{$\begin{array}{l}\text { PtCO}_{2} \text { during air and oxygen interventions } \\
\text { Mean (SD), } \mathrm{mmHg}\end{array}$} \\
\hline Oxygen $\mathrm{T}=0$ & $39.4(4.2)^{\wedge}$ & $38.5(2.6)$ & $37.0(3.2)^{\wedge \wedge \wedge}$ \\
\hline Oxygen $\mathrm{T}=30$ & $40.3(4.1)^{\wedge}$ & $39.6(2.8)^{\wedge \wedge}$ & $38.8(3.5)^{\wedge \wedge \wedge}$ \\
\hline Air $\mathrm{T}=0$ & $40.2(5.6)$ & $38.6(2.7)^{\wedge \wedge \wedge}$ & $37.3(3.5)^{\wedge \wedge \wedge}$ \\
\hline Air $\mathrm{T}=30$ & $39.7(3.6)^{* * *}$ & $38.9(2.9)^{\wedge \wedge \wedge}$ & $37.7(3.3)^{\wedge \wedge \wedge}$ \\
\hline \multicolumn{4}{|l|}{$\begin{array}{l}\text { Mixed linear model estimates }{ }^{\#} \\
(95 \% \mathrm{CI}), \mathrm{mmHg}\end{array}$} \\
\hline $\begin{array}{l}\text { Change at } 30 \text { minutes, oxygen } \\
\text { minus air }\end{array}$ & $\begin{array}{l}0.2(-0.4 \text { to } 0.9) \\
\qquad \mathrm{P}=0.40\end{array}$ & $\begin{array}{l}0.5(-0.2 \text { to } 1.2) \\
\qquad \mathrm{P}=0.18\end{array}$ & $\begin{array}{c}1.3(0.7 \text { to } 1.8) \\
P<0.001\end{array}$ \\
\hline $\begin{array}{l}\text { Change over duration of } \\
\text { intervention, oxygen minus } \\
\text { air }\end{array}$ & $\begin{array}{c}-0.07(-0.40 \text { to } 0.27) \\
\quad \mathrm{P}=0.70\end{array}$ & $\begin{array}{l}0.4(0.08 \text { to } 0.7) \\
\qquad \mathrm{P}=0.012\end{array}$ & $\begin{array}{l}1.3(1.0 \text { to } 1.5) \\
\quad \mathrm{P}<0.001\end{array}$ \\
\hline
\end{tabular}

\section{Table 5.6 $\mathrm{PtCO}_{2}$ outcomes}

Air: Air intervention, COPD: Chronic obstructive pulmonary disease, Oxygen: Oxygen intervention, $\mathrm{PtCO}_{2}$ : Transcutaneous partial pressure of carbon dioxide, $\mathrm{T}=0$ : Value taken at Time 0 minutes (i.e. following mask stabilisation and prior to start of intervention), $\mathrm{T}=30$ : Value taken at Time 30 minutes.

*Unless otherwise stated. ${ }^{* *}$ Change is $\mathrm{PtCO}_{2}$ at $\mathrm{T}=0$ minus last recorded $\mathrm{PtCO}_{2}$ value prior to placement of mask. ${ }^{* * *} \mathrm{~N}=17 .{ }^{\wedge} \mathrm{N}=18 .{ }^{\wedge} \mathrm{N}=22 .{ }^{\wedge} \wedge \wedge \mathrm{N}=23 .{ }^{*}$ Mixed linear model values represent oxygen minus air change from $\mathrm{T}=0 .{ }^{\#}$ Incorporated values are from $\mathrm{T}=10,20$ and 30 minutes.

The interaction between each time point (10, 20 and 30 minutes) was not significantly different, see Table 5.10 for $\mathrm{P}$ values. $\mathrm{N}$ values for $\mathrm{PtCO}_{2}$ at each time point during the study were as follows: Neuromuscular disease/kyphoscoliosis study oxygen intervention/washout: $\mathrm{N}=18$ at $\mathrm{T}=0$ to $\mathrm{T}=50, \mathrm{~N}=17$ at $\mathrm{T}=60$. Neuromuscular disease/kyphoscoliosis study air intervention/washout: $\mathrm{N}=20$ at $\mathrm{T}=0, \mathrm{~N}=19$ at $\mathrm{T}=10, \mathrm{~N}=18$ at $\mathrm{T}=20$ and $\mathrm{N}=17$ at all other time points. Bronchiectasis study oxygen intervention/washout: $\mathrm{N}=24$ at $\mathrm{T}=0$ and $\mathrm{T}=10, \mathrm{~N}=23$ at $\mathrm{T}=20, \mathrm{~N}=22$ at all other time points. Bronchiectasis study air intervention/washout: $\mathrm{N}=23$ at $\mathrm{T}=0$ to $\mathrm{T}=50$ and $\mathrm{N}=23$ at $\mathrm{T}=60$. COPD oxygen and air interventions/washouts: $\mathrm{N}=23$ at all time points.

See Textbox 5.2 for detail on data included/excluded. 
Figure 5.4 and Tables 5.7 to 5.9 demonstrate $\mathrm{PtCO}_{2}$ over the course of the study. $\mathrm{PtCO}_{2}$ did not increase or decrease by $\geq 4 \mathrm{mmHg}$ from $\mathrm{T}=0$ during the interventions, with the exception of one bronchiectasis and one COPD participant, during the oxygen intervention only (increases of 4.8 $\mathrm{mmHg}$ and $4.7 \mathrm{mmHg}$ respectively). The interaction terms between the time points (10, 20 and 30 minutes) were not significantly different (Table 5.10). When compared to the bronchiectasis participants, the COPD participants had a greater mean difference in $\mathrm{PtCO}_{2}$ adjusted for $\mathrm{T}=0$ between the oxygen and air interventions: $0.90 \mathrm{mmHg}$ (95\% CI 0.5 to1.3), $\mathrm{P}<0.001$. There was no change to this estimate after incorporation of $\mathrm{FEV}_{1}$ percentage predicted as a potential confounder. 
Neuromuscular disease/kyphoscoliosis

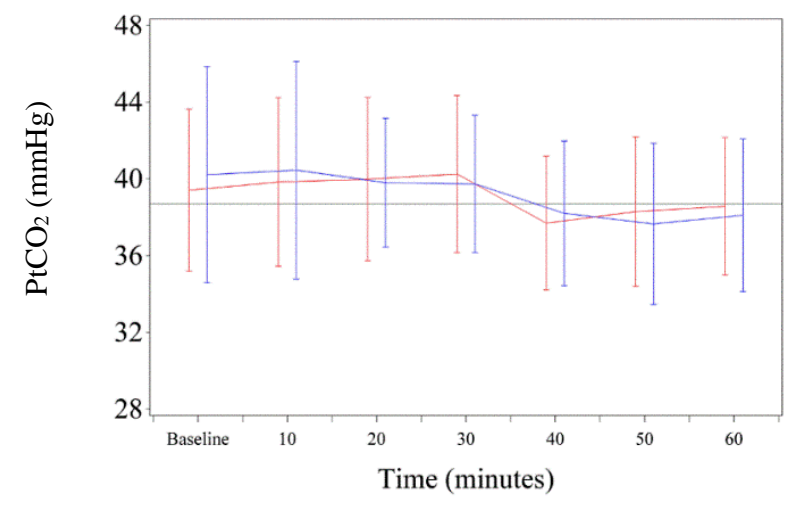

Bronchiectasis

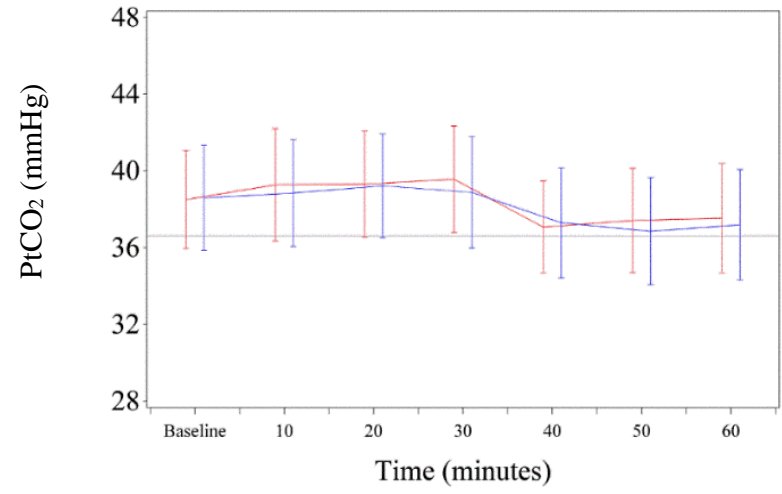

COPD

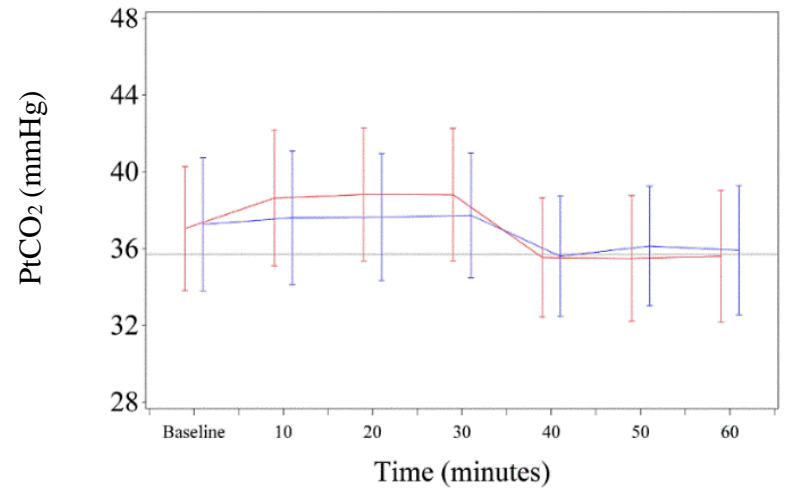

Figure 5.4 $\mathrm{PtCO}_{2}$ changes over time

COPD: Chronic obstructive pulmonary disease, $\mathrm{PtCO}_{2}$ : Transcutaneous partial pressure of carbon dioxide.

Blue lines represent oxygen intervention data, red represent air intervention data. Values are mean plus/minus 1SD. The solid grey line represents study baseline $\mathrm{PtCO}_{2}$ (prior to the start of the first intervention while breathing room air without a mask). $\mathrm{T}=0$ to $\mathrm{T}=30$ are measurements taken while wearing the study mask. $\mathrm{T}=40$ to $\mathrm{T}=60$ are washout measurements breathing room air, not wearing the study mask. See Textbox 5.2 for detail on data included/excluded. 


\begin{tabular}{|c|c|c|c|c|}
\hline & & $\begin{array}{l}\text { Time } \\
\text { point } \\
\text { (min) }\end{array}$ & $\mathbf{N}$ & $\begin{array}{c}\mathrm{PtCO}_{2} \\
\text { Mean (SD) }\end{array}$ \\
\hline \multirow[t]{7}{*}{$\begin{array}{l}\text { Oxygen } \\
\text { Intervention }\end{array}$} & $\begin{array}{l}\text { Immediately } \\
\text { prior to } \\
\text { intervention }\end{array}$ & 0 & 18 & $39.4(4.2)$ \\
\hline & & 10 & 18 & $39.8(4.4)$ \\
\hline & Intervention & 20 & 18 & $40(4.3)$ \\
\hline & & 30 & 18 & $40.3(4.1)$ \\
\hline & & 40 & 18 & $37.7(3.5)$ \\
\hline & Washout & 50 & 18 & $38.3(3.9)$ \\
\hline & & 60 & 17 & $38.6(3.6)$ \\
\hline \multirow[t]{7}{*}{$\begin{array}{l}\text { Air } \\
\text { Intervention }\end{array}$} & $\begin{array}{l}\text { Immediately } \\
\text { prior to } \\
\text { intervention }\end{array}$ & 0 & 20 & $40.2(5.6)$ \\
\hline & & 10 & 19 & $40.5(5.7)$ \\
\hline & Intervention & 20 & 18 & $39.8(3.4)$ \\
\hline & & 30 & 17 & 39.7 (3.6) \\
\hline & & 40 & 17 & $38.2(3.8)$ \\
\hline & Washout & 50 & 17 & $37.7(4.2)$ \\
\hline & & 60 & 17 & $38.1(4.0)$ \\
\hline \multirow{6}{*}{$\begin{array}{l}\text { Difference } \\
\text { from } T=0 \text {, } \\
\text { oxygen } \\
\text { minus air }\end{array}$} & & 10 & 18 & $-0.1(1.2)$ \\
\hline & Intervention & 20 & 18 & $-0.3(1.4)$ \\
\hline & & 30 & 17 & $0.2(1.3)$ \\
\hline & & 40 & 17 & $-0.9(2.0)$ \\
\hline & Washout & 50 & 17 & $0.3(2.2)$ \\
\hline & & 60 & 16 & $-0.6(2.6)$ \\
\hline
\end{tabular}

Table $5.7 \mathrm{PtCO}_{2}$ values at each time point for the neuromuscular disease/kyphoscoliosis study

$\mathrm{PtCO}_{2}$ : Transcutaneous partial pressure of carbon dioxide.

Grey cells are washout periods during which the participant breathed room air without a mask.

See Textbox 5.2 for detail on data included/excluded. 


\begin{tabular}{|c|c|c|c|c|}
\hline & & $\begin{array}{l}\text { Time } \\
\text { point } \\
\text { (min) }\end{array}$ & $\mathbf{N}$ & $\begin{array}{c}\mathrm{PtCO}_{2} \\
\text { Mean (SD) }\end{array}$ \\
\hline \multirow[t]{7}{*}{$\begin{array}{l}\text { Oxygen } \\
\text { Intervention }\end{array}$} & $\begin{array}{l}\text { Immediately } \\
\text { prior to } \\
\text { intervention }\end{array}$ & 0 & 24 & $38.5(2.6)$ \\
\hline & Intervention & 10 & 24 & $39.3(2.9)$ \\
\hline & & 20 & 23 & $39.3(2.8)$ \\
\hline & & 30 & 22 & $39.6(2.8)$ \\
\hline & Washout & 40 & 22 & $37.1(2.4)$ \\
\hline & & 50 & 22 & $37.4(2.7)$ \\
\hline & & 60 & 22 & $37.5(2.8)$ \\
\hline \multirow[t]{7}{*}{$\begin{array}{l}\text { Air } \\
\text { Intervention }\end{array}$} & $\begin{array}{l}\text { Immediately } \\
\text { prior to } \\
\text { intervention }\end{array}$ & 0 & 23 & $38.6(2.7)$ \\
\hline & Intervention & 10 & 23 & $38.8(2.8)$ \\
\hline & & 20 & 23 & $39.2(2.7)$ \\
\hline & & 30 & 23 & $38.9(2.9)$ \\
\hline & Washout & 40 & 23 & $37.3(2.9)$ \\
\hline & & 50 & 23 & $36.9(2.8)$ \\
\hline & & 60 & 22 & $37.2(2.9)$ \\
\hline \multirow{6}{*}{$\begin{array}{l}\text { Difference } \\
\text { from } T=0 \text {, } \\
\text { oxygen } \\
\text { minus air }\end{array}$} & Intervention & 10 & 23 & $0.6(1.2)$ \\
\hline & & 20 & 22 & $0.0(1.6)$ \\
\hline & & 30 & 22 & $0.5(1.7)$ \\
\hline & Washout & 40 & 22 & $-0.5(1.8)$ \\
\hline & & 50 & 22 & $0.3(2.3)$ \\
\hline & & 60 & 21 & $0.1(2.4)$ \\
\hline
\end{tabular}

Table 5.8 $\mathrm{PtCO}_{2}$ values at each time point for the bronchiectasis study

$\mathrm{PtCO}_{2}$ : Transcutaneous partial pressure of carbon dioxide.

Grey cells are washout periods during which the participant breathed room air without a mask.

See Textbox 5.2 for detail on data included/excluded. 


\begin{tabular}{|c|c|c|c|c|}
\hline & & $\begin{array}{l}\text { Time } \\
\text { point } \\
\text { (min) }\end{array}$ & $\mathbf{N}$ & $\begin{array}{c}\operatorname{PtCO}_{2} \\
\text { Mean (SD) }\end{array}$ \\
\hline \multirow[t]{7}{*}{$\begin{array}{l}\text { Oxygen } \\
\text { Intervention }\end{array}$} & $\begin{array}{l}\text { Immediately } \\
\text { prior to } \\
\text { intervention }\end{array}$ & 0 & 23 & $37.0(3.2)$ \\
\hline & Intervention & 10 & 23 & $38.6(3.5)$ \\
\hline & & 20 & 23 & $38.8(3.5)$ \\
\hline & & 30 & 23 & $38.8(3.5)$ \\
\hline & Washout & 40 & 23 & $35.5(3.1)$ \\
\hline & & 50 & 23 & $35.5(3.3)$ \\
\hline & & 60 & 23 & $35.6(3.4)$ \\
\hline \multirow[t]{7}{*}{$\begin{array}{l}\text { Air } \\
\text { Intervention }\end{array}$} & $\begin{array}{l}\text { Immediately } \\
\text { prior to } \\
\text { intervention }\end{array}$ & 0 & 23 & $37.3(3.5)$ \\
\hline & Intervention & 10 & 23 & $37.6(3.5)$ \\
\hline & & 20 & 23 & $37.6(3.3)$ \\
\hline & & 30 & 23 & $37.7(3.3)$ \\
\hline & Washout & 40 & 23 & $35.6(3.1)$ \\
\hline & & 50 & 23 & $36.1(3.1)$ \\
\hline & & 60 & 23 & $35.9(3.4)$ \\
\hline \multirow{6}{*}{$\begin{array}{l}\text { Difference } \\
\text { from } T=0, \\
\text { oxygen minus } \\
\text { air }\end{array}$} & Intervention & 10 & 23 & $1.2(1.4)$ \\
\hline & & 20 & 23 & $1.4(1.5)$ \\
\hline & & 30 & 23 & $1.3(1.3)$ \\
\hline & Washout & 40 & 23 & $0.2(1.8)$ \\
\hline & & 50 & 23 & $-0.4(2.0)$ \\
\hline & & 60 & 23 & $-0.1(2.4)$ \\
\hline
\end{tabular}

Table 5.9 $\mathrm{PtCO}_{2}$ values at each time point for the COPD study

COPD: Chronic obstructive pulmonary disease, $\mathrm{PtCO}_{2}$ : Transcutaneous partial pressure of carbon dioxide.

Grey cells are washout periods during which the participant breathed room air without a mask.

See Textbox 5.2 for detail on data included/excluded. 


\begin{tabular}{|l|ccc|}
\hline \multicolumn{1}{|c|}{ Variable } & $\begin{array}{c}\text { Neuromuscular } \\
\text { disease/ } \\
\text { kyphoscoliosis }\end{array}$ & Bronchiectasis & COPD \\
\hline $\mathrm{PtCO}_{2}$ & 0.38 & 0.52 & 0.87 \\
Minute ventilation & 0.61 & 0.18 & 0.14 \\
Respiratory rate & 0.85 & 0.09 & 0.27 \\
Tidal volume & 0.89 & 0.64 & 0.55 \\
Alveolar minute ventilation & 0.77 & 0.57 & 0.66 \\
Alveolar volume & 0.99 & 0.45 & 0.86 \\
ETCO & 0.63 & 0.64 & 0.83 \\
Volume of dead space & 0.73 & 0.83 & 0.35 \\
VD/VT & 0.94 & 0.12 & 0.86 \\
Heart rate & 0.15 & 0.60 & 0.57 \\
\hline
\end{tabular}

Table 5.10 Time-treatment interaction terms (P values)

COPD: Chronic obstructive pulmonary disease, $\mathrm{ETCO}_{2}$ : End tidal carbon dioxide, $\mathrm{PtCO}_{2}$ : Transcutaneous partial pressure of carbon dioxide, VD/VT: Dead space to tidal volume ratio.

See Textbox 5.2 for detail on data included/excluded. 
Secondary outcomes are presented in Table 5.11. In the bronchiectasis participants, the mean $\mathrm{ETCO}_{2}$ decreased by $1.0 \mathrm{mmHg}$ during the oxygen intervention, compared with air. This was associated with a small increase in dead space of $0.01 \mathrm{~L}$ and VD/VT of 0.03. In the COPD group the mean $\mathrm{ETCO}_{2}$ decreased by $1.1 \mathrm{mmHg}$, and this was associated with a small reduction in alveolar minute ventilation by $0.21 \mathrm{~L} / \mathrm{min}$ and increase in VD/VT of 0.023. Results at each time point are presented in Tables 5.12 to 5.20. 


\begin{tabular}{|c|c|c|c|c|c|c|c|c|c|}
\hline & \multicolumn{3}{|c|}{$\begin{array}{c}\text { Neuromuscular disease/ } \\
\text { kyphoscoliosis }\end{array}$} & \multicolumn{3}{|c|}{ Bronchiectasis } & \multicolumn{3}{|c|}{ COPD } \\
\hline & $\begin{array}{c}\begin{array}{c}\text { Oxy } \\
\text { T=0 }\end{array} \\
\text { Mean } \\
\text { (SD) } \\
\mathbf{N}=18\end{array}$ & $\begin{array}{c}\text { Air } \\
\text { T=0 } \\
\text { Mean } \\
\text { (SD) } \\
\mathbf{N}=\mathbf{2 0}\end{array}$ & $\begin{array}{c}\text { Estimate }(95 \% \text { CI) } \\
\text { P value* }\end{array}$ & $\begin{array}{c}\text { Oxy } \\
\text { T=0 } \\
\text { Mean } \\
(\text { SD) } \\
\mathbf{N}=\mathbf{2 4} \\
\end{array}$ & $\begin{array}{c}\text { Air } \\
\text { T=0 } \\
\text { Mean } \\
(\mathbf{S D}) \\
\mathbf{N}=23 \\
\end{array}$ & $\begin{array}{c}\text { Estimate (95\% CI) } \\
\text { P value* }\end{array}$ & $\begin{array}{c}\text { Oxy } \\
T=0 \\
\text { Mean } \\
(\mathbf{S D}) \\
\mathbf{N}=\mathbf{2 4} * *\end{array}$ & $\begin{array}{c}\text { Air } \\
\mathbf{T}=\mathbf{0} \\
\text { Mean } \\
\text { (SD) } \\
\mathbf{N}=\mathbf{2 4} * *\end{array}$ & $\begin{array}{c}\text { Estimate }(95 \% \text { CI }) \\
\text { P value* }\end{array}$ \\
\hline $\begin{array}{l}\text { Minute ventilation } \\
(\mathrm{L} / \mathrm{min})\end{array}$ & $\begin{array}{l}6.8 \\
(2.0)\end{array}$ & $\begin{array}{c}6.3 \\
(2.0)\end{array}$ & $\begin{array}{c}0.17(-0.26 \text { to } 0.59) \\
P=0.44\end{array}$ & $\begin{array}{l}7.56 \\
(2.49)\end{array}$ & $\begin{array}{c}7.13 \\
(1.88)\end{array}$ & $\begin{array}{c}0.41(-0.1 \text { to } 0.89) \\
\mathrm{P}=0.09\end{array}$ & $\begin{array}{l}8.08 \\
(2.72)\end{array}$ & $\begin{array}{l}8.03 \\
(2.48)\end{array}$ & $\begin{array}{c}-0.13(-0.55 \text { to } 0.29) \\
\mathrm{P}=0.55\end{array}$ \\
\hline $\begin{array}{l}\text { Respiratory rate } \\
\text { (breaths/minute) }\end{array}$ & $\begin{array}{l}15.7 \\
(5.1)\end{array}$ & $\begin{array}{l}15.9 \\
(5.6)\end{array}$ & $\begin{array}{c}-0.01(-0.73 \text { to } 0.71) \\
P=0.98\end{array}$ & $\begin{array}{l}15.5 \\
(2.9)\end{array}$ & $\begin{array}{l}14.7 \\
(3.1)\end{array}$ & $\begin{array}{c}0.4(-0.4 \text { to } 1.2) \\
\mathrm{P}=0.34\end{array}$ & $\begin{array}{l}15.4 \\
(5.0)\end{array}$ & $\begin{array}{l}14.5 \\
(4.4)\end{array}$ & $\begin{array}{c}-0.3(-1.0 \text { to } 0.3) \\
\quad P=0.31\end{array}$ \\
\hline $\begin{array}{l}\text { Tidal volume } \\
\text { (L) }\end{array}$ & $\begin{array}{c}0.48 \\
(0.21)\end{array}$ & $\begin{array}{l}0.44 \\
(0.2)\end{array}$ & $\begin{array}{c}0.004(-0.024 \text { to } 0.033) \\
P=0.77\end{array}$ & $\begin{array}{l}0.50 \\
(0.2)\end{array}$ & $\begin{array}{c}0.50 \\
(0.15)\end{array}$ & $\begin{array}{c}0.01(-0.03 \text { to } 0.05) \\
P=0.65\end{array}$ & $\begin{array}{l}0.56 \\
(0.18) \\
* * *\end{array}$ & $\begin{array}{l}0.58 \\
(0.17) \\
* * *\end{array}$ & $\begin{array}{c}-0.003(-0.03 \text { to } 0.03) \\
P=0.82\end{array}$ \\
\hline $\begin{array}{l}\text { Alveolar minute ventilation } \\
(\mathrm{L} / \mathrm{min})\end{array}$ & $\begin{array}{c}3.18 \\
(1.28)\end{array}$ & $\begin{array}{c}2.88 \\
(1.33)\end{array}$ & $\begin{array}{c}-0.03(-0.24 \text { to } 0.18) \\
P=0.78\end{array}$ & $\begin{array}{c}3.26 \\
(1.23)\end{array}$ & $\begin{array}{c}3.10 \\
(1.05)\end{array}$ & $\begin{array}{c}-0.06(-0.26 \text { to }-0.15) \\
P=0.58\end{array}$ & $\begin{array}{c}3.16 \\
(0.94) \\
* * *\end{array}$ & $\begin{array}{c}3.15 \\
(0.76) \\
* * *\end{array}$ & $\begin{array}{c}-0.21(-0.38 \text { to }-0.04) \\
\mathrm{P}=0.014\end{array}$ \\
\hline $\begin{array}{l}\text { Alveolar volume } \\
\text { (L) }\end{array}$ & $\begin{array}{c}0.24 \\
(0.15)\end{array}$ & $\begin{array}{c}0.21 \\
(0.13)\end{array}$ & $\begin{array}{c}-0.01(-0.023 \text { to } 0.01) \\
P=0.44\end{array}$ & $\begin{array}{c}0.22 \\
(0.10)\end{array}$ & $\begin{array}{c}0.22 \\
(0.09)\end{array}$ & $\begin{array}{c}-0.02(-0.04 \text { to } 0.01) \\
\mathrm{P}=0.14\end{array}$ & $\begin{array}{c}0.23 \\
(0.10) \\
* * *\end{array}$ & $\begin{array}{l}0.24 \\
(0.11) \\
* * *\end{array}$ & $\begin{array}{c}-0.01(-0.03 \text { to } 0.001) \\
P=0.065\end{array}$ \\
\hline $\begin{array}{l}\mathrm{ETCO}_{2} \\
(\mathrm{mmHg})\end{array}$ & $\begin{array}{l}34.1 \\
(2.9)\end{array}$ & $\begin{array}{l}33.7 \\
(3.4)\end{array}$ & $\begin{array}{c}-0.20(-1.0 \text { to } 0.60) \\
P=0.62\end{array}$ & $\begin{array}{l}31.8 \\
(3.6)\end{array}$ & $\begin{array}{l}31.2 \\
(4.4)\end{array}$ & $\begin{array}{c}-1.0(-1.7 \text { to }-0.3) \\
P=0.004\end{array}$ & $\begin{array}{l}29.0 \\
(3.9)\end{array}$ & $\begin{array}{l}29.2 \\
(4.0)\end{array}$ & $\begin{array}{l}-1.1(-1.7 \text { to }-0.5) \\
\quad \mathrm{P}<0.001\end{array}$ \\
\hline $\begin{array}{l}\text { Volume of dead space } \\
\text { (L) }\end{array}$ & $\begin{array}{c}0.24 \\
(0.09)\end{array}$ & $\begin{array}{c}0.23 \\
(0.08)\end{array}$ & $\begin{array}{c}0.012(-0.004 \text { to } 0.027) \\
P=0.13\end{array}$ & $\begin{array}{c}0.28 \\
(0.10)\end{array}$ & $\begin{array}{c}0.28 \\
(0.07)\end{array}$ & $\begin{array}{c}0.01(0.006 \text { to } 0.05) \\
P=0.011\end{array}$ & $\begin{array}{l}0.33 \\
(0.09) \\
* * *\end{array}$ & $\begin{array}{l}0.33 \\
(0.09) \\
* * *\end{array}$ & $\begin{array}{c}0.009(-0.007 \text { to } 0.03) \\
P=0.27\end{array}$ \\
\hline $\mathrm{VD} / \mathrm{VT}$ & $\begin{array}{c}0.54 \\
(0.11)\end{array}$ & $\begin{array}{c}0.56 \\
(0.09)\end{array}$ & $\begin{array}{c}0.009(-0.004 \text { to } 0.023) \\
P=0.17\end{array}$ & $\begin{array}{c}0.57 \\
(0.06)\end{array}$ & $\begin{array}{c}0.57 \\
(0.07)\end{array}$ & $\begin{array}{c}0.03(0.02 \text { to } 0.04) \\
\mathrm{P}<0.001\end{array}$ & $\begin{array}{l}0.60 \\
(0.07) \\
* * *\end{array}$ & $\begin{array}{l}0.59 \\
(0.09) \\
* * *\end{array}$ & $\begin{array}{c}0.023(0.01 \text { to } 0.037) \\
\mathrm{P}<0.001\end{array}$ \\
\hline
\end{tabular}

Table 5.11 Secondary outcomes Continued overleaf. 


\begin{tabular}{|c|c|c|c|c|c|c|c|c|c|}
\hline & \multicolumn{3}{|c|}{$\begin{array}{c}\text { Neuromuscular disease/ } \\
\text { kyphoscoliosis }\end{array}$} & \multicolumn{3}{|c|}{ Bronchiectasis } & \multicolumn{3}{|c|}{ COPD } \\
\hline & $\begin{array}{c}\text { Oxy } \\
\text { T=0 } \\
\text { Mean } \\
\text { (SD) } \\
\text { N=18 }\end{array}$ & $\begin{array}{c}\text { Air } \\
\text { T=0 } \\
\text { Mean } \\
(\text { SD) } \\
\mathbf{N}=20\end{array}$ & $\begin{array}{c}\text { Estimate }(95 \% \text { CI }) \\
\text { P value* }\end{array}$ & 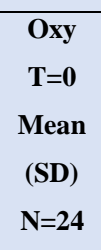 & $\begin{array}{c}\text { Air } \\
\text { T=0 } \\
\text { Mean } \\
\text { (SD) } \\
\mathbf{N}=\mathbf{2 3}\end{array}$ & $\begin{array}{c}\text { Estimate }(95 \% \mathrm{CI}) \\
\text { P value* }\end{array}$ & $\begin{array}{c}\text { Oxy } \\
\text { T=0 } \\
\text { Mean } \\
\text { (SD) } \\
\text { N=24** }\end{array}$ & $\begin{array}{c}\text { Air } \\
\text { T=0 } \\
\text { Mean } \\
\text { (SD) } \\
\text { N=24** }\end{array}$ & $\begin{array}{c}\text { Estimate }(95 \% \text { CI) } \\
\text { P value* }\end{array}$ \\
\hline $\begin{array}{l}\text { Heart rate } \\
\text { (beats/minute) }\end{array}$ & $\begin{array}{c}69.7 \\
(13.8)\end{array}$ & $\begin{array}{c}68.7 \\
(13.3)\end{array}$ & $\begin{array}{l}0.42(-1.0 \text { to } 1.9) \\
P=0.56\end{array}$ & $\begin{array}{c}73.7 \\
(10.0)\end{array}$ & $\begin{array}{c}74.9 \\
(11.7)\end{array}$ & $\begin{array}{c}-1.5(-2.8 \text { to }-0.1) \\
P=0.036\end{array}$ & $\begin{array}{l}71.9 \\
(11.7) \\
* * *\end{array}$ & $\begin{array}{l}69.9 \\
(11.8) \\
* * *\end{array}$ & $\begin{array}{l}-3.3(-4.6 \text { to }-2.1) \\
\mathrm{P}<0.001\end{array}$ \\
\hline
\end{tabular}

Table 5.11 Secondary outcomes continued

Air: Air intervention, COPD: Chronic obstructive pulmonary disease, $\mathrm{ETCO}_{2}$ : End tidal carbon dioxide, Oxy: Oxygen intervention, VD/VT: Dead space to tidal volume ratio.

*Mixed linear model results, oxygen minus air change from $T=0$. All models are pooled estimates across all measurement times (10, 20 or 30 minutes) as the interaction between time point was not significantly different for any of the time points for any of the above outcomes, see Table 5.10 for $\mathrm{P}$ values. **Unless otherwise stated. *** $\mathrm{N}=23$. See Textbox 5.2 for detail on data included/excluded. 


\begin{tabular}{|c|c|c|c|c|c|}
\hline & \multirow[b]{2}{*}{$\begin{array}{l}\text { Time } \\
\text { point } \\
\text { (min) }\end{array}$} & \multirow[b]{2}{*}{$\mathbf{N}$} & \multicolumn{3}{|c|}{ Mean (SD) } \\
\hline & & & $\begin{array}{c}\text { Minute } \\
\text { ventilation } \\
(\mathrm{L} / \mathrm{min})\end{array}$ & $\begin{array}{l}\text { Respiratory } \\
\text { rate (breaths } \\
\text { per minute) }\end{array}$ & $\begin{array}{c}\text { Tidal } \\
\text { volume }(L)\end{array}$ \\
\hline \multirow{4}{*}{$\begin{array}{l}\text { Oxygen } \\
\text { intervention }\end{array}$} & 0 & 18 & $6.8(2.0)$ & $15.7(5.1)$ & $0.48(0.21)$ \\
\hline & 10 & 18 & $6.6(2.1)$ & $15.9(4.3)$ & $0.45(0.20)$ \\
\hline & 20 & 18 & $6.8(1.7)$ & $15.3(5.9)$ & $0.48(0.14)$ \\
\hline & 30 & 18 & $6.9(2.1)$ & $15.2(4.6)$ & $0.48(0.17)$ \\
\hline \multirow[t]{4}{*}{ Air intervention } & 0 & 20 & $6.3(2.0)$ & $15.9(5.6)$ & $0.44(0.20)$ \\
\hline & 10 & 19 & $6.3(1.8)$ & $16.4(6.2)$ & $0.43(0.16)$ \\
\hline & 20 & 18 & $6.6(1.7)$ & $15.4(4.5)$ & $0.45(0.15)$ \\
\hline & 30 & 17 & $6.3(1.7)$ & $15.4(4.8)$ & $0.46(0.20)$ \\
\hline \multirow{3}{*}{$\begin{array}{l}\text { Difference from } \\
\mathrm{T}=0 \text {, oxygen minus } \\
\text { air interventions }\end{array}$} & 10 & 18 & $-0.2(1.3)$ & $0.4(2.4)$ & $-0.02(0.11)$ \\
\hline & 20 & 18 & $0.0(2.1)$ & $-0.1(3.3)$ & $0.0(0.10)$ \\
\hline & 30 & 17 & $0.3(2.1)$ & $-0.3(3.5)$ & $0.0(0.13)$ \\
\hline
\end{tabular}

Table 5.12 Neuromuscular disease/kyphoscoliosis study: Minute ventilation, respiratory rate and tidal volume

See Textbox 5.2 for detail on data included/excluded. 


\begin{tabular}{|c|c|c|c|c|}
\hline & \multirow[b]{2}{*}{$\begin{array}{l}\text { Time } \\
\text { point } \\
\text { (min) }\end{array}$} & \multirow[b]{2}{*}{$\mathbf{N}$} & \multicolumn{2}{|c|}{ Mean (SD) } \\
\hline & & & $\begin{array}{c}\text { Alveolar } \\
\text { minute } \\
\text { ventilation } \\
(\mathrm{L} / \mathrm{min})\end{array}$ & $\begin{array}{c}\text { Alveolar } \\
\text { volume }(\mathrm{L})\end{array}$ \\
\hline \multirow[t]{4}{*}{ Oxygen intervention } & 0 & 18 & $3.2(1.3)$ & $0.24(0.15)$ \\
\hline & 10 & 18 & $2.9(1.2)$ & $0.20(0.12)$ \\
\hline & 20 & 18 & $3.0(1.0)$ & $0.21(0.10)$ \\
\hline & 30 & 18 & $2.9(1.1)$ & $0.21(0.10)$ \\
\hline \multirow[t]{4}{*}{ Air intervention } & 0 & 20 & $2.9(1.3)$ & $0.21(0.13)$ \\
\hline & 10 & 19 & $2.8(1.0)$ & $0.19(0.09)$ \\
\hline & 20 & 18 & $3.0(1.1)$ & $0.21(0.10)$ \\
\hline & 30 & 17 & $2.8(1.1)$ & $0.21(0.12)$ \\
\hline \multirow{3}{*}{$\begin{array}{l}\text { Difference from } \mathrm{T}=0 \text {, } \\
\text { oxygen minus air } \\
\text { interventions }\end{array}$} & 10 & 18 & $-0.1(0.7)$ & $-0.02(0.05)$ \\
\hline & 20 & 18 & $-0.2(1.1)$ & $-0.01(0.07)$ \\
\hline & 30 & 17 & $0.0(1.1)$ & $-0.01(0.09)$ \\
\hline
\end{tabular}

Table 5.13 Neuromuscular disease/kyphoscoliosis study: Alveolar minute ventilation and alveolar volume

See Textbox 5.2 for detail on data included/excluded. 


\begin{tabular}{|c|c|c|c|c|c|c|}
\hline & \multirow{2}{*}{$\begin{array}{l}\text { Time } \\
\text { point } \\
\text { (min) }\end{array}$} & \multirow[b]{2}{*}{$\mathbf{N}$} & \multicolumn{4}{|c|}{ Mean (SD) } \\
\hline & & & $\begin{array}{c}\mathrm{ETCO}_{2} \\
(\mathrm{mmHg})\end{array}$ & $\begin{array}{l}\text { Volume of } \\
\text { dead space } \\
\text { (L) }\end{array}$ & VD/VT & $\begin{array}{c}\text { Heart rate } \\
\text { (beats/minute) }\end{array}$ \\
\hline \multirow{4}{*}{$\begin{array}{l}\text { Oxygen } \\
\text { Intervention }\end{array}$} & 0 & 18 & $34.1(2.9)$ & $0.24(0.09)$ & $0.54(0.11)$ & $69.7(13.8)$ \\
\hline & 10 & 18 & $33.1(3.2)$ & $0.25(0.10)$ & $0.57(0.09)$ & 69.6 (13.6) \\
\hline & 20 & 18 & $33.6(3.7)$ & $0.26(0.07)$ & $0.56(0.10)$ & $69.4(14.5)$ \\
\hline & 30 & 18 & $32.6(2.8)$ & $0.27(0.09)$ & $0.57(0.09)$ & $67.9(13.9)$ \\
\hline \multirow{4}{*}{$\begin{array}{l}\text { Air } \\
\text { Intervention }\end{array}$} & 0 & 20 & $33.7(3.4)$ & $0.23(0.08)$ & $0.56(0.09)$ & 68.7 (13.3) \\
\hline & 10 & 19 & $32.4(4.6)$ & $0.24(0.07)$ & $0.57(0.08)$ & $66.2(10.1)$ \\
\hline & 20 & 18 & $33.4(2.4)$ & $0.24(0.06)$ & $0.55(0.08)$ & $67.1(10.4)$ \\
\hline & 30 & 17 & $33.4(3.7)$ & $0.24(0.08)$ & $0.56(0.07)$ & $69.1(11.2)$ \\
\hline \multirow{3}{*}{$\begin{array}{l}\text { Difference } \\
\text { from } \mathrm{T}=0 \text {, } \\
\text { oxygen minus } \\
\text { air } \\
\text { interventions }\end{array}$} & 10 & 18 & $-0.4(3.5)$ & $0.00(0.07)$ & $0.02(0.04)$ & $1.2(6.0)$ \\
\hline & 20 & 18 & $-0.2(3.8)$ & $0.01(0.05)$ & $0.01(0.07)$ & $1.1(6.1)$ \\
\hline & 30 & 17 & $-0.9(3.7)$ & $0.02(0.06)$ & $0.01(0.07)$ & $-1.8(6.0)$ \\
\hline
\end{tabular}

Table 5.14 Neuromuscular disease/kyphoscoliosis study: $\mathrm{ETCO}_{2}$, volume of dead space, VD/VT and heart rate

$\mathrm{ETCO}_{2}$ : End tidal carbon dioxide, VD/VT: Dead space to tidal volume ratio.

See Textbox 5.2 for detail on data included/excluded. 


\begin{tabular}{|c|c|c|c|c|c|}
\hline & \multirow[b]{2}{*}{$\begin{array}{l}\text { Time } \\
\text { point } \\
\text { (min) }\end{array}$} & \multirow[b]{2}{*}{$\mathbf{N}$} & \multicolumn{3}{|c|}{ Mean (SD) } \\
\hline & & & $\begin{array}{c}\text { Minute } \\
\text { ventilation } \\
\text { (L/min) }\end{array}$ & $\begin{array}{l}\text { Respiratory } \\
\text { rate } \\
\text { (breaths per } \\
\text { minute) }\end{array}$ & $\begin{array}{l}\text { Tidal } \\
\text { volume } \\
\text { (L) }\end{array}$ \\
\hline \multirow{4}{*}{$\begin{array}{l}\text { Oxygen } \\
\text { intervention }\end{array}$} & 0 & 24 & $7.56(2.49)$ & $15.5(2.9)$ & $0.50(0.20)$ \\
\hline & 10 & 24 & $7.70(2.09)$ & $15.5(2.9)$ & $0.52(0.19)$ \\
\hline & 20 & 23 & $7.73(2.18)$ & $15.3(2.7)$ & $0.52(0.16)$ \\
\hline & 30 & 22 & $8.01(2.60)$ & $16.4(3.4)$ & $0.50(0.17)$ \\
\hline \multirow[t]{4}{*}{ Air intervention } & 0 & 23 & $7.13(1.88)$ & $14.7(3.1)$ & $0.50(0.15)$ \\
\hline & 10 & 23 & $7.07(1.55)$ & $14.4(3.4)$ & $0.54(0.25)$ \\
\hline & 20 & 23 & $7.60(2.11)$ & $16.0(3.1)$ & $0.49(0.15)$ \\
\hline & 30 & 23 & $6.74(2.16)$ & $15.0(3.9)$ & $0.47(0.18)$ \\
\hline \multirow{3}{*}{$\begin{array}{l}\text { Difference from } \\
\mathrm{T}=0 \text {, oxygen minus } \\
\text { air interventions }\end{array}$} & 10 & 23 & $0.04(1.83)$ & $0.1(3.5)$ & $-0.02(0.26)$ \\
\hline & 20 & 22 & $-0.55(2.83)$ & $-1.3(5.3)$ & $0.00(0.21)$ \\
\hline & 30 & 22 & $0.66(2.31)$ & $0.7(4.3)$ & $0.01(0.21)$ \\
\hline
\end{tabular}

Table 5.15 Bronchiectasis study: Minute ventilation, respiratory rate and tidal volume

See Textbox 5.2 for detail on data included/excluded. 


\begin{tabular}{|c|c|c|c|c|}
\hline & \multirow[b]{2}{*}{$\begin{array}{l}\text { Time } \\
\text { point } \\
\text { (min) }\end{array}$} & \multirow[b]{2}{*}{$\mathbf{N}$} & \multicolumn{2}{|c|}{ Mean (SD) } \\
\hline & & & $\begin{array}{c}\text { Alveolar } \\
\text { minute } \\
\text { ventilation } \\
\text { (L/min) }\end{array}$ & $\begin{array}{l}\text { Alveolar } \\
\text { volume } \\
\text { (L) }\end{array}$ \\
\hline \multirow[t]{4}{*}{ Oxygen intervention } & 0 & 24 & $3.26(1.23)$ & $0.22(0.10)$ \\
\hline & 10 & 24 & $3.07(0.97)$ & $0.21(0.09)$ \\
\hline & 20 & 23 & $3.07(0.95)$ & $0.21(0.07)$ \\
\hline & 30 & 22 & $3.11(1.06)$ & $0.20(0.08)$ \\
\hline \multirow[t]{4}{*}{ Air intervention } & 0 & 23 & $3.10(1.05)$ & $0.22(0.09)$ \\
\hline & 10 & 23 & $3.11(0.90)$ & $0.25(0.16)$ \\
\hline & 20 & 23 & $3.15(1.04)$ & $0.21(0.09)$ \\
\hline & 30 & 23 & $2.87(1.1)$ & $0.21(0.11)$ \\
\hline \multirow{3}{*}{$\begin{array}{l}\text { Difference from } \mathrm{T}=0 \text {, } \\
\text { oxygen minus air } \\
\text { interventions }\end{array}$} & 10 & 23 & $-0.28(0.98)$ & $-0.04(0.15)$ \\
\hline & 20 & 22 & $-0.36(1.18)$ & $-0.01(0.10)$ \\
\hline & 30 & 22 & $0.02(1.21)$ & $-0.01(0.11)$ \\
\hline
\end{tabular}

Table 5.16 Bronchiectasis study: Alveolar minute ventilation and alveolar volume

See Textbox 5.2 for detail on data included/excluded. 


\begin{tabular}{|c|c|c|c|c|c|c|}
\hline & \multirow[b]{2}{*}{$\begin{array}{l}\text { Time } \\
\text { point } \\
\text { (min) }\end{array}$} & \multirow[b]{2}{*}{$\mathbf{N}$} & \multicolumn{4}{|c|}{ Mean (SD) } \\
\hline & & & $\begin{array}{c}\mathrm{ETCO}_{2} \\
(\mathrm{mmHg})\end{array}$ & $\begin{array}{l}\text { Volume of } \\
\text { dead space } \\
\text { (L) }\end{array}$ & VD/VT & $\begin{array}{c}\text { Heart rate } \\
\text { (beats/minute) }\end{array}$ \\
\hline \multirow{4}{*}{$\begin{array}{l}\text { Oxygen } \\
\text { Intervention }\end{array}$} & 0 & 24 & $31.8(3.6)$ & $0.28(0.10)$ & $0.57(0.06)$ & $73.7(10.0)$ \\
\hline & 10 & 24 & $30.1(3.0)$ & $0.31(0.11)$ & $0.61(0.05)$ & $68.8(9.8)$ \\
\hline & 20 & 23 & $29.8(2.9)$ & $0.31(0.09)$ & $0.61(0.05)$ & $69.6(9.5)$ \\
\hline & 30 & 22 & $29.8(2.7)$ & $0.30(0.10)$ & $0.61(0.05)$ & $70.2(10.1)$ \\
\hline \multirow{4}{*}{$\begin{array}{l}\text { Air } \\
\text { Intervention }\end{array}$} & 0 & 23 & $31.2(4.4)$ & $0.28(0.07)$ & $0.57(0.06)$ & 74.9 (11.7) \\
\hline & 10 & 23 & $31.0(3.9)$ & $0.29(0.10)$ & $0.56(0.08)$ & $72.5(9.3)$ \\
\hline & 20 & 23 & $31.0(3.6)$ & $0.28(0.07)$ & $0.59(0.06)$ & $72.2(11.1)$ \\
\hline & 30 & 23 & $30.0(3.9)$ & $0.26(0.08)$ & $0.58(0.08)$ & $72.2(10.7)$ \\
\hline \multirow{3}{*}{$\begin{array}{l}\text { Difference } \\
\text { from } \mathrm{T}=0 \text {, } \\
\text { oxygen } \\
\text { minus air } \\
\text { interventions }\end{array}$} & 10 & 23 & $-1.3(3.4)$ & $0.01(0.12)$ & $0.04(0.05)$ & $-2.3(6.0)$ \\
\hline & 20 & 22 & $-1.6(4.2)$ & $0.01(0.12)$ & $0.02(0.04)$ & $-0.6(8.5)$ \\
\hline & 30 & 22 & $-0.9(3.5)$ & $0.03(0.11)$ & $0.03(0.05)$ & $0.0(6.7)$ \\
\hline
\end{tabular}

Table 5.17 Bronchiectasis study: $\mathrm{ETCO}_{2}$, volume of dead space, VD/VT and heart rate $\mathrm{ETCO}_{2}$ : End tidal carbon dioxide, VD/VT: Dead space to tidal volume ratio.

See Textbox 5.2 for detail on data included/excluded. 


\begin{tabular}{|c|c|c|c|c|c|}
\hline & \multirow[b]{2}{*}{$\begin{array}{l}\text { Time } \\
\text { point } \\
\text { (min) }\end{array}$} & \multirow[b]{2}{*}{$\mathbf{N}^{*}$} & \multicolumn{3}{|c|}{ Mean (SD) } \\
\hline & & & $\begin{array}{c}\text { Minute } \\
\text { ventilation } \\
(\mathrm{L} / \mathrm{min})\end{array}$ & $\begin{array}{c}\text { Respiratory } \\
\text { rate } \\
\text { (breaths per } \\
\text { minute) }\end{array}$ & $\begin{array}{c}\text { Tidal volume } \\
\text { (L) }\end{array}$ \\
\hline \multirow{4}{*}{$\begin{array}{l}\text { Oxygen } \\
\text { intervention }\end{array}$} & 0 & 24 & $8.08(2.72)$ & $15.4(5.0)$ & $0.56(0.18)^{* *}$ \\
\hline & 10 & 24 & $7.80(2.86)$ & $16.2(5.2)$ & $0.51(0.20)^{* *}$ \\
\hline & 20 & 24 & $8.26(3.15)$ & $16.7(4.6)$ & $0.53(0.17)^{* * *}$ \\
\hline & 30 & 24 & $7.72(2.98)$ & $15.2(4.2)$ & $0.52(0.19)^{* *}$ \\
\hline \multirow[t]{4}{*}{ Air intervention } & 0 & 24 & $8.03(2.48)$ & $14.5(4.4)$ & $0.58(0.17)^{* *}$ \\
\hline & 10 & 23 & $7.84(2.77)$ & $15.7(4.7)$ & $0.53(0.19) * * *$ \\
\hline & 20 & 23 & $7.90(2.49)$ & $15.8(3.9)$ & $0.52(0.15)$ \\
\hline & 30 & 23 & $8.36(3.14)$ & $15.6(4.4)$ & $0.54(0.16)$ \\
\hline \multirow{3}{*}{$\begin{array}{l}\text { Difference from } \\
\mathrm{T}=0 \text {, oxygen } \\
\text { minus air } \\
\text { interventions }\end{array}$} & 10 & 23 & $0.03(1.62)$ & $-0.3(2.5)$ & $0.02(0.16) * * *$ \\
\hline & 20 & 23 & $0.26(2.47)$ & $0.0(2.8)$ & $0.01(0.19) * * *$ \\
\hline & 30 & 23 & $-0.70(2.19)$ & $-1.2(3.2)$ & $0.00(0.18)$ \\
\hline
\end{tabular}

Table 5.18 COPD study: Minute ventilation, respiratory rate and tidal volume

COPD: Chronic obstructive pulmonary disease.

*Unless otherwise indicated. $* * \mathrm{~N}=23 . * * * \mathrm{~N}=22$.

See Textbox 5.2 for detail on data included/excluded. 


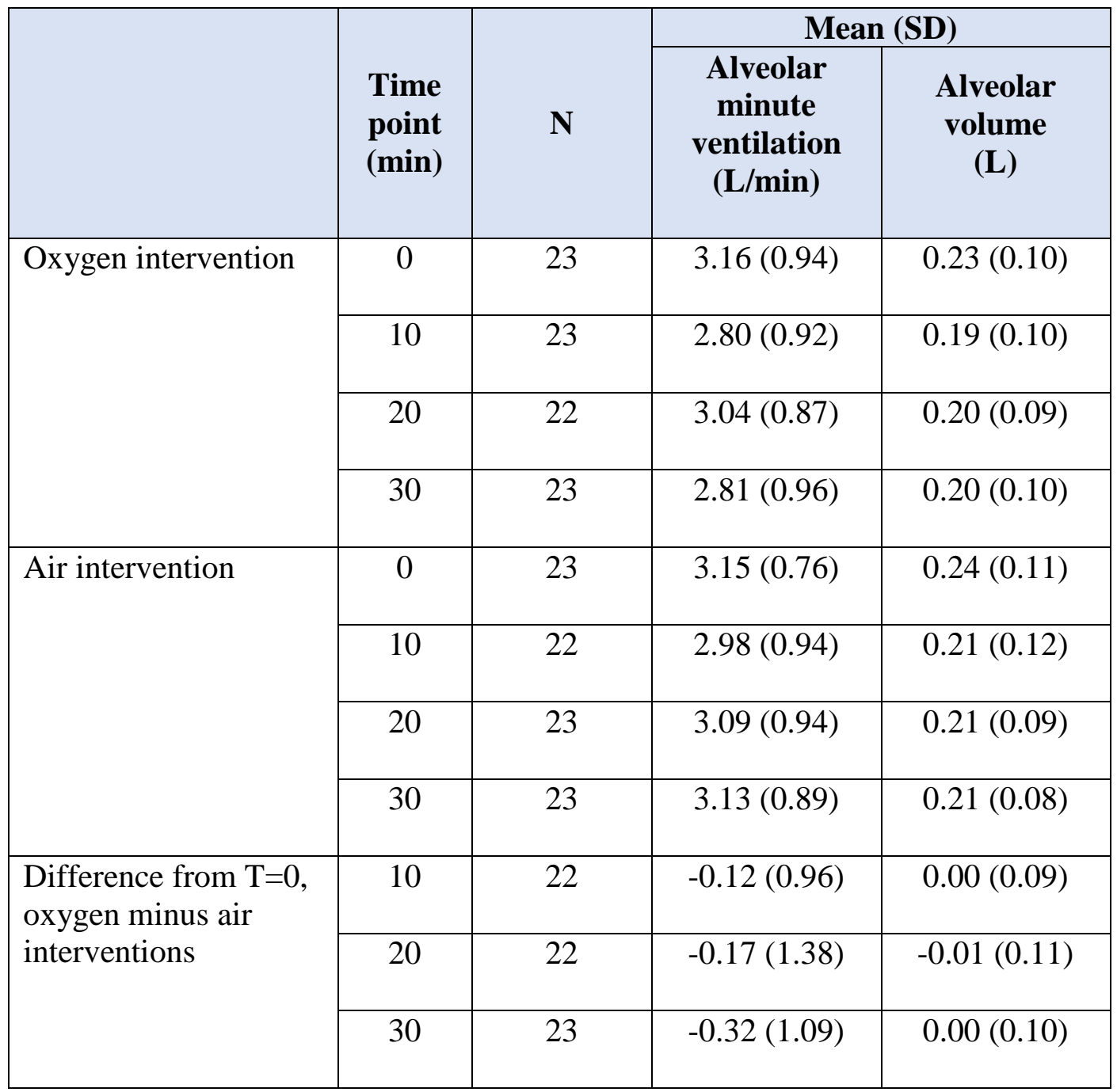

Table 5.19 COPD study: Alveolar minute ventilation and alveolar volume COPD: Chronic obstructive pulmonary disease.

See Textbox 5.2 for detail on data included/excluded. 


\begin{tabular}{|c|c|c|c|c|c|c|}
\hline & \multirow[b]{2}{*}{$\begin{array}{l}\text { Time } \\
\text { point } \\
\text { (min) }\end{array}$} & \multirow[b]{2}{*}{$\mathbf{N}^{*}$} & \multicolumn{4}{|c|}{ Mean (SD) } \\
\hline & & & $\begin{array}{c}\mathrm{ETCO}_{2} \\
(\mathrm{mmHg})\end{array}$ & $\begin{array}{c}\text { Volume of } \\
\text { dead space } \\
\text { (L) }\end{array}$ & VD/VT & $\begin{array}{c}\text { Heart rate } \\
\text { (beats/minute) }\end{array}$ \\
\hline \multirow{4}{*}{$\begin{array}{l}\text { Oxygen } \\
\text { Intervention }\end{array}$} & 0 & 23 & $29.0(3.9)^{* *}$ & $0.33(0.09)$ & $0.60(0.07)$ & 71.9 (11.7) \\
\hline & 10 & 23 & $28.1(3.7)^{* *}$ & $0.32(0.11)$ & $0.63(0.09)$ & $69.8(12.1)$ \\
\hline & 20 & 23 & $28.6(3.8)^{* * *}$ & $\begin{array}{c}0.33(0.10) \\
* * *\end{array}$ & $\begin{array}{c}0.63(0.07) \\
* * *\end{array}$ & $68.0(12.2)$ \\
\hline & 30 & 23 & $27.9(3.7)^{* *}$ & $0.33(0.11)$ & $0.63(0.07)$ & $68.9(11.7)^{* * *}$ \\
\hline \multirow{4}{*}{$\begin{array}{l}\text { Air } \\
\text { Intervention }\end{array}$} & 0 & 23 & $29.2(4.0)^{* *}$ & $0.33(0.09)$ & $0.59(0.09)$ & $69.9(11.8)$ \\
\hline & 10 & 23 & $29.3(4.0)$ & $\begin{array}{c}0.31(0.10) \\
* * *\end{array}$ & $\begin{array}{c}0.61(0.08) \\
* * *\end{array}$ & $71.2(10.5)$ \\
\hline & 20 & 23 & $29.6(3.7)$ & $0.31(0.08)$ & $0.60(0.07)$ & $71.0(11.2)$ \\
\hline & 30 & 23 & $29.3(4.1)$ & $0.33(0.10)$ & $0.61(0.07)$ & $69.8(11.5)$ \\
\hline \multirow{3}{*}{$\begin{array}{l}\text { Difference } \\
\text { from } \mathrm{T}=0 \text {, } \\
\text { oxygen } \\
\text { minus air } \\
\text { interventions }\end{array}$} & 10 & 23 & $-0.9(3.7)$ & $\begin{array}{c}0.02(0.08) \\
* * *\end{array}$ & $\begin{array}{c}0.01(0.09) \\
* * *\end{array}$ & $-3.4(6.5)$ \\
\hline & 20 & 23 & $-0.7(4.4)$ & $\begin{array}{c}0.02(0.10) \\
* * *\end{array}$ & $\begin{array}{c}0.02(0.09) \\
* * *\end{array}$ & $-5.0(6.9)$ \\
\hline & 30 & 23 & $-1.2(4.5)$ & $0.00(0.09)$ & $0.01(0.08)$ & $-3.9(6.3) * * *$ \\
\hline
\end{tabular}

\section{Table 5.20 COPD study: $\mathrm{ETCO}_{2}$, volume of dead space, VD/VT and heart rate}

COPD: Chronic obstructive pulmonary disease, $\mathrm{ETCO}_{2}$ : End tidal carbon dioxide, VD/VT: Dead space to tidal volume ratio.

$*$ Unless otherwise indicated. $* * \mathrm{~N}=24$. $* * * \mathrm{~N}=22$.

See Textbox 5.2 for detail on data included/excluded. 
Paired $\mathrm{PtCO}_{2}$ and $\mathrm{PcCO}_{2}$ values were available from 16 participants. The SenTec minus capillary blood gas values had a mean bias of $-2.8 \mathrm{mmHg}$ with limits of agreement of -8.4 to $2.7 \mathrm{mmHg}$. Drift data were available in 48 participants. Over the course of the 30 minute interventions drift contributed to no more than plus or minus $0.5 \mathrm{mmHg}$ on change in $\mathrm{PtCO}_{2}$ in any of the studies. For further detail and discussion see Appendix 1. 


\subsection{Discussion}

These randomised cross over studies have shown that 50\% oxygen for 30 minutes increased $\mathrm{PtCO}_{2}$ at 30 minutes in patients with stable COPD, but not bronchiectasis or neuromuscular disease/kyphoscoliosis. The mean $1.3 \mathrm{mmHg} \mathrm{PtCO}_{2}$ increase in stable COPD patients with high concentration oxygen therapy contrasts with the marked increases in $\mathrm{PaCO}_{2}$ seen in the setting of AECOPD (Figure 5.5 and Tables 1.1 to 1.2 in Chapter 1). ${ }^{2,3,12}$ This suggests that the results of all three studies in stable patients are unlikely to be generalisable to the use of oxygen therapy in the acute clinical setting. 


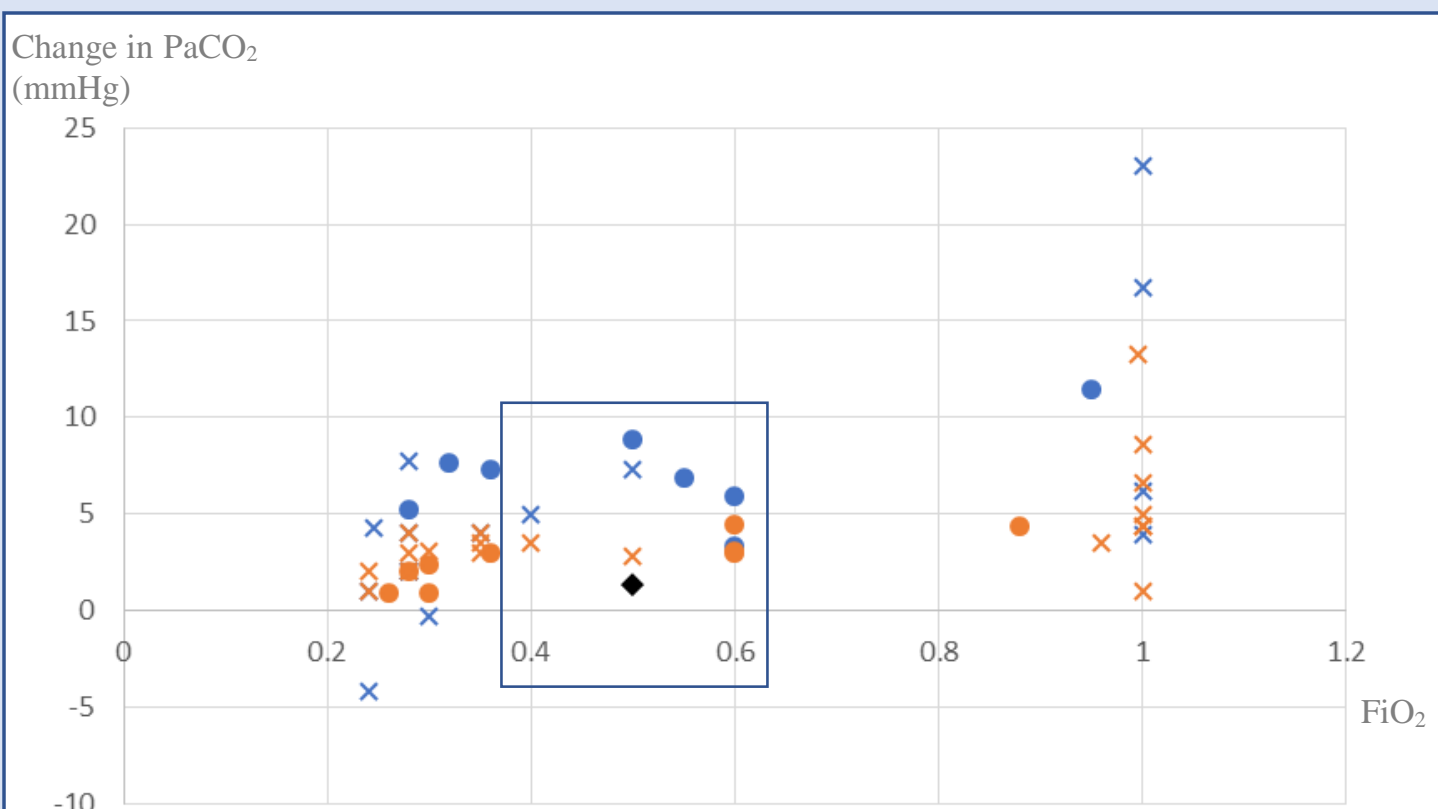

$-10$

- Randomised trial in AECOPD

- Randomised trial in stable COPD

- Current study

\section{$\times$ Non-randomised trial in AECOPD}

$\times$ Non-randomised trial in stable COPD

Data from interventions with $\mathrm{FiO}_{2} 0.4$ to 0.6

\begin{tabular}{|c|c|c|c|c|}
\hline $1^{\text {st }}$ author & $\mathbf{N}$ & $\mathrm{FiO}_{2}$ & $\begin{array}{l}\text { Baseline } \\
\mathrm{PaCO}_{2} \\
(\mathrm{mmHg})\end{array}$ & $\begin{array}{l}\text { Change in } \\
\mathrm{PaCO}_{2} \\
(\mathrm{mmHg})\end{array}$ \\
\hline Bone $^{94}$ & 20 & 0.40 & 42 & 3.5 \\
\hline Lejeune $^{68}$ & 10 & 0.40 & 51 & 5 \\
\hline Current study & 23 & 0.50 & 35.7 & 1.3 \\
\hline Aubier $^{66}$ (stable COPD) & 12 & 0.50 & 46.8 & 2.8 \\
\hline Aubier $^{66}($ AECOPD) & 20 & 0.50 & 61 & 7.3 \\
\hline Eldridge $^{58}$ & 9 & 0.50 & 62 & 8.9 \\
\hline O'Donnell $^{59}$ & 10 & 0.55 & 51 & 6.9 \\
\hline O'Donnell $^{73}$ & 11 & 0.60 & 41 & 3 \\
\hline Edwards $^{81}$ & 18 & 0.60 & 47.8 & 3.1 \\
\hline Bardsley $^{57}$ & 89 & 0.60 & 37.6 & 3.3 \\
\hline O’Donnell $^{80}$ & 20 & 0.60 & NR & 4.5 \\
\hline Gunawardena $^{31}$ & 16 & 0.60 & 49.3 & 5.97 \\
\hline
\end{tabular}

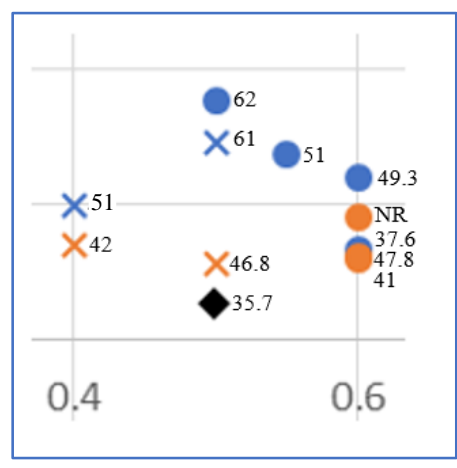

Figures in black adjacent to data points above are baseline $\mathrm{PaCO}_{2}(\mathrm{mmHg})$

Figure 5.5 Change in $\mathrm{PaCO}_{2}$ by $\mathrm{FiO}_{2}$ in studies investigating the effects of oxygen on $\mathrm{PaCO}_{2}$ in $\mathrm{COPD}$

AECOPD: Acute exacerbation of chronic obstructive pulmonary disease, COPD: Chronic obstructive pulmonary disease, $\mathrm{FiO}_{2}$ : Fraction of inspired oxygen. NR: Not reported. $\mathrm{PaCO}_{2}$ : Arterial partial pressure of carbon dioxide.

Figure derived from Figure 1.7 in Chapter 1.

Table and zoomed in portion of the graph demonstrate baseline $\mathrm{PaCO}_{2}$ and change in $\mathrm{PaCO}_{2}$ for data on a $\mathrm{FiO}_{2}$ of 0.4 to 0.6, as comparable $\mathrm{FiO}_{2}$ values to the current randomised cross over trial in COPD. Note that data are not weighted by number of participants and $\mathrm{FiO}_{2}$ values are only estimates based on descriptions of data in the Tables 1.1 to 1.4. See Legend from Figure 1.7 for further detail. 
The risk of oxygen-induced hypercapnia has been well established through RCTs comparing high-flow and titrated oxygen regimens in hospital inpatients with acute COPD exacerbations, ${ }^{12}$ acute severe asthma, ${ }^{13}$ pneumonia ${ }^{14}$ and obesity. ${ }^{184}$ To our knowledge there have been no RCTs in acutely unwell patients with neuromuscular disease, kyphoscoliosis or bronchiectasis. We undertook the current studies in patients with these conditions while stable, recognising that the results from stable patients in the laboratory setting may not translate to the clinical setting. We therefore conducted the study in COPD patients, as a comparator group in which clinically relevant oxygen-induced $\mathrm{PaCO}_{2}$ elevations have been demonstrated. ${ }^{2,3,12}$ The study baseline $\mathrm{SpO}_{2}$ and $\mathrm{PtCO}_{2}$ values were comparable across all three studies, and $\mathrm{FEV}_{1}$ percentage predicted matching between the COPD and bronchiectasis patients ensured recruitment of patients with similar physiological impairment in terms of airflow obstruction. Contrary to findings in the acute setting, ${ }^{2,3,12}$ oxygen administration did not result in a clinically significant change in $\mathrm{PtCO}_{2}$ in the stable COPD patients, indicating that the study model was not an appropriate method to detect the potential for oxygen-induced hypercapnia in patients with neuromuscular disease, kyphoscoliosis or bronchiectasis in clinical practice.

A number of factors may explain the minimal $\mathrm{PtCO}_{2}$ change in the COPD participants. Firstly, oxygen delivery was via a closed-circuit system, rather than standard masks used in clinical practice. This ensured precise $\mathrm{FiO}_{2}$ administration and allowed dead space and ventilation measurement. However, this method of delivery may have affected participant's responses to the interventions, particularly as breathing through the study mask consistently resulted in a small increase in $\mathrm{PtCO}_{2}$. Secondly, the studies were conducted in stable, rather than acutely unwell, patients. This allowed randomised cross over trial design and meant that participants were more likely to tolerate study procedures. However, the physiological response to oxygen in stable patients may not translate to the acute setting. As outlined in Chapter 1, previous studies investigating oxygen delivery to stable COPD patients have had variable results, ranging from no or small changes in mean $\mathrm{PaCO}_{2}$ or $\mathrm{PtCO}_{2}{ }^{66,74,75,77-}$ $80,82,87,88,90,93,95,191$ to marked increases. ${ }^{73,76,85,86,89,91,92,94,96,97,192}$ Two studies have compared the effects of identical oxygen regimens in patients when having an acute exacerbation of their respiratory disease and when stable. Rudolf et al found that a $\mathrm{FiO}_{2}$ of up to 0.28 for 1 hour increased $\mathrm{PaCO}_{2}$ by 9, 15 and $31 \mathrm{mmHg}$ compared with air in three patients with 
exacerbation of chronic respiratory failure. ${ }^{100}$ However, the same oxygen regimen did not alter $\mathrm{PaCO}_{2}$ more than $3 \mathrm{mmHg}$ when the same three patients were stable. Similarly, Aubier et al found 30 minutes of oxygen via a mouthpiece increased average $\mathrm{PaCO}_{2}$ by $10.1 \mathrm{mmHg}$ in 12 patients during a COPD exacerbation. ${ }^{66}$ It increased by only $2.8 \mathrm{mmHg}$ when the same patients were stable. The differences in response between acute and stable disease may relate to lower tidal volumes and/or a greater degree of hypoxic pulmonary vasoconstriction and V/Q mismatch occurring in AECOPD, which are further modified by oxygen therapy. ${ }^{103,193}$ Additionally, acutely unwell patients are more likely to have lower $\mathrm{SpO}_{2}$ levels and hypercapnia; both of which have been associated with increased likelihood and magnitudes of oxygen-induced elevations in $\mathrm{PaCO}_{2} \cdot{ }^{15,66,73,91,97,184}$ In support of this, previous studies in stable COPD demonstrating significant oxygen-induced increases in $\mathrm{PaCO}_{2}$ have had participants with lower mean baseline blood oxygen levels, ${ }^{76,85,89}$ and/or higher mean baseline $\mathrm{PaCO}_{2}$ values ${ }^{73,76,85,86,89,91,92,94,96,97,192}$ than the participants in the current three studies. Figure 5.5 further demonstrates the baseline $\mathrm{PaCO}_{2}$ values measured in studies delivering a similar $\mathrm{FiO}_{2}$ to the current study in COPD patients. While not consistent for all data points, the overall trend is towards a higher increase in $\mathrm{PaCO}_{2}$ in datasets with higher baseline $\mathrm{PaCO}_{2}$ values. Additionally, one of the participants, from the COPD study, had a study baseline $\mathrm{SpO}_{2}$ of $87 \%$. All other participants had saturations $\geq 91 \%$, meaning they were well above the $\mathrm{SpO}_{2}$ level at which initiation of oxygen therapy is recommended in the acute clinical setting. ${ }^{10,11}$

Oxygen therapy has previously been demonstrated to increase VD/VT ${ }^{15,16,73,75,76}$ and reduce $\mathrm{ETCO}_{2} \cdot{ }^{194}$ However, caution is needed in interpreting the small increases in VD/VT and reductions in $\mathrm{ETCO}_{2}$ during the oxygen intervention in the bronchiectasis and COPD studies. These values were recorded by $\mathrm{CO}_{2} \mathrm{SMO}$ and increased oxygen concentrations in the respiratory circuit could systematically decrease the displayed $\mathrm{ETCO}_{2}$ while still keeping it within the manufacturer's error range of up to 5\% (User manual Oct 10 1997). This decrease could explain the small changes in VD/VT and $\mathrm{ETCO}_{2}$ observed.

There are a number of methodological issues relevant to interpretation of the study findings. Transcutaneous monitoring was used as a surrogate for $\mathrm{PaCO}_{2}$ by $\mathrm{ABG}$ as it provides continuous non-invasive measurement. Our study outcome measures were change in $\mathrm{PtCO}_{2}$ over time, which the SenTec has been demonstrated to accurately determine, ${ }^{175,195}$ with an 
estimate of bias for change in $\mathrm{PtCO}_{2}$ of $-0.03 \mathrm{mmHg}$ (95\% CI -0.44 to 0.38 ) $\mathrm{P}=0.89$ when compared to arterialised capillary blood gas values in COPD patients. ${ }^{175}$ Drift corrected $\mathrm{PtCO}_{2}$ data showed little effect on the evaluation of change in $\mathrm{PtCO}_{2}$ over time. The wide limits of agreement between the simultaneous $\mathrm{PtCO}_{2}$ and $\mathrm{PcCO}_{2}$ in the COPD participants sat within the range of those reported in previous studies of SenTec accuracy, ${ }^{195-204}$ and highlight the limitations of interpreting single $\mathrm{PtCO}_{2}$ values. ${ }^{205}$ Further details are in Appendix 1.

Delivery of oxygen at a concentration of $50 \%$ was selected to reflect oxygen delivery levels occurring in the clinical setting. It is also likely to provide a comparable $\mathrm{FiO}_{2}$ to that used in the RCT of oxygen administration in inpatients with obesity in Chapter 4, where $8 \mathrm{~L} / \mathrm{min}$ of oxygen via Hudson mask was associated with a statistically significant increase in $\mathrm{PtCO}_{2}$ compared to titrated therapy (mean difference $3.2 \mathrm{mmHg}, \mathrm{P}=0.002$ ). The minimum washout period of at least 30 minutes was based on work by Rudolf et al which found $\mathrm{PaCO}_{2}$ approximately returned to baseline at 30 minutes following 60 minutes of oxygen administration. ${ }^{64}$ Only 20 participants were recruited to the neuromuscular disease/kyphoscoliosis study, however this did not affect the power to detect a difference in $\mathrm{PtCO}_{2}$ between the interventions, given the SD was lower than that used for sample size calculation.

In conclusion, delivery of $50 \%$ oxygen for 30 minutes did not result in a clinically significant increase in $\mathrm{PtCO}_{2}$ in stable outpatients with neuromuscular disease, kyphoscoliosis, bronchiectasis or COPD. This indicates the model used is an inappropriate method for evaluating the risks of oxygen-induced hypercapnia in the acute clinical setting and highlights the limitations of interpreting results from studies in stable patients in the laboratory setting. It is recommended that future studies into the risks of oxygen-induced hypercapnia are undertaken through comparison of high concentration oxygen to titrated oxygen in the acute respiratory illnesses that complicate neuromuscular disease, kyphoscoliosis and bronchiectasis. In the interim, current evidence of the potential for oxygen-induced hypercapnia to occur across a range of respiratory conditions ${ }^{12-14,184}$ supports guideline recommendations to titrate oxygen therapy in all patients to avoid the risks of hyperoxaemia as well as hypoxaemia. 
Chapter 6: Conclusions 
The studies in this thesis were all based around the concept that high concentration oxygen could cause harm in the acute clinical setting. The most clinically relevant study in this area is Austin's 2010 RCT demonstrating an over two-fold increase in mortality in patients with AECOPD who received high concentration oxygen, compared to titrated therapy to avoid both hypoxaemia and hyperoxaemia. ${ }^{12}$

The systematic review in Chapter 1 outlined studies which support the rationale for titrated oxygen therapy by demonstrating that oxygen-induced hypercapnia can occur to a clinically significant degree across a range of $\mathrm{FiO}_{2}$ values, in a dose responsive manner, and across a range of respiratory conditions. Interestingly, baseline hypercapnia was not a prerequisite for oxygen-induced elevations in hypercapnia in a number of studies, and further research into what patient factors influence the risk of developing clinically significant oxygeninduced hypercapnia are needed. Additionally, there is a need for further work to investigate the optimal target oxygen saturations to titrate oxygen therapy to, as reflected by the differing targets set between the TSANZ and BTS guidelines. ${ }^{10,11}$ The variability in $\mathrm{PaCO}_{2}$ response to oxygen therapy within and between studies, and the lack of predictability in which patients are at risk of oxygen-induced hypercapnia, further support the rationale for titrated oxygen therapy. They also highlight the importance of considering factors which may influence the clinical applicability of study data, such as length of oxygen exposure, method of oxygen administration and whether patients are studied when acutely unwell or stable.

The last two factors turned out to play key roles in the randomised cross over trials investigating the effects of oxygen compared to room air on $\mathrm{PtCO}_{2}$ in patients with bronchiectasis, neuromuscular disease or kyphoscoliosis in Chapter 5. Essential to the interpretation of the results of these studies was the recognition that findings in stable outpatients might not translate to the acute clinical setting. There was not a clinically significant change in $\mathrm{PtCO}_{2}$ in response to oxygen when the study was conducted in stable COPD patients. This indicated the data from these studies was unlikely to be generalisable to the clinical setting. The recommendation from these findings is that future studies are undertaken to identify the risks of oxygen-induced hypercapnia through comparison of high concentration oxygen to titrated oxygen in the acute setting. 
A key objective for the RCT of high concentration versus titrated oxygen in obese hospital inpatients in Chapter 4 was to investigate the clinical applicability of the findings from two studies in stable patients with OHS. ${ }^{15,16}$ In 22 obese hospital inpatients, who were not selected for a pre-existing diagnosis of OHS, the mean change in $\mathrm{PtCO}_{2}$ from baseline was $3.2 \mathrm{mmHg}$ higher during high concentration oxygen administration, compared to titrated administration. $\mathrm{PtCO}_{2}$ increased by $\geq 8 \mathrm{mmHg}$ from baseline in three of the participants during high concentration oxygen therapy. Two thirds of the participants who had a $\mathrm{PtCO}_{2}$ rise $\geq 4 \mathrm{mmHg}$ on high concentration oxygen were not hypercapnic at baseline. Not only do these findings support guideline recommendations to titrate oxygen in the acute setting, they demonstrate that baseline hypercapnia or a diagnosis of OHS are not prerequisites for patients with obesity to be at risk of oxygen-induced hypercapnia.

Practical factors which could affect the titration of oxygen therapy in clinical practice were investigated in the studies in Chapters 2 and 3. The implementation of an education program, which incorporated guideline recommendations on oxygen titration, was associated with a marked decrease the administration of supplemental high concentration oxygen therapy in patients with AECOPD. The finding that oxygen exposure was still occurring through the use of oxygen-driven nebulisers resulted in the implementation of ultrasonic nebulisers, which were subsequently found to further reduce potentially unnecessary oxygen exposure. ${ }^{170}$ The assessment of pulse oximeter accuracy in multiple hospitals across Australia and New Zealand demonstrated the importance of oximeter accuracy to the titration of oxygen to avoid both hypoxaemia and hyperoxaemia. As well as supporting the $92-96 \%$ titration range recommended by the TSANZ, ${ }^{11}$ the results highlight the importance of recognising potential inaccuracies in oximetry, and that $\mathrm{SpO}_{2}$ needs to be interpreted within clinical context.

Overall the studies in this thesis support the use of titrated oxygen therapy in the acute setting. The limits of applying data from stable patients to the clinical setting are demonstrated, as is the importance of considering practical factors that may affect oxygen titration in clinical practice. The studies sit within the growing evidence base which supports the current guideline recommendations to titrate oxygen therapy to a target oxygen saturation range in the acute clinical setting, and highlight the significance of the original recommendation to avoid high concentration oxygen therapy by Barach 80 years ago. ${ }^{1}$ 


\section{References}

1 Barach AL. Physiological methods in the diagnosis and treatment of asthma and emphysema. Ann Intern Med 1938; 12: 454-81.

2 Murphy R, Driscoll P, O’Driscoll R. Emergency oxygen therapy for the COPD patient. Emerg Med J 2001; 18: 333-9.

3 Pilcher J, Weatherall M, Perrin K, Beasley R. Oxygen therapy in acute exacerbations of chronic obstructive pulmonary disease. Expert Rev Respir Med 2015; 9: 287-93.

4 Pilcher J, Beasley R. Acute use of oxygen therapy. Aust Prescr 2015; 38: 98-100.

5 Pilcher J, Perrin K, Beasley R. The effect of high concentration oxygen therapy on $\mathrm{PaCO} 2$ in acute and chronic respiratory disorders. Transl Respir Med 2013; 1: 1-3.

6 Campbell EJ. A method of controlled oxygen administration which reduces the risk of carbon-dioxide retention. Lancet 1960; 2: 12-4.

7 Westlake EK, Simpson T, Kaye M. Carbon dioxide narcosis in emphysema. Q J Med 1955; 24: 155-73.

8 Hadfield JW, Stinchcombe SJ, Bateman JR. Oxygen as a driving gas for nebulisers: safe or dangerous? Br Med J (Clin Res Ed) 1984; 288: 795.

9 Austin SJ, Chan C. Oxygen as a driving gas for nebulisers: safe or dangerous? $\mathrm{Br}$ Med J (Clin Res Ed) 1984; 288: 488.

10 O’Driscoll BR, Howard LS, Earis J, Mak V, British Thoracic Society Emergency Oxygen Guideline Group, BTS Emergency Oxygen Guideline Development Group. BTS guideline for oxygen use in adults in healthcare and emergency settings. Thorax 2017; 72: ii1-ii90.

11 Beasley R, Chien J, Douglas J, et al. Thoracic Society of Australia and New Zealand 
oxygen guidelines for acute oxygen use in adults: 'Swimming between the flags'. Respirology 2015; 20: 1182-91.

12 Austin MA, Wills KE, Blizzard L, Walters EH, Wood-Baker R. Effect of high flow oxygen on mortality in chronic obstructive pulmonary disease patients in prehospital setting: randomised controlled trial. BMJ 2010; 341: c5462.

13 Perrin K, Wijesinghe M, Healy B, et al. Randomised controlled trial of high concentration versus titrated oxygen therapy in severe exacerbations of asthma. Thorax 2011; 66: 937-41.

14 Wijesinghe M, Perrin K, Healy B, Weatherall M, Beasley R. Randomized controlled trial of high concentration oxygen in suspected community-acquired pneumonia. $J R$ Soc Med 2012; 105: 208-16.

15 Wijesinghe M, Williams M, Perrin K, Weatherall M, Beasley R. The effect of supplemental oxygen on hypercapnia in subjects with obesity-associated hypoventilation: a randomized, crossover, clinical study. Chest 2011; 139: 1018-24.

16 Hollier CA, Harmer AR, Maxwell LJ, et al. Moderate concentrations of supplemental oxygen worsen hypercapnia in obesity hypoventilation syndrome: a randomised crossover study. Thorax 2014; 69: 346-53.

17 Santos C, Ferrer M, Roca J, Torres A, Hernandez C, Rodriguez-Roisin R. Pulmonary gas exchange response to oxygen breathing in acute lung injury. Am J Respir Crit Care Med 2000; 161: 26-31.

18 Collins J-A, Rudenski A, Gibson J, Howard L, O’Driscoll R. Relating oxygen partial pressure, saturation and content: the haemoglobin-oxygen dissociation curve. Breathe 2015; 11: 194-201.

19 Cooper CB, Celli B. Venous admixture in COPD: pathophysiology and therapeutic approaches. COPD 2008; 5: 376-81. 
20 Barberà JA, Roca J, Ferrer A, et al. Mechanisms of worsening gas exchange during acute exacerbations of chronic obstructive pulmonary disease. Eur Respir J 1997; 10: 1285-91.

21 Naeije R, Brimioulle S. Physiology in medicine: importance of hypoxic pulmonary vasoconstriction in maintaining arterial oxygenation during acute respiratory failure. Crit Care 2001; 5: 67-71.

22 O 'Donnell DE, Parker CM. COPD exacerbations 3: Pathophysiology. Thorax 2006; 61: $354-61$.

23 Papi A, Luppi F, Franco F, Fabbri LM. Pathophysiology of Exacerbations of Chronic Obstructive Pulmonary Disease. Proc Am Thorac Soc 2006; 3: 245-51.

24 Petersson J, Glenny RW. Gas exchange and ventilation-perfusion relationships in the lung. Eur Respir J 2014; 44: 1023-41.

25 World Health Organization. Burden of COPD. http://www.who.int/respiratory/copd/burden/en/. Accessed March 2018.

26 Lozano R, Naghavi M, Foreman K, et al. Global and regional mortality from 235 causes of death for 20 age groups in 1990 and 2010: a systematic analysis for the Global Burden of Disease Study 2010. Lancet 2010; 380: 2095-128.

27 Global Strategy for the Diagnosis, Management and Prevention of COPD, Global Initiative for Chronic Obstructive Lung Disease (GOLD) 2017. http://goldcopd.org. Accessed March 2018.

28 Ministry of Health.Tatau Kahukura: Māori Health Chart Book 3rd Edition. 2015.

29 Sylvester JT, Shimoda LA, Aaronson PI, Ward JPT. Hypoxic Pulmonary Vasoconstriction. Physiol Rev 2012; 92: 367-520.

30 Bardsley PA, Tweney J, Morgan N, Howard P. Oral almitrine in treatment of acute respiratory failure and cor pulmonale in patients with an exacerbation of chronic 
obstructive airways disease. Thorax 1991; 46: 493-8.

31 Gunawardena K, Patel B, Campbell I, MacDonald J, Smith A. Oxygen as a driving gas for nebulisers: safe or dangerous? Br Med J (Clin Res Ed) 1984; 288: 272-4.

32 Donald KW. Neurological effecs of oxygen. Lancet 1949; 254: 1056-7.

33 Lim TK, Tan WC. Acute carbon dioxide narcosis during inhalational therapy with oxygen powered nebulizers in patients with chronic airflow limitation. Ann Acad Med Singapore 1985; 14: 439-41.

34 Plant PK, Owen JL, Elliott MW. One year period prevalence study of respiratory acidosis in acute exacerbations of COPD: implications for the provision of noninvasive ventilation and oxygen administration. Thorax 2000; 55: 550-4.

35 Denniston AK, O'Brien C, Stableforth D. The use of oxygen in acute exacerbations of chronic obstructive pulmonary disease: a prospective audit of pre-hospital and hospital emergency management. Clin Med 2002; 2: 449-51.

36 Joosten SA, Koh MS, Bu X, Smallwood D, Irving LB. The effects of oxygen therapy in patients presenting to an emergency department with exacerbation of chronic obstructive pulmonary disease. Med J Aust 2007; 186: 235-8.

37 Wijesinghe M, Perrin K, Healy B, et al. Pre-hospital oxygen therapy in acute exacerbations of chronic obstructive pulmonary disease. Intern Med J 2011; 41: 61822.

38 Steer J, Gibson GJ, Bourke SC. Predicting outcomes following hospitalization for acute exacerbations of COPD. Qjm 2010; 103: 817-29.

39 Cameron L, Pilcher J, Weatherall M, Beasley R, Perrin K. The risk of serious adverse outcomes associated with hypoxaemia and hyperoxaemia in acute exacerbations of COPD. Postgr Med J 2012; 88.

40 Jeffrey AA, Warren PM, Flenley DC. Acute hypercapnic respiratory failure in 
patients with chronic obstructive lung disease: risk factors and use of guidelines for management. Thorax 1992; 47: 34-40.

41 O'Driscoll BR, Howard LS, Davison AG. BTS guideline for emergency oxygen use in adult patients. Thorax 2008; 63 Suppl 6: vi1-68.

42 New A. Oxygen: kill or cure? Prehospital hyperoxia in the COPD patient. Emerg Med J 2006; 23: 144-6.

43 Austin MA, Wood-Baker R. Oxygen therapy in the pre-hospital setting for acute exacerbations of chronic obstructive pulmonary disease. Cochrane Database Syst Rev 2006; 19: CD005534.

44 Gomersall CD, Joynt GM, Freebairn RC, Lai CK, Oh TE. Oxygen therapy for hypercapnic patients with chronic obstructive pulmonary disease and acute respiratory failure: a randomized, controlled pilot study. Crit Care Med 2002; 30: $113-6$.

45 Daly WJ, Bondurant S. Effects of oxygen breathing on the heart rate, blood pressure, and cardiac index of normal men-resting, with reactive hyperemia, and after atropine. J Clin Invest 1962; 41: 126-32.

46 Kety SS, Schmidt CF. The effects of altered arterial tensions of carbon dioxide and oxygen on cerebral blood flow and cerebral oxygen consumption of normal young men. J Clin Invest 1948; 27: 484-92.

47 Eggers GWN, Paley HW, Leonard JJ, Warren JV. Hemodynamic responses to oxygen breathing in man. J Appl Physiol 1962; 17: 75-9.

48 Aber GM, Harris AM, Bishop JM. The effect of acute changes in inspired oxygen concentration on cardiac, respiratory and renal function in patients with chronic obstructive airways disease. Clin Sci 1964; 26: 133-43.

49 Kenmure AC, Murdoch WR, Beattie AD, Marshall JC, Cameron AJ. Circulatory and 
metabolic effects of oxygen in myocardial infarction. Br Med J 1968; 4: 360-4.

50 Bourassa MG, Campeau L, Bois MA, Rico O. The effects of inhalation of 100 per cent oxygen on myocardial lactate metabolism in coronary heart disease. Am J Cardiol 1969; 24: 172-7.

51 Wagner PD, Laravuso RB, Uhl RR, West JB. Continuous distributions of ventilationperfusion ratios in normal subjects breathing air and 100 per cent O2. J Clin Invest 1974; 54: 54-68.

52 Garner WL, Downs JB, Reilley TE, Frolicher D, Kargi A, Fabri PJ. The effects of hyperoxia during fulminant sepsis. Surgery 1989; 105: 747-51.

53 Baron JF, Vicaut E, Hou X, Duvelleroy M. Independent role of arterial O2 tension in local control of coronary blood flow. Am J Physiol 1990; 258: H1388-94.

54 Haque WA, Boehmer J, Clemson BS, Leuenberger UA, Silber DH, Sinoway LI. Hemodynamic effects of supplemental oxygen administration in congestive heart failure. J Am Coll Cardiol 1996; 27: 353-7.

55 Beasley R, Aldington S, Robinson G. Is it time to change the approach to oxygen therapy in the breathless patient? Thorax 2007; 62: 840-1.

56 Downs JB. Has oxygen administration delayed appropriate respiratory care? Fallacies regarding oxygen therapy. Respir Care 2003; 48: 611-20.

57 Bardsley G, Pilcher J, McKinstry SJ, et al. Oxygen versus air-driven nebulizers for exacerbations of chronic obstructive pulmonary disease: A randomised controlled trial. Pending Publication.

58 Eldridge F, Gherman C. Studies of oxygen administration in respiratory failure. Ann Intern Med 1968; 68: 569.

59 O’Donnell D, Kelly CP, Cotter P, Clancy L. Use of oxygen driven nebulizer delivery systems for beta-2 agonists in chronic bronchitis. Ir J Med Sci 1985; 154: 198-200. 
60 Comroe JH, Bahnson ER, Coates EO. Mental changes occurring in chronically anoxemic patients during oxygen therapy. J Am Med Assoc 1950; 143: 1044-8.

61 Miller A, Teirstein AS, Duberstein J, Chusid EL, Bader ME, Bader RA. Use of oxygen inhalation in evaluation of respiratory acidosis in patients with apparent metabolic alkalosis. Am J Med 1968; 45: 513-9.

62 Smith JP, Stone RW, Muschenheim C. Acute respiratory failure in chronic lung disease. Observations on controlled oxygen therapy. Am Rev Respir Dis 1968; 97: 791-803.

63 Warrell DA, Edwards RH, Godfrey S, Jones NL. Effect of controlled oxygen therapy on arterial blood gases in acute respiratory failure. $\mathrm{Br}$ Med J 1970; 1: 452-5.

64 Rudolf M, Turner JA, Harrison BD, Riordan JF, Saunders KB. Changes in arterial blood gases during and after a period of oxygen breathing in patients with chronic hypercapnic respiratory failure and in patients with asthma. Clin Sci 1979; 57: 38996.

65 DeGaute JP, Domenighetti G, Naeije R, Vincent JL, Treyvaud D, Perret C. Oxygen delivery in acute exacerbation of chronic obstructive pulmonary disease. Effects of controlled oxygen therapy. Am Rev Respir Dis 1981; 124: 26-30.

66 Aubier M, Murciano D, Fournier M, Milic-Emili J, Pariente R, Derenne JP. Central respiratory drive in acute respiratory failure of patients with chronic obstructive pulmonary disease. Am Rev Respir Dis 1980; 122: 191-9.

67 Aubier M, Murciano D, Milic-Emili J, et al. Effects of the administration of O2 on ventilation and blood gases in patients with chronic obstructive pulmonary disease during acute respiratory failure. Am Rev Respir Dis 1980; 122: 747-54.

68 Lejeune P, Mols P, Naeije R, Hallemans R, Melot C. Acute hemodynamic effects of controlled oxygen therapy in decompensated chronic obstructive pulmonary disease. 
Crit Care Med 1984; 12: 1032-5.

69 Robinson TD, Freiberg DB, Regnis JA, Young IH. The role of hypoventilation and ventilation-perfusion redistribution in oxygen-induced hypercapnia during acute exacerbations of chronic obstructive pulmonary disease. Am J Respir Crit Care Med 2000; 161: 1524-9.

70 Moloney ED, Kiely JL, McNicholas WT. Controlled oxygen therapy and carbon dioxide retention during exacerbations of chronic obstructive pulmonary disease. Lancet 2001; 357: 526-8.

71 Jensen AG, Johnson A, Sandstedt S. Rebreathing during oxygen treatment with face mask. The effect of oxygen flow rates on ventilation. Acta Anaesthesiol Scand 1991; 35: 289-92.

72 Bethune DW, Collis JM. The evaluation of oxygen masks. A mechanical method. Anaesthesia 1967; 22: 43-54.

73 O'Donnell DE, D'Arsigny C, Fitzpatrick M, Webb KA. Exercise hypercapnia in advanced chronic obstructive pulmonary disease: The role of lung hyperinflation. Am J Respir Crit Care Med 2002; 166: 663-8.

74 King A, Cooke N, Leitch A, Flenley D. The effects of $30 \%$ oxygen on the respiratory response to treadmill exercise in chronic respiratory failure. Clin Sci 1973; 44: 15162.

75 Castaing Y, Manier G, Guenard H. Effect of $26 \%$ oxygen breathing on ventilation and perfusion distribution in patients with COLD. Clin Respir Physiol 1985; 21: 1723.

76 Sassoon CS, Hassell KT, Mahutte CK. Hyperoxic-induced hypercapnia in stable chronic obstructive pulmonary disease. Am Rev Respir Dis 1987; 135: 907-11.

77 Liss HP, Grant BJ. The effect of nasal flow on breathlessness in patients with chronic 
obstructive pulmonary disease. Am Rev Respir Dis 1988; 137: 1285-8.

78 Light RW, Mahutte CK, Stansbury DW, Fischer CE, Brown SE. Relationship between Improvement in Exercise Performance with Supplemental Oxygen and Hypoxic Ventilatory Drive in Patients with Chronic Airflow Obstruction. Chest 1989; 95: 751-6.

79 Saadjian A, Philip-Joet F, Levy S, Arnaud A. Vascular and cardiac reactivity in pulmonary hypertension due to chronic obstructive lung disease: assessment with various oxygen concentrations. Eur Respir J 1992; 5: 525-30.

80 O'Donnell DE, Bain DJ, Webb KA. Factors contributing to relief of exertional breathlessness during hyperoxia in chronic airflow limitation. Am J Respir Crit Care Med 1997; 155: 530-5.

81 Edwards L, Perrin K, Williams M, Weatherall M, Beasley R. Randomised controlled crossover trial of the effect on $\mathrm{PtCO} 2$ of oxygen-driven versus air-driven nebulisers in severe chronic obstructive pulmonary disease. Emerg Med J 2012; 29: 894-8.

82 Mithoefer JC, Keighley JF, Cook WR. The AaDO2 and venous admixture at varying inspired oxygen concentrations in chronic obstructive pulmonary disease. Crit Care Med 1978; 6: 131-5.

83 Massaro DJ, Katz S, Luchsinger PC. Effect of various modes of oxygen administration on the arterial gas values in patients with respiratory acidosis. $\mathrm{Br} \mathrm{Med}$ $J$ 1962; 2: 627-9.

84 Richards DW, Fritts HW, Davis AL. Observations on the control of respiration in emphysema: the effects of oxygen on ventilatory response to $\mathrm{CO} 2$ inhalation. Trans Assoc Am Physicians 1958; 71: 142-51.

85 Prime FJ, Westlake EK. The respiratory response to $\mathrm{CO} 2$ in emphysema. Clin Sci 1954; 13: 321-32. 
86 Wilson RH, Hoseth W, Dempsey ME. Respiratory acidosis: I. Effects of decreasing respiratory minute volume in patients with severe chronic pulmonary emphysema, with specific reference to oxygen, morphine and barbiturates. Am J Med 1954; 17: 464-70.

87 Said SI, Banerjee CM. Venous admixture to the pulmonary circulation in human subjects breathing 100 per cent oxygen. J Clin Invest 1963; 42: 507-15.

88 Mithoefer JC, Karetzky MS, Mead GD. Oxygen therapy in respiratory failure. $N$ Engl J Med 1967; 277: 947-9.

89 Schiff MM, Massaro D. Effect of oxygen administration by a Venturi apparatus on arterial blood gas values in patients with respiratory failure. N Engl J Med 1967; 277: $950-3$.

90 Astin TW. The relationships between arterial blood oxygen saturation, carbon dioxide tension, and $\mathrm{pH}$ and airway resistance during 30 per cent oxygen breathing in patients with chronic bronchitis with airway obstruction. Am Rev Respir Dis 1970; 102: $382-7$.

91 Lopez-Majano V, Dutton RE. Regulation of respiration during oxygen breathing in chronic obstructive lung disease. Am Rev Respir Dis 1973; 108: 232-40.

92 Sherter CB, Jabbour SM, Kovnat DM, Snider GL. Prolonged rate of decay of arterial PO2 following oxygen breathing in chronic airways obstruction. Chest 1975; 67: 259-61.

93 Pietak S, Weenig CS, Hickey R, Fairley HB. Anesthetic effects on ventilation in patients with chronic obstructive pulmonary disease. Anesthesiology 1975; 42: 1606.

94 Bone RC, Pierce AK, Johnson Jr. RL. Controlled oxygen administration in acute respiratory failure in chronic obstructive pulmonary disease: a reappraisal. Am J Med 
1978; 65: 896-902.

95 Kawakami Y, Kishi F, Yamamoto H, Miyamoto K. Relation of oxygen delivery, mixed venous oxygenation, and pulmonary hemodynamics to prognosis in Chronic Obstructive Pulmonary Disease. N Engl J Med 1983; 308: 1045-9.

96 Dick CR, Liu Z, Sassoon CS, Berry RB, Mahutte CK. O2-induced change in ventilation and ventilatory drive in COPD. Am J Respir Crit Care Med 1997; 155 : 609-14.

97 Chiang LL, Hung TC, Ho SC, et al. Respiratory response to carbon dioxide stimulation during low flow supplemental oxygen therapy in chronic obstructive pulmonary disease. J Formos Med Assoc 2002; 101: 607-15.

98 Perrin K. High concentration oxygen therapy in acute respiratory disease: $\mathrm{PhD}$ Thesis. 2010.

99 Kawakami Y, Terai T, Yamamoto H, Murao M. Exercise and oxygen inhalation in relation to prognosis of Chronic Obstructive Pulmonary Disease. Chest 1982; 81: $182-8$.

100 Rudolf M, Banks RA, Semple SJ. Hypercapnia during oxygen therapy in acute exacerbations of chronic respiratory failure. Hypothesis revisited. Lancet 1977; 2: 483-6.

101 Abdo WF, Heunks LMA. Oxygen-induced hypercapnia in COPD: myths and facts. Crit Care 2012; 16: 323.

102 Brill SE, Wedzicha JA. Oxygen therapy in acute exacerbations of chronic obstructive pulmonary disease. Int J Chron Obstruct Pulmon Dis 2014; 9: 1241-52.

103 Stradling JR. Hypercapnia during oxygen therapy in airways obstruction: a reappraisal. Thorax 1986; 41: 897-902.

104 Tang Y, Turner MJ, Baker AB. Effects of alveolar dead-space, shunt and V/Q 
distribution on respiratory dead-space measurements. Br J Anaesth 2005; 95: 53848.

105 Verscheure S, Massion PB, Verschuren F, Damas P, Magder S. Volumetric capnography: lessons from the past and current clinical applications. Crit Care 2016; 20: 184 .

106 Feller-Kopman D, Schwartzstein R. The role of hypoventilation and ventilationperfusion redistribution in oxygen-induced hypercapnia during acute exacerbations of chronic obstructive pulmonary disease. Am J Respir Crit Care Med 2001; 163: 1755.

107 Hanson CW, Marshall BE, Frasch HF, Marshall C. Causes of hypercarbia with oxygen therapy in patients with chronic obstructive pulmonary disease. Crit Care Med 1996; 24: 23-8.

108 Rodrigo GJ, Rodriquez Verde M, Peregalli V, Rodrigo C. Effects of short-term 28\% and $100 \%$ oxygen on $\mathrm{PaCO} 2$ and peak expiratory flow rate in acute asthma: a randomized trial. Chest 2003; 124: 1312-7.

109 Chien JW, Ciufo R, Novak R, et al. Uncontrolled oxygen administration and respiratory failure in acute asthma. Chest $2000 ; 117: 728-33$.

110 World Health Organization. Obesity and overweight. http://www.who.int/en/newsroom/fact-sheets/detail/obesity-and-overweight. Accessed March 2018.

111 Ministry of Health New Zealand. Obesity statistics. https://www.health.govt.nz/nzhealth-statistics/health-statistics-and-data-sets/obesity-statistics. Accessed March 2018.

112 Bahammam AS, Al-Jawder SE. Managing acute respiratory decompensation in the morbidly obese. Respirology 2012; 17: 759-71.

113 Shepherd A, Tsai SC. Hypoventilation Syndromes. Curr Pulmonol Reports 2017; 6: 
$82-9$.

114 Mokhlesi B, Tulaimat A. Recent advances in obesity hypoventilation syndrome. Chest 2007; 132: 1322-36.

115 Mokhlesi B. Obesity hypoventilation syndrome: a state-of-the-art review. Respir Care 2010; 55: 1347-65.

116 Nowbar S, Burkart KM, Gonzales R, et al. Obesity-associated hypoventilation in hospitalized patients: prevalence, effects, and outcome. Am J Med 2004; 116: 1-7.

117 Calzavara G, Lusiani GB, Gambari PF, Barbui T, Castellani A. The effect of O2 inhalation on respiratory function in obese patients. G Clin Med 1969; 50: 310-22.

118 Barrera F, Hillyer P, Ascanio G, Bechtel J. The distribution of ventilation, diffusion, and blood flow in obese patients with normal and abnormal blood gases. Am Rev Respir Dis 1973; 108: 819-30.

119 AL-Shirawi N, AL-Jahdali H, Al Shimemeri A. Pathogenesis, etiology and treatment of bronchiectasis. Ann Thorac Med 2006; 1: 41-51.

120 O’Donnell AE. Bronchiectasis. Chest 2008; 134: 815-23.

121 King PT. The pathophysiology of bronchiectasis. Int J Chron Obstruct Pulmon Dis 2009; 4: 411-9.

122 Barnard LT, Zhang J. Asthma Respiratory Foundation NZ. The impact of respiratory disease in New Zealand: 2016 update. https://s3-ap-southeast2.amazonaws.com/assets.asthmafoundation.org.nz/documents/REPORT-Theimpact-on-respiratory-disease-in-New-Zealand-2016-update.pdf. Accessed March 2018.

123 Spier S, Rivlin J, Hughes D, Levison H. The Effect of oxygen on sleep, blood gases, and ventilation in cystic fibrosis. Am Rev Respir Dis 1984; 129: 712-8.

124 Gozal D. Nocturnal ventilatory support in patients with cystic fibrosis: comparison 
with supplemental oxygen. Eur Respir J 1997; 10: 1999-2003.

125 Marcus CL, Bader D, Stabile MW, Wang CI, Osher AB, Keens TG. Supplemental oxygen and exercise performance in patients with cystic fibrosis with severe pulmonary disease. Chest 1992; 101: 52-7.

126 Hutchinson D, Whyte K. Neuromuscular disease and respiratory failure. Pract Neurol 2008; 8: 229-37.

127 Walshaw MJ, Pearson MG. Hypoxia in patients with acute hemiplegia. $\mathrm{Br}$ Med $J$ (Clin Res Ed) 1984; 288: 15-7.

128 Gay PC, Edmonds LC. Severe hypercapnia after low-flow oxygen therapy in patients with neuromuscular disease and diaphragmatic dysfunction. Mayo Clin Proc 1995; 70: $327-30$.

129 Chiou M, Bach JR, Saporito R, Albert O. Quantitation of oxygen-induced hypercapnia in respiratory pump failure. Rev Port Pneumol (English Ed) 2016; 22: $262-5$.

130 BTS guidelines for the management of chronic obstructive pulmonary disease. The COPD Guidelines Group of the Standards of Care Committee of the BTS. Thorax 1997; 52: S1-28.

131 Pauwels RA, Buist AS, Calverley PMA, Jenkins CR, Hurd SS. Global Strategy for the Diagnosis, Management, and Prevention of Chronic Obstructive Pulmonary Disease. Am J Respir Crit Care Med 2001; 163: 1256-76.

132 McKenzie DK, Frith PA, Burdon JGW, Town GI, Australian Lung Foundation, Thoracic Society of Australia and New Zealand. The COPDX Plan: Australian and New Zealand Guidelines for the management of Chronic Obstructive Pulmonary Disease 2003. Med J Aust 2003; 178 Suppl: S7-39.

133 Chow JWY, Khullar K, Katechia K, Klim S, Kelly A-M. Do ambulance paramedics 
administer too much oxygen to patients with acute exacerbations of chronic obstructive airways disease? Emerg Med Australas 2015; 27: 275-6.

134 Susanto C, Thomas PS. Assessing the use of initial oxygen therapy in chronic obstructive pulmonary disease patients: a retrospective audit of pre-hospital and hospital emergency management. Intern Med J 2015; 45: 510-6.

135 Cousins J, Wark P, McDonald V. Acute oxygen therapy: a review of prescribing and delivery practices. Int J Chron Obstruct Pulmon Dis 2016; 11: 1067-75.

136 Beasley R, Chien J, Douglas J, et al. Target oxygen saturation range: 92-96\% versus 94-98\%. Respirology 2017; 22: 200-2.

137 Pu LJ, Shen Y, Lu L, Zhang RY, Zhang Q, Shen WF. Increased blood glycohemoglobin A1c levels lead to overestimation of arterial oxygen saturation by pulse oximetry in patients with type 2 diabetes. Cardiovasc Diabetol 2012; 11: 110.

138 Kelly AM, McAlpine R, Kyle E. How accurate are pulse oximeters in patients with acute exacerbations of chronic obstructive airways disease? Respir Med 2001; 95: $336-40$.

139 Amalakanti S, Pentakota MR. Pulse oximetry overestimates oxygen saturation in COPD. Respir Care 2016; 61: 423-7.

140 Kohyama T, Moriyama K, Kanai R, et al. Accuracy of pulse oximeters in detecting hypoxemia in patients with chronic thromboembolic pulmonary hypertension. PLoS One 2015. DOI:10.1371/journal.pone.0126979.

141 Mckeever TM, Hearson G, Housley G, et al. Using venous blood gas analysis in the assessment of COPD exacerbations : a prospective cohort study. Thorax 2016; 71: $210-5$.

142 Ghayumi SMA, Khalafi-Nezhad A, Jowkar Z. Pulse oximeter oxygen saturation in prediction of arterial oxygen saturation in liver transplant candidates. Hepat Mon 
2014; 14: e15449.

143 Feiner JR, Rollins MD, Sall JW, Eilers H, Au P, Bickler PE. Accuracy of carboxyhemoglobin detection by pulse CO-oximetry during hypoxemia. Anesth Analg 2013; 117: 847-58.

144 Chen G, Zhu Z, Liu J, Wei W. Esophageal pulse oximetry is more accurate and detects hypoxemia earlier than conventional pulse oximetry during general anesthesia. Front Med 2012; 6: 406-10.

145 Nesseler N, Fre’nel J-V, Launey Y, Morcet J, Melle'dant Y, Seguin P. Pulse oximetry and high-dose vasopressors : a comparison between forehead reflectance and finger transmission sensors. Physiol Tech Notes 2012; 38: 1718-22.

146 Wax D, Rubin P, Neustein S. A Comparison of Transmittance and Reflectance Pulse Oximetry During Vascular Surgery. Int Anesth Res Soc 2009; 109: 1847-9.

147 Hodgson CL, Tuxen DV, Holland AE, Keating JL. Comparison of forehead MaxFast pulse oximetry sensor with finger sensor at high positive end-expiratory pressure in adult patients with acute respiratory distress syndrome. Anaesth Intensive Care 2009; 37: 953-60.

148 Thomas FO, Hoffman TL, Handrahan DL, Crapo RO, Snow G. The measure of treatment agreement between portable and laboratory blood gas measurements in guideing protocol-driven ventilator management. J Trauma-Injury Infect Crit Care 2009; 67: 303-14.

149 Perkins GD, McAuley DF, Giles S, Routledge H, Gao F. Do changes in pulse oximeter oxygen saturation predict equivalent changes in arterial oxygen saturation? Crit Care 2003; 7: R67.

150 Munoz X, Torres F, Sampol G, Rios J, Marti S, Escrich E. Accuracy and reliability of pulse oximetry at different arterial carbon dioxide pressure levels. Eur Respir J 
2008; 32: 1053-9.

151 Feiner JR, Severinghaus JW, Bickler PE. Dark skin decreases the accuracy of pulse oximeters at low oxygen saturation: The effects of oximeter probe type and gender. Int Anesth Res Soc 2007; 105: S18-23.

152 Haynes JM. The ear as an alternative site for a pulse oximeter finger clip sensor. Respir Care 2007; 52: 727-9.

153 Fernandez M, Burns K, Calhoun B, George S, Martin B, Weaver C. Evaluation of a new pulse oximeter sensor. Am J Crit Care 2007; 16: 147-52.

154 Hinkelbein J, Genzwuerker HV, Sogl R, Fiedler F. Effect of nail polish on oxygen saturation determined by pulse oximetry in critically ill patients. Resuscitation 2007 ; 72: 82-91.

155 Hinkelbein J, Koehler H, Genzwuerker HV, Fiedler F. Artificial acrylic finger nails may alter pulse oximetry measurement. Resuscitation 2007; 74: 75-82.

156 Schallom L, Sona C, McSweeney M, Mazuski J. Comparison of forehead and digit oximetry in surgical / trauma patients at risk for decreased peripheral perfusion. Hear Lung 2007; 36: 188-94.

157 Peng L, Yan C, Lu H, Xia Y. Evaluation of analytic and motion-resistant performance of the Mindray 9006 Pulse Oximeter. Med Sci Monit 2007; 13: 19-28.

158 Lee WW, Mayberry K, Crapo R, Jensen RL. The accuracy of pulse oximetry in the emergency department. Am J Emerg Med 2000; 18: 427-31.

159 Wilson BJ, Cowan HJ, Lord JA, Zuege DJ, Zygun DA. The accuracy of pulse oximetry in emergency department patients with severe sepsis and septic shock: a retrospective cohort study. BMC Emerg Med 2010; 10: 9.

160 Wouters PF, Gehring H, Meyfroidt G, et al. Accuracy of pulse oximeters: the European multi-center trial. Anesth Analg 2002; 94: S13-6. 
161 Van de Louw A, Cracco C, Cerf C, et al. Accuracy of pulse oximetry in the intensive care unit. Intensive Care Med 2001; 27: 1606-13.

162 Ebmeier SJ, Bacon M, Barker M, et al. A Two Center Observational Study of Simultaneous $\mathrm{SpO} 2$ and $\mathrm{SaO} 2$ Recordings in ICU Patients. Anaesth Intensive Care 2017; Pending Publication.

163 Singh AK, Sahi MS, Mahawar B, Rajpurohit S. Comparative evaluation of accuracy of pulse oximeters and factors affecting their performance in a tertiary intensive care unit. J Clin Diagnostic Res 2017; 11: OC05-OC08.

164 Yamamoto A, Burioka N, Eto A, Amisaki T, Shimizu E. Usefulness of pulse oximeter that can measure $\mathrm{SpO} 2$ to one digit after decimal point. Yonago Acta Mediica 2017; 60: 133-4.

165 Hale KE, Gavin C, O’Driscoll BR. Audit of oxygen use in emergency ambulances and in a hospital emergency department. Emerg Med J 2008; 25: 773-6.

166 Roberts CM, Stone RA, Buckingham RJ, Pursey NA, Lowe D. Acidosis, noninvasive ventilation and mortality in hospitalised COPD exacerbations. Thorax 2011; 66: $43-8$.

167 Beasley R, Patel M, Perrin K, O’Driscoll BR. High-concentration oxygen therapy in COPD. Lancet 2011; 378: 969-70.

168 Wellington Free Ambulance Incorporated. Clinical Practice Guidelines Comprehensive Edition, 2.4 Exacerbation of CORD. 2009.

169 Turner MO, Patel A, Ginsburg S, FitzGerald JM. Bronchodilator delivery in acute airflow obstruction. A meta-analysis. Arch Intern Med 1997; 157: 1736-44.

170 Heys D, Swain A, Knowles S, Waugh A, Bailey M. An audit of change in clinical practice: from oxygen-driven to air-driven nebulisers for prehospital patients with Acute Exacerbations of Chronic Obstructive Pulmonary Disease (AECOPD). Intern 
Med J 2017; published online Nov 29. DOI:10.1111/imj.13684.

171 Pretto JJ, Roebuck T, Beckert L, Hamilton G. Clinical use of pulse oximetry: official guidelines from the Thoracic Society of Australia and New Zealand. Respirology 2014; 19: 38-46.

172 FDA. Pulse Oximeters - Premarket Notification Submissions: Guidance for Industry andFood and Drug Administration Staff. 2013.

173 Roberts WE. Skin type classification systems old and new. Dermatol Clin 2009; 27: 529-33, viii.

174 Beasley R, Chien J, Douglas J, et al. Target oxygen saturation range: 92-96\% versus 94-98. Respirology 2017; 22: 200-2.

175 Fingleton J, McKinstry S, Pilcher J, Weatherall M, Beasley R, Bardsley G. Accuracy of transcutaneous carbon dioxide measurement for change over time: TSANZ Oral presentations. Respirology 2017; 22: 18-100.

176 Senn O, Clarenbach CF, Kaplan V, Maggiorini M, Bloch KE. Monitoring carbon dioxide tension and arterial oxygen saturation by a single earlobe sensor in patients with critical illness or sleep apnea. Chest 2005; 128: 1291-6.

177 Kocher S, Rohling R, Tschupp A. Performance of a digital PCO2/SPO2 ear sensor. J Clin Monit Comput 2004; 18: 75-9.

178 Miller MR, Hankinson J, Brusasco V, et al. Standardisation of spirometry. Eur Respir J 2005; 26: 319-38.

179 Pilcher J, Cameron L, Braithwaite I, et al. Comparative audit of oxygen use in the prehospital setting, in acute COPD exacerbation, over 5 years. Emerg Med $J$, emermed-2013-203094, Publ Online First 2013.

180 Wagstaff TAJ, Soni N. Performance of six types of oxygen delivery devices at varying respiratory rates. Anaesthesia 2007; 62: 492-503. 
181 Ambrosino N, Carpene N, Gherardi M. Chronic respiratory care for neuromuscular diseases in adults. Eur Respir $J$ 2009; 34: 444-51.

182 Hollier CA, Maxwell LJ, Harmer AR, et al. Validity of arterialised-venous PCO2, $\mathrm{pH}$ and bicarbonate in obesity hypoventilation syndrome. Respir Physiol Neurobiol 2013. DOI:10.1016/j.resp.2013.05.031.

183 Brazzale DJ, Pretto JJ, Schachter LM. Optimizing respiratory function assessments to elucidate the impact of obesity on respiratory health. Respirology $2015 ; \mathbf{2 0}$ : $715-$ 21.

184 Pilcher J, Richards M, Eastlake L, et al. High flow or titrated oxygen for obese medical inpatients: a randomised crossover trial. Med J Aust 2017; 207: 430-4.

185 Johnston CE, Richards BS, Sucato DJ, Bridwell KH, Lenke LG, Erickson M. Correlation of preoperative deformity magnitude and pulmonary function tests in adolescent idiopathic scoliosis. Spine 2011; 36: 1096-102.

186 Uldry C, Fitting JW. Maximal values of sniff nasal inspiratory pressure in healthy subjects. Thorax 1995; 50: 371-5.

187 Miller MR, Crapo R, Hankinson J, et al. General considerations for lung function testing. Eur Respir J 2005; 26: 153-61.

188 Nice guidelines. Chronic obstructive pulmonary disease in over 16s: diagnosis and management. Clinical guideline published: 23 June 2010. https://www.nice.org.uk/guidance/cg101/resources/chronic-obstructive-pulmonarydisease-in-over-16s-diagnosis-and-mana. Accessed March 2018.

189 Domingo C, Canturri E, Moreno A, Espuelas H, Vigil L, Luján M. Optimal clinical time for reliable measurement of transcutaneous $\mathrm{CO} 2$ with ear probes: Counterbalancing overshoot and the vasodilatation effect. Sensors 2010; 10: 491500. 
190 Kagawa S, Otani N, Kamide M, Gisiger PA, Eberhard P, Severinghaus JW. Initial transcutaneous $\mathrm{PCO} 2$ overshoot with ear probe at $42^{\circ} \mathrm{C}$. J Clin Monit Comput 2004; 18: $343-5$.

191 Saadjian AY, Philip-Joet FF, Barret A, Levy S, Amaud AG. Effect of almitrine bismesylate on pulmonary vasoreactivity to hypoxia in chronic obstructive pulmonary disease. Eur Respir J 1994; 7: 862-8.

192 Vos PJ, Folgering HT, de Boo TM, Lemmens WJ, van Herwaarden CL. Effects of chlormadinone acetate, acetazolamide and oxygen on awake and asleep gas exchange in patients with chronic obstructive pulmonary disease (COPD). Eur Respir J 1994; 7: $850-5$.

193 Calverley PM. Respiratory failure in chronic obstructive pulmonary disease. Eur Respir Journal Supplement 2003; 47: 26s-30s.

194 Yamauchi H, Ito S, Sasano H, Azami T, Fisher J, Sobue K. Dependence of the gradient between arterial and end-tidal P CO2 on the fraction of inspired oxygen. $\mathrm{Br}$. J. Anaesth. 2011; 107: 631-5.

195 Rodriguez P, Lellouche F, Aboab J, Buisson CB, Brochard L. Transcutaneous arterial carbon dioxide pressure monitoring in critically ill adult patients. Intensive Care Med 2006; 32: 309-12.

196 Nishiyama T, Kohno Y, Koishi K. Comparison of ear and chest probes in transcutaneous carbon dioxide pressure measurements during general anesthesia in adults. J Clin Monit Comput 2011; 25: 323-8.

197 Roediger R, Beck-Schimmer B, Theusinger OM, et al. The revised digital transcutaneous $\mathrm{PCO} 2 / \mathrm{SpO} 2$ ear sensor is a reliable noninvasive monitoring tool in patients after cardiac surgery. J Cardiothorac Vasc Anesth 2011; 25: 243-9.

198 Storre JH, Magnet FS, Dreher M, Windisch W. Transcutaneous monitoring as a 
replacement for arterial PCO 2 monitoring during nocturnal non-invasive ventilation. Respir Med 2011; 105: 143-50.

199 Chhajed PN, Miedinger D, Baty F, et al. Comparison of combined oximetry and cutaneous capnography using a digital sensor with arterial blood gas analysis. Scand J Clin Lab Invest 2010; 70: 60-4.

200 Storre JH, Steurer B, Kabitz HJ, Dreher M, Windisch W. Transcutaneous PCO2 monitoring during initiation of noninvasive ventilation. Chest 2007; 132: 1810-6.

201 Baulig W, Schütt P, Roth HR, Hayoz J, Schmid ER. Clinical validation of a digital transcutaneous $\mathrm{PCO} 2 / \mathrm{SpO} 2$ ear sensor in adult patients after cardiac surgery. J Clin Monit Comput 2007; 21: 303-9.

202 Bolliger D, Steiner LA, Kasper J, Aziz OA, Filipovic M, Seeberger MD. The accuracy of non-invasive carbon dioxide monitoring: A clinical evaluation of two transcutaneous systems. Anaesthesia 2007; 62: 394-9.

203 Herrejón A, Inchaurraga I, Palop J, et al. Usefulness of transcutaneous carbon dioxide pressure monitoring to measure blood gases in adults hospitalized for respiratory disease. Arch Bronconeumol 2006; 42: 225-9.

204 Domingo C, Canturri E, Luján M, Moreno A, Espuelas H, Marín A. Transcutaneous measurement of partial pressure of carbon dioxide and oxygen saturation: validation of the SenTec monitor. Arch Bronconeumol 2006; 42: 246-51.

205 Restrepo RD, Hirst KR, Wittnebel L, Wettstein R. AARC clinical practice guideline: transcutaneous monitoring of carbon dioxide and oxygen: 2012. Respir Care 2012; 57: $1955-62$.

206 Zavorsky GS, Cao J, Mayo NE, Gabbay R, Murias JM. Arterial versus capillary blood gases: a meta-analysis. Respir Physiol Neurobiol 2007; 155: 268-79. 
Appendix 1: Original study data and assessments of transcutaneous monitor function 


\section{A.1 Overview}

\section{A.1.1 Original and repeat studies in this thesis}

The studies in Chapters 4 and 5 were originally conducted using a TOSCA transcutaneous monitor (Radiometer, Denmark). However, concerns regarding the TOSCA probe accuracy led to the decision to discard the $\mathrm{PtCO}_{2}$ data, and that the studies needed to be repeated. The findings from the repeat studies are reported in Chapters 4 and 5.

Outlined in this Section are an overview of the principles of transcutaneous monitoring, detail of the events leading to concerns regarding the accuracy of transcutaneous monitoring in the original studies and the actions taken to address them.

\section{A.1.2 Principles of transcutaneous monitoring and potential sources of error}

\section{Equipment details}

The monitors and probes that have been used in the studies in this thesis are the TOSCA 500 monitor with the 92 sensor probe and the SenTec monitor with the V-sign sensor probe. Based on manual recommendations, both were used with a heating temperature of 42 degrees. Information included in this Section is from the TOSCA 500 manual (July 2010), SenTec manuals (Technical manual HB-005752-g-SDM and Instruction manual HB005771-h), or as referenced.

\section{How the monitors work}

The TOSCA and SenTec measure $\mathrm{CO}_{2}$ via a probe that can be painlessly positioned on the skin of the earlobe with a disposable clip. The probe is heated to encourage arterialisation of the vessels beneath the skin. $\mathrm{CO}_{2}$ is able to diffuse through the tissue and skin of the 
earlobe to the surface of the probe. The surface is covered by a membrane which is highly gas permeable and protected by a thin plate. Underneath the membrane sits an electrolyte layer. The membranes and electrolyte layer need to be changed frequently; every 14 days for the TOSCA and every month for the SenTec. Both devices have automated alarms and warnings that appear on their screens when a membrane change is due.

Inside the probe is a Severinghous electrode, which measures $\mathrm{CO}_{2}$ by determining $\mathrm{pH}$ changes. As well as $\mathrm{PtCO}_{2}$, transcutaneous monitors can also measure $\mathrm{SpO}_{2}$ and heart rate. All three measures can be uploaded to device specific computer software for review.

\section{Discrepancies between $\mathrm{PaCO}_{2}$ and $\mathrm{PtCO}_{2}$}

$\mathrm{PtCO}_{2}$ is an indirect measurement of $\mathrm{PaCO}_{2}$. The temperature of the probe (which can increase local blood and tissue $\mathrm{PCO}_{2}$ ) and $\mathrm{CO}_{2}$ production by the skin mean that $\mathrm{PtCO}_{2}$ values tend to be higher than $\mathrm{PaCO}_{2}$. Both the TOSCA and SenTec monitors apply correction factors to their displayed $\mathrm{PtCO}_{2}$ values to account for this.

Factors that may affect monitor accuracy may be device related (such as issues with probe stabilisation, calibration or membrane placement) or clinical (such as perfusion, skin thickness or patient movement). ${ }^{205}$ Guidelines recommend validation of $\mathrm{PtCO}_{2}$ values against simultaneously measured $\mathrm{PaCO}_{2}$ via $\mathrm{ABG}$ at the start of monitoring. Additional comparisons to $\mathrm{PaCO}_{2}$ are also recommended during monitoring, depending on the patient's condition. ${ }^{205}$ TOSCA and SenTec both have functions where a simultaneously measured $\mathrm{PaCO}_{2}$ value can be entered and subsequent $\mathrm{PtCO}_{2}$ values are corrected by any discrepancy.

Another potential source of error is drift. This occurs when changes in the electrolyte composition under the membrane (such as water content or contamination) change the measured potential of the probe. This is addressed by calibration of the probe against a gas with a known $\mathrm{CO}_{2}$ concentration. The TOSCA and SenTec monitors have chambers in which the probes sit and calibration automatically occurs when the device is switched on and at regular intervals thereafter when the probe is in the chamber. When the SenTec and TOSCA probes are functioning correctly drift has been reported to be minimal over the space of an hour. ${ }^{197,198,200}$ 


\section{Issues with calibration and stabilisation}

If a probe cannot be calibrated within a certain time period (10 minutes for the TOSCA, or 14 minutes for the SenTec) a message stating "extended calibration" is displayed. If the calibration cannot be completed successfully the TOSCA monitor asks for the probe to be remembraned. In the SenTec, specific error messages stating 'sensor problem' with a specific code number are displayed. Codes describe factors such as slow responsiveness of the probe or instability of the probe. Additionally, the SenTec will display a 'recommended sensor stabilisation interval' to improve probe stability in certain situations, such as a recent membrane change (recommended stability period of 90 minutes before use). In this case, the probe was not used until the recommended stabilisation interval had passed.

Over time, chemical changes can occur on the surface of the probe. Specific to the TOSCA, if there are issues with the calibration, sensitivity, stability or drift of a probe (which are not solved by cleaning the probe or calibration chamber), Radiometer use a 'regeneration' solution applied to the probe's surface which may result in improvement in probe function.

Physiological stabilisation is required when a transcutaneous probe is positioned on a patient. This is the time taken for arterialisation and for the gases between the skin and probe to reach equilibrium. In the TOSCA manual it states that it takes up to 5 minutes for arterialisation to occur. The SenTec manual states stabilisation takes between 2 and 10 minutes. Based on manual instructions and literature on stabilisation, ${ }^{189,190}$ a 12 minute stabilisation period was used for the TOSCA. If $\mathrm{PtCO}_{2}$ values were not within $1 \mathrm{mmHg}$ of each other at the 10 minute and 12 minute time points, stabilisation was extended until values were within $1 \mathrm{mmHg}$ at the start and end of a subsequent one minute period. There was a minimum 20 minute stabilisation period for the SenTec in the RCT of oxygen in obese hospital inpatients. This was extended if values were not within $1 \mathrm{mmHg}$ at 18 and 20 minutes. Based on this study, the minimum stabilisation period for the cross over trials in COPD, neuromuscular disease/kyphoscoliosis and bronchiectasis was 30 minutes, with extension if the 28 minute and 30 minute values were not within $1 \mathrm{mmHg}$ of each other. 


\section{A.1.3 Events leading to concerns regarding the accuracy of transcutaneous monitoring in the original studies and actions taken}

The original RCT in obese hospital patients recruited participants between November 2011 and October 2013. The recruitment of the original cross over trials in stable COPD, neuromuscular disease/kyphoscoliosis and bronchiectasis took place between June 2012 and January 2015.

It was noted that the TOSCA probes used often required extended calibration times in 2011. After consulting with Radiometer, their use was continued. By June 2014 the requirement for extended calibration was occurring frequently. When one of the probes gave physiologically unlikely values during testing, Radiometer was contacted again. It was suggested that the membrane batch was at fault so we were supplied with a new batch. This did not solve the issue. On review by Radiometer in August 2014 one of the probes was found to have surface changes that could have resulted in measurement errors. This probe was regenerated by Radiometer and returned to us, but was not used for subsequent study visits. Another probe was subsequently not recommended for use in the period following testing due to ongoing extended calibrations and failures of calibration (with request for membrane replacement prior to the 14-day lifespan of the membrane). We were also informed that while there is no set 'use by' date for the probes, they have a lifespan of approximately two years. The two probes were thought to be over 3 years old at the start of recruitment for the RCT in obese hospital inpatients in November 2011.

A new TOSCA probe was ordered in August 2014. On arrival this probe had ongoing issues with calibration and there were $\mathrm{PtCO}_{2}$ discrepancies between the new probe, the resurfaced probe and a third probe available for use. The RCT in obese patients and the cross over study in bronchiectasis patients had been fully recruited by this stage. There were 18 participants recruited to the neuromuscular disease/kyphoscoliosis study and 9 recruited to the COPD study. All upcoming study visits were cancelled and the equipment (probes and monitors) sent to Radiometer for assessment. Radiometer found no causes for the discrepancies, however it did appear that the new probe had previously required regeneration. A replacement probe was offered, which arrived in October 2014. 
On consultation with Radiometer the following measures were implemented to potentially improve calibration methods:

- Calibration gas canisters were to be discarded within 4 months of attachment to the TOSCA

- The TOSCA monitor was to remain on for at least 2 hours prior to use (despite display saying 'ready to use')

- The TOSCA monitor was not to be used for at least 4 hours after membrane replacement (despite display saying 'ready to use')

- Low threshold for asking Radiometer for review- particularly upon messages for extended calibration or failed calibration.

In January 2015 it was decided, in conjunction with my supervisor Professor Richard Beasley, and MRINZ Deputy Director Dr Irene Braithwaite, to develop a strategy whereby a decision could be made as to whether the $\mathrm{PtCO}_{2}$ data obtained to date was valid. This involved recruiting a second set of 24 participants to repeat the RCT of oxygen in obesity. This would serve two purposes. Firstly, it would allow comparison of the magnitude of change in $\mathrm{PtCO}_{2}$ between the two studies. Secondly, it was considered worthwhile undertaking the study again, regardless of the validity of the first study findings, because the generalisability of results to the general hospital patient population would be improved by the removal of a number of exclusion criteria (see Section A.2.1). Additionally, 12 patients from each of the neuromuscular disease/kyphoscoliosis and bronchiectasis studies were to be invited to a repeat study visit to assess data repeatability.

By June 2015 it was apparent that there were significant differences in the data from the original and repeat RCTs of oxygen in obesity (4 of the 24 participants (16\%) had an increase in $\mathrm{PtCO}_{2} \geq 4 \mathrm{mmHg}$ during oxygen delivery in the original study, in the repeat study it was 8 of the 12 participants monitored by TOSCA (67\%)). Recruitment had not yet started for the repeat participants in the neuromuscular disease/kyphoscoliosis and bronchiectasis studies. This was discussed with Professor Richard Beasley and Dr Irene Braithwaite and it was considered that the difference in findings provided further evidence of the uncertain validity of the $\mathrm{PtCO}_{2}$ data from the original studies. Given the uncertainty regarding the accuracy of the transcutaneous data from the original RCT in obesity and the cross over 
trials in stable COPD, neuromuscular disease/kyphoscoliosis and bronchiectasis, all transcutaneous data and data derived from transcutaneous measurements were to be discarded. A decision was made that in addition to completing the repeat oxygen in obesity study, the cross over trials in stable COPD, neuromuscular disease/kyphoscoliosis and bronchiectasis would also be repeated, using SenTec transcutaneous monitors.

In July 2015, the new TOSCA probe started failing calibrations (with repeated requests for membrane replacement) and the surface appeared discoloured. The probe was returned to Radiometer immediately and after a lengthy maintenance check it was determined to have 'no issue'. In the interim it was decided that the rest of the participants would have their transcutaneous measurements done by the SenTec monitors.

To monitor the performance of the SenTec monitors a system was developed where every year contact is made with SenTec New Zealand to discuss whether a maintenance check is required or probes need to be inspected. As per the manual, SenTec were also to be contacted if any maintenance checks were failed or any alarm occurred that required contact such the messages of 'gas leak', 'extended calibration' or ' $\mathrm{PCO}_{2}$ slow'. After switching the SenTec on or changing the probe membrane there was a four hour period prior to use (despite the device display reporting it is 'ready for use'), to ensure stabilisation.

Additionally, the following four studies were performed to assess SenTec probe function. They ran as part of, or concurrently with, the studies in Chapters 4 and 5.

1. Assessment of drift corrected SenTec data from the cross over trials in COPD, neuromuscular disease/kyphoscoliosis and bronchiectasis (Chapter 5), to identify any issues in calibration and probe drift that may affect data

2. Assessment of SenTec versus arterialised capillary blood gas measured $\mathrm{PCO}_{2}$ in the cross over study in COPD participants (Chapter 5), to assess $\mathrm{PtCO}_{2}$ accuracy in the study setting

3. Assessment of SenTec versus ABG data in hospital patients requiring an $A B G$ as part of their clinical assessment, to evaluate accuracy of single $\mathrm{PtCO}_{2}$ measures

4. Assessment of repeated SenTec versus arterialised capillary blood gas measurements of $\mathrm{PCO}_{2}$ in a study of oxygen vs air-driven nebulisers, to assess accuracy of $\mathrm{PtCO}_{2}$ measures in detecting changes in $\mathrm{PCO}_{2}$. 


\section{A.2 The original RCT of oxygen in obese hospital inpatients}

For clarity, the original RCT of oxygen in obese hospital inpatients is referred to as 'the

Original Study', while the study presented in Chapter 4 is referred to as the 'Repeat Study' throughout Section A.2.

\section{A.2.1 Original Study methodology}

The Original Study had identical methodology to the Repeat Study with the exception of the transcutaneous monitors used and the following differences:

\section{Inclusion /exclusion criteria}

The Original Study included the following exclusion criteria:

- Administration of respiratory suppressant medications, including opiate analgesia and benzodiazepines within 24 hours

- $\quad$ FEV1 / Forced vital capacity (FVC) is $<0.7$

These inclusion/exclusion criteria were subsequently removed in the Repeat Study. This was done in response to the unexpected finding that over 300 patients had to be screened in the Original Study to gain 24 participants meeting the study inclusion/exclusion criteria. This unexpectedly large number of patient exclusions may have limited the generalisability of these study findings to obese patients presenting to hospital. Many patients had to be excluded as they were on small doses of benzodiazepines or opioid medications within 24 hours. Exclusions were originally included to avoid potential respiratory suppression impacting on results, however the doses that most excluded patients were on were too low to have an effect on the respiratory system. In addition, a number of potential participants were excluded as they could not or would not perform the spirometry required to assess the $\mathrm{FEV}_{1} / \mathrm{FVC}$ entry criteria. For the Repeat Study in Chapter 4 the exclusion criteria "Any 
other condition which, at the investigator's discretion, is believed may present a safety risk or impact on the feasibility of study results" was able to be used in situations where there was concern that a potential participant was on levels of medication could affect respiratory drive or had spirometry values and/or a history that could not reasonably rule out COPD.

\section{Ethical approval and trial registration}

The Repeat Study was retained under the same Ethics Committee study number. Prior to recruitment for the Repeat Study the Central Health and Disability Ethics Committee approved an amendment request to repeat the study in a further 24 participants and alter the inclusion/exclusion criteria as outlined above.

Both the Original and Repeat Studies have the same ANZCTR number: ACTRN12610000522011.

\section{A.2.2 Original Study results and interpretation}

Participants were recruited between November 2011 and October 2013. Three hundred and fifty three inpatients were screened, with 24 randomised (Figure 6.1). Respiratory rate was the only outcome measure that was not dependent on TOSCA data. 


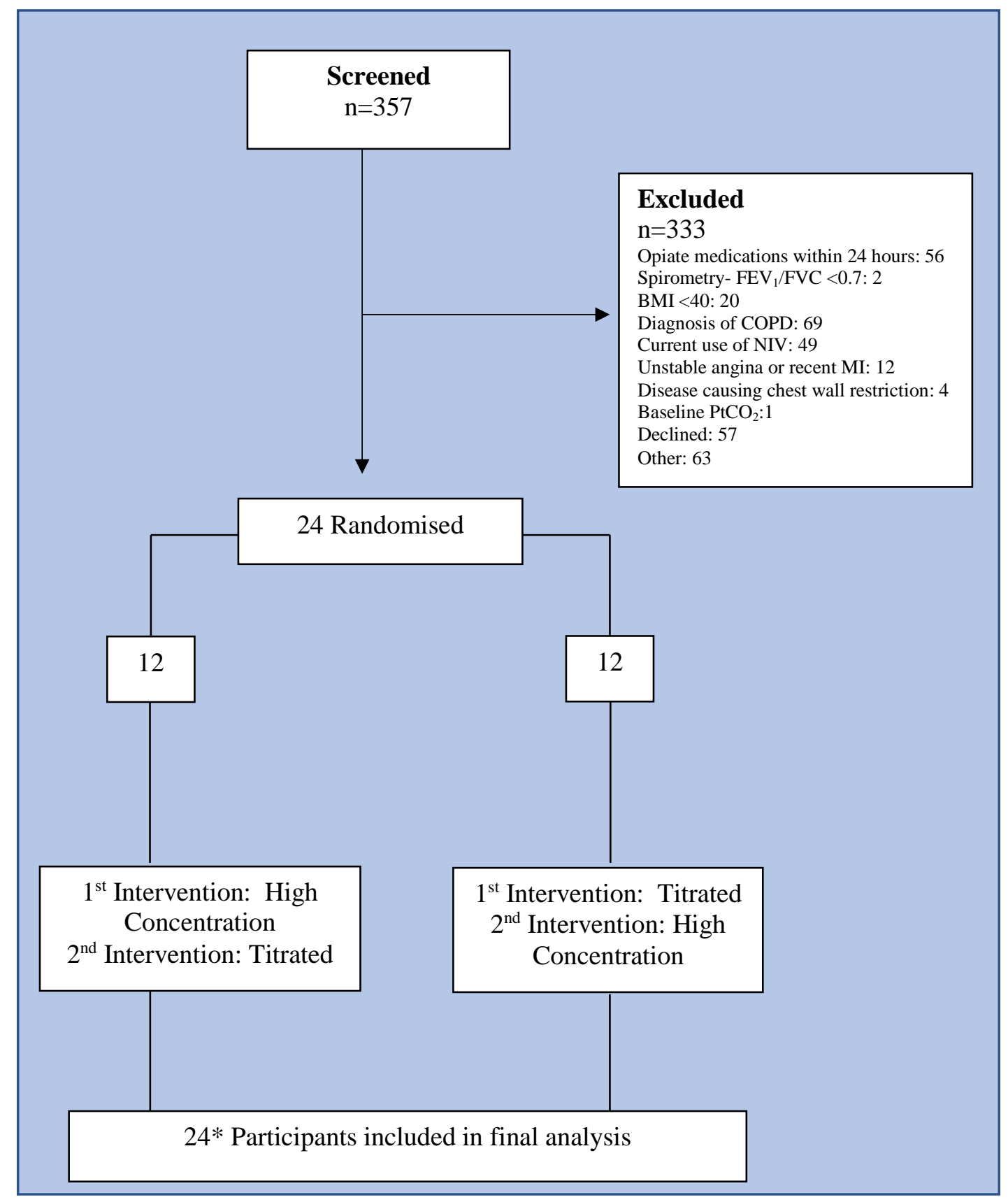

\section{Figure 6.1 Flow of participants through the study}

BMI: Body mass index, COPD: Chronic obstructive pulmonary disease, $\mathrm{FEV}_{1} / \mathrm{FVC}$ : Forced expiratory volume over 1 second/forced vital capacity, MI: Myocardial infarction, NIV: Non-invasive ventilation, $\mathrm{PtCO}_{2}$ : Transcutaneous partial pressure of carbon dioxide.

* 60 minute data for respiratory rate missing due to early withdrawal for treatment of low blood glucose during high concentration arm in one participant and outcome not being measured in error in titrated arm in one participant. 
Patients were studied a median (range) of 1.7 ( 0 to 5) days after admission. Table 6.1 shows the baseline characteristics of the participants. The mean BMI was $51.7 \mathrm{~kg} / \mathrm{m}^{2}$. None of the participants had a previous physician's diagnosis of OHS. Eight participants reported a history of witnessed apnoea and snoring, although none had a diagnosis of obstructive sleep apnoea. One participant had an admission diagnosis of asthma. None of the participants required oxygen during the titrated arm. The only outcome that was not measured via TOSCA was respiratory rate, presented in Table 6.2. 


\begin{tabular}{|lc|}
\hline Characteristic & Mean (SD) \\
\hline Age (years) & $44.9(12.4)$ \\
$\mathrm{BMI}\left(\mathrm{kg} / \mathrm{m}^{2}\right)$ & $51.7(8.6)$ \\
$\mathrm{FEV}_{1} / \mathrm{FVC}$ & $82.0(0.07)$ \\
\hline & $\mathbf{n}(\%)$ \\
\hline Male sex & $13(54.2)$ \\
\hline Ethnicity & \\
Māori & $7(29.2)$ \\
NZ European & $6(25.0)$ \\
Pacific Island & $8(33.3)$ \\
European other & $3(12.5)$ \\
\hline Days since admission & $16(66.7)$ \\
$\leq 1$ & $4(16.7)$ \\
2 & $4(16.7)$ \\
\hline 3 or more & $15(62.5)$ \\
\hline Diagnosis & $2(8.3)$ \\
Cellulitis & $1(4.2)$ \\
Diabetes (poor control) & $6(24.0)$ \\
Asthma & $4(16.7)$ \\
Other* & $6(24.0)$ \\
\hline Smoking status** & $11(45.8)$ \\
Current & \\
Ex smoker & \\
\hline
\end{tabular}

\section{Table 6.1 Baseline characteristics}

BMI: Body mass index, $\mathrm{FEV}_{1}$ : Forced expiratory volume in one second, FVC: Forced vital capacity.

*1 participant for each of the following diagnoses: nephrotic syndrome, gout, shortness of breath (unknown cause), collapse, pyelonephritis, anaemia. ** $\mathrm{N}=21$ (data unavailable for 3 participants).

$\mathrm{N}=24$ unless otherwise stated. 


\begin{tabular}{|c|c|c|c|c|}
\hline \multirow[b]{2}{*}{$\begin{array}{l}\text { Time } \\
(\text { min) }\end{array}$} & \multicolumn{2}{|c|}{ Mean (SD) } & \multirow{2}{*}{$\begin{array}{c}\text { High } \\
\text { concentration } \\
\text { minus titrated } \\
\text { oxygen therapy } \\
(95 \% \mathrm{CI})\end{array}$} & \multirow[b]{2}{*}{$\mathbf{P}$} \\
\hline & $\begin{array}{c}\text { High } \\
\text { concentration } \\
\text { oxygen }\end{array}$ & $\begin{array}{c}\text { Titrated } \\
\text { oxygen }\end{array}$ & & \\
\hline 0 & $20.3(5.1)$ & $20.3(4.0)$ & & \\
\hline 10 & $19.8(4.0)$ & $19.6(4.6)$ & $0.3(-1.4$ to 1.9$)$ & 0.75 \\
\hline 20 & $20.5(4.1)$ & $20.0(4.2)$ & $0.5(-1.4$ to 2.4$)$ & 0.58 \\
\hline 30 & 20.7 (3.9) & $19.9(5.2)$ & 0.8 (-1.3 to 2.9$)$ & 0.45 \\
\hline 40 & $20.3(4.0)$ & $20.0(5.0)$ & 0.3 (-1.7 to 2.2$)$ & 0.76 \\
\hline 50 & $20.3(4.0)$ & $20.1(5.0)$ & 0.1 (-1.9 to 2.1$)$ & 0.90 \\
\hline 60 & $20.7(4.0)^{*}$ & $19.9(4.2)^{* *}$ & $0.6(-1.2$ to 2.3$)$ & 0.52 \\
\hline
\end{tabular}

Table 6.2 Mean values and mixed linear model differences for respiratory rate (breaths per minute)

* $\mathrm{N}=23$ due to early withdrawal for treatment of low blood glucose. ${ }^{* *} \mathrm{~N}=23$ due to outcome not being measured in error.

$\mathrm{N}=24$ unless otherwise stated. 
In both studies mean respiratory rate values at sat around 18 to 20 breaths per minute, and there was no difference in respiratory rate between the high concentration and titrated regimens. The respiratory rate values from the Original Study therefore support the findings in the Repeat Study and suggest repeatability between the two studies for this outcome. 


\section{A.3 The original studies in patients with COPD, bronchiectasis and neuromuscular disease or kyphoscoliosis}

For clarity, the original cross over studies in patients with stable COPD, bronchiectasis and neuromuscular disease or kyphoscoliosis are referred to as the 'Original Studies', while the studies presented in Chapter 5 are referred to as the 'Repeat Studies' throughout Section A.3.

\section{A.3.1 Original Study methodology}

The Original Studies had identical methodology to the Repeat Studies with the exception of the transcutaneous monitor used and the following differences:

\section{Inclusion /exclusion criteria:}

The Original Studies did not require the exception to $\mathrm{FEV}_{1}$ matching between COPD and bronchiectasis participants for the three bronchiectasis participants that had $\mathrm{FEV}_{1}$ percentage predicted values of $109 \%$ or higher (a match could be made with COPD participants with an $\mathrm{FEV}_{1}$ percent predicted of $80 \%$ or over). Otherwise all criteria were the same.

\section{SenTec drift correction data and arterialised capillary blood gas sampling}

Drift correction is a function specific to the SenTec so was added to the Repeat Studies and not applicable to the Original Studies (See Section A.4.1 for further detail).

Arterialised capillary blood gas samples were added to the repeat COPD study as an assessment of SenTec accuracy (See Section A.4.2 for further detail). 


\section{Statistical analysis}

In response to peer review comments of the obesity study, a mixed linear model was developed to incorporate data from all time points and assess changes over time between the interventions for each outcome. This differed from the original analyses which reported mixed linear models for each time point (10, 20 or 30 minutes). The primary outcome of $\mathrm{PtCO}_{2}$ at the single time point of 30 minutes was retained.

\section{Ethical approval and trial registration}

The Repeat Studies were kept under the same Ethics Committee study numbers (Table 6.3). Prior to recruitment for the Repeat Studies the relevant Health and Disability Ethics Committees approved amendment requests to repeat each study in a further 24 participants, alterations to exclusion criteria, and, in the case of the COPD study, to take an arterialised capillary blood gas.

The ANZCTR requested separate trial registrations for each study. The Original Study registration numbers are presented in Table 6.3. 


\begin{tabular}{|l|l|l|}
\hline \multicolumn{1}{|c|}{ Study } & \multicolumn{1}{|c|}{ Registration Number } & \multicolumn{1}{|c|}{ Ethical Approval Details } \\
\hline $\begin{array}{l}\text { Neuromuscular disease/ } \\
\text { kyphoscoliosis }\end{array}$ & ACTRN12612000393853 & $\begin{array}{l}\text { Submission number: } \\
\text { CEN/11/11/065 } \\
\text { Committee: Central Health and } \\
\text { Disability Ethics Committee New } \\
\text { Zealand }\end{array}$ \\
\hline Bronchiectasis & ACTRN12612000356864 & $\begin{array}{l}\text { Submission number: } \\
\text { CEN/11/12/075 } \\
\text { Committee: Central Health and } \\
\text { Disability Ethics Committee New } \\
\text { Zealand }\end{array}$ \\
\hline COPD & ACTRN12614000361606 & $\begin{array}{l}\text { Submission number: 13/STH/200 } \\
\text { Committee: Southern Health and } \\
\text { Disability Ethics Committee New } \\
\text { Zealand }\end{array}$ \\
\hline & & \\
\hline
\end{tabular}

Table 6.3 Ethical approval and trial registration details for the Original Studies

COPD: Chronic Obstructive Pulmonary Disease. 


\section{A.3.2 Original Study results and interpretation}

Participants were recruited between June 2012 and January 2015. Participant characteristics are summarised in Tables 6.4 to 6.6. The COPD group had higher smoking rates than the other two groups, and had similar airflow obstruction severity when compared to the bronchiectasis group. 


\begin{tabular}{|c|c|c|c|}
\hline & $\begin{array}{c}\text { Neuromuscular/ } \\
\text { kyphoscoliosis } \\
\text { N=24* } \\
\end{array}$ & $\begin{array}{c}\text { Bronchiectasis } \\
\mathrm{N}=\mathbf{2 4} *\end{array}$ & $\begin{array}{l}\text { COPD } \\
\mathrm{N}=\mathbf{2 4 *}\end{array}$ \\
\hline \multicolumn{4}{|l|}{ n $(\%)$} \\
\hline Diagnosis & $\begin{array}{l}\text { Neuromuscular } \\
\text { disease: } 24 \\
\text { Kyphoscoliosis: } 0\end{array}$ & $\begin{array}{c}\text { Bronchiectasis: } \\
22 \\
\text { Cystic Fibrosis: } 2\end{array}$ & COPD: 24 \\
\hline Male & $17(71 \%)$ & $9(38 \%)$ & $16(67 \%)$ \\
\hline Home NIV & $8(33 \%)$ & $0(0 \%)$ & $2(8 \%)$ \\
\hline Home oxygen & $1(4 \%)$ & $0(0 \%)$ & $1(4 \%)$ \\
\hline Ever smoked & $7(29 \%)$ & $11(46 \%)$ & $24(100 \%)$ \\
\hline \multicolumn{4}{|l|}{ Mean (SD) } \\
\hline Age (years) & $54.3(15.7)$ & $60.8(15.5)$ & $67.1(8.4)$ \\
\hline $\mathrm{BMI}\left(\mathrm{kg} / \mathrm{m}^{2}\right)$ & $25.1(6.4)$ & $24.1(5.0)$ & $26.9(4.4)$ \\
\hline Smoking pack years & $4.1(7.8)^{* * *}$ & $1.3(2.4)$ & $33.1(26.5)$ \\
\hline $\mathrm{FEV}_{1}$ percentage predicted $(\%)$ & $58.8(19.6) * * *$ & $51.2(23.0)$ & $51.5(22.0)$ \\
\hline $\mathrm{FEV}_{1} / \mathrm{FVC}$ ratio $(\%)$ & $0.81(0.06)^{* * *}$ & $0.59(0.16)$ & $0.50(0.12)$ \\
\hline $\begin{array}{l}\text { Respiratory rate } \\
\text { (breaths/minute) }\end{array}$ & $17(4.0) * * * *$ & $17(4.2)$ & $18(6.6)$ \\
\hline
\end{tabular}

\section{Table 6.4 Participant characteristics}

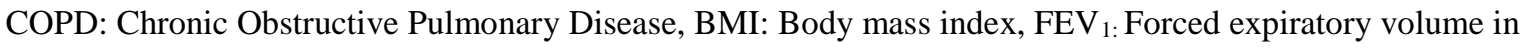
1 second, FVC: Forced vital capacity, NIV: Non-invasive ventilation.

*Unless otherwise stated. $* * \mathrm{~N}=22$, three participants had a pack year history of $>10$ years, all were able to perform forced spirometry to demonstrate FEV/FVC $<0.7$. $* * * \mathrm{~N}=21$ as three participants were unable to perform forced spirometry. $* * * * \mathrm{~N}=23$. 


\begin{tabular}{|l|ccc|}
\hline \multicolumn{1}{|c|}{ Ethnicity } & $\begin{array}{c}\text { Neuromuscular/ } \\
\text { kyphoscoliosis } \\
\mathbf{N = 2 4}\end{array}$ & $\begin{array}{c}\text { Bronchiectasis } \\
\mathbf{N = 2 4}\end{array}$ & $\begin{array}{c}\text { COPD } \\
\text { N=24 }\end{array}$ \\
\hline NZ European & 21 & 18 & 16 \\
Māori & 0 & 2 & 4 \\
Pacific Island & 0 & 0 & 1 \\
Other & 3 & 4 & 3 \\
\hline
\end{tabular}

Table 6.5 Participant ethnicity

COPD: Chronic Obstructive Pulmonary Disease, NZ: New Zealand.

Data are $\mathrm{n}$ values. 


\begin{tabular}{|ll|}
\hline \multicolumn{1}{|c|}{ Diagnosis } & n \\
\hline Ehlers Danlos & 1 \\
Facioscapulohumeral muscular dystrophy & 1 \\
Motor neuron disease & 6 \\
Myotonic dystrophy & 6 \\
Phrenic nerve palsy & 5 \\
Muscular dystrophy- unspecified & 1 \\
Tetraplegia & 1 \\
Myasthenia gravis & 1 \\
Inclusion body myositis & 1 \\
Chromosome cause & 1 \\
\hline
\end{tabular}

Table 6.6 Neuromuscular disease diagnoses for neuromuscular disease/ kyphoscoliosis study 
Minute ventilation, respiratory rate and $\mathrm{ETCO}_{2}$ were the outcomes that were not measured or calculated using the TOSCA. The mean values and mixed linear models for each time point are presented in Table 6.7. Note that mixed linear model data in Chapter 5 are presented as values over the 30 minute intervention, rather than at individual time points. 


\begin{tabular}{|c|c|c|c|c|c|c|c|c|c|c|}
\hline \multirow{2}{*}{\multicolumn{2}{|c|}{\begin{tabular}{|c|} 
Outcome $\&$ \\
time point \\
(min)
\end{tabular}}} & \multicolumn{3}{|c|}{$\begin{array}{l}\text { Neuromuscular/kyphoscoliosis } \\
\qquad \mathrm{N}=24 *\end{array}$} & \multicolumn{3}{|c|}{$\begin{array}{l}\text { Bronchiectasis } \\
\mathrm{N}=\mathbf{2 4}\end{array}$} & \multicolumn{3}{|c|}{$\begin{array}{l}\text { COPD } \\
\mathrm{N}=24\end{array}$} \\
\hline & & \multirow{2}{*}{$\begin{array}{c}\text { Oxygen } \\
7.7(1.7)\end{array}$} & \multirow{2}{*}{$\begin{array}{c}\text { Air } \\
7.5(1.6)\end{array}$} & \multirow{2}{*}{$\begin{array}{c}\text { Oxygen-air change } \\
\text { from baseline } * *\end{array}$} & \multirow{2}{*}{$\begin{array}{c}\text { Oxygen } \\
7.8(2.4)\end{array}$} & \multirow{2}{*}{$\begin{array}{c}\text { Air } \\
7.3(2.4)\end{array}$} & \multirow{2}{*}{$\begin{array}{c}\begin{array}{c}\text { Oxygen-air change } \\
\text { from baseline }\end{array} \\
\text { NA }\end{array}$} & \multirow{2}{*}{$\begin{array}{c}\text { Oxygen } \\
9.3(2.2)\end{array}$} & \multirow{2}{*}{$\begin{array}{c}\text { Air } \\
9.4(1.5)\end{array}$} & \multirow{2}{*}{$\begin{array}{c}\begin{array}{c}\text { Oxygen-air change } \\
\text { from baseline }\end{array} \\
\text { NA }\end{array}$} \\
\hline Minute & $\mathbf{0}$ & & & & & & & & & \\
\hline Ventilation & 10 & $6.8(1.8)$ & $7.2(1.7)$ & $-0.52(-0.95$ to -0.09$) P=0.02$ & $7.9(2.3)$ & $7.4(2.3)$ & $0.2(-0.5$ to 0.8$) \mathrm{P}=0.60$ & $9.1(2.2)$ & $9.4(2.0)$ & $-0.22(-1.04$ to 0.62$) \mathrm{P}=0.61$ \\
\hline & 20 & $7.4(1.8)$ & $7.4(1.9)$ & $0.03(-0.58$ to 0.52$) \mathrm{P}=0.91$ & $7.9(2.4)$ & $7.5(2.2)$ & $0.09(-0.5$ to 0.7$) \mathrm{P}=0.77$ & $8.8(2.2)$ & $9.3(2.3)$ & $-0.44(-1.25$ to 0.37$) \mathrm{P}=0.28$ \\
\hline & 30 & $7.4(1.8)$ & $7.4(1.6)$ & $-0.06(-0.73$ to 0.61$) \mathrm{P}=0.86$ & $8.0(2.4)$ & $7.2(2.1)$ & $0.4(-0.5$ to 1.3$) \mathrm{P}=0.40$ & $9.2(2.6)$ & $9.1(2.6)$ & $0.16(-1.0$ to 1.32$) \mathrm{P}=0.77$ \\
\hline \multirow{4}{*}{$\begin{array}{l}\text { Respiratory } \\
\text { Rate } \\
\text { (breaths per } \\
\text { min) }\end{array}$} & $\mathbf{0}$ & $17.0(4.3)$ & $16.5(5.2)$ & NA & $15.6(4.1)$ & $16.0(4.2)$ & NA & $15.8(4.3)$ & $15.8(3.8)$ & NA \\
\hline & 10 & $17.5(4.9)$ & $16.4(4.5)$ & $0.8(-0.4$ to 2.0$) \mathrm{P}=0.20$ & $16.6(4.8)$ & $16.3(4.3)$ & $0.7(-0.5$ to 1.9$) \mathrm{P}=0.23$ & $16.6(4.9)$ & $16.3(4.8)$ & $0.3(-1.4$ to 2.0$) \mathrm{P}=0.71$ \\
\hline & 20 & $17.7(4.3)$ & $17.4(6.1)$ & $-0.2(-1.7$ to 1.4$) \mathrm{P}=0.84$ & $16.9(5.0)$ & $17.0(4.6)$ & $0.4(-1.1$ to 1.9$) \mathrm{P}=0.55$ & $15.8(4.4)$ & $16.8(4.8)$ & $-0.9(-2.5$ to 0.6$) \mathrm{P}=0.22$ \\
\hline & 30 & $17.3(3.7)$ & $17.2(4.8)$ & $-0.3(-1.6$ to 1.0$) \mathrm{P}=0.67$ & $17.0(4.9)$ & $16.2(4.0)$ & $1.0(-0.9$ to 2.9$) \mathrm{P}=0.31$ & $16.5(5.2)$ & $16.4(4.6)$ & $0.1(-1.7$ to 1.9$) \mathrm{P}=0.88$ \\
\hline \multirow{4}{*}{$\begin{array}{l}\mathrm{ETCO}_{2} \\
(\mathrm{mmHg})\end{array}$} & $\mathbf{0}$ & $35.1(3.5)^{* * *}$ & $35.6(3.7)$ & NA & $31.7(3.2)$ & $31.0(3.6)$ & NA & $31.8(4.5)$ & $32.0(4.8)$ & NA \\
\hline & 10 & $34.3(4.0)^{* * *}$ & $34.9(3.6)$ & $-0.24(-1.67$ to 1.20$) \mathrm{P}=0.74$ & $30.5(3.5)$ & $31.3(3.7)$ & $-1.3(-2.4$ to -0.1$) P=0.035$ & $32.5(5.7)$ & $32.5(5.1)$ & $0.22(-1.55$ to 1.98$) \mathrm{P}=0.80$ \\
\hline & 20 & $35.2(3.2)^{* * *}$ & $35.4(4.2)$ & $0.20(-1.34$ to 1.73$) \mathrm{P}=0.80$ & $30.2(2.9)$ & $31.2(3.6)$ & $-1.4(-2.6$ to -0.2$) P=0.022$ & $32.5(5.1)$ & $31.8(5.3)$ & $0.95(-0.94$ to 2.83$) \mathrm{P}=0.31$ \\
\hline & 30 & $34.4(4.2)^{* * *}$ & $34.8(4.1)$ & $-0.05(-1.78$ to 1.68$) \mathrm{P}=0.95$ & $29.7(2.8)$ & $31.5(3.8)$ & $-2.2(-3.6$ to -0.81$) P=0.003$ & $31.1(6.0)$ & $31.8(4.2)$ & $-0.49(-2.82$ to 1.85$) \mathrm{P}=0.68$ \\
\hline
\end{tabular}

Table 6.7 Minute ventilation, respiratory rate and $\mathrm{ETCO}_{2}$

COPD: Chronic obstructive pulmonary disease, $\mathrm{ETCO}_{2}$ : End tidal carbon dioxide, NA: Not applicable.

Values are mean (SD) unless otherwise stated.

* Unless otherwise stated. ** By mixed linear model adjusted for baseline value with fixed effects for room air versus oxygen, treatment administration order and randomisation effect for participant to account for cross over design. Values are followed by $95 \%$ CI in brackets. Cells in green indicate statistically significant results. $* * * \mathrm{~N}=23$. 
The $\mathrm{T}=0$ values were similar between the Original Studies and Repeat Studies (Tables 5.11 and 6.7). In the Original Study there was a significant reduction in minute ventilation at 10 minutes in the neuromuscular disease/kyphoscoliosis patients of $-0.52 \mathrm{~L} / \mathrm{min}(-0.95$ to 0.09) $\mathrm{P}=0.02$. In the Repeat Study there was also a decrease, however it did not reach statistical significance at -0.02 ( -0.66 to 0.63$) \mathrm{P}=0.96$. For the other patient groups, in both the Original Study and Repeat Study, none of the mixed linear models showed a significant difference in minute ventilation from baseline after high concentration oxygen, compared with titrated oxygen (Tables 5.11 and 6.7).

For both the Original Studies and Repeat Studies, none of the mixed linear models showed a significant difference in respiratory rate from baseline after high concentration oxygen, compared with titrated oxygen (Tables 5.11 and 6.7). This was also the case for $\mathrm{ETCO}_{2}$ in the neuromuscular disease/kyphoscoliosis patients. These findings support repeatability in these data between the two studies.

Mixed linear model results for $\mathrm{ETCO}_{2}$ demonstrated no difference from baseline between the high concentration oxygen and room air regimen in the COPD participants in the Original Study (Table 6.7). This is in contrast to the small but significant decrease observed in the COPD participants in the Repeat Study on a mixed linear model for high concentration oxygen compared to room air (Table 5.11). The participants with bronchiectasis in the Original Study had small but statistically significant decreases in mixed linear model results for $\mathrm{ETCO}_{2}$ on high concentration oxygen compared to room air (Table 6.7), which were similar to the decrease in $\mathrm{ETCO}_{2}$ observed in the Repeat Study (Table 5.11). As concluded in Chapter 5, these small changes in $\mathrm{ETCO}_{2}$ should be interpreted with caution, particularly as they are similar to the manufacturer's error range of up to 5\% (User manual Oct 10 1997). 


\section{A.4 Studies assessing SenTec function}

\section{A.4.1 Assessment of SenTec drift and accuracy}

Figure 6.2 provides an example of the SenTec software data presentation, including drift corrected $\mathrm{PtCO}_{2}$ data (blue line). Drift correction is performed by the $\mathrm{V}$-sign software by comparing the data from the gas calibrations just before and just after the measurement period. Data are available in spreadsheet form for analysis. Drift corrected data was not available for all participants as some had data inadvertently uploaded prior to the second calibration after the measurement period. Analysis of drift corrected $\mathrm{PtCO}_{2}$ data was able to be performed in 48 of the included participants (14 neuromuscular disease/kyphoscoliosis, 17 bronchiectasis and 17 COPD participants). 


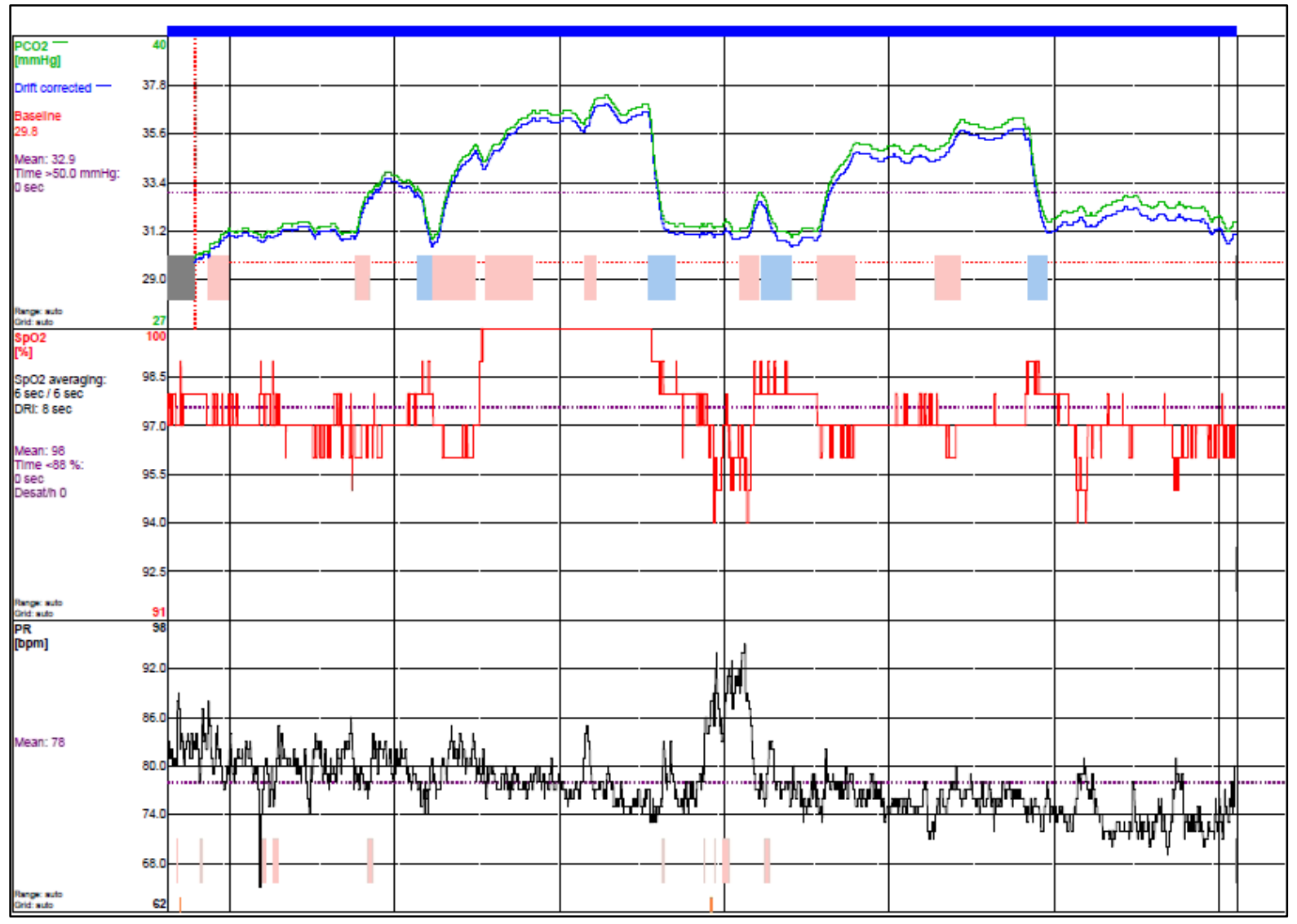

Figure 6.2 Example of drift corrected (blue) and uncorrected (green) $\mathrm{PtCO}_{2}$ data

$\mathrm{PtCO}_{2}$ : Transcutaneous partial pressure of carbon dioxide $(\mathrm{mmHg})$.

Red line represents $\mathrm{SpO}_{2}(\%)$. Black line represents pulse rate (beats per minute). Pink and blue boxes represent automatic software derived identification of increases or decreases in an outcome measure (not used in analysis). Grey box indicates probe stabilisation period- note that this was shorter than the minimum of 30 minutes stabilisation period that we had in the study protocol. The two periods of increased $\mathrm{PtCO}_{2}$ correspond with the application of the study mask for each intervention, the order was oxygen then air in this participant. 
Over the course of the 30 minute interventions drift was very small, contributing to no more than plus or minus $0.5 \mathrm{mmHg}$ to change in $\mathrm{PtCO}_{2}$ from baseline in any of the participants with drift corrected data. In 41 participants $(85 \%)$ the difference was $\leq 0.1 \mathrm{mmHg}$. This suggests that the effect of drift on results is minimal in these studies.

\section{A.4.2 Assessment of SenTec accuracy in the laboratory setting}

Transcutaneous monitoring guidelines recommend an initial $\mathrm{PtCO}_{2}$ value is compared with an $\mathrm{ABG}$ measured $\mathrm{PaCO}_{2}$ to check validity of monitoring. ${ }^{205}$ Comparative $\mathrm{ABG}$ samples were not taken during any of the studies in this thesis. This was a decision based on two factors. Firstly, $\mathrm{PtCO}_{2}$ values were collected to monitor trends (difference from baseline), rather than absolute values. Secondly, ABGs were not considered appropriate as part of the studies as they are invasive and cause discomfort, as well as carrying risk of ischaemia.

In the cross over trial in COPD participants, $\mathrm{PtCO}_{2}$ values were instead compared to an arterialised capillary blood gas measured $\mathrm{PcCO}_{2}$. Arterialised capillary blood gases have significantly less risk and discomfort compared to an $\mathrm{ABG}$, and have been demonstrated to accurately reflect $\mathrm{PaCO}_{2}$ values. ${ }^{206}$ The capillary blood gas was done at the completion of the study visit. This was to ensure that the study procedures in the COPD participants matched those in the neuromuscular disease/kyphoscoliosis and bronchiectasis patients exactly. It also meant that any inaccuracy due to drift would be maximal.

Paired $\mathrm{PtCO}_{2}$ and $\mathrm{PcCO}_{2}$ values were available from 16 participants. The SenTec minus capillary blood gas values had a mean bias of $-2.8 \mathrm{mmHg}$ with limits of agreement of -8.4 to $2.7 \mathrm{mmHg}$. These findings suggest the SenTec monitors and probes were performing in line with use in other SenTec validation studies, as they sat within the range of reported limits of agreement. ${ }^{195-204}$ The limits of agreement were also similar to the data from the study presented in Section A.4.3. Overall these findings highlight the limitations of interpreting single $\mathrm{PtCO}_{2}$ values and the importance of recommendations to interpret them against $\mathrm{ABG}$ values. ${ }^{205}$ 


\section{A.4.3 Assessment of SenTec accuracy in comparison to ABG values}

A prospective observational study was also conducted in 16 patients requiring an $\mathrm{ABG}$ as part of their clinical care at Wellington Regional Hospital. Peer reviewed journal publication is pending at the time of submission of this thesis. The study was prospectively registered with ANZCTR (ACTRN12615001154594).

Dr George Bardsley was the coordinating investigator on this study, and will be the first author on the manuscript. Data are also presented in his MD thesis submission to University of Newcastle upon Tyne. My roles in the study were study conception, initial protocol development, Māori consultation, application for ethical approval, and staff training/supervision.

The study assessed data from the same two SenTecs and probes that were used in the studies presented in Chapters 4 and 5. Recruitment took place between November 2015 and January 2016. Briefly, participants had a SenTec probe applied at each earlobe, with stabilisation for at least 30 minutes. $\mathrm{PtCO}_{2}$ was then recorded at the time blood was first visualised for the ABG.

Bias and limits of agreement are presented in Table 6.8. For both SenTecs the mean bias of $\mathrm{PtCO}_{2}$ minus $\mathrm{PaCO}_{2}$ was $2.2 \mathrm{mmHg}$, with limits of agreement of plus or minus $6.2 \mathrm{mmHg}$. The bias was in the opposite direction to the values from the COPD study comparing $\mathrm{PtCO}_{2}$ minus arterialised blood gas measured $\mathrm{PCO}_{2}(-2.8 \mathrm{mmHg})$, however the magnitude of the limits of agreement were similar (plus or minus $5.5 \mathrm{mmHg}$ ). These findings reinforce the conclusions made in Section A.4.2, that the SenTec monitors and probes were performing in line with reported limits of agreement in other studies evaluating SenTec accuracy, ${ }^{195-204}$ and there are limitations in interpreting single $\mathrm{PtCO}_{2}$ values without $\mathrm{ABG}$ validation. ${ }^{205}$ 


\begin{tabular}{|c|c|c|}
\hline Comparison & Bias & Limits of agreement \\
\hline \multicolumn{3}{|c|}{ SenTec 1 minus ABG } \\
\hline $\mathrm{PCO}_{2}(\mathrm{mmHg})$ & 2.2 & -4 to 8.4 \\
\hline $\mathrm{SO}_{2}(\%)$ & 0.6 & -3.8 to 5 \\
\hline \multicolumn{3}{|c|}{ SenTec 2 minus ABG } \\
\hline $\mathrm{PCO}_{2}(\mathrm{mmHg})$ & 2.2 & -4 to 8.4 \\
\hline $\mathrm{SO}_{2}(\%)$ & 0.8 & -4.6 to 6.2 \\
\hline \multicolumn{3}{|c|}{ SenTec 1 minus 2} \\
\hline $\mathrm{PCO}_{2}(\mathrm{mmHg})$ & -0.3 & -2.9 to 2.3 \\
\hline $\mathrm{SO}_{2}(\%)$ & -0.1 & -2.5 to 2.3 \\
\hline \multicolumn{3}{|c|}{$\begin{array}{l}\text { Table } 6.8 \text { Bias and limits of agreement between SenTec and ABG measured values of } \\
\mathrm{PCO}_{2}\end{array}$} \\
\hline \multicolumn{3}{|c|}{$\begin{array}{l}\text { ABG: Arterial blood gas, } \mathrm{PCO}_{2} \text { : Partial pressure of carbon dioxide (transcutaneous or arterial), } \mathrm{SO}_{2} \text { : Oxygen } \\
\text { saturation (transcutaneous or arterial). }\end{array}$} \\
\hline
\end{tabular}




\section{A.4.4 Assessment of SenTec accuracy in comparison to repeated capillary blood gas values}

The accuracy of transcutaneous monitoring was also assessed during a RCT investigating the effects of oxygen versus air-driven nebulisers in AECOPD. The study collected data from the same SenTecs and probes that were used in the studies presented in Chapters 4 and 5. Peer reviewed journal publication is pending at the time of submission of this thesis. The study was prospectively registered with ANZCTR (ACTRN12615000389505).

Dr George Bardsley was the coordinating investigator on this study, and will be the first author on the manuscript. Data are also presented in his MD thesis submission to University of Newcastle upon Tyne. My roles in the study were study conception, initial protocol development, Māori consultation, application for initial ethical approval and staff training. I also assisted as a co-investigator in study visits occasionally as required.

The trial was a parallel randomised study that administered two 15 minute nebulisers, run by either air or oxygen, and separated by a 5 minute interval. Arterialised capillary blood gas values were taken at the start and end of each 35 minute intervention. $\mathrm{PtCO}_{2}$ displayed on the SenTec at the time of visualisation of capillary blood entering the sample tube was recorded. This allowed comparison of the accuracy of the SenTec to arterialised blood gas measurement in detecting change in values over time.

Recruitment took place between May 2015 and June 2016. Data were available from 80 participants. The estimate of bias for change in $\mathrm{PcCO}_{2}$ minus change in $\mathrm{PtCO}_{2}$ was -0.03 mmHg (95\% CI -0.44 to 0.38 ) $\mathrm{P}=0.89$. The limits of agreement were plus or minus 3.8 mmHg. Differences between capillary blood gas and $\mathrm{PtCO}_{2}$ values are summarised in Table 6.9. These findings support the accuracy of the SenTec in detecting physiologically and clinically significant changes in $\mathrm{PaCO}_{2}$. 


\begin{tabular}{|l|lll|}
\hline & Mean (SD) & Median (IQR) & Min to Max \\
\hline $\begin{array}{l}\text { Change in } \mathrm{PcCO}_{2} \\
\text { minus change in } \\
\mathrm{PtCO}_{2}, \mathrm{~N}=80\end{array}$ & $-0.03(1.9)$ & $0.0(-0.95$ to 1.15$)$ & -6.6 to 4.5 \\
\hline
\end{tabular}

Table 6.9 Comparisons in capillary blood gas measured $\mathrm{PCO}_{2}$ and SenTec measured $\mathrm{PCO}_{2}$

$\mathrm{PcCO}_{2}$ : Partial pressure of capillary carbon dioxide, $\mathrm{PCO}_{2}$ : Partial pressure of carbon dioxide (transcutaneous or arterial), $\mathrm{PtCO}_{2}$ : Transcutaneous partial pressure of carbon dioxide. 
Appendix 2: Supporting information and documents 


\section{A.5 Publications relevant to this thesis}

\section{A.5.1 Publications included in this thesis}

\section{Chapter 2: Audit of oxygen use in AECOPD}

Pilcher J, Cameron L, Braithwaite I, Bowles D, Swain A, Bailey M, Weatherall M, Beasley R, Perrin K. Comparative audit of oxygen use in the prehospital setting, in acute COPD exacerbation, over 5 years. Emerg Med J. 2013 Nov 15:emermed-2013. For permission for use in this thesis, please see Permissions Section

\section{Chapter 4: Randomised controlled trial of oxygen in obese hospital inpatients}

Pilcher J, Richards M, Eastlake L, McKinstry SJ, Bardsley G, Jefferies S, Braithwaite I, Weatherall M, Beasley R. High flow or titrated oxygen for obese medical inpatients: a randomised crossover trial. The Medical journal of Australia. 2017 Nov 20;207(10):430-4. For permission for use in this thesis, please see Permissions Section.

\section{A.5.2 Planned publications resulting from this thesis}

Chapter 3: Multicentre study comparing arterial blood gas values to those obtained by pulse oximeters used in Australian and New Zealand hospitals

Janine Pilcher, Laura Ploen, Steve McKinstry, George Bardsley, Jimmy Chien, Lesley Howard, Lutz Beckert, Maureen Swanney, Sharon Lee, Mark Weatherall, Richard Beasley, for the TSANZ Oxygen Guidelines Group.* A multicentre study comparing arterial blood gas values to those obtained by oximeters used in Australian and New Zealand hospitals. Journal and publication date pending. 
* TSANZ Oxygen Guidelines Group: Richard Beasley, Lutz Beckert, Jimmy Chien, James Douglas, Claude Farah, Gregory King, Christine McDonald, Rosemary Moore, Janine Pilcher, Leonie Eastlake, Michael Richards, Sheree Smith, Haydn Walters, Mark Weatherall.

\section{Chapter 5: Randomised cross over trials on the effect of 50\% oxygen on $\mathrm{PtCO}_{2}$ in patients with stable COPD, bronchiectasis, and neuromuscular disease or kyphoscoliosis}

Janine Pilcher, Darmiga Thayabaran, Stefan Ebmeier, Mathew Williams, Geraldine Back, Hamish Collie, Michael Richards, Susan Bibby, Ruth Semprini, Mark Weatherall and Richard Beasley. The effect of $50 \%$ oxygen on $\mathrm{PtCO}_{2}$ in patients with stable COPD, bronchiectasis, and neuromuscular disease or kyphoscoliosis: randomised cross-over trials. Journal and publication date pending.

\section{A.5.3 Abstract relevant to this thesis}

The following abstract was presented by Laura Ploen at the Thoracic Society of Australia and New Zealand Conference in 2016. The data presented were for the Christchurch site only. None of the text from the abstract has been directly reproduced in this thesis.

Ploen L, Pilcher J, Beckert L, Swanney M, Beasley R. An investigation into the bias of pulse oximeters. Respirology. 2016 Apr 1;21:6.

\section{A.5.4 Publications in the field of oxygen therapy since enrolment in this $\mathrm{PhD}$}

Beasley R, Chien J, Douglas J, Eastlake L, Farah C, King G, Moore R, Pilcher J, Richards M, Smith S, Walters H. Target oxygen saturation range: 92-96\% versus 94-98. Respirology. 2017 Jan;22(1):200-202. doi: 10.1111/resp.12879. Epub 2016.

Beasley R, Chien J, Douglas J, Eastlake L, Farah C, King G, Moore R, Pilcher J, Richards M, Smith S, Walters H. Thoracic Society of Australia and New Zealand oxygen guidelines 
for acute oxygen use in adults: 'Swimming between the flags'. Respirology. 2015 Nov;20(8):1182-91.

Pilcher J, Beasley R. Acute use of oxygen therapy. Aust Prescr. 2015Jun;38(3):98-100. Epub 2015 .

Pilcher J, Weatherall M, Perrin K, Beasley R. Oxygen therapy in acute exacerbations of chronic obstructive pulmonary disease. Expert Rev Respir Med. 2015 Jun;9(3):287-93.

Pilcher J, Perrin K, Beasley R. The effect of high concentration oxygen therapy on PaCO2 in acute and chronic respiratory disorders. Transl Respir Med. 2013.

Young P, Pilcher J, Patel M, Cameron L, Braithwaite I, Weatherall M, Beasley R. Delivery of titrated oxygen via a self-inflating resuscitation bag. Resuscitation. 2013 Mar;84(3):3914.

Cameron L, Pilcher J, Weatherall M, Beasley R, Perrin K. The risk of serious adverse outcomes associated with hypoxaemia and hyperoxaemia in acute exacerbations of COPD. Postgrad Med J. 2012 Dec;88(1046):684-9.

Pilcher J, Weatherall M, Shirtcliffe P, Bellomo R, Young P, Beasley R. The effect of hyperoxia following cardiac arrest - A systematic review and meta-analysis of animal trials. Resuscitation. 2012 Apr;83(4):417-22. 


\section{A.6 Permissions}

\section{A.6.1 Audit of oxygen use in AECOPD (Chapter 2): Permission to}

include publication information in this thesis

\begin{tabular}{|c|c|}
\hline \multicolumn{2}{|r|}{$\begin{array}{l}\text { BMJ PUBLISHING GROUP LTD. LICENSE } \\
\text { TERMS AND CONDITIONS }\end{array}$} \\
\hline $\begin{array}{l}\text { This Agreement between Ja } \\
\text { Publishing Group Ltd."') cor } \\
\text { provided by BMJ Publishin }\end{array}$ & $\begin{array}{l}\text { anine Pilcher ("You") and BMJ Publishing Group Ltd. ("BMJ } \\
\text { nsists of your license details and the terms and conditions } \\
\text { ig Group Ltd. and Copyright Clearance Center. }\end{array}$ \\
\hline License Number & 4317230228453 \\
\hline License date & Mar 27, 2018 \\
\hline Licensed Content Publisher & BMJ Publishing Group Ltd. \\
\hline Licensed Content Publication & Emergency Medicine Journal \\
\hline Licensed Content Title & $\begin{array}{l}\text { Comparative audit of oxygen use in the prehospital setting in acute } \\
\text { COPD exacerbation over } 5 \text { years }\end{array}$ \\
\hline Licensed Content Author & $\begin{array}{l}\text { Janine Pilcher, Laird Cameron,Irene Braithwaite, Darren } \\
\text { Bowles,Andrew Swain,Mark Bailey,Mark Weatherall,Richard } \\
\text { Beasley,Kyle Perrin }\end{array}$ \\
\hline Licensed Content Date & Mar 1, 2015 \\
\hline Licensed Content Volume & 32 \\
\hline Licensed Content Issue & 3 \\
\hline Type of Use & Dissertation/Thesis \\
\hline Requestor type & Author of this article \\
\hline Format & Print and electronic \\
\hline Portion & Figure/table/extract \\
\hline $\begin{array}{l}\text { Number of } \\
\text { figure/table/extracts }\end{array}$ & 5 \\
\hline $\begin{array}{l}\text { Descriptionof } \\
\text { figure/table/extracts }\end{array}$ & Figures 1 through 2, Tables 1 though 3 and full text. \\
\hline Will you be translating? & No \\
\hline Circulation/distribution & 30 \\
\hline $\begin{array}{l}\text { Title of your thesis / } \\
\text { dissertation }\end{array}$ & $\begin{array}{l}\text { HIGH CONCENTRATION OXYGEN AND HYPERCAPNIA IN } \\
\text { RESPIRATORY DISEASE }\end{array}$ \\
\hline Expected completion date & May 2018 \\
\hline Estimated size(pages) & 300 \\
\hline Requestor Location & $\begin{array}{l}\text { Janine Pilcher } \\
\text { Private Bag } 7902 \\
\text { Newtown } \\
\text { Wellington, } 6242 \\
\text { New Zealand } \\
\text { Attn: Janine Pilcher }\end{array}$ \\
\hline Publisher Tax ID & GB674738491 \\
\hline Billing Type & Invoice \\
\hline Billing Address & $\begin{array}{l}\text { Janine Pilcher } \\
\text { Private Bag } 7902 \\
\text { Newtown } \\
\text { Wellington, New Zealand } 6242 \\
\text { Attn: Janine Pilcher }\end{array}$ \\
\hline Total & $0.00 \mathrm{AUD}$ \\
\hline
\end{tabular}


Terms and Conditions

BMJ Group Terms and Conditions for Permissions

When you submit your orderyou are subject to the terms and conditions set out below. You will also haveagreed to the Copyright Clearance Center's ("CCC") terms and conditionsregarding billing and payment https://s100.copyright.com/App/PaymentTerms.AndConditions.jsp. CCC are acting as the BMJ Publishing Group Limited's ("BMJ Group's") agent.

Subject to the terms set outherein, the BMJ Group hereby grants to you (the Licensee) a nonexclusive,non-transferable licence to re-use material as detailed in your request forthis/those purpose(s) only and in accordance with the following conditions:

1) Scope of Licence: Useof the Licensed Material(s) is restricted to the ways specified by you duringthe order process and any additional use(s) outside of those specified in thatrequest, require a further grant of permission.

2) Acknowledgement: Inall cases, due acknowledgement to the original publication with permission fromthe BMJ Group should be stated adjacent to the reproduced Licensed Material.The format of such acknowledgement should read as follows:

"Reproduced from [publicationtitle, author(s), volume number, page numbers, copyright notice year] withpermission from BMJ Publishing Group Ltd."

3) Third Party Material:BMJ Group acknowledges to the best of its knowledge, it has the rights to licenceyour reuse of the Licensed Material, subject always to the caveat thatimages/diagrams, tables and other illustrative material included within, whichhave a separate copyright notice, are presumed as excluded from the licence. Therefore,you should ensure that the Licensed Material you are requesting is original toBMJ Group and does not carry the copyright of another entity (as credited inthe published version). If the credit line on any part of the material you haverequested in any way indicates that it was reprinted or adapted by BMJ Groupwith permission from another source, then you should seek permission from thatsource directly to re-use the Licensed Material, as this is outside of thelicence granted herein.

4) Altering/ModifyingMaterial: The text of any material for which a licence is granted may notbe altered in any way without the prior express permission of the BMJ Group. Subject to Clause 3 above however, single figure adaptations do not require BMJGroup's approval; however, the adaptation should be credited as follows:

"Adapted by permission fromBMJ Publishing Group Limited. [publication title, author, volume number, pagenumbers, copyright notice year]

5) Reservation of Rights: The BMJ Group reserves all rights not specifically granted in the combinationof (i) the licence details provided by you and accepted in the course of thislicensing transaction, (ii) these terms and conditions and (iii) $\mathrm{CCC}^{\prime}$ s Billing and Payment Terms and Conditions.

6) Timing of Use: Firstuse of the Licensed Material must take place within 12 months of the grant ofpermission.

7). Creation of Contractand Termination: Once you have submitted an order via Rightslink and thisis received by $\mathrm{CCC}$, and subject to you completing accurate details of yourproposed use, this is when a binding contract is in effect and our acceptanceoccurs. As you are ordering rights from a periodical, to the fullest extentpermitted by law, you will have no right to cancel the contract from this pointother than for BMJ Group's material breach or fraudulent misrepresentation oras otherwise permitted under a statutory right. Payment must be made inaccordance with $\mathrm{CCC}^{\prime} \mathrm{s}$ Billing and Payment Terms and conditions. In the eventthat you breach any material condition of these terms and condition or any of CCC's Billing and Payment Terms and Conditions, the license is automatically terminated uponwritten notice from the BMJ Group or $\mathrm{CCC}$ or as otherwise provided for in CCC's Billing and Payment Terms and Conditions, where these apply.. Continued use of materials wherea licence has been terminated, as well as any use of the Licensed Materialsbeyond the scope of an unrevoked licence, may constitute intellectual propertyrights infringement and BMJ Group reserves the right to take any and all actionto protect its intellectual property rights in the Licensed Materials.

8. Warranties: BMJGroup makes no express or implied representations or warranties with respect tothe Licensed Material and to the fullest extent permitted by law this isprovided on an "as is" basis. For the avoidance of doubt BMJ Group does notwarrant that the Licensed Material is accurate or fit for any particularpurpose. 
9. Limitation ofLiability: To the fullest extent permitted by law, the BMJ Group disclaimsall liability for any indirect, consequential or incidental damages (includingwithout limitation, damages for loss of profits, information or interruption)arising out of the use or inability to use the Licensed Material or theinability to obtain additional rights to use the Licensed Material. To thefullest extent permitted by law, the maximum aggregate liability of the BMJGroup for any claims, costs, proceedings and demands for direct losses causedby BMJ Group's breaches of its obligations herein shall be limited to twice theamount paid by you to $\mathrm{CCC}$ for the licence granted herein.

10. Indemnity: You hereby indemnify and holdharmless the BMJ Group and their respective officers, directors, employees andagents, from and against any and all claims, costs, proceeding or demands arisingout of your unauthorised use of the Licensed Material.

11. No Transfer of License: This licence ispersonal to you, and may not be assigned or transferred by you without priorwritten consent from the BMJ Group or its authorised agent(s). BMJ Groupmay assign or transfer any of its rights and obligations under this Agreement, upon written notice to you.

12. No Amendment Except inWriting: This licence may not be amended except in a writing signed by bothparties (or, in the case of BMJ Group, by CCC on the BMJ Group's behalf).

13. Objection to Contraryterms: BMJ Group hereby objects to any terms contained in any purchaseorder, acknowledgment, check endorsement or other writing prepared by you, which terms are inconsistent with these terms and conditions or CCC's Billing and Payment Terms and Conditions. These terms and conditions, together with $\mathrm{CCC}^{\prime}$ B Billing and Payment Terms and Conditions (which to the extent they are consistent areincorporated herein), comprise the entire agreement between you and BMJ Group (and $\mathrm{CCC}$ ) and the Licensee concerning this licensing transaction. In the event ofany conflict between your obligations established by these terms and conditionsand those established by CCC's Billing and Payment Terms and Conditions, theseterms and conditions shall control.

14. Revocation: BMJGroup or $\mathrm{CCC}$ may, within 30 days of issuance of this licence, deny thepermissions described in this licence at their sole discretion, for any reasonor no reason, with a full refund payable to you should you have not been ableto exercise your rights in full. Notice of such denial will be made using thecontact information provided by you. Failure to receive such notice from BMJGroup or CCC will not, to the fullest extent permitted by law alter orinvalidate the denial. For the fullest extent permitted by law in no event willBMJ Group or CCC be responsible or liable for any costs, expenses or damageincurred by you as a result of a denial of your permission request, other thana refund of the amount(s) paid by you to BMJ Group and/or CCC for denied permissions.

\section{Restrictions to thelicense:}

15.1 Promotion: BMJ Group will not give permission to reproduce infull or in part any Licensed Material for use in the promotion of thefollowing:

a) non-medical products thatare harmful or potentially harmful to health: alcohol, baby milks and/or, sunbeds

b) medical products that donot have a product license granted by the Medicines and Healthcare productsRegulatory Agency (MHRA) or its international equivalents. Marketing of theproduct may start only after data sheets have been released to members of themedical profession and must conform to the marketing authorization contained inthe product license.

16. Translation: This permission is granted for non-exclusive worldEnglish language rights only unless explicitly stated in your licence. Iftranslation rights are granted, a professional translator should be employedand the content should be reproduced word for word preserving the integrity ofthe content.

17. General:Neither party shall be liable for failure, default or delay in performingits obligations under this Licence, caused by a Force Majeure event which shallinclude any act of God, war, or threatened war, act or threatened act ofterrorism, riot, strike, lockout, individual action, fire, flood, drought,tempest or other event beyond the reasonable control of either party.

17.1 Inthe event that any provision of this Agreement is held to be invalid, theremainder of the provisions shall continue in full force and effect. 
17.2 Thereshall be no right whatsoever for any third party to enforce the terms andconditions of this Agreement. The Parties hereby expressly wish to exclude theoperation of the Contracts (Rights of Third Parties) Act 1999 and any otherlegislation which has this effect and is binding on this agreement.

17.3 Tothe fullest extent permitted by law, this Licence will be governed by the lawsof England and shall be governed and construed in accordance with the laws of England. Any action arising out of or relating to this agreement shall be brought in courtssituated in England save where it is necessary for BMJ Group for enforcement tobring proceedings to bring an action in an alternative jurisdiction. 


\section{A.6.2 RCT of oxygen in obese hospital inpatients (Chapter 4):}

\section{Permission to include publication information in this thesis}

$\begin{array}{ll}\text { From: } & \text { Janine Pilcher } \\ \text { To: } & \\ \text { Subject: } & \text { RE: Permission for use of an article in thesis } \\ \text { Date: } & \text { Wednesday, } 28 \text { February } 2018 \text { 2:39:44 p.m. }\end{array}$

Dear Kerrie,

Thank you very much for your quick reply. I confirm acceptance of the conditions in the text of your email below.

With Kind Regards,

Janine

Dr Janine Pilcher MBChB, PGDipClinRes, BSc

Medical Research Institute of New Zealand

janine,pilcher@mrinz.ac.nz

$+644805044$

Statement of confidentiality:

This e-mail message and any accompanying attachments may contain informakion that is confidential and subject to legal privilege. If you are not the intended recipient, do not read, use, disseminate, distribute or copy this message or attachments. If you have received this message in error, please notify the sender immediately and delete this message.

Sent: Wednesday, 28 February 2018 2:16 p.m. To: Janine Pilcher 〈Janine.Pilcher@mrinz.ac.nz>

Subject: RE: Permission for use of an article in thesis

Dear Janine,

As owners of copyright for material published in the Medical Journal of Australia (MJA), we grant you a non-exclusive licence to use the material described in your email below in your thesis, subject to the conditions below.

This permission is conditional on all intended publications fully acknowledging the MJA as the original source of the content in the following manner: 
Pilcher J, Richards M, Eastlake L, et al. High flow or titrated oxygen for obese medical inpatients: a randomised crossover trial. Med J Aust 2017; 207 (10): 430-434. (C) Copyright 2017. The Medical Journal of Australia. Reproduced with permission.

Could you please confirm your acceptance of these terms by return email?

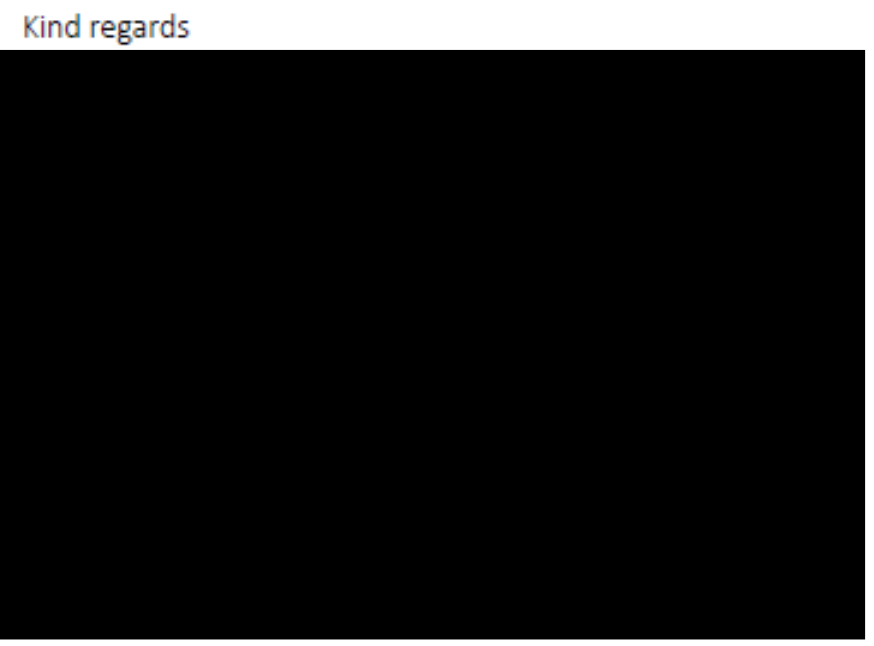

From: Janine Pilcher [mailto」Janine.Pilcher@mrinz.ac.nz]

Sent: Wednesday, 28 February 2018 12:04 PM

To:

Subject: Permission for use of an article in thesis

To whom it may concern.

I was hoping to please request written permission to use information from the following article, on which I am first author, in my PhD thesis.

Pilcher J, Richards M, Eastlake L, McKinstry SJ, Bardsley G, Jefferies S, Braithwaite I, Weatherall M, Beasley R. High flow or titrated oxygen for obese medical inpatients: a randomised crossover trial. The Medical journal of Australia. 2017 Nov 20;207(10):430-4.

If you could please advise how to go about this process I would much appreciate it,

With Kind Regards,

Janine

Dr Janine Pilcher MBChB, PGDipClinRes, BSc

Medical Research Institute of New Zealand 
janine,pilcher@mrinz,ac.nz

$+6448050147$

Statement of confidentiality:

This e-mail message and any accompanying attachments may contain information that is confidential and subject to legal privilege. If you are not the intended recipient, do not read, use, disseminate, distribute or copy this message or attachments. If you have received this message in error, please notify the sender immediately and delete this message. 


\section{A.7 Contribution Statements}

\section{A.7.1 Audit of oxygen use in AECOPD (Chapter 2)}

\section{Co-investigators and affiliations}

1,2,3 Janine Pilcher, ${ }^{1,2}$ Laird Cameron, ${ }^{1,2,3}$ Irene Braithwaite, ${ }^{1,2}$ Darren Bowles, ${ }^{2,4,5}$ Andrew Swain, ${ }^{5}$ Mark Bailey, ${ }^{2,4}$ Mark Weatherall, ${ }^{1-4}$ Richard Beasley , ${ }^{1,2,4}$ and Kyle Perrin.

${ }^{1}$ Medical Research Institute of New Zealand, Wellington, New Zealand

${ }^{2}$ Capital \& Coast District Health Board, Wellington, New Zealand

${ }^{3}$ Victoria University Wellington, Wellington, New Zealand

${ }^{4}$ University of Otago Wellington, Wellington, New Zealand

${ }^{5}$ Wellington Free Ambulance, Wellington, New Zealand

\section{My roles}

\section{Data collection}

Collection of data from clinical records, as a shared role with Laird Cameron, Irene Braithwaite and Darren Bowles. Data entry to excel spreadsheets for analysis. Liaison with study statistician Mark Weatherall regarding data formatting and provision, statistical analyses undertaken, and data interpretation.

\section{Publication}

First author on manuscript. Drafting of manuscript and revisions based on co-author input. Submission for publication, drafting, amending and submitting response to reviewers. Primary responsibility for review of Journal proofs prior to publication. 


\section{A.7.2 Multicentre study comparing arterial blood gas values to those obtained by pulse oximeters used in Australian and New Zealand Hospitals (Chapter 3)}

\section{Co-investigators and affiliations}

1,2,3 Janine Pilcher, ${ }^{4}$ Laura Ploen, ${ }^{1}$ Steve McKinstry, 1,2 George Bardsley, ${ }^{5}$ Jimmy Chien,

${ }^{5}$ Lesley Howard, ${ }^{4}$ Lutz Beckert, ${ }^{4}$ Maureen Swanney, ${ }^{5}$ Sharon Lee, ${ }^{6}$ Mark Weatherall, ${ }^{1,2}$ and Richard Beasley, for the TSANZ Oxygen Guidelines Group.*

${ }^{1}$ Medical Research Institute of New Zealand, Wellington, New Zealand

${ }^{2}$ Capital \& Coast District Health Board, Wellington, New Zealand

${ }^{3}$ Victoria University, Wellington, New Zealand

${ }^{4}$ Canterbury District Health Board, Christchurch, New Zealand

${ }^{5}$ Department of Respiratory and Sleep Medicine, Ludwig Engel Centre for Respiratory Research, Westmead Millennium Institute, University of Sydney at Westmead Hospital, Australia

${ }^{6}$ University of Otago, Dunedin, New Zealand

* TSANZ Oxygen Guidelines Group: Richard Beasley, Lutz Beckert, Jimmy Chien, James Douglas, Claude Farah, Gregory King, Christine McDonald, Rosemary Moore, Janine Pilcher, Leonie Eastlake, Michael Richards, Sheree Smith, Haydn Walters, Mark Weatherall.

\section{My roles as Coordinating Investigator}

\section{Initial set up}

Study conception and protocol, revisions of protocol to reflect co-author additions. Submission for New Zealand ethical approval to Health and Disability Ethics Committee. Submission for Māori consultation (Regional Advisory Group Māori), submission for locality approval at Wellington Regional Hospital. Creation of participant information sheets, case report forms (CRFs), and log templates for participant inclusion/exclusion and staff delegation log templates. ANZCTR trial registration. Training of all Wellington investigators (Steve 
McKinstry, George Bardsley and Leonie Eastlake) in protocol and CRFs. Conduct of site initiation meetings to educate sites on protocol, CRFs and transfer of de-identified data.

Ongoing approvals and registrations

Maintenance of ANZCTR website submission, including updates and responsibility for responses to website queries. Ethical approval updates with responsibility for submission of yearly progress reports, notification of study conclusion and a final report. Responsibility for ongoing liaison with Regional Advisory Group Māori and provision of a final report.

\section{Data collection}

Monitoring of all CRFs and sending data query forms to the relevant sites/investigators. This was performed by me for all CRFs and repeated independently by study monitor James Gilchrist (MRINZ staff). Data entry from all CRFs. Reconciliation of this data with double entered data (second set of data entry was shared by Steve McKinstry, George Bardsley, James Gilchrist and Darmiga Thayabaran (MRINZ staff)). Liaison with study statistician Mark Weatherall regarding data formatting and provision, statistical analyses undertaken, and data interpretation.

\section{Publication}

First author on manuscript. Interpretation of data and first draft of manuscript. Incorporation of manuscript revisions based on co-author input. The manuscript is yet to be published at the time of thesis submission. 


\section{A.7.3 Randomised controlled trials of oxygen in obese hospital inpatients (Chapter 4 and Appendix 1)}

\section{Co-investigators and affiliations}

1,2,3 Janine Pilcher, ${ }^{1,2}$ Michael Richards, ${ }^{1,2}$ Leonie Eastlake, ${ }^{1,2,3}$ Steven McKinstry

${ }^{1,2}$ George Bardsley, ${ }^{2}$ Sarah Jefferies, ${ }^{1,2,3}$ Irene Braithwaite, ${ }^{1,2}$ Mitesh Patel (original trials only), ${ }^{4}$ Mark Weatherall and ${ }^{1,2,3}$ Richard Beasley.

${ }^{1}$ Capital and Coast District Health Board, Wellington, New Zealand

${ }^{2}$ Medical Research Institute of New Zealand, Wellington, New Zealand

${ }^{3}$ Victoria University Wellington, Wellington, New Zealand

${ }^{4}$ Wellington School of Medicine \& Health Sciences, Wellington, New Zealand

\section{Other staff involved}

Corentin Maillot (MRINZ Elective Student from Montpellier University) and Emily Tweedale (University of Otago Summer Student) assisted with double data entry and reconciliation for the original study.

James Gilchrist took on a monitoring role of the CRFs for the repeat study. He also assisted in data entry, reconciliation and analysis for the repeat study.

Kyle Perrin (MRINZ and Capital and Coast District Health Board staff member) was involved in the initial design and set up of the study and trained me on how to use TOSCA and $\mathrm{CO}_{2} \mathrm{SMO}$ equipment.

\section{My roles as Coordinating Investigator}

\section{Initial set up}

Revisions to protocol prior to recruitment, and responsibility for Health and Disability Ethics Committee and ANZCTR updates. 
Note that study conception, initial protocol draft, original submission for ethical approval to the Health and Disability Ethics Committee, Māori consultation and initial ANZCTR trial registration was by Dr Kyle Perrin and/or Sarah Jefferies.

Training of new investigators (Michael Richards, Leonie Eastlake, Steven McKinstry, George Bardsley) in study protocol.

\section{Ongoing approvals and registrations}

Maintenance of ANZCTR website submission, including updates and responsibility for responses to website queries. Ethical approval updates with responsibility for submission of yearly progress reports, notification of study conclusion and a final report. Responsibility for ongoing liaison with Matire Harwood (Māori Consultation) and provision of a final report.

\section{Data collection}

Investigator for recruitment and study visits. Note Michael Richards, Leonie Eastlake, Steven McKinstry, George Bardsley, Mitesh Patel, Sarah Jefferies, and Irene Braithwaite all took part in recruitment and/or study visits as co-investigators. I had an investigator role in the recruitment for and conduct of visits for 18 of the randomised participants.

Monitoring of all CRFs. Data entry from all CRFs. Reconciliation of this data with double entered data (in the original study the double entry was by Corentin Maillot and Emily Tweedale, for the repeat studies it was by Steve McKinstry and James Gilchrist). Liaison with study statistician Mark Weatherall regarding data formatting and provision, statistical analyses undertaken, and data interpretation.

\section{Publication}

First author on manuscript. Interpretation of data and first draft of manuscript. Incorporation of manuscript revisions based on co-author input. 


\title{
A.7.4 Randomised cross over trials on the effect of $50 \%$ oxygen on $\mathrm{PtCO}_{2}$ in patients with stable COPD, bronchiectasis, and
} neuromuscular disease or kyphoscoliosis (Chapter 5 and Appendix 1)

\section{Co-investigators and affiliations}

1,2,3 Janine Pilcher, ${ }^{1,2}$ Darmiga Thayabaran, ${ }^{1,2}$ Stefan Ebmeier, ${ }^{1}$ Mathew Williams, ${ }^{2}$ Geraldine Back, ${ }^{2}$ Hamish Collie, ${ }^{1,2}$ Michael Richards, ${ }^{1,2}$ Susan Bibby, ${ }^{1,2}$ Ruth Semprini, ${ }^{1,2}$ Leonie Eastlake (original trials only), ${ }^{1,2}$ Mitesh Patel (original trials only), ${ }^{1,2}$ Sharon Power (original trials only), ${ }^{4}$ Mark Weatherall and ${ }^{1,2,3}$ Richard Beasley

\author{
${ }^{1}$ Medical Research Institute of New Zealand, Wellington, New Zealand \\ ${ }^{2}$ Capital \& Coast District Health Board, Wellington, New Zealand \\ ${ }^{3}$ Victoria University of Wellington, Wellington, New Zealand \\ ${ }^{4}$ University of Otago Wellington, Wellington, New Zealand
}

\section{Students}

As well as being co-investigators, Geraldine Back and Hamish Collie undertook Masters in Health Science during conduct of the study at Charles Sturt University, Australia. They used data from the studies as part of submitted assignments for their degrees (from the original study in stable COPD, and the original study in neuromuscular disease/kyphoscoliosis patients, respectively).

I was the primary supervisor for Emily Tweedale, who was involved in the studies as an Otago University Summer Studentship student. She used data from the original study in stable bronchiectasis as part of a submitted write up for the Studentship.

I was the primary supervisor for Leslie Dervieux who attended a number of study visits as a research elective student from Montpellier University and submitted a presentation and report to the University about her experiences. 


\section{Other staff}

James Gilchrest took on a monitoring role of the CRFs. He also assisted in double data entry, reconciliation and analysis.

Alice McDouall and Jo Singer (MRINZ staff members) assisted Ruth Semprini in study visits.

Irene Braithwaite (Deputy Director, MRINZ) provided support and guidance regarding TOSCA transcutaneous monitoring data.

\section{My roles as Coordinating Investigator}

\section{Initial set up}

Study conception and protocols, revisions of protocols to reflect co-author additions. Submissions for New Zealand ethical approval to the Health and Disability Ethics Committee. Submissions for Māori consultation (Regional Advisory Group Māori) and submissions for locality approval at Wellington Regional Hospital.

Creation of participant information sheets, CRFs, and log templates for participant inclusion/exclusion and staff delegation. ANZCTR trial registrations.

Training of co-investigators (Darmiga Thayabaran, Stefan Ebmeier, Geraldine Back, Hamish Collie, Michael Richards, Susan Bibby, Ruth Semprini, Leonie Eastlake, Mitesh Patel and Sharon Power) in protocol and CRFs.

\section{Ongoing approvals and registrations}

Maintenance of ANZCTR website submissions, including updates and responsibility for responses to website queries. Ethical approval updates with responsibility for submission of yearly progress reports, notification of study conclusion and a final report. Responsibility for ongoing liaison with Regional Advisory Group Māori and provision of final reports.

\section{Data collection}

Investigator for recruitment and study visits. Note Darmiga Thayabaran, Stefan Ebmeier, Mathew Williams, Geraldine Back, Hamish Collie, Michael Richards, Susan Bibby, Ruth 
Semprini, Leonie Eastlake, Mitesh Patel, Sharon Power and Kyle Perrin all took part in recruitment and/or study visits as blinded or unblinded investigators. I had an investigator role in the recruitment for and/or conduct of visits for 24 neuromuscular disease/kyphoscoliosis, 28 bronchiectasis and 22 COPD randomised participants.

Monitoring of all CRFs. Reconciliation/data entry from all CRFs. Data was double entered, and reconciliation was made with datasets entered by Emily Tweedale, Sue Bibby, James Gilchrist or Michael Richards for the original studies. Reconciliation was made with datasets entered by James Gilchrist or Darmiga Thayabaran for the repeat studies.

Liaison with study statistician Mark Weatherall regarding data formatting and provision, statistical analyses undertaken, and data interpretation.

\section{Publication}

First author on draft manuscript. Interpretation of data and first draft of manuscript. Incorporation of manuscript revisions based on co-author input. The manuscript is yet to be published at the time of thesis submission. 

A.8 Participant information sheet, consent form: examples from the bronchiectasis study. 
Participant Information Form

Title:

\section{High Concentration Oxygen in Bronchiectasis}

Principal investigator:

Dr Janine Pilcher

Medical Research Institute of New Zealand, Wellington Hospital, Private Bag 7902, Wellington South. Phone: 048050147

\section{Lead investigator:}

Dr Darmiga Thayabaran

Medical Research Institute of New Zealand, Wellington Hospital, Private Bag 7902, Wellington South. Phone: 048050266

Please feel free to contact the investigator if you have any questions about this study.

\section{Introduction}

You are invited to take part in a study investigating the effect of oxygen on patients with bronchiectasis or cystic fibrosis.

Whether or not you take part is your choice. If you don't want to take part, you don't have to give a reason, and it won't affect the care you receive. If you do want to take part now, but change your mind later, you can pull out of the study at any time. Participation in this study may also be stopped if the study doctor decides it is not in your best interests to continue.

This Participant Information Sheet will help you decide if you'd like to take part. It sets out why we are doing the study, what your participation would involve, what the benefits and risks to you might be, and what would happen after the study ends. We will go through this information with you and answer any questions you may have. You do not have to decide today whether or not 
you will participate in this study. Before you decide you may want to talk about the study with other people, such as family, whānau, friends, or healthcare providers. Feel free to do this.

If you agree to take part in this study, you will be asked to sign the Consent Form on the last page of this document. You will be given a copy of both the Participant Information Sheet and the Consent Form to keep.

This document is 8 pages long, including the Consent Form. Please make sure you have read and understood all the pages.

\section{What is the aim of the study?}

It is recognised that treatment with oxygen may increase the concentration of carbon dioxide in the blood. Carbon dioxide is a waste product that is removed from the body through the lungs.

This adverse effect has not been well studied in people with bronchiectasis or cystic fibrosis, even though oxygen is administered to them as part of clinical practice.

We therefore wish to gain more knowledge in this area by measuring carbon dioxide levels in people with bronchiectasis or cystic fibrosis while breathing room air and compare this to levels after they have breathed oxygen. This is easily measured using a small device clipped painlessly to the earlobe.

\section{What does the study involve?}

24 people will take part in the study, which will be conducted at the Medical Research Institute of New Zealand situated at Wellington Regional Hospital in Newtown.

If you choose to participate in the study it will involve one visit taking approximately 3 to 3.5 hours to complete. We will first discuss the study and answer any questions you may have. If you are comfortable to proceed you will be asked to sign a consent form to acknowledge you understand what is involved and are willing to take part in the study. 
We will then measure your height, weight and lung function. The lung function tests involve breathing through a mouthpiece into a machine to measure how much you can blow. If you are eligible to participate you will then be given a mask to breathe through while sitting comfortably. You will be asked to breathe in random order treatment $A$ (oxygen for 30 minutes) and treatment B (normal room air for 30 minutes) through the mask. Prior to and after each treatment you will have a period for at least 30 minutes during which time you will be breathing room air without any masks or equipment. You will be randomly assigned to either receive treatment $A$ then treatment $B$, or treatment $B$ then treatment $A$. To ensure the best data collection, you and one of the investigators will not know which order you will receive.

During the study you will have the amount of carbon dioxide in your blood measured using a small device that painlessly clips on to your earlobe. It can also measure the amount of oxygen in the blood.

We will also measure the rate of your breathing and your pulse. While you breathe through the mask during treatments $\mathrm{A}$ and $\mathrm{B}$ the amount of air you breathe will be recorded.

After the study visit is complete there are no further study visits to attend.

The study is supported by funding from the Health Research Council of New Zealand and Capital and Coast District Health Board.

\section{Confidentiality and data privacy}

If you decide to participate in the study, the study doctor and research staff will collect medical and personal information about you as part of doing the study.

By agreeing to take part in this research, you will allow your medical information and results to be seen by people who check that the research was done properly. You are able to ask to see your results. During the study visit you are able to stop your participation at any time. You can also ask us not to use the data we have collected. 
No material which could personally identify you will be used in any reports on this study. Your subject data will be identified by a code number. Original data records will be kept in a secure place for ten years and then destroyed.

During the study we may find results that could be applicable to your future health care. With your permission we can forward these through to your doctor.

\section{What are the risks and safety issues?}

A marked increase in blood carbon dioxide levels for a long period of time can lead to increased heart rate, drowsiness and headache. However, if your carbon dioxide levels increase during the study treatment it is unlikely you will experience any untoward effects as the oxygen is being administered for a very short period of time and the treatment will be stopped immediately if your carbon dioxide levels increase above a certain level ( $10 \mathrm{mmHg}$ from baseline).

You will be monitored very closely throughout the study by the study Doctor. If your carbon dioxide levels do rise by $10 \mathrm{mmHg}$ and you do develop any of the above side effects, they will be short lived.

Spirometry will involve breathing hard and fast through a tube to measure how your lungs are functioning. In some people it can make them feel light headed and cause them to cough.

Participation in the study is free; however you may have travel expenses to get to Wellington Regional Hospital for which you will be provided reimbursement.

\section{What are the benefits?}

Knowledge of your responses to oxygen therapy and a full assessment of your respiratory function can be provided to your specialist doctor and may help to guide your treatment in the future. Another benefit of taking part is that you are contributing valuable information to an important study that may change the way we treat patients with bronchiectasis and cystic fibrosis. 
Participants in the study

Participants are eligible to take part in this study if they have bronchiectasis or cystic fibrosis which affects their breathing (which will be tested at the study visit).

Participants will not be eligible if they are under 14 years of age or have:

1. A diagnosis of infection with Burkholderia

2. A high blood carbon dioxide level prior to the study (over $60 \mathrm{mmHg}$ )

3. Chronic obstructive pulmonary disease (COPD)

4. A history of heavy smoking

5. A body mass index (a relationship between your height and weight) of $\geq 40$ (this will be measured during your visit)

6. Any other condition which, at the investigator's discretion, is believed may present a safety risk or impact the feasibility of the study or the study results

\section{Patient's rights}

An interpreter can be provided for you if you require one. You may have a friend, family or Whānau member to support and help you understand the risks and/or benefits of this study and any other explanation you may require.

If you have any queries or concerns regarding your rights as a participant in this study, you may wish to contact an independent health and disability advocate:

Free phone: 0800555 050, Free fax: 08002 SUPPORT (0800 2787 7678)

Email: advocacy@hdc.org.nz

For Māori health support please contact Whānau Care Services on: 0800999442 


\section{Compensation for injury}

If you were injured in this study, which is unlikely, you would be eligible for compensation from ACC just as you would be if you were injured in an accident at work or at home. You will have to lodge a claim with ACC, which may take some time to assess. If your claim is accepted, you will receive funding to assist in your recovery.

If you have private health or life insurance, you may wish to check with your insurer that taking part in this study won't affect your cover.

\section{Statement of Approval}

This study has received ethical approval from the Central Ethics Committee, ethics reference number CEN/11/12/075. This study has been registered at https://www.anzctr.org.au. 


\section{Consent Form}

If you need an INTERPRETER, please tell us.

Please tick to indicate you consent to the following

\begin{tabular}{l}
\hline $\begin{array}{l}\text { I have read, or have had read to me in my first language, and I } \\
\text { understand the Participant Information Sheet. }\end{array}$ \\
$\begin{array}{l}\text { I have been given sufficient time to consider whether or not to } \\
\text { participate in this study. }\end{array}$ \\
\hline $\begin{array}{l}\text { I have had the opportunity to use a legal representative, whanau/ } \\
\text { family support or a friend to help me ask questions and understand } \\
\text { the study. }\end{array}$ \\
\hline $\begin{array}{l}\text { I am satisfied with the answers I have been given regarding the } \\
\text { study and I have a copy of this consent form and information sheet. }\end{array}$ \\
\hline $\begin{array}{l}\text { I understand that taking part in this study is voluntary (my choice) } \\
\text { and that I may withdraw from the study at any time without this } \\
\text { affecting my medical care. }\end{array}$ \\
\hline $\begin{array}{l}\text { I consent to the research staff collecting and processing my } \\
\text { information, including information about my health. }\end{array}$ \\
\hline
\end{tabular}

If I decide to withdraw from the study, I agree that the information collected about me up to the point when I withdraw may continue to Yes $\square$ be processed.

I consent to my GP or current provider being informed about my participation in the study and of any significant abnormal results obtained during the study.

I agree to an approved auditor appointed by the New Zealand Health and Disability Ethic Committees, or any relevant regulatory authority or their approved representative reviewing my relevant medical records for the sole purpose of checking the accuracy of the information recorded for the study.

I understand that my participation in this study is confidential and that no material, which could identify me personally, will be used in any reports on this study.

I understand the compensation provisions in case of injury during the study. 


\begin{tabular}{lc}
\hline $\begin{array}{l}\text { I know who to contact if I have any questions about the study in } \\
\text { general. }\end{array}$ & Yes $\square$ \\
\hline I understand my responsibilities as a study participant. & Yes $\square$ \\
\hline
\end{tabular}

I wish to receive a summary of the results from the study.

Address to send results:

Yes $\square \quad$ No $\square$

Please note there may be a significant delay before results are sent

Declaration by participant:

I hereby consent to take part in this study.

Participant's name:

Signature: Date:

Declaration by member of research team:

I have given a verbal explanation of the research project to the participant, and have answered the participant's questions about it.

I believe that the participant understands the study and has given informed consent to participate.

Researcher's name:

Signature:

Date: 


\section{A.9 Ethical approval documents}

A.9.1 Multicentre study comparing arterial blood gas values to those obtained by pulse oximeters used in Australian and New Zealand Hospitals (Chapter 3)

\section{Approval of all documentation prior to study commencement}

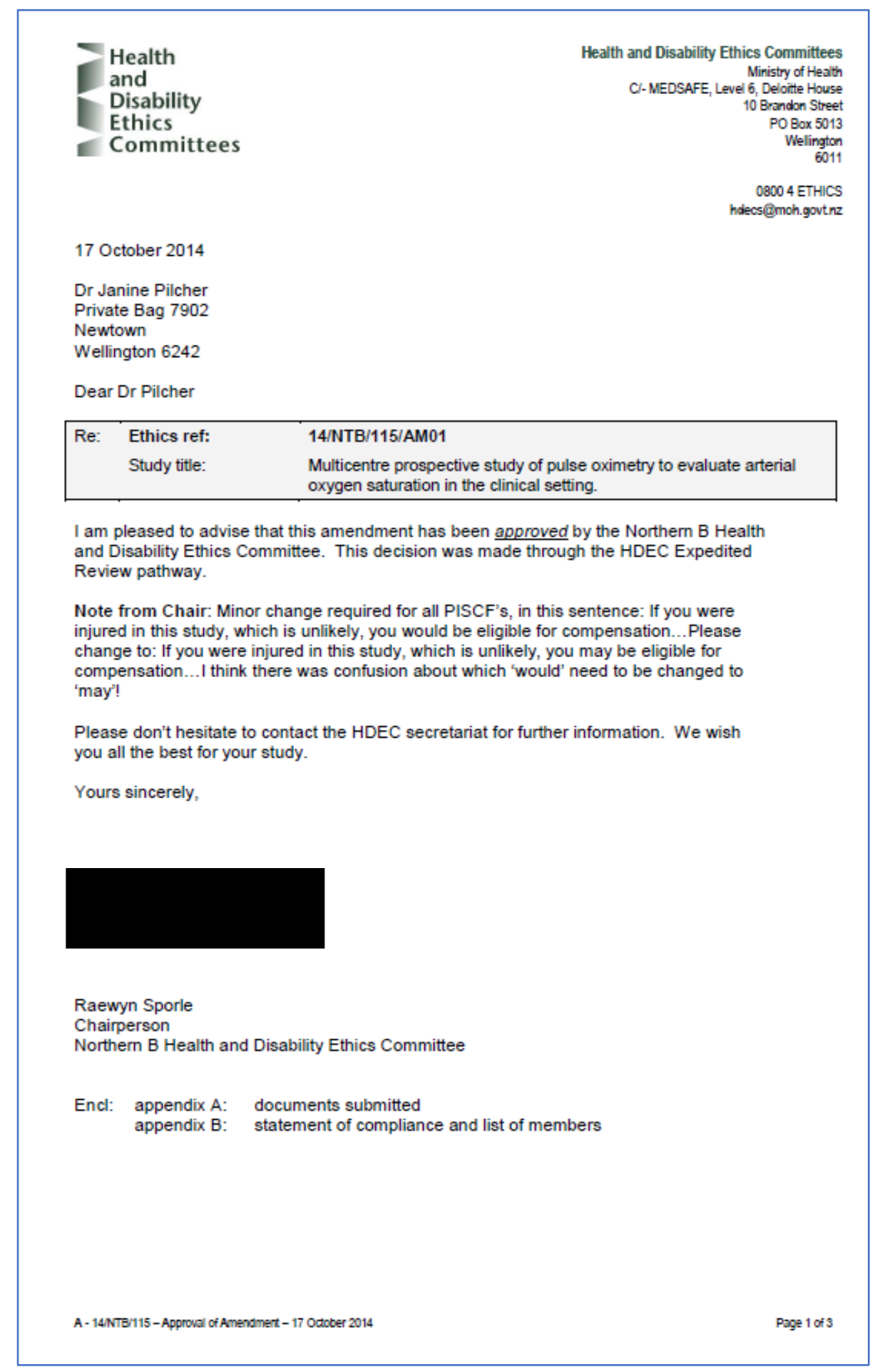




\section{A.9.2 Randomised controlled trials of oxygen in obese hospital inpatients (Chapter 4 and Appendix 1)}

Initial approval after amendments to include me as an Investigator (prior to study commencement)

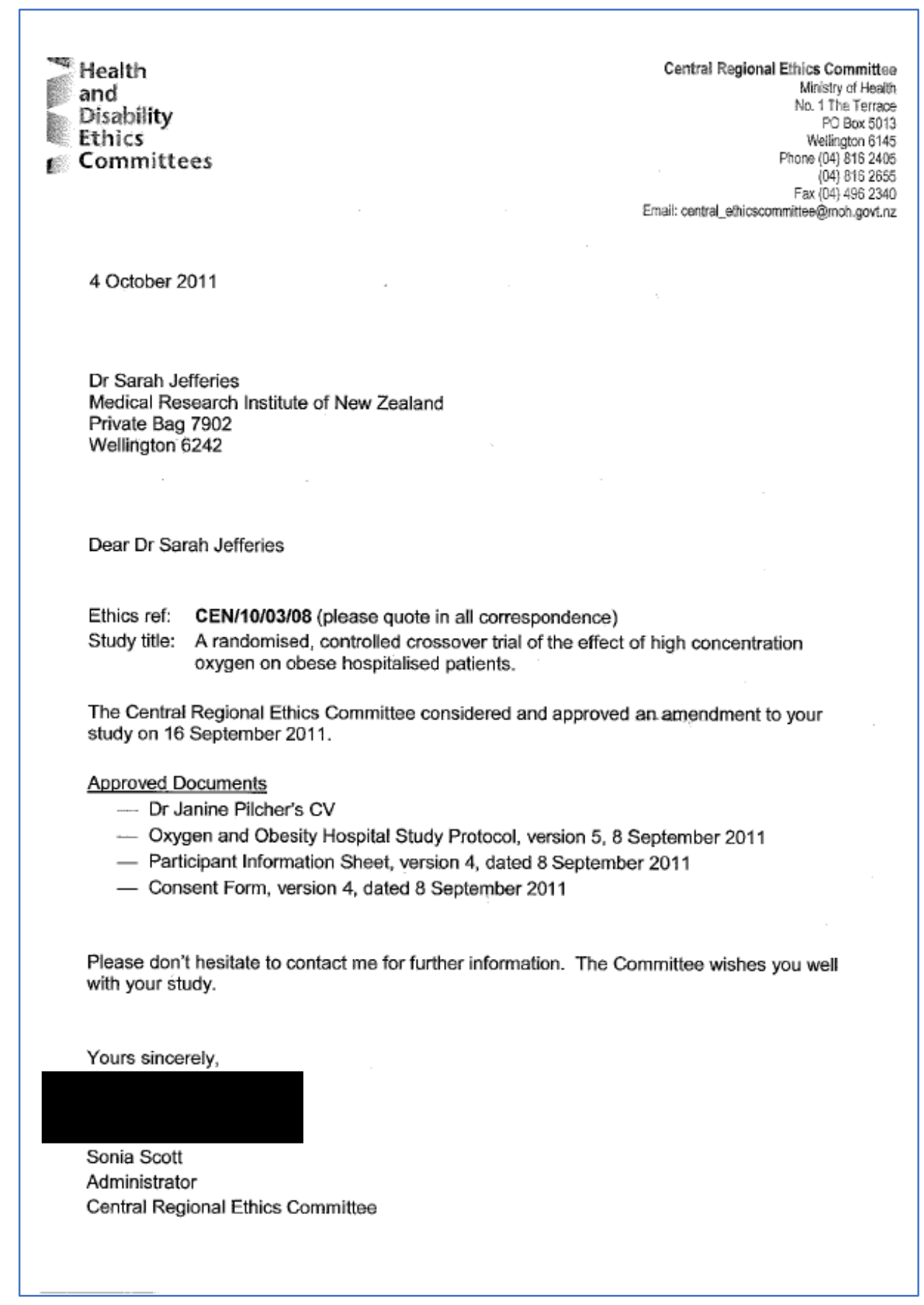




\section{Approval for repeat study}

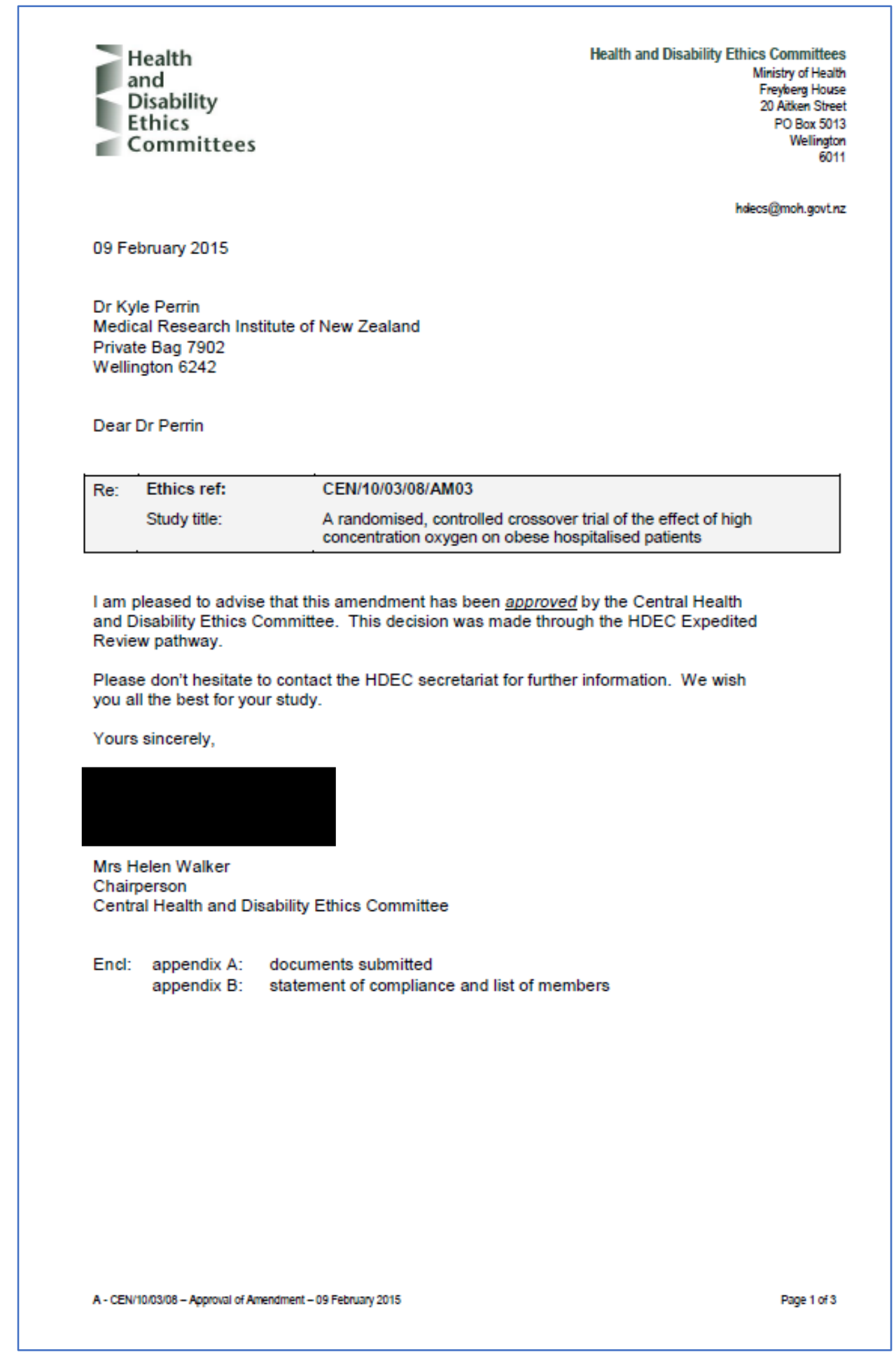




\section{A.9.3 Randomised cross over trials on the effect of $50 \%$ oxygen on}

$\mathrm{PtCO}_{2}$ in patients with stable COPD, bronchiectasis, and neuromuscular disease or kyphoscoliosis (Chapter 5 and Appendix 1)

Initial approval for neuromuscular disease/kyphoscoliosis study

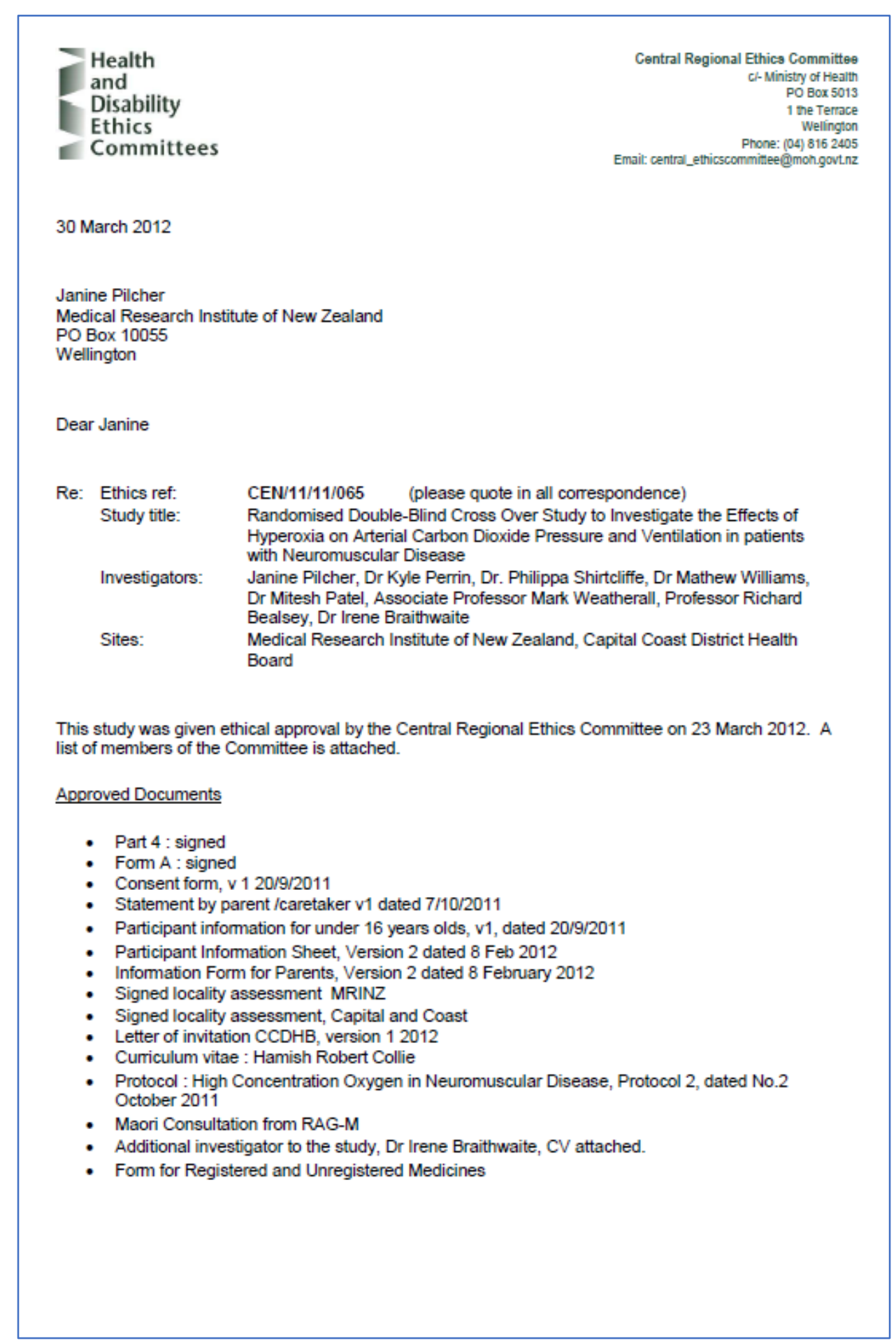




\section{Initial approval for bronchiectasis study}

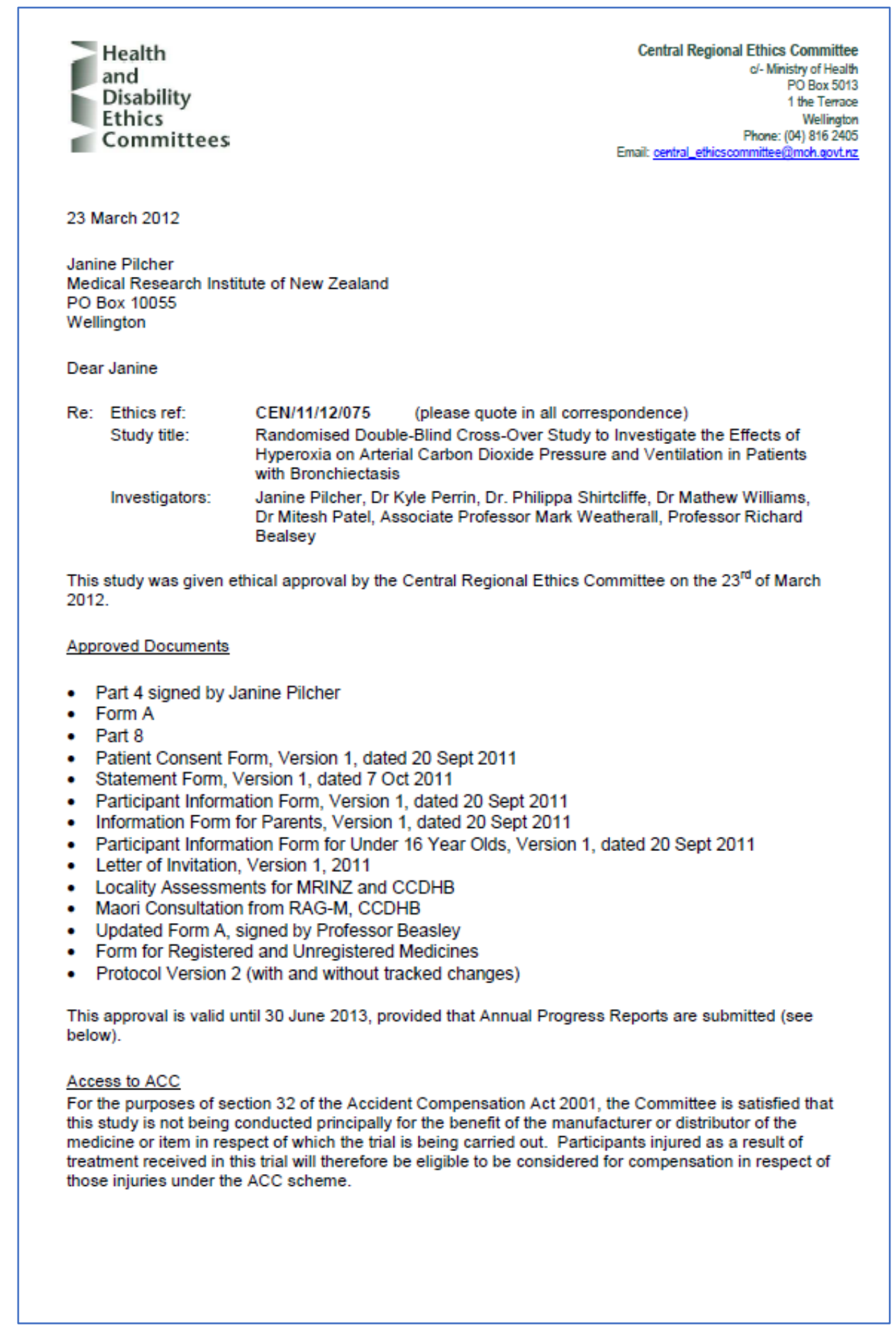




\section{Initial approval for COPD study}

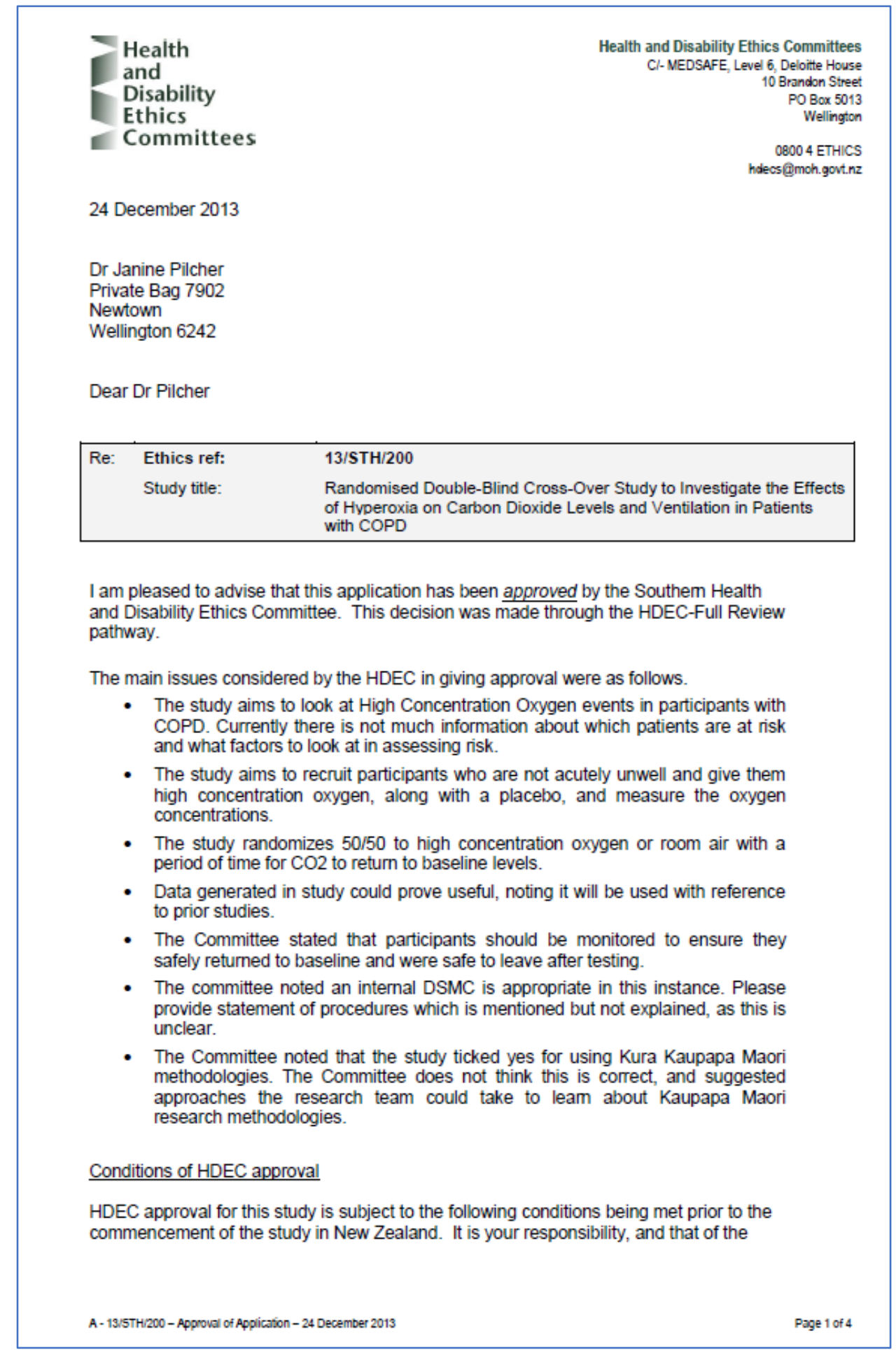


study's sponsor, to ensure that these conditions are met. No further review by the Southern Health and Disability Ethics Committee is required.

Standard conditions:

1. Before the study commences at any locality in New Zealand, all relevant regulatory approvals must be obtained.

2. Before the study commences at any locality in New Zealand, it must be registered in a WHO-approved clinical trials registry (such as the Australia New Zealand Clinical Trials Registry, www.anzctr.orq.au).

3. Before the study commences at a given locality in New Zealand, it must be authorised by that locality in Online Forms. Locality authorisation confirms that the locality is suitable for the safe and effective conduct of the study, and that local research governance issues have been addressed.

\section{After HDEC review}

Please refer to the Standard Operating Procedures for Health and Disability Ethics Committees (available on www.ethics.health.govt.nz) for HDEC requirements relating to amendments and other post-approval processes.

Your next progress report is due by 24 December 2014

\section{Participant access to $A C C$}

The Southem Health and Disability Ethics Committee is satisfied that your study is not a clinical trial that is to be conducted principally for the benefit of the manufacturer or distributor of the medicine or item being trialled. Participants injured as a result of treatment received as part of your study may therefore be eligible for publicly-funded compensation through the Accident Compensation Corporation (ACC).

Please don't hesitate to contact the HDEC secretariat for further information. We wish you all the best for your study.

Yours sincerely

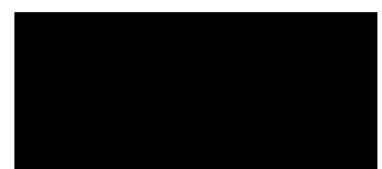

Ms Raewyn Idoine

Chairperson

Southern Health and Disability Ethics Committee

Encl: appendix A: documents submitted

appendix B: statement of compliance and list of members 


\section{Repeat study approval for neuromuscular disease/kyphoscoliosis study}

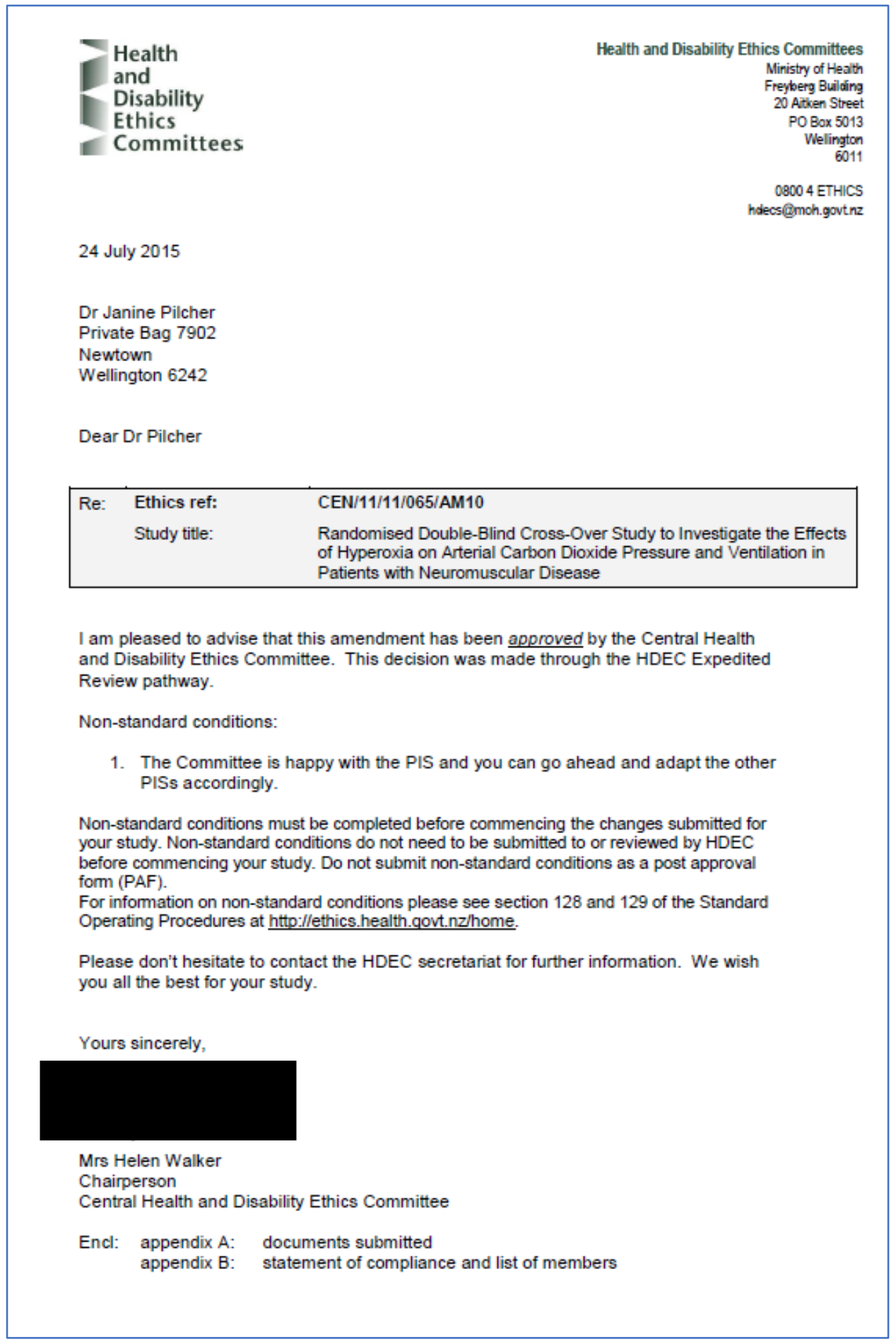




\section{Repeat study approval for bronchiectasis study}

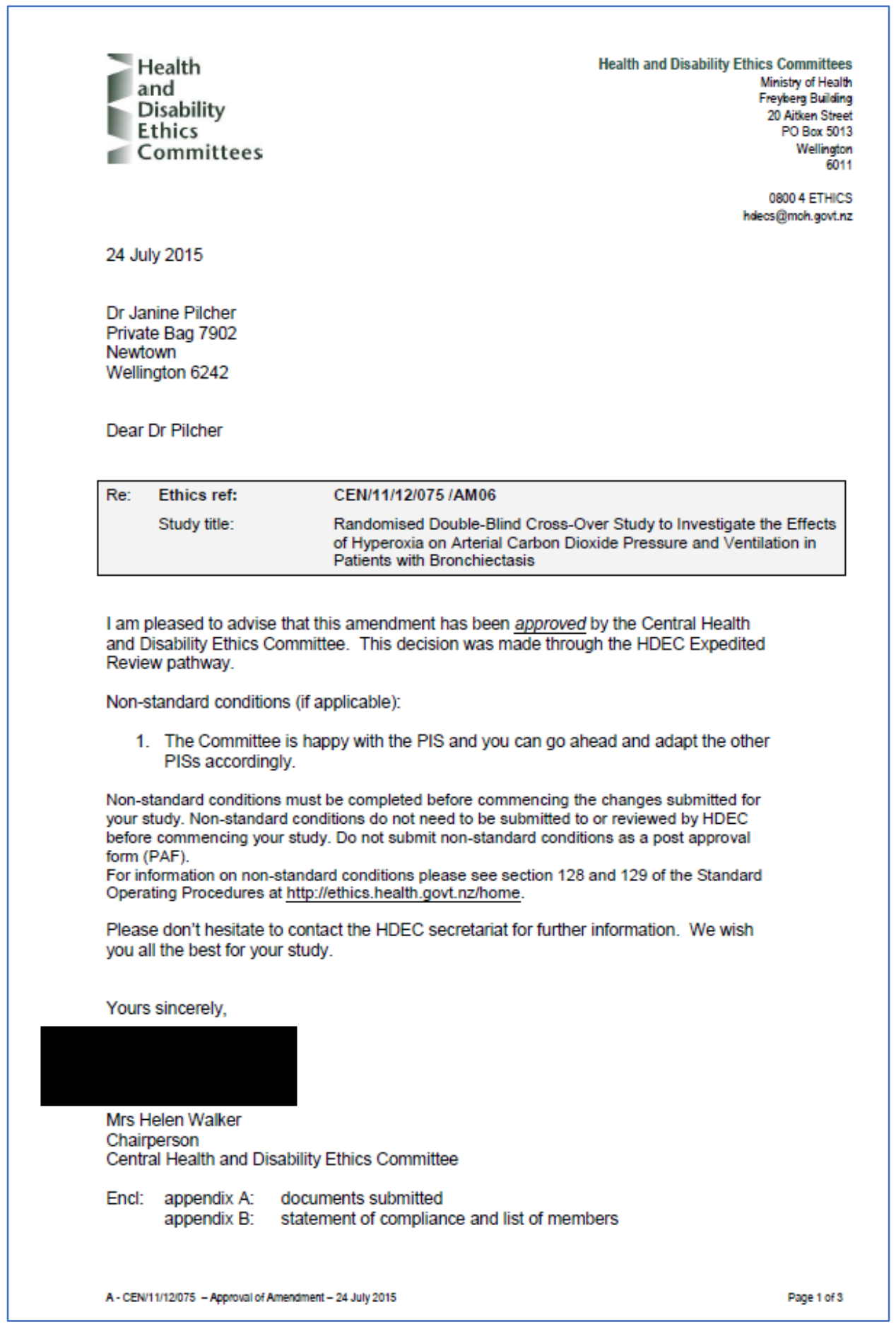




\section{Repeat study approval for COPD study}

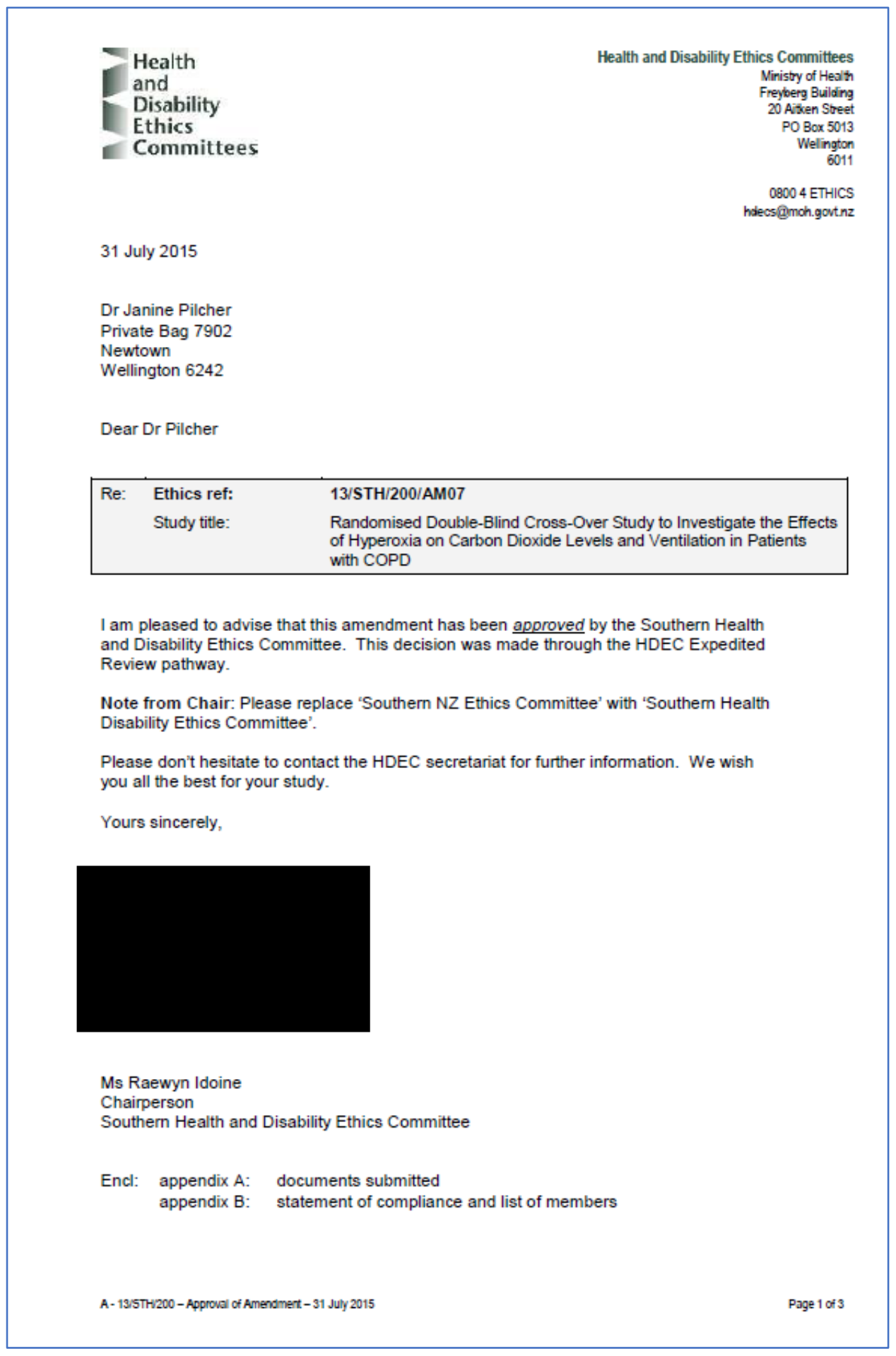

